\title{
Exceptional Ground Accelerations and Velocities Caused by Earthquakes
}

\section{Report Document Identifier:}

TR-NQ-022-2

Cooperative Agreement \# DE-FC28-04RW12232

Project Activity ORD-FY06-022

Final Technical Report Part B (for subtask 2)

REVISION: 0

Author: John G. Anderson

PI: John G. Anderson and James N. Brune 
Date Completed: January 17, 2008

Final Technical Report on a Project Sponsored by the US Department of Energy Yucca Mountain Project

Funding provided through Cooperative Agreement with the Nevada System of Higher Education

Project Number ORD-FY06-022.

Nevada Seismological Laboratory and Department of Geological Sciences and Engineering,

Mackay School of Earth Sciences and Engineering, College of Science, University of Nevada, Reno, Nevada 89557.

Anderson: 775-784-4265; jga@seismo.unr.edu 


\subsection{Table of Contents}

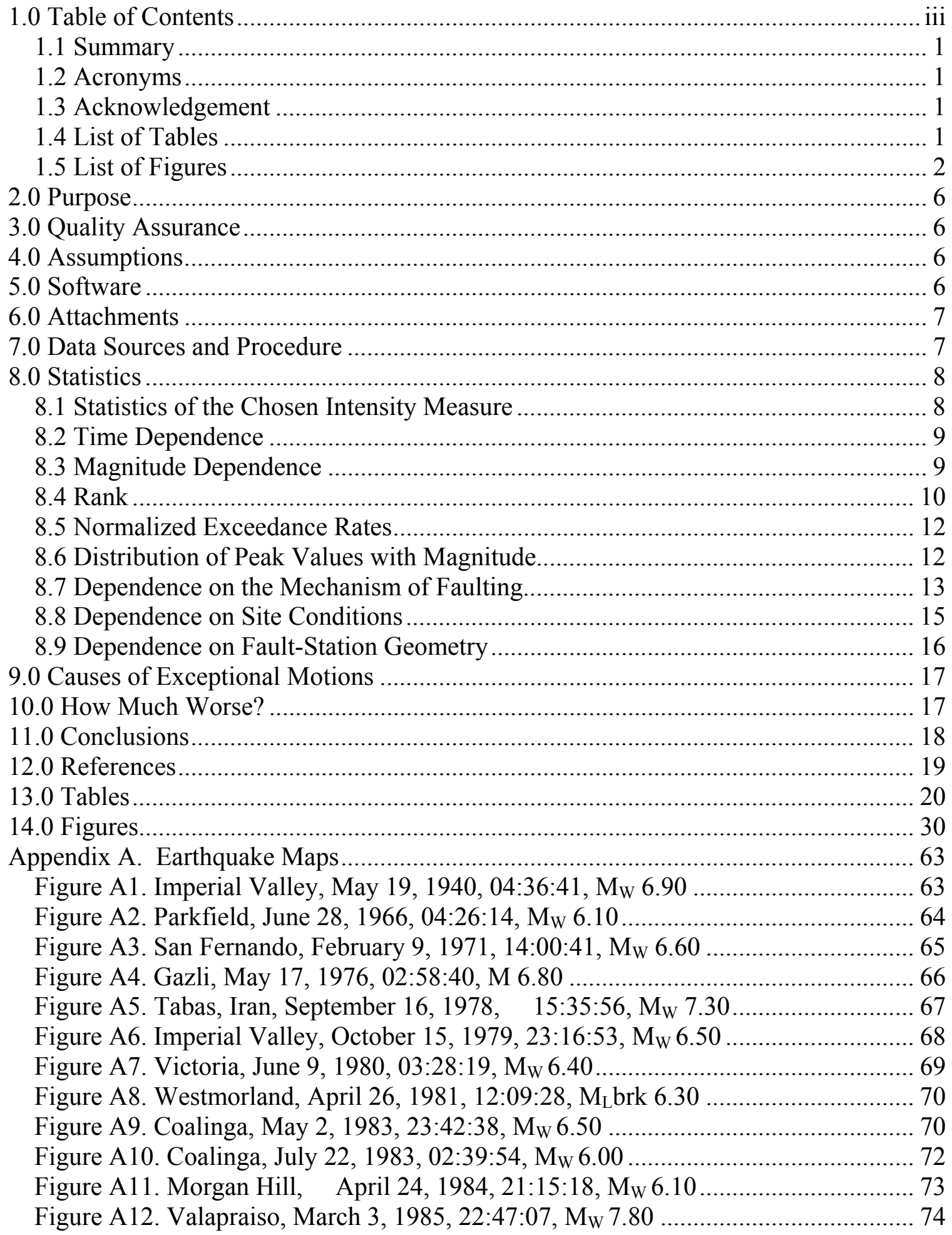


Figure A13. Michoacan Aftershock, September 21, 1985, 01:37:13, $\mathrm{M}_{\mathrm{W}} 7.50 \ldots \ldots \ldots . .75$

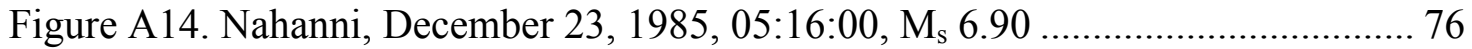

Figure A15. North Palm Springs, July 8, 1986, 09:20:44, $\mathrm{M}_{\mathrm{W}} 6.20$.......................... 77

Figure A16. Whittier Narrows, October 1, 1987, 14:42:20, $\mathrm{M}_{\mathrm{W}} 6.10$........................ 78

Figure A17. Superstition Hills, November 24, 1987, 13:15:56, $\mathrm{M}_{\mathrm{L}}$ brk 6.70 ............. 79

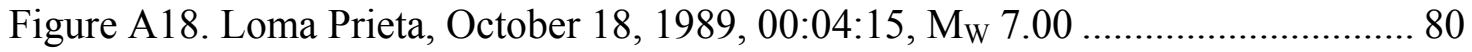

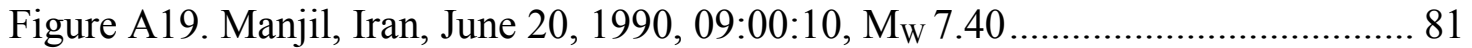

Figure A20. Erzican, March 13, 1992, 17:18:40, Msbrk 6.90 ….............................. 82

Figure A21. Cape Mendocino, April 25, 1992, 18:06:04, $\mathrm{M}_{\mathrm{W}} 7.00$......................... 83

Figure A22. Landers, June 28, 1992, 11:57:34, $\mathrm{M}_{\mathrm{W}} 7.30$....................................... 84

Figure A23. Northridge, January 17, 1994, 12:30:55, $\mathrm{M}_{\mathrm{W}} 6.70$.............................. 85

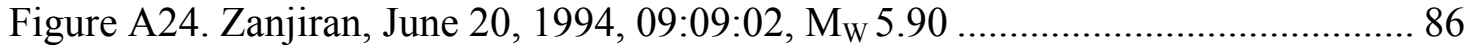

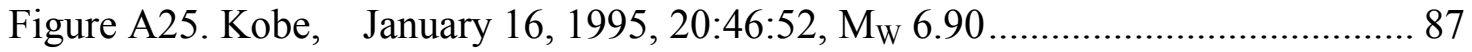

Figure A26. East Coast Honshu , May 23, 1996, 09:36:31, $\mathrm{M}_{\mathrm{W}} 5.00$..................... 88

Figure A27. Central Honshu, August 13, 1996, 02:13:00, Mjma 5.00...................... 89

Figure A28. Honshu, December 21, 1996, 01:28:51, mb-GS 5.70 .......................... 90

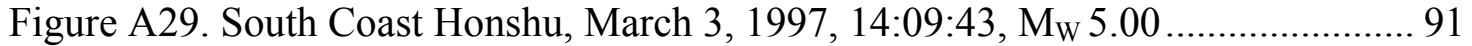

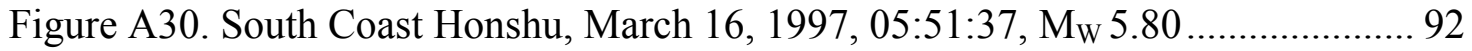

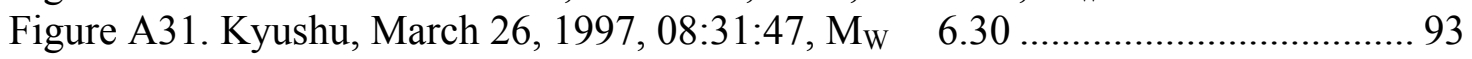

Figure A32. Kyushu, May 13, 1997, 05:38:30, $\mathrm{M}_{\mathrm{W}} 6.20$..................................... 94

Figure A33. Umbria Marche, Italy foreshock, September 26, 1997, 00:33:16, Mw

5.72 and 09:40:33, Mw 6.04 .................................................... 95

Figure A34. Chamoli, March 28, 1999, 19:05:11, $\mathrm{M}_{\mathrm{W}} 6.60$................................. 96

Figure A35. Karehbas, May 6, 1999, 23:00:53, MW 5.90 ...................................... 97

Figure A36. Kocaeli, Turkey, August 17, 1999, 00:01:40, $\mathrm{M}_{\mathrm{w}}$-hrv 7.60 ................. 98

Figure A37. Southern Honshu, August 20, 1999, 20:33:00, Mjma 5.40 ................... 99

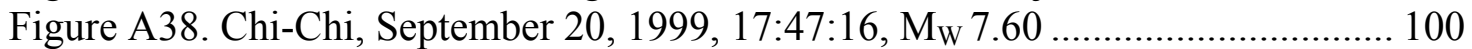

Figure A39. Duzce, November 12, 1999, 16:57:27, $\mathrm{M}_{\mathrm{W}} 7.10$................................ 101

Figure A40. South Iceland, June 17, 2000, 15:40:41, $\mathrm{M}_{\mathrm{W}} 6.57$ and $00: 51: 48, \mathrm{M}_{\mathrm{W}}$

$6.49 \quad$..................... 102

Figure A41. Japan , July 14, 2000, 16:18:00, Mjma 3.90 ................................. 103

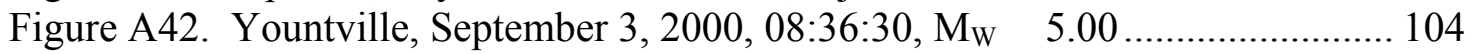

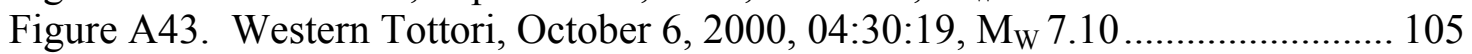

Figure A44. Honshu, October 30, 2000, 16:42:52, Mjma 5.50 .............................. 106

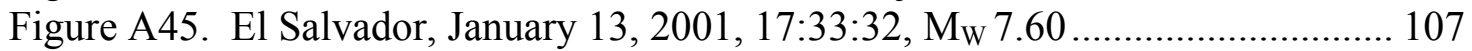

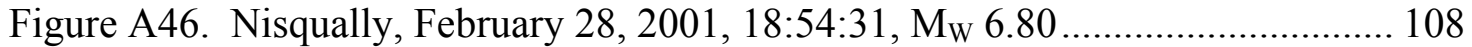

Figure A47. Southern Honshu, March 24, 2001, 06:27:54, $\mathrm{M}_{\mathrm{W}} 6.40 \ldots \ldots \ldots \ldots \ldots . . . . . . .109$

Figure A48. Japan, June 14, 2002, 02:42:00, Mjma 4.90 .................................... 110

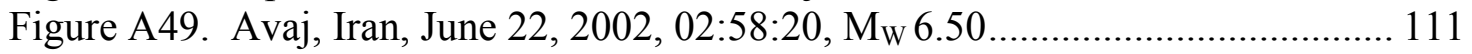

Figure A50. Denali, Alaska, November 3, 2002, 22:13:00, $\quad \mathrm{M}_{\mathrm{s}}$ 7.90..................... 112

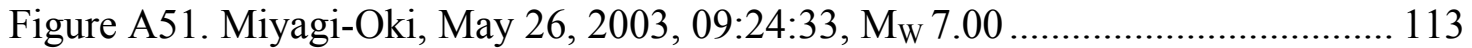

Figure A52. Tokachi-Oki, September 25, 2003, 19:50:07, $\mathrm{M}_{\mathrm{W}} 8.00 \ldots \ldots \ldots \ldots \ldots \ldots \ldots \ldots . . . . . . . . . .114$

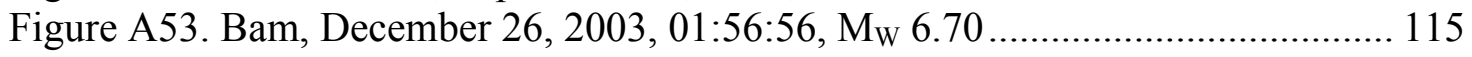

Figure A54. Honshu, July 9, 2004, 10:54:00, Mjma 4.40 ..................................... 116 
Figure A55. Parkfield, September 28, 2004, 17:15:24, $\mathrm{M}_{\mathrm{W}} 6.00$

Figure A56. Niigata-Ken Chuetsu, October 23, 2004, 08:56:00, $\mathrm{M}_{\mathrm{W}} 6.60 \ldots \ldots \ldots \ldots . . . .118$

Figure A57. Niigata-Ken Chuetsu, October 23, 2004, 09:34:07 $\mathrm{M}_{\mathrm{W}} 6.30$................ 119

Figure A58. Hokkaido, November 28, 2004, 18:32:00, Mjma 7.10 ........................ 120

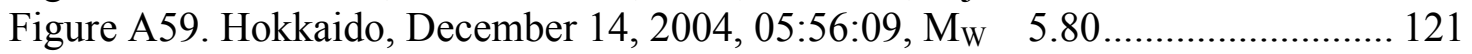

Figure A60. Honshu, August 16, 2005, 02:46:00, Mjma 7.20 ............................... 122

Figure A61. Anza, June 12, 2005, 15:41:46, $\mathrm{M}_{\mathrm{W}} 5.20$..................................... 123

Figure A62. Southern Honshu, March 25, 2007, 00:42:00, Mjma 6.90 ............... 124

Figure A63. Southern Honshu, April 15, 2007, 03:19:00, Mjma 5.40 ..................... 125

Figure A64. Off Southern Shikoku, April 26, 2007, 00:03:00, Mjma 5.30.............. 126 


\subsection{Summary}

This project aims to understand the characteristics of the free-field strong-motion records that have yielded the 100 largest peak accelerations and the 100 largest peak velocities recorded to date. The peak is defined as the maximum magnitude of the acceleration or velocity vector during the strong shaking. This compilation includes 35 records with peak acceleration greater than gravity, and 41 records with peak velocities greater than $100 \mathrm{~cm} / \mathrm{s}$. The results represent an estimated 150,000 instrument-years of strong-motion recordings. The mean horizontal acceleration or velocity, as used for the NGA ground motion models, is typically 0.76 times the magnitude of this vector peak. Accelerations in the top 100 come from earthquakes as small as magnitude 5, while velocities in the top 100 all come from earthquakes with magnitude 6 or larger. Records are dominated by crustal earthquakes with thrust, oblique-thrust, or strike-slip mechanisms. Normal faulting mechanisms in crustal earthquakes constitute under $5 \%$ of the records in the databases searched, and an even smaller percentage of the exceptional records. All NEHRP site categories have contributed exceptional records, in proportions similar to the extent that they are represented in the larger database.

\subsection{Acronyms}

GMPE Ground Motion Prediction Equation

NEHRP National Earthquake Hazard Reduction Program

NGA New Generation Attenuation

NSHE Nevada System of Higher Education

PEER Pacific Earthquake Engineering Research

PGA Peak Ground Acceleration

PGV Peak Ground Velocity

PSHA Probablistic Seismic Hazard Analysis

\subsection{Acknowledgement}

Justin Flint, Nicholas Hockensmith and Selena Willoughby provided significant assistance in identifying, downloading, and documenting the data. Yuichiro Miyata provided major assistance in map preparation. Rasool Anooshehpoor served as a technical reviewer of the document. This project was supported by the US Department of Energy Yucca Mountain Project, via a Cooperative Agreement with the Nevada System of Higher Education, Project Number ORD-FY06-022.

\subsection{List of Tables}

Table 1: List of earthquakes and stations included in this study

Table 2: Selected points on the cumulative distribution curves in Figures 2, 3, and 4 Table 3: Top 100 accelerations and velocities

Table 4: Estimate of level of instrumentation effort for selected accelerograph networks 


\subsection{List of Figures}

Figure 1: Locations of earthquakes represented in our data set of exceptional accelerograms. The earthquakes are listed in Table 1.

Figure 2: Distribution of ratios among various peak acceleration intensity measures. The denominator ("Peak Vector") in all cases is the peak magnitude of the 3component acceleration vector. "Peak Horizontal" is the peak magnitude of the 2-component horizontal acceleration vector. "Peak Component" is the peak acceleration on the largest of the three individual components as recorded. "Mean Horizontal" is the geometrical mean of the peak accelerations of the two horizontal components as recorded. "Peak Vertical" is the peak acceleration on the vertical component. All 255 accelerograms in Table 1 are used to develop this distribution. For records where one of the horizontal components is missing, the peak on that component is treated as equal to zero.

Figure 3: Distribution of ratios among various peak velocity intensity measures. See the caption for an explanation of the variables, which are applied to the velocity rather than acceleration in this figure.

Figure 4: Distribution of angles between the peak 3-component vectors and horizontal. For each 3-component accelerogram, the angle between the acceleration vector and the horizontal is measured at the time when the magnitude of the 3component acceleration is maximum. The algorithm for velocity is the same. All 255 accelerograms in Table 1 are used to develop this distribution.

Figure 5: Distribution of the ratio of the peak value of the second (generally more northerly) observed horizontal component to the first (generally more easterly) component. The upper figure is for peak acceleration, and the lower is for peak velocity. The pale black line is the best-fitting lognormal distribution for these ratios; the mean $(\mu)$ and standard deviation $(\sigma)$ of the distribution are given in the figure.

Figure 6: Distribution of peak acceleration and peak velocity for the accelerograms listed in Table 1. PGA and PGV are the vector peak values. The "predicted" line is the relationship: $\ln (P G V)=4.22+0.776 \ln (P G A)$, where the units of $P G A$ are fraction of the acceleration of gravity, and the units of $P G V$ are $\mathrm{cm} / \mathrm{s}$. This relationship was developed for the PEGASOS project (Abrahamson et al, 2002). The points in this figure represent only the upper-right tip of other compilations of strongmotion data.

Figure 7: Exceptional ground motions over time. Peak acceleration and peak velocity of the records in Table 1, shown as a function of the time that they were recorded. Figure 8: Exceptional ground motions vs moment magnitude. Peak acceleration and peak velocity for all events in Table 1, shown as a function of the magnitude of the earthquake.

Figure 8. Exceptional ground motions vs moment magnitude. Peak acceleration and peak velocity for all events in Table 1, shown as a function of the magnitude of the earthquake. 
Figure 9: Ranking of exceptional records as a function of peak accelerations. The observations are shown as points. The axes are chosen such that data consistent with a power law distribution (Equation 1) of exceptional values would fall on a straight line. The green line, with parameters given in the figure, is the best fit, using an L2 norm, to the data with ranks of 6 to 100 .

Figure 10: Ranking of exceptional records as a function of peak velocities. The observations are shown as points. The axes are chosen such that data consistent with a power law distribution (Equation 1) of exceptional values would fall on a straight line. The green line, with parameters given in the figure, is the best fit, using an L2 norm, to the data with ranks of 20 to 100.

Figure 11: Ranking of exceptional records as a function of peak accelerations. The observations are shown as points. The axes are chosen such that data consistent with an exponential distribution (Equation 2) of values would fall on a straight line. The green line, with parameters given in the figure, is the best fit, using an L2 norm, to the data with ranks of 10 to 80 .

Figure 12: Ranking of exceptional records as a function of peak velocities. The observations are shown as points. The axes are chosen such that data consistent with an exponential distribution (Equation 2) of exceptional values would fall on a straight line. The green line, with parameters given in the figure, is the best fit, using an L2 norm, to the data with ranks of 5 to 80 .

Figure 13: Ranking of exceptional records as a function of peak accelerations. The observations are shown as points. The axes are chosen such that data consistent with an extreme value distribution (Equation 3) of exceptional values would fall on a straight line. The green line, with parameters given in the figure, is the best fitting exponential distribution, using an L2 norm, to the data with ranks of 10 to 100.

Figure 14: Ranking of exceptional records as a function of peak velocities. The observations are shown as points. The axes are chosen such that data consistent with an extreme value distribution (Equation 3) of exceptional values would fall on a straight line. The green line, with parameters given in the figure, is the best fitting exponential distribution, using an L2 norm, to the data with ranks of 10 to 100.

Figure 15: Estimated exceedance rate of peak acceleration per instrument year. The points are obtained by dividing the rank in Figure 9 by the estimate that these data represent about 150,000 instrument-years of data collection effort.

Figure 16: Estimated exceedance rate of peak velocity per instrument year. The points are obtained by dividing the rank in Figure 9 by the estimate that these data represent about 150,000 instrument-years of data collection effort.

Figure 17: Magnitudes of the earthquakes for all of the records included in Table 1. Earthquakes that generated more than one exceptional ground motion record are counted once for each record.

Figure 18: Magnitude distribution of earthquakes causing the top 100 acceleration records, compared with the distribution of magnitudes in the NGA database. 
Earthquakes that generated more than one of the top 100 ground motion records are counted once for each record.

Figure 19: Magnitude distribution of earthquakes causing the top 100 velocity records, compared with the distribution of magnitudes in the NGA database. Earthquakes that generated more than one of the top 100 ground motion records are counted once for each record.

Figure 20: Magnitudes of earthquakes causing the top 100 accelerations, displayed by quartile. Earthquakes that generated more than one of the top 100 ground motion records are counted once for each record.

Figure 21: Magnitudes of earthquakes causing the top 100 velocities, displayed by quartile. Earthquakes that generated more than one of the top 100 ground motion records are counted once for each record.

Figure 22: Distribution of focal mechanisms for the earthquake generating each record in Table 1. The mechanism code is as follows: 0) strike-slip faulting in continental crust; 1) normal faulting in continental crust; 2) thrust faulting in continental crust; 3) oblique thrust faulting in continental crust; 4) oblique normal faulting in continental crust; 6) normal faulting associated with the downgoing slab in a subduction zone; 7) thrust faulting in an oceanic subduction zone; and 8) oblique thrust faulting in an oceanic subduction zone. A code of -1 indicates that the mechanism for that record was not available.

Figure 23: Distribution of focal mechanisms of earthquakes causing the top 100 acceleration records, compared with the distribution of focal mechanism in the NGA database. The NGA database does not include subduction zone earthquakes. Therefore, the bars giving the percentage of "Top Crustal Accelerations" is generated for comparison with NGA by renormalizing those top 100 records with mechanisms $0,1,2,3$, or 4 to a total of $100 \%$. Mechanism codes are given in the caption to Figure 22. For earthquakes causing more than one record in Table 1, the earthquake is counted once for each record.

Figure 24: Distribution of focal mechanism for the top 100 velocities, compared with the distribution of focal mechanism in the NGA database. See Figure 23 for a detailed explanation.

Figure 25: Focal mechanisms of earthquakes causing the top 100 accelerations, displayed by quartile. See Figure 22 for mechanism codes. For earthquakes causing more than one record in Table 1, the earthquake is counted once for each record.

Figure 26: Focal mechanisms of earthquakes causing the top 100 velocities, displayed by quartile.

Figure 27: Distribution of site categories for all records in Table 1. Site category $1=$ not available, $2=$ NEHRP E, $3=$ NEHRP D, 4=NEHRP C, 5-NEHRP B, 6-NEHRP A. Earthquakes causing more than one record are displayed once for each record.

Figure 28: Distribution of site categories for the top 100 accelerations, compared with the distribution of site categories in the NGA database. See the caption to Figure 27 for a definition of Site Category. 
Figure 29: Distribution of site categories for the top 100 velocity records, compared with the distribution of site categories in the NGA database. See the caption to Figure 27 for a definition of Site Category.

Figure 30: Peak acceleration and peak velocity for all records in Table 1, as a function of estimated $V_{S} 30$. Records for which the value of $V_{S} 30$ is not available are plotted at $\mathrm{V}_{\mathrm{S}} 30=0$.

Figure 31: Distribution of average horizontal kappa for all records in Table 1. For each component, $\kappa$ was calculated as described in the text, and then the average of the horizontal components used to create this histogram. Units of $\kappa$ are seconds.

Figure 32: Distribution of average horizontal kappa for the top 100 Distribution of average horizontal kappa for the top 100 acceleration records, by quartile. Units of $\kappa$ are seconds.

Figure 33: Distribution of average horizontal kappa for the top 100 velocity records, by quartile. Units of $\kappa$ are seconds. 


\subsection{Purpose}

This paper reviews the global set of ground motion recordings from earthquakes, with the object of identifying those records with the largest recorded peak accelerations and peak velocities. The intent is to identify the 100 strongest records in each category. The topic is of general interest for estimating upper bounds on motions that might need to be resisted by the most critical facilities. The study is also motivated by results of a probabilistic seismic hazard analysis for the designated Yucca Mountain High Level Nuclear Repository in southern Nevada, for which the extrapolations to occurrence rates of $10^{-7}$ per year result in peak accelerations of $5.8 \mathrm{~g}$, and peak velocities of $650 \mathrm{~cm} / \mathrm{s}$ (DTN: MO0401MWDRPSHA.000; Bechtel SAIC, 2004). These high ground motions have been challenged and criticized as not physically reasonable.

\subsection{Quality Assurance}

This report is entirely unqualified.

\subsection{Assumptions}

This report uses unqualified data that has been recovered from hundreds of earthquakes by dozens of different agencies. We assume first that these data are valid records of the ground motion. This requires that the agency that gathered the data carefully digitized and properly calibrated each record, even though it is not possible to qualify the data. For many records that were obtained on analog instruments, we assume that the time base when the records were digitized is the same for all three components.

The site conditions for stations in Japan are documented in tables that give the shear velocity as a function of depth from the surface to $20 \mathrm{~m}$ depth. In the US, many models need the average shear velocity to $30 \mathrm{~m}$ depth. Thus to use the Japanese information we assume that the shear velocity at $20 \mathrm{~m}$ depth is the same as the velocity from $20 \mathrm{~m}$ to $30 \mathrm{~m}$ depth.

\subsection{Software}

MATLAB v 7.0.1.24704 (R14) Service Pack 1, September 13, 2004, License Number 244191 run under MS Windows environment.

Microsoft Office Excel 2003 (11-8146-8311) SP2 run on MS Windows environment.

Internet Explorer run on MS Windows environment.

Microsoft Office Word 2003 SP2 run on MS Windows environment. 


\subsection{Attachments}

There are no attachments to this report. The scientific notebook that controlled this project is Notebook Number NSHE-UNR-109 Vol. 1, assigned to Task ORD-FY06-022. There is an electronic attachment to the notebook that is being submitted for general use.

\subsection{Data Sources and Procedure}

Relevant data is recorded on strong-motion accelerographs, which are instruments that are triggered by initial ground motions of a strong earthquake. The first significant strong-motion accelerogram was recorded in March, 1933, during the Long Beach, California earthquake. Since then the global data set has grown to over 30,000 records. Much of the global set of strong-motion data is now accessible over the internet (http://www.cosmos-eq.org/, http://www.k-net.bosai.go.jp/, http://www.kik.bosai.go.jp/, http://www.bhrc.ac.ir/Bhrc/d-stgrmo/D-StGrMo.htm), and the majority of the records used in this study were mined from those sources. Our study uses data from older analog instruments that has been digitized, and from newer equipment where the acceleration is digitized by the instrument and recorded in digital format.

Our search started with a list of strong records compiled by PEER NGA project (Power et al, 2006). This established that the 100 largest accelerations would all be greater than $500 \mathrm{~cm} / \mathrm{s}^{2}$, and that the 100 largest velocities would all be greater than $50 \mathrm{~cm} / \mathrm{s}$. Our search of several available databases thus aimed to obtain every accelerogram for which at least one component matches either of those two conditions. This report refers to accelerograms for which at least one component of acceleration exceeds $500 \mathrm{~cm} / \mathrm{s}^{2}$, or for which at least one component of the corresponding velocity exceeds $50 \mathrm{~cm} / \mathrm{s}$ as an exceptional record. Since data is collected as acceleration, and is not necessarily integrated to velocity, our results likely have missed some exceptional velocity records, even though in many cases we endeavored to understand the fault-station geometry and download records that we considered possible to have velocities exceeding $50 \mathrm{~cm} / \mathrm{s}$, even though the peak acceleration did not meet our threshold.

In general, the zero-level of an accelerogram must be inferred from the average properties of the time series. Because of noise, in general this "baseline correction" needs to apply a high-pass filter. For much of the data, the agency that operates the instrument has applied an instrument correction and filter. For records that are only available in the uncorrected form, we applied a high-pass 2-pole causal Butterworth filter, with a default corner frequency of $0.1 \mathrm{~Hz}$. Agency corrections may use a larger corner frequency or a filter with more poles, depending on the signal-to-noise level at low frequencies, and in some cases we also used larger corner frequencies for the filters. Peak values will generally depend on how the records are filtered, with peak velocity being more sensitive than peak acceleration. Thus the peaks described here may not agree exactly with other published values for the same records. 
Table 1 lists all of the records we obtained. Figure 1 shows locations of the earthquakes that are represented by this data set. There are 255 records identified in Table 1 . These time series have been submitted to the Yucca Mountain Record Center

(MOL.20071127.0003).

This study defines peak ground acceleration (PGA) and peak ground velocity (PGV) as the maximum magnitude of the three-dimensional acceleration and velocity vectors, after calculating those magnitudes for each point in time in the record. Thus in general the direction of the peak vector is not horizontal.

\subsection{Statistics}

\subsection{Statistics of the Chosen Intensity Measure}

Figure 2 begins an exploration of the relationship of the chosen intensity measures and other measures that have been used. Specifically, we consider the relationship of the peak vector to the peak vector in the horizontal plane, the largest of the three components in the recorded orientations, the geometrical mean of the two horizontal components, and the peak on the vertical component. Figure 2 shows the distributions of the ratios of these four intensity measures of acceleration to the peak vector acceleration. Figure 3 shows the equivalent information for peak velocity. Figure 4 shows the distribution of angles between the three-dimensional vector and horizontal. Table 2 lists selected points on these distributions.

Figures 2 - 4 show that in this data set, the peak velocity is more concentrated in the horizontal direction than the peak acceleration vector. This feature also shows up in the distribution of peak vertical amplitudes, where the median for acceleration is about half $(0.47)$ of the three-dimensional peak, while it is about a third $(0.30)$ for velocity. These data also show that for both acceleration and velocity, the peak vector is within 20 degrees of horizontal in the vast majority of cases. The NGA relations use the geometrical mean of the two horizontal components as the intensity measure of an accelerogram. Figures 2 and 3 show that in the selected data, the median value of this parameter is about $3 / 4(0.76)$ of the three-dimensional peak for both acceleration and velocity.

Figure 5 shows one other statistic in these data, namely the ratio of the peak value on the second horizontal component to the peak value on the first horizontal. In this data, we aimed to use the convention to report the more east-west of the horizontal components as the first horizontal, and the more north-south component as the second horizontal. But the horizontal axes are in general oriented randomly relative to coordinate axes fixed to the fault, so our naming convention should have no effect on the statistics of this ratio. Because these two peaks can thus be considered as random numbers drawn from the same distribution, the ratios have a median value that is insignificantly different from 1.0, and can be approximated with a lognormal distribution. The standard deviation of this distribution is larger for peak velocity ( 0.50 in natural log (base $e$ units)) than for peak 
acceleration (0.39 in natural log units). We believe that the smaller differences in peak acceleration are because this measure is dominated by higher-frequency waves, which are more scattered and randomized than peak velocity.

Figure 6 shows how the values of peak velocity and peak acceleration of each record are distributed. The effects of the search parameters are the dominant features of this plot, as there are practically no records in the data for which both peak acceleration is under 500 $\mathrm{cm} / \mathrm{s}^{2}$ and peak velocity is under $50 \mathrm{~cm} / \mathrm{s}$. The points that do fall in this zone represent records that were obtained close to the source, and thus even though we knew the peak acceleration did not meet the search parameters we considered it possible that peak velocity would qualify.

\subsection{Time Dependence}

Figure 7 shows the values of peak accelerations and peak velocities plotted as a function of the time the earthquake occurred. The first digital strong-motion accelerograms in our data were obtained in 1980, and the percentage of data that is digitally recorded has been increasing since that time. The majority of the records were recorded digitally.

There is not a convincing trend for either the peak acceleration or peak velocity to be increasing over time. While we can certainly expect some additional high readings, these plots suggest that the increasing numbers of instruments that have been recording for the past decade have not had the effect of observing significantly higher values acceleration or velocity than what had been observed over the twenty prior years.

\subsection{Magnitude Dependence}

Figure 8 shows the magnitude dependence of PGA and PGV. Table 1 and Figure 8 use the moment magnitude for most earthquakes. The differences between moment magnitude and the other magnitude scales, used for a few of the earthquakes, are not large enough to affect the overall trends displayed in Figure 8. The PGA shows little correlation with magnitude - an upper bound for this scatter plot could be a constant. The highest values of the PGV do show a magnitude dependence. These results are predicted from basic physics and earthquake source theory (e.g. Aki and Richards, 1980). In particular, assuming linear wave propagation through the earth, the representation theorem relates peak acceleration at the surface to peak acceleration at the source, and similarly for peak velocity. Simplified source models in Aki and Richards show singularities in the slip velocity at the source, implying that infinite accelerations are possible for a theoretical crack model for failure of a brittle solid, and thus the representation theorem allows infinite accelerations at the station. This reasoning is not limited to large earthquakes. On the other hand, peak velocity at the source is proportional to the stress drop at the source (e.g. Brune, 1970), which is necessarily limited by the strength of the rock. The representation theorem shows that contributions from different parts of the fault can contribute constructively at the station, so the size of the fault may also control the peak velocity. The earthquake magnitude is closely 
correlated with the size of the fault rupture (Wells and Coppersmith, 1994). Thus a relationship between peak velocity and magnitude is expected.

The magnitude dependence is explored in more detail later in this report.

\subsection{Rank}

Table 3 lists the 100 largest accelerations and the 100 largest velocities in the database. Figures 9-14 plot the ranks of the entire set of 255 records as a function of their peak acceleration and peak velocity, on differing axes to compare the distributions of these values with different mathematical shapes. The rank, $R$, is defined as $R=1$ for the largest record, $R=2$ for the second largest, and so forth. Thus for each accelerogram, $R$ gives the number of records with PGA or PGV greater than or equal to those statistics.

The largest acceleration in this database is $2381 \mathrm{~cm} / \mathrm{s}^{2}$, recorded on the hanging wall of the thrust fault during the Nahanni earthquake in northern Canada on December 23, 1985 $(\mathrm{MS}=6.9)$. These data include 35 records of acceleration greater than gravity. We are aware of one record with a peak acceleration that was probably greater than $2.5 \mathrm{~g}$ (FZ16, Parkfield 2004, Shakal et al, 2006), but it is not available at this time. Both the Nahanni and FZ16 records were recorded on analog accelerographs, and the traces go off the edge of the film during an isolated high-frequency spike, so the peak values are uncertain.

The largest velocity is $318 \mathrm{~cm} / \mathrm{s}$, recorded on the hanging wall of the thrust fault during the Chi-Chi, Taiwan earthquake on September 20, 1999 (MW=7.6). These data include 41 records with peak velocity exceeding $100 \mathrm{~cm} / \mathrm{s}$.

Figures 9 and 10 test whether these values can be fit by a power law distribution with the form:

$$
R=\alpha A^{-\beta}
$$

where $A$ represents either PGA or PGV, and $\alpha$ and $\beta$ are parameters to be determined. Data following this relationship should appear as a linear trend on log-log axes:

$$
\log R=\log \alpha-\beta \log A
$$

as in Figures 9 and 10. These figures show fits of a power law to the central portion of the distributions. When these fit lines are extrapolated to higher ranks (ranks closer to one), they predict greater peak accelerations and greater peak velocities than have been observed. Thus the distribution of peak acceleration and peak velocity appears to have a tail that decays more rapidly than a power law.

Figures 11 and 12 test whether these values can be fit by an exponential distribution with the form:

$$
R=\alpha e^{-\beta A}
$$

In Equation 2, $\alpha$ and $\beta$ are again parameters to be determined from the data. These figures show fits of an exponential function to the central portion of the distributions. When these fit lines are extrapolated to higher ranks (ranks closer to one), they predict 
smaller peak accelerations and smaller peak velocities than have been observed. Thus the distribution of peak acceleration and peak velocity appears to have a tail that does not decay as rapidly as an exponential distribution.

Gumbel (1958) proposed that a double exponential distribution is appropriate to fit the distribution of extreme samples. The experiment that he modeled is somewhat different from the experiment represented by the sample of accelerograms gathered here. The classical Gumbel experiment, applied to strong motion, would take the largest acceleration recorded each year at some individual station. Nevertheless, Figures 13 and 14 test whether these values can be fit by a double exponential (Gumbel) distribution of the form:

$$
R=\exp \left[-e^{\alpha+\beta A}\right]
$$

In Equation 3, $\alpha$ and $\beta$ are again parameters to be determined from the data. These figures show fits of a Gumbel distribution to the central portion of the empirical distributions. When these fit lines are extrapolated to higher ranks (ranks closer to one), they predict smaller peak accelerations and smaller peak velocities than have been observed. Thus the distribution of peak acceleration and peak velocity appears to have a tail that does not decay as rapidly as a Gumbel distribution function.

As the peak acceleration decreases (for higher-ranked records), all three types of distributions diverge from the data at some point. For peak acceleration the divergence from the power law occurs at about $750 \mathrm{~cm} / \mathrm{s}^{2}$. It occurs at about $550 \mathrm{~cm} / \mathrm{s}^{2}$ for the other two distributions. We know that the empirical distribution is incomplete at small amplitudes, and the nature of divergence is consistent with the direction expected from incomplete data. The empirical distribution of peak velocities diverges from all three of the models at about $60 \mathrm{~cm} / \mathrm{s}$. Considering that our search criteria are based on the peak amplitude of the largest component, and considering that the ratio of the largest component to the three-dimensional vector amplitude is distributed to values less than one (Figures 2 and 3), it is expected that our database is not complete for some range of PGA above $500 \mathrm{~cm} / \mathrm{s}^{2}$ and for some range of PGV above $50 \mathrm{~cm} / \mathrm{s}$. Thus the amplitudes where $R$ begins to diverge from any of these distributions are reasonable. As is done in looking at earthquake catalogs, where divergence from the power law is considered to occur at the threshold of completeness, we suggest that Figures 9 and 10 imply that our collection of data is uniformly complete for peak accelerations above $750 \mathrm{~cm} / \mathrm{s}^{2}$ and peak velocity above $60 \mathrm{~cm} / \mathrm{s}$.

In the context of probabilistic seismic hazard analysis (PSHA), a general concern is often that the tails of the distribution of accelerations or velocities at a single station, given by a ground motion prediction equation (GMPE) are overestimated and responsible for driving the analyses to extreme motions at very low probabilities. It can be shown that at extremely low probabilities, the exceedance rate of an intensity measure at a single station will have the same dependence as the distribution in a GMPE. If combining multiple stations as is done here were valid, and if the lognormal distribution used in 
most GMPE is valid, then we would predict that the empirical distribution would have an exponential tail, as in Figures 11 and 12. The data might be consistent with an exponential distribution provided there is a different set of physics that comes to dominate the peak values above the break in the slope.

\subsection{Normalized Exceedance Rates}

An interesting question is what is the level of effort that has been involved in collecting the accelerograms listed in Table 1. The measure of effort that we propose is instrumentyears. For example, the Guerrero accelerograph network, consisting of 30 instruments that have operated continuously from 1985 through 2006 (and continuing), or for about 21 years, would represent 630 instrument-years of effort. Table 4 considers seven selected networks, from which the data produced were thoroughly searched and that are extensively represented in Table 1, and finds that among these networks there are about 100,000 instrument-years of effort represented. Considering that roughly a quarter of the records in Table 1 are from other networks, one might scale the 100,000 instrument-years effort by $4 / 3$ to account for the instrument effort of the remaining accelerograms. However, considering that there may be some bias caused by preferential reporting of records with high peak values, we guess that scaling by $4 / 3$ is not enough, so we use the estimate that Table 1 represents roughly 150,000 instrument-years of effort.

Starting with this number, we generate Figures 15 and 16 showing the appproximate exceedance rate of these exceptional accelerations and velocities per instrument year. These figures represent a spatial average of the seismic activity, in which most of the points represent relatively active regions. If one wanted to estimate the exceedance rate for a randomly chosen location that is in a region with $1 / 100$ times as much activity as the "average" site in the accelerograph networks represented, we hypothesize that an initial empirical approach might be to multiply these curves by $1 / 100$. There are numerous reasons to object to this simple approximation, of course, but we see no reason why these objections would cause an order-of-magnitude error.

\subsection{Distribution of Peak Values with Magnitude}

It is, of course, possible to classify the records in Table 1 according to some of the physical characteristics that are believed to have important effects on strong ground motions. We explore three such classifications: magnitude, focal mechanism, and site conditions.

Figures 17-21 expand the consideration of the magnitude distribution of contributing earthquakes. Figure 17 shows a histogram with the number of earthquake records in halfmagnitude bins included in Table 1 . The modal bin is for magnitude $\mathrm{M}=6.5$. We note that the Gutenberg-Richter distribution predicts numbers of earthquakes increasing rapidly as magnitude decreases, so a modal value at $M=6.5$ is only possible if there is a decreasing probability of smaller earthquakes generating an exceptional record. 
Figures 18 and 19 compare the distributions of magnitudes of the top 100 accelerations and top 100 velocities in Table 1 with the distributions of magnitudes in the NGA database. The NGA database made an effort to be complete for crustal earthquakes in North America, Europe, and southern Asia (excluding Japan). Thus it can be considered to be fairly representative of the complete set of crustal earthquakes, and without doubt is the best choice of any data set if one must be chosen to represent the larger body of strong-motion records. Figure 18 shows that earthquakes with $\mathrm{M} \geq 6.25$ are represented much more strongly in the top 100 records than in the NGA database. This tendency for the top 100 records to have larger magnitudes is expressed much more strongly for peak velocity, in Figure 19. About 55\% of the NGA data falls in a magnitude bin for magnitude $5,5.5$, or 6 , but only about $9 \%$ of the exceptional observations come from earthquakes in any of those ranges.

Figures 20 and 21 show the magnitudes of the top 100 accelerations and velocities in Table 1, separated by quartiles. Within these quartiles, we are not convinced that one can see any significant trends, as the few points are not sufficient to overcome the randomness in the statistics of small numbers.

\subsection{Dependence on the Mechanism of Faulting}

We have broadly classified these earthquakes into several categories, expanding on the classification used by PEER for the NGA database. Those categories, and the number of seismograms in the top 100 and in our complete database of 255 records, are as follows:

0) strike-slip faulting in continental crust (73);

1) normal faulting in continental crust (2),

2) thrust faulting in continental crust (60),

3) oblique thrust faulting in continental crust (54),

4) oblique normal faulting in continental crust (0),

6) normal faulting associated with the downgoing slab in a subduction zone (15),

7) thrust faulting in an oceanic subduction zone (33), and

8) oblique thrust faulting in an oceanic subduction zone (3).

Mechanisms for the earthquakes that caused 15 smaller records are not available from the Harvard CMT catalog. The numbers of records in these different categories are displayed in Figure 22.

Figure 22 shows that the overwhelming majority of the exceptional records are associated with thrust, oblique-thrust, or strike-slip faulting in the continental crust. Thus to the extent that strong-motion instruments are distributed in areas that are representative of the seismic hazard as a whole, continental thrust faults are the most likely to cause exceptional velocities and accelerations, and crustal strike-slip earthquakes are second, with other categories of faulting, in particular faulting related to subduction zones, much less represented. 
To interpret this distribution of exceptional records, we again normalize by the rates of earthquakes in each category that are represented in the NGA strong-motion database. These comparisons are shown in Figure 23 for peak acceleration, and in Figure 24 for peak velocity. These figures contain two normalizations based on the exceptional data set. Besides the normalization over all the mechanism categories, it shows the subset of shallow earthquakes in continental crust. This subset of crustal events is the most appropriate to compare with the distribution of NGA mechanisms.

Figure 23 shows that the number of top 100 accelerations is comparable from strike-slip and from thrust earthquakes, while the number of oblique-thrust earthquakes contributing is about half as large. In relative terms, strike-slip is over-represented, while the number of records from crustal thrust earthquakes is under-represented, compared with the numbers in the NGA database. Figure 24 shows that a comparable number of exceptional velocities have been observed from earthquakes crustal strike-slip, oblique thrust, and thrust mechanisms. Compared with NGA, strike-slip earthquakes are slightly over-represented in the top 100 velocities, while the number of oblique thrust events is significantly overrepresented, and the number of thrust mechanisms is underrepresented. These results are somewhat surprising, since thrust earthquakes are often considered the source of stronger shaking than strike-slip earthquakes.

The limitations of the NGA database might be important in evaluating whether thrust mechanisms are actually less likely to cause exceptional motions. Because the NGA database does not include earthquakes from Japan, and because Japanese earthquakes are more likely to have a thrust mechanism than a strike-slip mechanism, thrust mechanisms may be underrepresented in the NGA database compared to the exceptional motions database. If that is the case, the anomalies associated with Figures 23 and 24 become even more striking.

Our overall impression is that subduction zone earthquakes (category 8 ) are significantly more common in the overall strong-motion database than in the list of exceptional records in Table 1. Normal faulting at 50-100 km depth in subduction zones (Category 7) similarly is perhaps surprisingly well represented among the highest-ranking acceleration records, considering the earthquake depth. There are quite a few earthquakes of this type, including records from Nisqually, Mexico, and Japan, represented in the searched strongmotion database. Both of these mechanisms are more represented at high values of peak acceleration than peak velocity. This is perhaps somewhat surprising, especially since the searched dataset include records from three subduction earthquakes with $\mathrm{M}>8$ (Chile, Guerrero, Hokkaido) with very large mean slips capable of generating high velocities if the stress drop is sufficient.

Normal and oblique-normal mechanisms are very sparsely represented in the NGA database, so it is not surprising that there are few records from these mechanisms in either the top 100 accelerations or velocities. Only two records from these categories are in our selected dataset; the largest of these is $\mathrm{M}_{\mathrm{w}} \sim 6.0$. However, considering Figures 23 and 24, 
there is the suggestion that these mechanisms might be considered underrepresented even after adjusting for the sparsity of such records.

Figures 25 and 26 show the mechanisms in the quartiles of the top acceleration and velocity categories. As with the magnitude dependence, we do not think these figures reveal any significant trends.

\subsection{Dependence on Site Conditions}

The near-surface geology is also well-known to have a significant effect on the amplitudes of strong ground motions. Figure 27 therefore shows the distribution of site categories in Table 1, associated with the NEHRP classifications. Figures 28 and 29 compare the site classifications of the top 100 accelerations and velocities with the site classifications of the NGA database.

The source of the data for $\mathrm{V}_{\mathrm{s}} 30$ is either the NGA flatfile (published on their web site at http://peer.berkeley.edu/products/rep nga models.html ) or data on site conditions for California Strong Motion Instrumentation Program, K-net and KiK-net, given on their respective web sites (http://www.consrv.ca.gov/CGS/smip/about.htm, http://www.knet.bosai.go.jp/, http://www.kik.bosai.go.jp/, respectively). For the K-net stations, most sites have profiles of $\mathrm{V}_{\mathrm{s}}$ to a depth of $20 \mathrm{~m}$. In estimating $\mathrm{Vs} 30$, we assumed that the shear velocity at the greatest depth given extends to $30 \mathrm{~m}$. On average, this will result in the estimates of $\mathrm{V}_{\mathrm{s}} 30$ for these stations biased slightly low, because the velocity is more likely to increase somewhat than to remain constant. When data is available to $20 \mathrm{~m}$ depth, the true value is at most $50 \%$ greater than the estimate obtained by this procedure: this extreme can only occur if the velocity from 20-30 meters is so large that the travel time through this depth range is negligible compared to the travel time from $0-20 \mathrm{~m}$. Thus usually the bias will be much smaller than 50\%, and we conclude that for our purposes the uncertainty is not important. The NGA database assigns a value of V30 for every station, often based on its geology. However, for stations in this study that are outside of the NGA study, we did not assign an estimate for $\mathrm{V}_{\mathrm{s}} 30$ other than the procedure described here for Japan. This is the explanation for many unknown sites in Table 1 while there are none in the NGA.

In Figures 28 and 29, to first order the site conditions in this study have the same distribution as in the NGA study. The most notable possible difference is that two of the highest peak accelerations are observed on NEHRP A sites, while in NGA the fraction of sites in NEHRP A is much smaller than $2 \%$. We consider the statistical basis too small to draw a conclusion.

Figure 30 shows the PGA and PGV observations as a function of the value of $\mathrm{V}_{\mathrm{s}} 30$ where known for each site. We see no evidence of dependence of PGA on $V_{s} 30$ in Figure 4. The site with $\mathrm{V}_{\mathrm{s}} 30=2016 \mathrm{~m} / \mathrm{s}$ is Pacoima Dam, which had an exceptional record during both the San Fernando and Northridge earthquakes. It might be surprising to some that an acceleration of over $1500 \mathrm{~cm} / \mathrm{s}^{2}$ has been observed on a site with $\mathrm{V}_{\mathrm{s}} 30$ as low as 200 
$\mathrm{m} / \mathrm{s}$, as very soft sediments are presumed to not transmit the strains that will cause such high accelerations. This is recorded during the 1979 Imperial Valley earthquake at station El Centro Array \#6, in which the peak acceleration occurs on the vertical component and is dominated by $\mathrm{P}$-waves. S-waves arriving 3 seconds later cause obvious nonlinear site response on the accelerogram.

There is perhaps some hint that the upper bound of PGV decreases as $\mathrm{V}_{\mathrm{s}} 30$ increases. However, the data is so sparse for high values of Vs30 that we have no confidence in such a trend. The three points plotted at $\mathrm{V}_{\mathrm{s}} 30=1433 \mathrm{~m} / \mathrm{s}$ were recorded at the K-net station MYG011 (Oshika) from earthquakes with hypocentral depths from $42-71 \mathrm{~km}$. Models of peak acceleration in Japan (e.g. Si and Midorikawa, 2000) find that deep earthquakes tend to have higher motions than shallow earthquakes at the same hypocentral distance, consistent with the high values observed here. But because of the large hypocentral and presumed fault distances, these points can not be considered to constrain an upper bound on PGV.

Another parameter that is at least in part related to the site condition is kappa $(\kappa)$. This was defined by Anderson and Hough (1984) from the slope of the Fourier spectrum of acceleration, which they modeled as $\sim \exp (-\pi \kappa f)$. Anderson and Hough (1984) and Anderson (1986) presented evidence that that $\kappa$ is dominantly controlled by attenuation in the region and especially in the shallow crust below the station. However, Purvance and Anderson (2003) also demonstrated that there is a source contribution to $\kappa$.

Following the procedure of Anderson and Hough (1984), the value of $\kappa$ was estimated for each horizontal component over the frequency band from $5-20 \mathrm{~Hz}$, for a 30 -second window starting 10 seconds before the peak velocity. Figure 31 shows the distribution of the average of the two horizontal components for the 255 records in the database. The mode of this larger data set has $\kappa=0.02 \mathrm{~s}$. This is perhaps a surprisingly small value, as most published values of $\kappa$ for the western US are greater.

Figure 32 compares the distribution in Figure 31 with the values of the top 100 accelerations, by quartile. The top quartile of records have a distribution that is skewed towards smaller values than the full distribution. Figure 33 is the equivalent of Figure 32 for peak velocity. In this case, the top quartile of the records have a distribution that is skewed towards larger values than the full distribution. Since $\kappa$ is measuring the relative amplitudes of high frequencies in the accelerograms, this shows that the records with the highest peak accelerations tend to be rich in high frequency energy. Conversely the records with the highest peak velocities tend to be relatively depleted in high frequency energy.

\subsection{Dependence on Fault-Station Geometry}

Appendix A contains a map for many of the earthquakes in Table 1. The maps show the earthquake epicenter, the locations of the stations in Table 1 that recorded the earthquake, 
and the locations of aftershocks. The default catalog of aftershocks is the USGS global earthquake catalog (searchable at http://neic.usgs.gov/neis/epic/epic global.html). If a regional catalog was located the aftershocks from that catalog were substituted for the global file. The aftershock distribution may be an indication of the extent of fault rupture, particularly in locations where the catalog is well constrained. The information in Appendix A was supplemented by a review of literature about the earthquakes.

Perusing Appendix A, we conclude that most of the exceptional records were obtained in a location close to the fault. Indeed, virtually all of the top 25 accelerations and top 25 velocities can be identified as being located on the hanging wall of a thrust fault, being located in a forward directivity direction from the hypocenter, or both.

The exceptional peak accelerations are caused by the Miyagi-Oki earthquake, which occurred at $70 \mathrm{~km}$ depth below some stations.

\subsection{Causes of Exceptional Motions}

From the review above, we conclude that 100 most exceptional accelerations and velocities can be seen on all types of site conditions. Most of the highest values are associated with forward directivity, with a location on the hanging wall of a thrust fault, or sometimes both. The exceptions to this generalization are high stress-drop earthquakes at 40-80 km depth. Since the earthquakes that have been located in the vicinity of Yucca Mountain are nearly all shallower than $15 \mathrm{~km}$, these deep earthquakes are not relevant to the seismicity at Yucca Mountain.

\subsection{How Much Worse?}

An important question is how near the observations compiled here are to the "upper limit", to the extent that such limit might exist. This is a difficult question. In the discussion of Figure 7, it was noted that the upper bound of the peak observations has not been increasing rapidly with time, in spite of the substantial increase in the number of instruments. This might be taken as weak evidence that the ground motions that have been recorded are near the upper limit of what occurs during earthquakes.

On the other hand, Midorikawa (1994) has compiled a summary of cases where rocks or other objects have been thrown by an earthquake for distances of up to four meters. None of the records in this compilation are capable of throwing objects. Thus by the intensity measure of throwing an object, the ground motion can be stronger. It is recommended that this phenomenon be carefully investigated in order to understand the implications for strong motions. We could also note that objects that are potentially thrown by exceptional motions are abundant everyplace. Thus the number of "instrument-years" represented by these objects is enormous compared with the instrumentation program summarized in Table 4. It is recommended that the information about the frequency of objects being thrown or not thrown be considered as a part of the analysis of the ground motions necessary to throw objects. 


\subsection{Conclusions}

This project defines exceptional ground motions as those for which either peak acceleration exceeds $500 \mathrm{~cm} / \mathrm{s}^{2}$ or peak velocity exceeds $50 \mathrm{~cm} / \mathrm{s}$. A global review of strong motions uncovered 255 time histories in this category. Based on an estimate that the data represent roughly 150,000 instrument years, records in this category have occurred at a rate of roughly once for every 600 instrument years. Of these, 35 records have peak acceleration greater than gravity and 41 records have peak velocity greater than $100 \mathrm{~cm} / \mathrm{s}$.

Earthquakes with magnitudes as small as 5 are included in this compilation. Some earthquakes this small qualify to be included in the 100 largest accelerations, but the 100 largest velocities all originate with earthquakes with magnitudes of 6.5 or larger. The data are dominated by records from shallow crustal earthquakes with thrust, obliquethrust, or strike-slip focal mechanisms. Earthquakes with a normal faulting mechanism are not well represented in the larger data set of accelerograms, from which these records were identified. Thus it would be inappropriate to conclude that normal faulting mechanisms are unlikely to cause exceptional motions. There is a hint that hard sites (NEHRP category A) might be more strongly represented in the set of exceptional records than it is in the larger data base, but other than that, all NEHRP site categories are represented in roughly the same proportion as in the larger data set. The distribution of values of kappa among the exceptional records peaks at kappa $=0.02 \mathrm{sec}$. Records with the highest peak accelerations (> gravity) tend to have smaller values of kappa. Records with the highest peak accelerations tend to have smaller values of kappa.

One can speculate on how these results might apply to Yucca Mountain. The geological deformation rates at Yucca Mountain are probably about two orders of magnitude smaller than they are at the "average" station contributing data to this study. Thus scaling the exceedance rate downwards by two orders of magnitude would suggest that accelerations of $2 \mathrm{~g}$, or velocities of $200 \mathrm{~cm} / \mathrm{s}$ might have an exceedance rate of $10^{-7}$ per year. There are however flaws with that line of reasoning. The most prominent one is that the highest acceleration in the database, from Nahanni, comes from aftershock monitoring in a region with an even smaller deformation rate. It could be possible that regions with small deformation rates have higher stress drops and higher ground motions than the average.

Perhaps the more important conclusion is that the highest peak accelerations and peak velocities recorded to date are far below the values predicted by the probabilistic seismic hazard analysis for Yucca Mountain. 


\subsection{References}

Aki, K. and P. G. Richards (1980). Quantitative Seismology Theory and Methods, Volume I and II, W. H. Freeman and Company, San Francisco.

Anderson, J. G. (1986). Implication of attenuation for studies of the earthquake source, in Earthquake Source Mechanics, Maurice Ewing Series 6, S. Das, J. Boatright, and C. H. Scholz (Editors), American Geophysical Union, Washington, D.C., 311318.

ANDERSON, J. G. and S. E. HOUGH (1984). A model for the shape of the Fourier amplitude spectrum of acceleration at high frequencies, Bulletin of the Seismological Society of America, Oct 1984; 74: 1969 - 1993.

Bechtel SAIC (2004). Technical Basis Document No. 14: Low Probability Seismic Events. Revision 1, 306 pages.

Brune, J. N. (1970). Tectonic stress and the spectra of seismic shear waves for earthquakes, J. Geophys. Res. 75,4997-5009.

Gumbel, E. J. (1958). Statistics of Extremes, Columbia University Press, New York, 375 pages.

Midorikawa, S. (1994). Case histories of upthrow of objects during earthquakes (in Japanese), JISHIN (Journal of the Seismological Society of Japan) 47, 333-340.

Power, M., B. Chiou, N. Abrahamson, and C. Roblee (2006). The next generation of ground motion attenuation models (NGA) project: An overview. Proc. Eighth National Conf. Earthquake Engineering, Paper No. 22.

Matthew D. Purvance and John G. Anderson (2003). A Comprehensive Study of the Observed Spectral Decay in Strong-Motion Accelerations Recorded in Guerrero, Mexico, Bulletin of the Seismological Society of America, Apr 2003; 93: 600 611.

Shakal, A. F., H. R. Haddadi, and M. J. Huang (2006). Note on the Very-HighAcceleration Fault Zone 16 Record from the 2004 Parkfield Earthquake, Bulletin of the Seismological Society of America, 96, S119 - S128.

Si, H. and Midorikawa, S., 2000, New Attenuation relations for peak ground acceleration and velocity considering effects of fault type and site condition, Proceedings of Twelfth World Conference on Earthquake Engineering, paper\#532.

Wells, D. G. and K. J. Coppersmith (1994). New empirical relationships among magnitude, rupture length, rupture width, rupture area, and surface displacement, Bull. Seism. Soc. Am. 84, 974-1002. 


\subsection{Tables}

Table 1. List of earthquakes and stations included in this study.

\begin{tabular}{|c|c|c|c|c|c|c|c|c|c|c|c|c|c|c|}
\hline Earthquake Name & Date & Time & Magnitude & $\begin{array}{c}\text { Magnitude } \\
\text { Type }\end{array}$ & Latitude & Longitude & $\begin{array}{l}\text { Depth } \\
(\mathrm{km})\end{array}$ & Mechanism & Station & Latitude & Longitude & $\begin{array}{c}\text { Preferred } \\
\text { NEHRP } \\
\mathrm{V}_{\mathrm{s}} 30\end{array}$ & $\begin{array}{l}\text { Preferred } \\
\mathrm{V}_{\mathrm{s} 30}(\mathrm{~m} / \mathrm{s})\end{array}$ & File Name \\
\hline Imperial Valley 1940 & $5 / 19 / 1940$ & 4:36:41 & 6.90 & MW & 32.73 & -115.5 & 8.8 & 0 & El Centro & 32.794 & -115.549 & $\mathrm{D}$ & 213.4 & avcnto1940.dat \\
\hline Parkfield & 6/28/1966 & 4:26:14 & 6.10 & Mw & 36 & -120.5 & 10 & 0 & Cholome 2wa & 35.733 & -120.29 & D & 184.8 & avcholame0.dat \\
\hline San Fernando & $2 / 9 / 1971$ & 14:00:41 & 6.60 & Mw & 34.44 & -118.41 & 13 & 2 & Pacoima Dam & 34.334 & -118.396 & A & 2016.1 & avsanfer00.dat \\
\hline Gazli & $5 / 17 / 1976$ & $2: 58: 40$ & 6.80 & & 40.465 & 63.462 & 18.2 & 2 & Karakyr & 40.35 & 63.47 & c & 659.6 & avkarakyro.dat \\
\hline Imperial Valley 1979 & 10/15/1979 & $23: 16: 53$ & 6.50 & Mw & 32.6435 & -115.3088 & 9.96 & 0 & El Centro Array \#4 & 32.864 & -115.5 & D & 208.9 & avcentro40.dat \\
\hline Imperial Valley 1979 & 10/15/1979 & $23: 16: 53$ & 6.50 & Mw & 32.6435 & -115.3088 & 9.96 & 0 & El Centro Array \#5 & 32.855 & -115.47 & D & 205.6 & avcentro50.dat \\
\hline Imperial Valley 1979 & $10 / 15 / 1979$ & 23:16:53 & 6.50 & Mw & 32.6435 & -115.3088 & 9.96 & 0 & El Centro Array \#6 & 32.839 & -115.49 & D & 203.2 & avcentro60.dat \\
\hline Imperial Valley 1979 & $10 / 15 / 1979$ & 23:16:53 & 6.50 & Mw & 32.6435 & -115.3088 & 9.96 & 0 & El Centro Array \#7 & 32.829 & -115.5 & D & 210.5 & avcentro70.dat \\
\hline Imperial Valley 1979 & 10/15/1979 & 23:16:53 & 6.50 & Mw & 32.6435 & -115.3088 & 9.96 & 0 & Differential Array & 32.796 & -115.535 & D & 202.3 & avdiffar00.dat \\
\hline Imperial Valley 1979 & 10/15/1979 & $23: 16: 53$ & 6.50 & Mw & 32.6435 & -115.3088 & 9.96 & 0 & Bonds Corner & 32.6932 & -115.3382 & D & 223.0 & avimperial.dat \\
\hline Imperial Valley 1979 & $10 / 15 / 1979$ & 23:16:53 & 6.50 & Mw & 32.6435 & -115.3088 & 9.96 & 0 & El Centro Array \#8 & 32.811 & -115.53 & $\mathrm{D}$ & 206.1 & avimpvallo dat \\
\hline Imperial Valley & $10 / 15 / 1979$ & 23:16:53 & $\begin{array}{l}6.50 \\
6.50\end{array}$ & Mw & $\begin{array}{l}32.6435 \\
32.6435\end{array}$ & $\begin{array}{l}-111.50388 \\
-115.3088\end{array}$ & $\begin{array}{l}9.96 \\
9.96\end{array}$ & 0 & Westmorland & $\begin{array}{l}33.037 \\
337\end{array}$ & $\begin{array}{l}-115.448 \\
-115.623\end{array}$ & D & $\begin{array}{l}186.2 \\
193.7\end{array}$ & $\begin{array}{l}\text { avoveirpass.ada } \\
\text { awwmorland.dat }\end{array}$ \\
\hline Imperial Valley & $10 / 15 / 1979$ & 23:16:53 & $\begin{array}{l}6.50 \\
6.50\end{array}$ & Mw & $\begin{array}{l}32.6435 \\
32.6435\end{array}$ & $\begin{array}{l}-111.50388 \\
-115.3088\end{array}$ & $\begin{array}{l}9.96 \\
9.96\end{array}$ & 0 & Agrarias & $\begin{array}{l}32.0371 \\
32.621\end{array}$ & $\begin{array}{l}-115.623 \\
-115.301\end{array}$ & D & $\begin{array}{l}193.1 \\
274.5\end{array}$ & $\begin{array}{l}\text { avagrarias.dat } \\
\text { avatian }\end{array}$ \\
\hline Victoria & $6 / 9 / 1980$ & $3: 28: 19$ & 6.40 & Mw & 32.185 & -115.076 & 11 & 0 & Victoria & 32.29 & -115.1 & D & 274.5 & avvictoria.dat \\
\hline Victoria & 6/9/1980 & 3:28:19 & 6.40 & Mw & 32.185 & -115.076 & 11 & 0 & Cerro Prieto & 32.421 & -115.301 & $\mathrm{C}$ & 659.6 & avceprieto.dat \\
\hline Westmorland & 4/26/1981 & $\begin{aligned} 12: 09: 28 \\
\end{aligned}$ & 6.30 & MLbrk & 33.33 & -115.65 & 6 & 0 & Westmorland & 33.037 & -115.623 & D & 193.7 & avwmorln81.dat \\
\hline Coalinga & $5 / 2 / 1983$ & $23: 42: 38$ & 6.50 & $\mathrm{Mw}$ & 36.233 & -120.31 & 4.6 & 2 & Pleasant Valley P.P. yard & 36.308 & -120.249 & D & 257.4 & avppyard00.dat \\
\hline Coalinga aftershock & $5 / 9 / 1983$ & 2:49:11 & 5.20 & MLGS & 36.23 & -120.31 & 12 & 2 & $\begin{array}{l}\text { Anticline Ridge } \\
\text { R.r. yar }\end{array}$ & 36.233 & -120.333 & $\mathrm{c}$ & 376.1 & avanticlin.dat \\
\hline Coalinga & $7 / 22 / 1983$ & $2: 39: 54$ & 6.00 & $\mathrm{Mw}$ & 36.241 & -120.409 & 7.4 & 2 & $\begin{array}{l}\text { Oil City } \\
\text { Olinge }\end{array}$ & $\begin{array}{l}0.020 \\
36.229\end{array}$ & -120.36 & $\mathrm{c}$ & 376.1 & $\begin{array}{l}\text { avoilityo.dat } \\
\text { avalutions }\end{array}$ \\
\hline Coalinga & $7 / 22 / 1983$ & $2: 39: 54$ & 6.00 & Mw & 36.241 & -120.409 & 7.4 & 2 & Transmitter Hill & 36.249 & -120.343 & $\mathrm{c}$ & 376.1 & avtranhill.dat \\
\hline Coalinga & $7 / 25 / 1983$ & 22:31:39 & 5.30 & Mw & 36.229 & -120.398 & 8.4 & 2 & Old Chp & 36.151 & -120.353 & D & 338.5 & avoldchp00.dat \\
\hline Morgan Hill & $4 / 24 / 1984$ & 21:15:18 & 6.10 & Mw & 37.306 & -121.695 & 8.5 & 0 & Coyote Lake Dam & 37.118 & -121.55 & $\mathrm{c}$ & 597.1 & avmorgan00.dat \\
\hline Valapraiso & $3 / 3 / 1985$ & 22:47:07 & 7.80 & Mw & -33.135 & -71.871 & 33 & 7 & $\begin{array}{l}\text { Melipilla } \\
\text { Sum }\end{array}$ & -33.68 & -71.22 & & -1 & avmelipill.dat \\
\hline Valapraiso & $3 / 3 / 1985$ & 22:47:07 & 7.80 & Mw & -33.135 & .71 .871 & 33 & 7 & Llolleo & -32.635 & -71.63 & & -1 & $\begin{array}{l}\text { avllolleo1.dat } \\
\text { ant }\end{array}$ \\
\hline Nahanni & $12 / 23 / 1985$ & 5:16:00 & 6.90 & Ms & 62.222 & -124.239 & 6 & 2 & Site 1 & 62.199 & -124.338 & c & 659.6 & avnahannio.dat \\
\hline Nahanni & $12 / 23 / 1985$ & $5: 16: 00$ & 6.90 & Ms & 62.222 & -124.239 & 6 & 2 & Site 2 & 62.227 & -124.168 & $\mathrm{c}$ & 659.6 & avnahanni2.dat \\
\hline North Palm Springs & $778 / 1986$ & $\begin{array}{l}9: 20: 44 \\
9\end{array}$ & 6.20 & Mw & 33.533 & -116.578 & 14.1 & 3 & Desert Hot Springs & 33.962 & -116.509 & D & 345.4 & avnorth000.dat \\
\hline North Palm Springs & $7 / 8 / 1986$ & 9:20:44 & 6.20 & Mw & 34 & -116.6117 & 11 & 3 & $\begin{array}{l}\text { North Palm Springs Post } \\
\text { Office }\end{array}$ & 33.924 & -116.543 & D & 345.4 & avnps00000.dat \\
\hline North Palm Springs & $7 / 8 / 1986$ & 9:20:44 & 6.20 & Mw & 34 & -116.6117 & 11 & 3 & $\begin{array}{l}\text { Whitewater Canyon - } \\
\text { WWTrout Farm }\end{array}$ & 33.989 & -116.655 & D & 345.4 & aunwt00000.dat \\
\hline North Palm Springs & $7 / 8 / 1986$ & 9:20:44 & 6.20 & Mw & 34 & -116.6117 & 11 & 3 & Devers Substation & 33.932 & -116.579 & & -1 & avdevers00.dat \\
\hline Whittier Narrows & $10 / 1 / 1987$ & $14: 42: 20$ & 6.10 & Mw & 34.0493 & -118.081 & 14.6 & 3 & Tarzana & 34.16 & -118.534 & D & 257.2 & avwhittier.dat \\
\hline Whittier Narrows & 10/1/1987 & $14: 42: 20$ & 6.10 & Mw & 34.0493 & -118.081 & 14.6 & 3 & $\begin{array}{l}\text { Whititier Narrows Dam } \\
\text { Upstream }\end{array}$ & 34.002 & -118.053 & D & 298.7 & avwhitndam.dat \\
\hline Superstition Hills & $11 / 24 / 1987$ & 13:15:56 & 6.70 & MLbrk & 33.01 & -115.84 & 2 & 0 & Parachute Test Site & 32.93 & -115.7 & D & 348.7 & avparachut.dat \\
\hline on Hills & $11 / 24 / 1987$ & $13: 16: 00$ & 6.70 & MLbrk & 33.01 & -115.84 & 2 & 0 & Superstition Mtn. Camera & 32.955 & -115.823 & $\mathrm{c}$ & 362.4 & avsuphill0.dat \\
\hline Loma $\mathrm{F}$ & $10 / 18 / 1989$ & 0:04:15 & 7.00 & Mw & 37.0407 & -121.8829 & 17.48 & 3 & BRAN & & & $\mathrm{c}$ & 376.1 & avbran0000.dat \\
\hline Loma Prieta & $10 / 18 / 1989$ & 0:04:15 & 7.6. & Mw & 37.0407 & -121 & 17.48 & 3 & Co & 37.046 & -121.803 & $\mathrm{c}$ & 462.2 & avcorra000.dat \\
\hline Loma Prieta & $10 / 18 / 1$ & $0: 04$ & 7.0 & Mw & 37. & -121 & 17.48 & 3 & & 36.974 & 52 & $\mathrm{D}$ & 288.6 & avcapito \\
\hline Loma Prieta & 10/18/1989 & 0:04:15 & 7.00 & Mw & 37.0407 & -121.8829 & 17.48 & 3 & Gilroy Array \#3 & 36.987 & -121.536 & D & 349.9 & avgilroya3.dat \\
\hline Loma Prieta & $10 / 18 / 1989$ & $0: 04: 15$ & 7.00 & Mw & 37.0407 & -121.8829 & 17.48 & 3 & Los Gatos Lexington & 37.202 & -121.949 & B & 1070.3 & avgatos 000 .dat \\
\hline Loma Prieta & 10/18/1989 & $0: 04: 15$ & 7.00 & Mw & 37.0407 & -121.8829 & 17.48 & 3 & $\begin{array}{l}\text { Dam } \\
\text { Hollister South Pine }\end{array}$ & 36.848 & -121.397 & c & 370.8 & avhollio00.dat \\
\hline
\end{tabular}




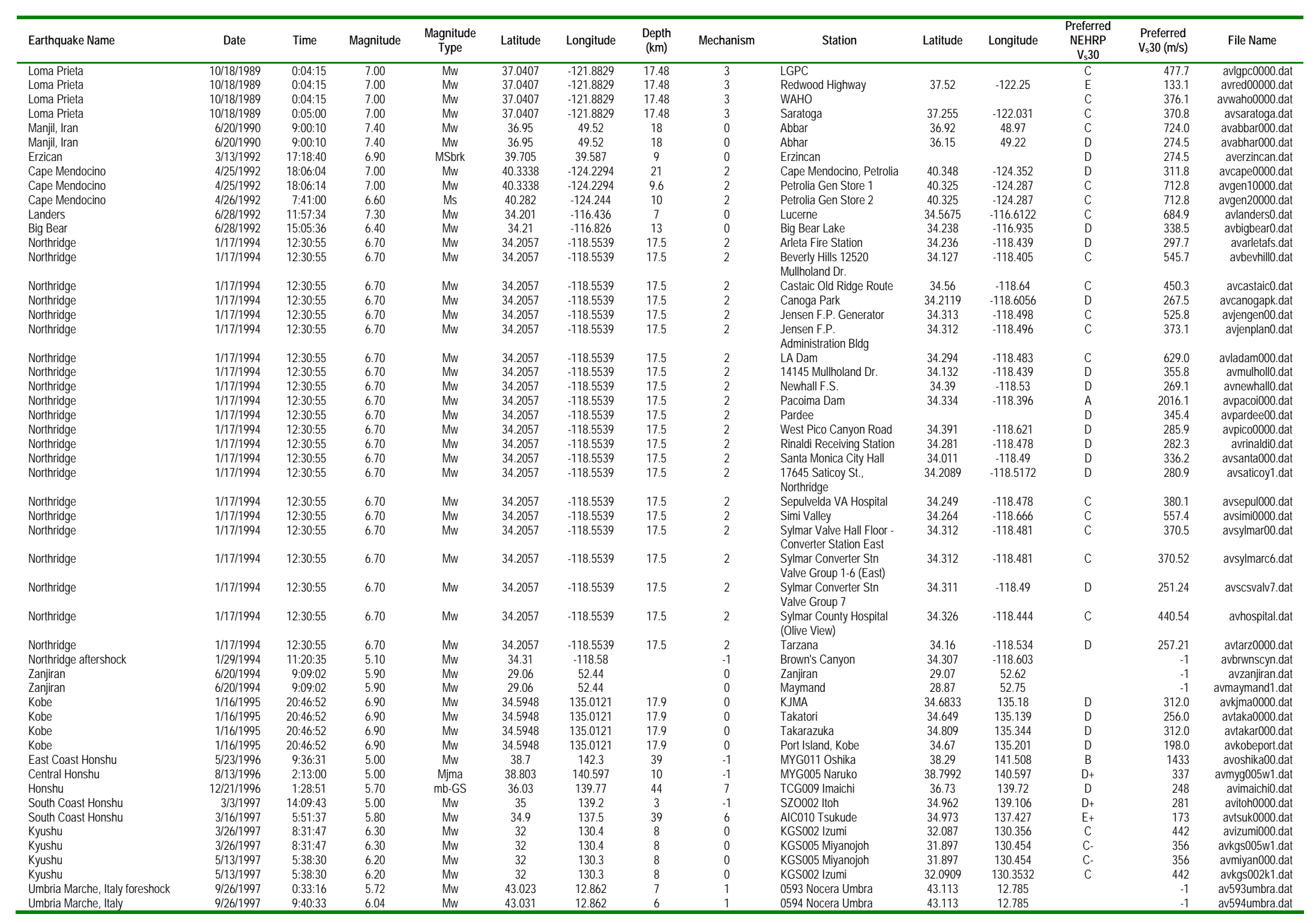

ORD-FY06-022 Subtask 2: Final Technical Report 


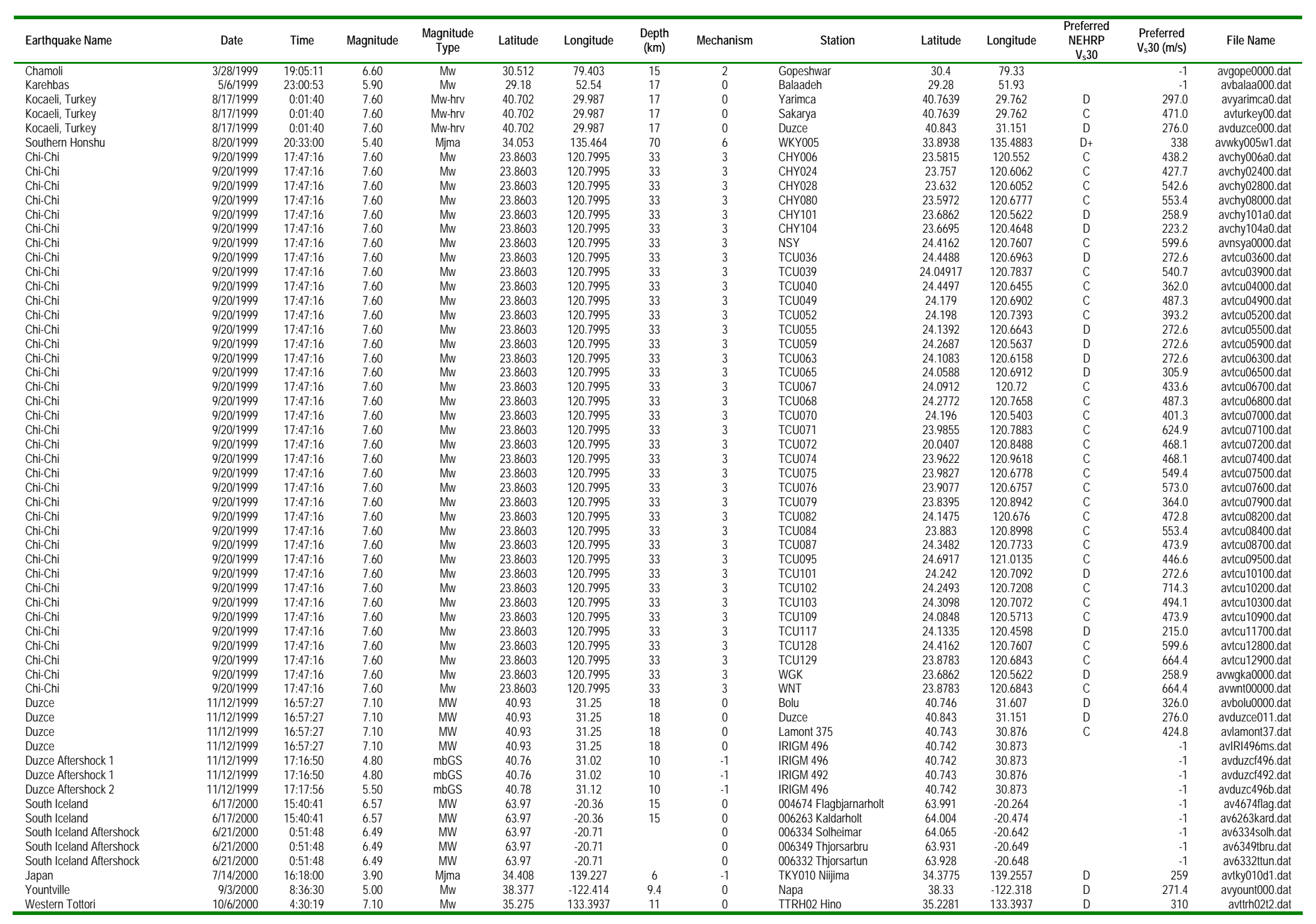

ORD-FY06-022 Subtask 2: Final Technical Report 


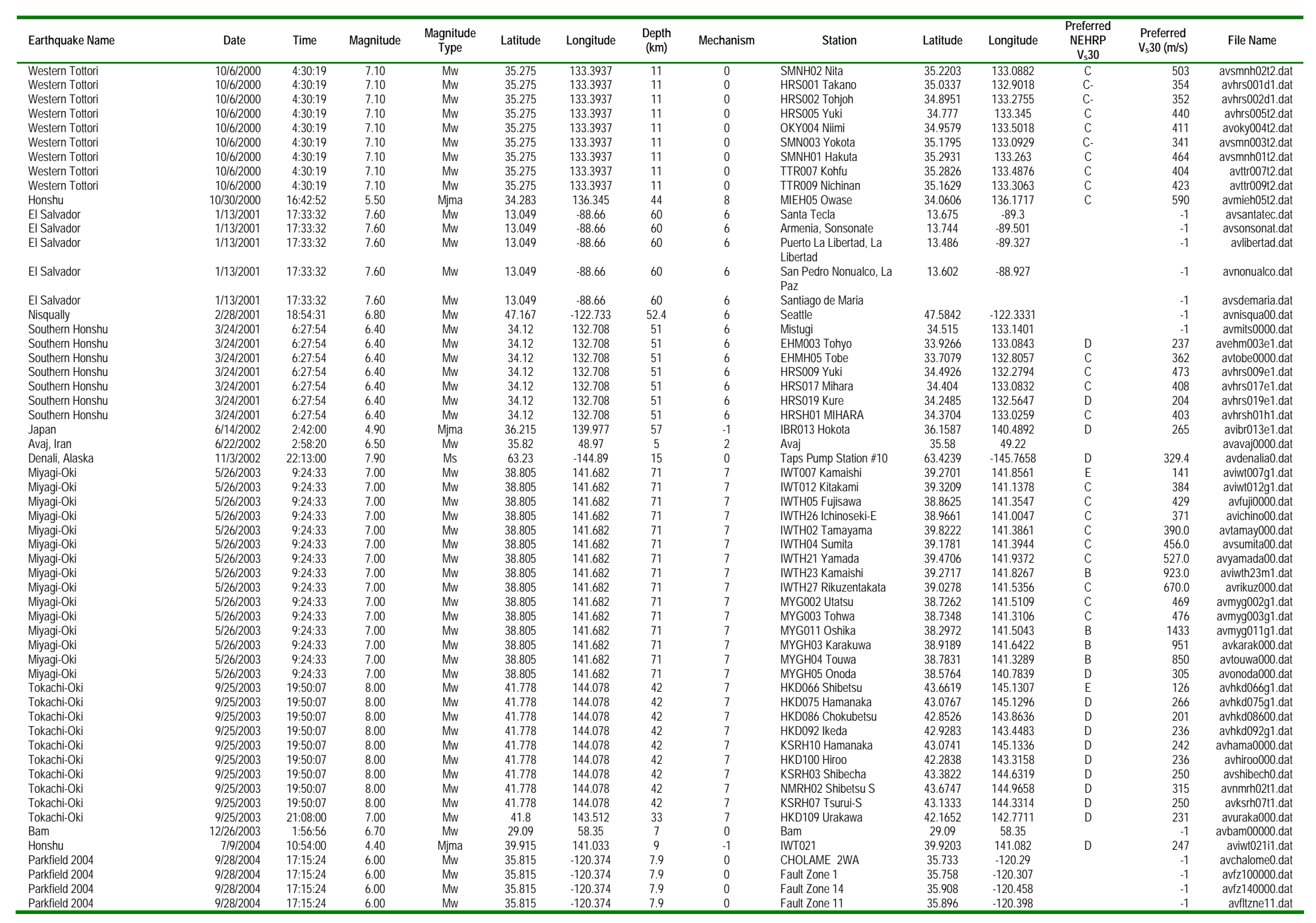

ORD-FY06-022 Subtask 2: Final Technical Report 


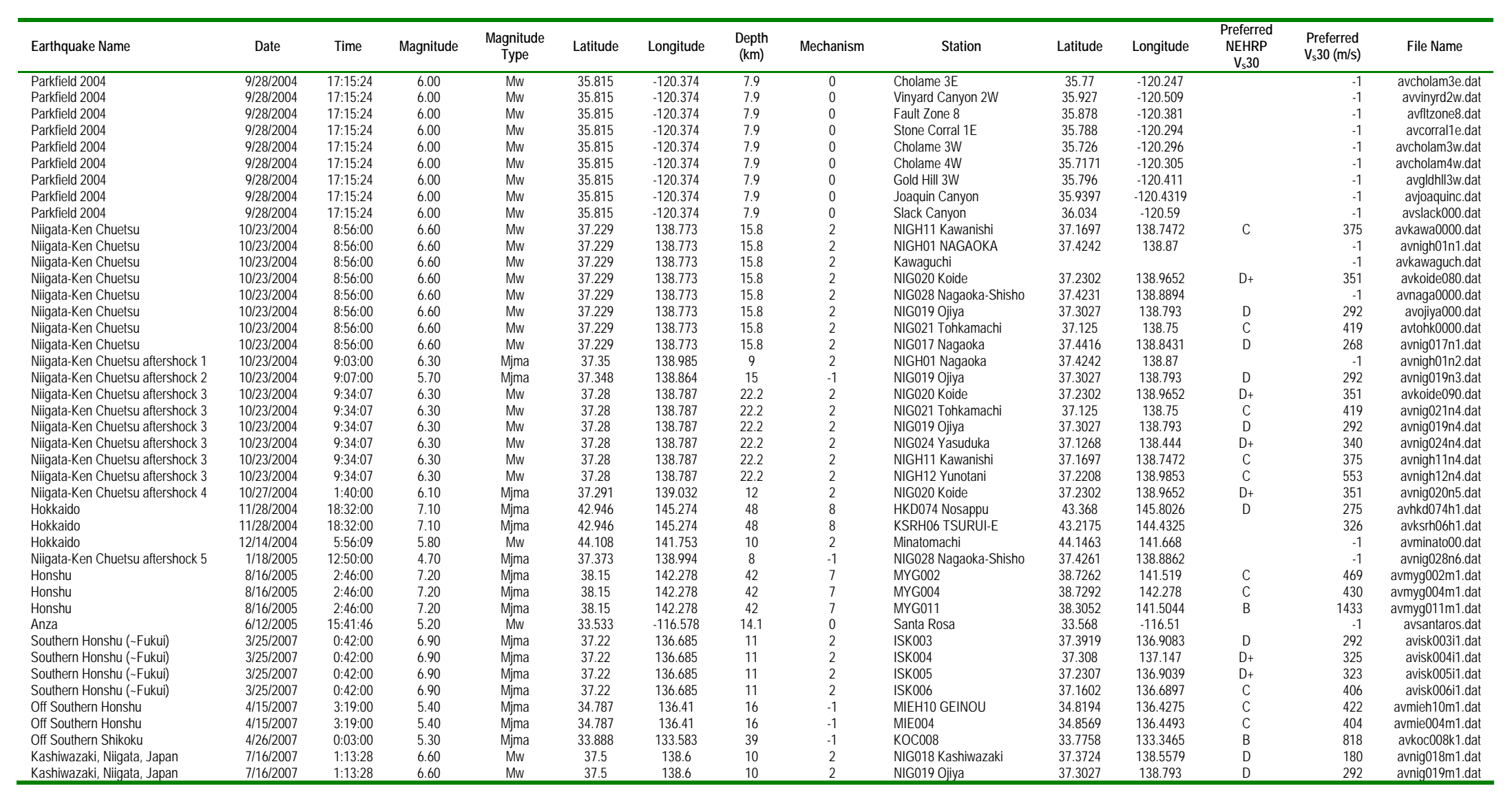


Table 2. Selected Points on the Cumulative Distribution Curves in Figures 2, 3, and 4.

\begin{tabular}{|c|c|c|}
\hline Paramter & Peak Acceleration & Peak Velocity \\
\hline Peak Vertical / Three-Dimensional Peak: Median & .47 & .30 \\
\hline Peak Vertical / Three-Dimensional Peak: $10^{\text {th }}$ Percentile & .24 & .17 \\
\hline Geometric Mean of Horizontals / Three-Dimensional Peak: Median & .76 & .76 \\
\hline Geometric Mean of Horizontals / Three-Dimensional Peak: $10^{\text {th }}$ Percentile & .64 & 0.62 \\
\hline Largest Peak on Any Component / Three-Dimensional Peak: Median & .93 & .94 \\
\hline Largest Peak on Any Component / Three-Dimensional Peak: $10^{\text {th }}$ Percentile & .82 & .79 \\
\hline Peak Rotated Horizontal / Three-Dimensional Peak: Median & .99 & .995 \\
\hline Peak Rotated Horizontal / Three-Dimensional Peak: $10^{\text {th }}$ Percentile & .84 & .96 \\
\hline Angle Between Three-Dimensional Peak and Horizontal: $90^{\text {th }}$ Percentile & 35 & 12 \\
\hline Angle Between Three-Dimensional Peak and Horizontal: Median & 1.5 & -1.6 \\
\hline Angle Between Three-Dimensional Peak and Horizontal: $10^{\text {th }}$ Percentile & -15 & -14 \\
\hline
\end{tabular}

Table 3. Top 100 accelerations and velocities

A. Top 100 accelerations

\begin{tabular}{|c|c|c|c|c|c|c|c|c|c|c|c|c|c|c|c|c|}
\hline Rank & Earthquake Name & Date & Time & Magnitude & $\begin{array}{c}\text { Magnitude } \\
\text { Type }\end{array}$ & $\begin{array}{c}\text { Earthquake } \\
\text { Loatitude }\end{array}$ & $\begin{array}{l}\text { Earthquake } \\
\text { Longitude }\end{array}$ & $\begin{array}{c}\text { Depth } \\
(\mathrm{km})\end{array}$ & Mechanism & Station & $\begin{array}{l}\text { Station } \\
\text { Latitude }\end{array}$ & $\begin{array}{c}\text { Station } \\
\text { Longitude }\end{array}$ & $\begin{array}{l}\text { Preferred } \\
\text { NEHRP } \\
\text { Vs30 } \\
\end{array}$ & $\begin{array}{l}\text { Preferred } \\
\mathrm{V}_{\mathrm{s} 30}(\mathrm{~m} / \mathrm{s})\end{array}$ & $\begin{array}{c}\text { PGA } \\
\text { 3D-Vec. } \\
\left(\mathrm{cm} / \mathrm{s}^{2}\right)\end{array}$ & $\begin{array}{c}\text { PGV } \\
\text { 3D-Vec. } \\
(\mathrm{cm} / \mathrm{s})\end{array}$ \\
\hline 1 & Nahanni & $12 / 23 / 1985$ & 5:16:00 & 6.90 & Ms & 62.222 & -124.239 & 6 & 2 & Site 1 & 62.199 & -124.338 & $c$ & 659.6 & 2380.6 & 52.27 \\
\hline 2 & Northridge & 1/17/19994 & $12: 30: 55$ & 6.70 & Mw & 34.2057 & -118.5539 & 17.5 & 2 & Tarzana & 34.16 & -118.534 & D & 257.21 & 1970.7 & 109.88 \\
\hline 3 & Cape Mendocino & 4/25/1992 & 18:06:04 & 7.00 & Mw & 40.3338 & -124.2294 & 21 & 2 & $\begin{array}{l}\text { Cape Mendocino, } \\
\text { Petrolia }\end{array}$ & 40.348 & -124.352 & D & 311.8 & 1843.5 & 138.15 \\
\hline 4 & Niigata-Ken Chuetsu & 10/23/2004 & 8:56:00 & 6.60 & Mw & 37.229 & 138.773 & 15.8 & 2 & Kawaguchi & & & & -1 & 1839.3 & 144.63 \\
\hline 5 & Imperial Valley 1979 & 10/15/1979 & 23:16:53 & 6.50 & Mw & 32.6435 & -115.3088 & 9.96 & 0 & El Centro Array \#6 & 32.839 & -115.49 & D & 203.2 & 1777.9 & 111.09 \\
\hline 6 & Niigata-Ken Chuetsu & 10/23/2004 & 8:56:00 & 6.60 & Mw & 37.229 & 138.773 & 15.8 & 2 & NIG021 Tohkamachi & 37.125 & 138.75 & C & 419 & 1765.7 & 74.10 \\
\hline 7 & Northridge & 1/17/1994 & $12: 30: 55$ & 6.70 & Mw & 34.2057 & -118.5539 & 17.5 & 2 & Pacoima Dam & 34.334 & -118.396 & A & 2016.1 & 1743.4 & 111.05 \\
\hline 8 & Miyagi-Oki & $5 / 26 / 2003$ & 9:24:33 & 7.00 & Mw & 38.805 & 141.682 & 71 & 7 & MYG011 Oshika & 38.2972 & 141.5043 & B & 1433 & 1586.7 & 60.52 \\
\hline 9 & Niigata-Ken Chuetsu & $10 / 23 / 2004$ & $8: 56: 00$ & 6.60 & Mw & 37.229 & 138.773 & 15.8 & 2 & NIG019 Ojiya & 37.3027 & 138.793 & D & 292 & 1533.3 & 136.60 \\
\hline 10 & Gazli & $5 / 17 / 1976$ & $2: 58: 40$ & 6.80 & & 40.465 & 63.462 & 18.2 & 2 & Karakyr & 40.35 & 63.47 & c & 659.6 & 1429.5 & 76.86 \\
\hline 11 & San Fernando & $2 / 9 / 1971$ & 14:00:41 & 6.60 & Mw & 34.44 & -118.41 & 13 & 2 & Pacoima Dam & 34.334 & -118.396 & A & 2016.1 & 1389.6 & 125.10 \\
\hline 12 & Miyagi-Oki & $5 / 26 / 2003$ & 9:24:33 & 7.00 & Mw & 38.805 & $\begin{array}{l}141.682 \\
141.41\end{array}$ & 71 & 7 & IWTH04 Sumita & 39.1781 & $\begin{array}{l}141.3944 \\
\end{array}$ & $\hat{c}$ & 456.0 & 1311.7 & 40.54 \\
\hline 13 & Parkfield 2004 & 9/28/2004 & 17:15:24 & 6.00 & Mw & 35.815 & -120.374 & 7.9 & 0 & Fault Zone 14 & 35.908 & -120.458 & 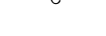 & -1 & 1287.1 & 88.50 \\
\hline 14 & Victoria & $6 / 9 / 1980$ & 3:28:19 & 6.40 & Mw & 32.185 & -115.076 & 11 & 0 & Victoria & 32.29 & -115.1 & D & 274.5 & $\begin{array}{l}1280.0 \\
-1\end{array}$ & 111.95 \\
\hline 15 & North Palm Springs & $7 / 8 / 1986$ & 9:20:44 & 6.20 & Mw & 34 & -116.6117 & 11 & 3 & Devers Substation & 33.932 & -116.579 & & -1 & 1269.0 & 107.43 \\
\hline 16 & Chi-Chi & 9/20/1999 & $17: 47: 16$ & 7.60 & Mw & 23.8603 & 120.7995 & 33 & 3 & CHY080 & 23.5972 & 120.6777 & C & 553.4 & 1254.2 & 128.06 \\
\hline 17 & Coalinga & $7 / 22 / 1983$ & $2: 39: 54$ & 6.00 & Mw & 36.241 & -120.409 & 7.4 & 2 & Transmitter Hill & 36.249 & -120.343 & c & 376.1 & 1250.1 & 65.81 \\
\hline 18 & Hokkaido & $12 / 14 / 2004$ & 5:56:09 & 5.80 & Mw & 44.108 & 141.753 & 10 & 2 & Minatomachi & 44.1463 & 141.668 & & -1 & 1206.8 & 70.86 \\
\hline 19 & Iran & 9/16/1978 & $15: 35: 56$ & 7.30 & MW & 33.37 & 57.02 & 11 & 2 & Tabas & 33.6 & 56.92 & B & 766.8 & 1201.5 & 36.51 \\
\hline 20 & El Salvador & $1 / 13 / 2001$ & 17:33:32 & 7.60 & Mw & 13.049 & -88.66 & 60 & 6 & $\begin{array}{l}\text { Puerto La Libertad, } \\
\text { La Libertad }\end{array}$ & 13.486 & -89.327 & & -1 & 1200.3 & 55.36 \\
\hline 21 & Morgan Hill & 4/24/1984 & 21:15:18 & 6.10 & Mw & 37.306 & -121.695 & 8.5 & 0 & Coyote Lake Dam & 37.118 & -121.55 & C & 597.1 & 1193.5 & 77.25 \\
\hline 22 & Loma Prieta & 10/18/1989 & 0:04:15 & 7.00 & Mw & 37.0407 & -121.8829 & 17.48 & 3 & LGPC & & & C & 477.7 & 1134.3 & 117.89 \\
\hline 23 & Bam & $12 / 26 / 2003$ & $1: 56: 56$ & 6.70 & Mw & 29.09 & 58.35 & 7 & 0 & Bam & 29.09 & 58.35 & & -1 & 1133.6 & 122.46 \\
\hline
\end{tabular}




\begin{tabular}{|c|c|c|c|c|c|c|c|c|c|c|c|c|c|c|c|c|}
\hline Rank & Earthquake Name & Date & Time & Magnitude & $\begin{array}{c}\text { Magnitude } \\
\text { Type }\end{array}$ & $\begin{array}{l}\text { Earthquake } \\
\text { Loatitude }\end{array}$ & $\begin{array}{l}\text { Earthquake } \\
\text { Longitude }\end{array}$ & $\begin{array}{l}\text { Depth } \\
(\mathrm{km})\end{array}$ & Mechanism & Station & $\begin{array}{l}\text { Station } \\
\text { Latitude }\end{array}$ & $\begin{array}{c}\text { Station } \\
\text { Longitude }\end{array}$ & $\begin{array}{l}\text { Preferred } \\
\text { NEHRP } \\
\text { Vs30 }\end{array}$ & $\begin{array}{l}\text { Preferred } \\
\mathrm{V}_{\mathrm{s} 30}(\mathrm{~m} / \mathrm{s})\end{array}$ & $\begin{array}{l}\text { PGA } \\
\text { 3D-Vec. } \\
\left(\mathrm{cm} / \mathrm{s}^{2}\right)\end{array}$ & $\begin{array}{c}\text { PGV } \\
\text { 3D-Vec. } \\
\text { (cm/s) }\end{array}$ \\
\hline 24 & Zanjiran & 6/20/1994 & 9:09:02 & 5.90 & Mw & 29.06 & 52.44 & & 0 & Zanjiran & 29.07 & 52.62 & & -1 & 1119.2 & 42.68 \\
\hline 25 & Northridge & 1/17/1994 & $12: 30: 55$ & 6.70 & Mw & 34.2057 & -118.5539 & 17.5 & 2 & $\begin{array}{l}\text { Jensen F.P. } \\
\text { Generator }\end{array}$ & 34.313 & -118.498 & c & 525.8 & 1114.9 & 98.91 \\
\hline 26 & Duzce Aftershock 1 & 11/12/1999 & 17:16:50 & 4.80 & mbGS & 40.76 & 31.02 & 10 & -1 & IRIGM 496 & 40.742 & 30.873 & & -1 & 1105.8 & 37.96 \\
\hline 27 & Western Tottori & $10 / 6 / 2000$ & 4:30:19 & 7.10 & $\mathrm{Mw}$ & 35.275 & 133.3937 & 11 & 0 & TTRHO2 Hino & 35.2281 & 133.3937 & D & 310 & 1104.5 & 125.36 \\
\hline 28 & Miyagi-Oki & $5 / 26 / 2003$ & $\begin{array}{l}9: 24: 33 \\
9\end{array}$ & 7.00 & Mw & 38.805 & 141.682 & 71 & 7 & $\begin{array}{l}\text { IWTH27 } \\
\text { Rikuzentakata }\end{array}$ & 39.0278 & 141.5356 & c & 670.0 & $\begin{array}{l}1099.7 \\
\end{array}$ & $\begin{array}{r}17.52 \\
\end{array}$ \\
\hline 29 & Duzce & 11/12/1999 & 16:57:27 & 7.10 & MW & 40.93 & 31.25 & 18 & 0 & $\begin{array}{l}\text { IRIGM } 496 \\
\text { In }\end{array}$ & 40.742 & 30.873 & & -1 & 1071.2 & 50.95 \\
\hline 30 & Mivagi-Oki & $5 / 2612003$ & $9: 24: 33$ & 7.00 & Mw & 38.805 & 141.682 & 71 & 7 & IWT007 Kamaishi & 39.2701 & 141.8561 & $E$ & 141 & 1061.6 & 25.07 \\
\hline 31 & Northridge & $1 / 17 / 1994$ & $12: 30: 55$ & 6.70 & Mw & 34.2057 & -118.5539 & 17.5 & 2 & $\begin{array}{l}\text { Rinaldi Receiving } \\
\text { Station }\end{array}$ & 34.281 & -118.478 & D & 282.3 & 1035.5 & 160.48 \\
\hline 32 & Chi-Chi & 9/20/1999 & 17:47:16 & 7.60 & Mw & 23.8603 & 120.7995 & 33 & 3 & $\begin{array}{l}\text { SCU084 } \\
\text { TCU0 }\end{array}$ & 23.883 & 120.8998 & c & 553.4 & 1034.0 & 124.10 \\
\hline 33 & Chi-Chi & 9/20/1999 & 17:47:16 & 7.60 & Mw & 23.8603 & 120.7995 & 33 & 3 & TCU129 & 23.8783 & 120.6843 & $\mathrm{c}$ & 664.4 & 1002.9 & 71.43 \\
\hline 34 & $\begin{array}{l}\text { Nigata-Ken Chuetsu } \\
\text { aftershock } 3\end{array}$ & 10/23/2004 & 9:34:07 & 6.30 & Mw & 37.28 & 138.787 & 22.2 & 2 & NIG021 Tohkamachi & 37.125 & 138.75 & $\mathrm{c}$ & 419 & 993.7 & 57.70 \\
\hline 35 & Tokachi-Oki & 9/25/2003 & 19:50:07 & 8.00 & Mw & 41.778 & 144.078 & 42 & 7 & HKD100 Hiroo & 42.2838 & 143.3158 & D & 236 & 992.2 & 52.12 \\
\hline 36 & $\begin{array}{l}\text { Southern Honshu } \\
\text { (-Fukui) }\end{array}$ & $3 / 25 / 2007$ & 0:42:00 & 6.90 & Mjma & 37.22 & 136.685 & 11 & 2 & ISK006 & 37.1602 & 136.6897 & c & 406 & 975.8 & 57.24 \\
\hline 37 & Duzce & 11/12/1999 & $16: 57: 27$ & 7.10 & MW & 40.93 & 31.25 & 18 & 0 & Lamont 375 & 40.743 & 30.876 & c & 424.8 & 971.7 & 35.72 \\
\hline 38 & Anza & 6/12/2005 & 15:41:46 & 5.20 & Mw & 33.533 & -116.578 & 14.1 & 0 & Santa Rosa & 33.568 & -116.51 & & -1 & 959.9 & 17.32 \\
\hline 39 & Coalinga & $7 / 22 / 1983$ & 2:39:54 & 6.00 & Mw & 36.241 & -120.409 & 7.4 & 2 & Oil City & 36.229 & -120.36 & c & 376.1 & 958.8 & 47.56 \\
\hline 40 & Kyushu & $5 / 13 / 1997$ & $5: 38: 30$ & 6.20 & Mw & 32 & 130.3 & 8 & 0 & KGSO05 Miyanojoh & 31.897 & 130.454 & c- & 356 & 958.2 & 47.46 \\
\hline 41 & Northridge & 1/17/19994 & $12: 30: 55$ & 6.70 & Mw & 34.2057 & -118.5539 & 17.5 & 2 & $\begin{array}{l}\text { Sepulvelda VA } \\
\text { Hospital }\end{array}$ & 34.249 & -118.478 & c & 380.1 & 949.6 & 80.26 \\
\hline 42 & Miyagi-Oki & $5 / 26 / 2003$ & $9: 24: 33$ & 7.00 & Mw & 38.805 & 141.682 & 71 & 7 & MYG002 Utatsu & 38.7262 & 141.5109 & c & 469 & 948.8 & 22.96 \\
\hline 43 & Chi-Chi & 9/20/1999 & $17: 47: 16$ & 7.60 & Mw & 23.8603 & 120.7995 & 33 & 3 & WNT & 23.8783 & 120.6843 & c & 664.4 & 946.7 & 66.45 \\
\hline 44 & $\begin{array}{l}\text { Southern Honshu } \\
\text { (-Fukui) }\end{array}$ & $3 / 25 / 2007$ & $0: 42: 00$ & 6.90 & Mjma & 37.22 & 136.685 & 11 & 2 & ISK005 & 37.2307 & 136.9039 & D+ & 323 & 945.5 & 102.53 \\
\hline 45 & Parkfield 2004 & 9/28/2004 & 17:15:24 & 6.00 & Mw & 35.815 & -120.374 & 7.9 & 0 & Fault Zone 11 & 35.896 & -120.398 & & -1 & 940.6 & 28.71 \\
\hline 46 & Imperial Valley & $10 / 15 / 1979$ & 23:16:53 & 6.50 & Mw & 32.6435 & -115.3088 & 9.96 & 0 & Agrarias & 32.621 & -115.301 & D & 274.5 & 939.4 & 46.63 \\
\hline 47 & Niigata-Ken Chuetsu & $10 / 23 / 2004$ & 8:56:00 & 6.60 & Mw & 37.229 & 138.773 & $\begin{array}{l}9.90 \\
15.8\end{array}$ & 2 & $\begin{array}{l}\text { NIG028 Nagaoka- } \\
\text { Shisho }\end{array}$ & 37.4231 & 138.8894 & U & -1 & 913.2 & $\begin{array}{l}40.05 \\
67.22\end{array}$ \\
\hline 48 & Parkfield 2004 & 9/28/2004 & 17:15:24 & 6.00 & Mw & 35.815 & -120.374 & 7.9 & 0 & Stone Corral 1E & 35.788 & -120.294 & & -1 & 912.7 & 43.61 \\
\hline 49 & El Salvador & $1 / 13 / 2001$ & $17: 33: 32$ & 7.60 & Mw & 13.049 & -88.66 & 60 & 6 & Santiago de Maria & & & & -1 & 911.5 & 41.00 \\
\hline 50 & Chi-Chi & $\begin{array}{l}9 / 20 / 1999 \\
9\end{array}$ & 17:47:16 & 7.60 & Mw & 23.8603 & 120.7995 & 33 & 3 & TCU079 & 23.8395 & 120.8942 & c & 364.0 & 908.6 & 50.24 \\
\hline 51 & Kyushu & 3/26/1997 & 8:31:47 & 6.30 & Mw & 32 & 130.4 & 8 & 0 & KGS002 Izumi & 32.087 & 130.356 & c & 442 & 903.9 & 16.63 \\
\hline 52 & Duzce & $11 / 12 / 1999$ & $16: 57: 27$ & 7.10 & MW & 40.93 & 31.25 & 18 & 0 & Bolu & 40.746 & 31.607 & D & 326.0 & 901.5 & 64.19 \\
\hline 53 & Hokkaido & $11 / 28 / 2004$ & 18:32:00 & 7.10 & Mjma & 42.946 & 145.274 & 48 & 8 & KSRH06 TSURUI-E & 43.2175 & 144.4325 & & 326 & 886.5 & 31.75 \\
\hline 54 & Kobe & 1/16/1995 & 20:46:52 & 6.90 & $\mathrm{Mw}$ & 34.5948 & 135.0121 & 17.9 & 0 & KJMA & 34.6833 & 135.18 & D & 312.0 & 884.0 & 99.78 \\
\hline 55 & Northridge & $\begin{array}{l}1 / 177 / 1994 \\
1 / 19\end{array}$ & $12: 30: 55$ & 6.70 & Mw & $\begin{array}{l}34.2057 \\
34.05\end{array}$ & -118.5539 & 17.5 & 2 & Newhall F.S. & $\begin{array}{l}34.39 \\
34.000\end{array}$ & $\begin{array}{l}-118.53 \\
-11.53\end{array}$ & D & 269.1 & 878.6 & $\begin{array}{r}391.70 \\
121\end{array}$ \\
\hline 56 & Western Tottori & $10 / 6 / 2000$ & $4: 30: 19$ & 7.10 & Mw & 35.275 & 133.3937 & 11 & 0 & OKYOO4 Nimi & 34.9579 & 133.5018 & $\mathrm{c}$ & 411 & $\begin{array}{l}878.2 \\
878.2\end{array}$ & 26.42 \\
\hline 57 & Valapraiso & $3 / 3 / 1985$ & 22:47:07 & 7.80 & Mw & -33.135 & -71.871 & 33 & 7 & Llolleo & -32.635 & -71.63 & & -1 & 878.2 & 43.25 \\
\hline 58 & Miyagi-Oki & $5 / 26 / 2003$ & $9: 24: 33$ & 7.00 & Mw & 38.805 & 141.682 & 71 & 7 & MYGHO3 Karakuwa & 38.9189 & 141.6422 & B & 951 & 874.1 & 14.50 \\
\hline 59 & Northridge & $1 / 17 / 1994$ & $12: 30: 55$ & 6.70 & Mw & 34.2057 & -118.5539 & 17.5 & 2 & $\begin{array}{l}\text { Sylmar Valve Hall } \\
\text { Floor- Converter } \\
\text { Station East }\end{array}$ & 34.312 & -118.481 & $\mathrm{c}$ & 370.5 & 872.2 & 122.56 \\
\hline 60 & El Salvador & 1/13/2001 & $17: 33: 32$ & 7.60 & Mw & 13.049 & -88.66 & 60 & 6 & Santa Tecla & 13.675 & -89.3 & & -1 & 868.6 & 60.48 \\
\hline 61 & South Iceland & $6 / 17 / 2000$ & $15: 40: 41$ & 6.57 & MW & 63.97 & -20.36 & 15 & 0 & 006263 Kaldarholt & 64.004 & -20.474 & & -1 & 868.5 & 45.07 \\
\hline 62 & Northridge & 1/17/1994 & $12: 30: 55$ & 6.70 & $\mathrm{Mw}$ & 34.2057 & -118.5539 & 17.5 & 2 & $\begin{array}{l}\text { Santa Monica City } \\
\text { Hall }\end{array}$ & 34.011 & -118.49 & D & 336.2 & 866.4 & 43.29 \\
\hline 63 & Off Southern Honshu & 4/15/2007 & 3:19:00 & 5.40 & Mjma & 34.787 & 136.41 & 16 & -1 & MIEH10 GEINOU & 34.8194 & 136.4275 & c & 422 & 862.4 & 27.54 \\
\hline 64 & Parkfield 2004 & - 9/28/2004 & 17:15:24 & 6.00 & Mw & 35.815 & -120.374 & 7.9 & 0 & $\begin{array}{l}\text { Fault Zone } 1 \\
\end{array}$ & $\begin{array}{l}35.758 \\
35.758\end{array}$ & -120.307 & & -1 & 861.3 & 82.30 \\
\hline $\begin{array}{l}04 \\
65\end{array}$ & Nisqually & $2 / 28 / 2001$ & 18:54:31 & 6.80 & Mw & 47.167 & $\begin{array}{l}-122.733 \\
-123\end{array}$ & 52.4 & 6 & Seattle & 47.5842 & -122.3331 & & -1 & 859.2 & 42.30 \\
\hline $\begin{array}{l}65 \\
66\end{array}$ & Miyagi-Oki & $5 / 26 / 2003$ & $\begin{array}{l}10.54 .31 \\
9: 24: 33\end{array}$ & $\begin{array}{l}0.00 \\
7.00\end{array}$ & Mw & $\begin{array}{l}47.101 \\
38.805\end{array}$ & $\begin{array}{l}-122.135 \\
141.682\end{array}$ & $\begin{array}{l}52.4 \\
71\end{array}$ & 7 & $\begin{array}{l}\text { IWTHOE Tamayama } \\
\text { IWTO2 }\end{array}$ & $\begin{array}{l}41.5084 \\
39.8222\end{array}$ & $\begin{array}{l}-12.23351 \\
141.3861\end{array}$ & c & $\begin{array}{c}-1 \\
390.0\end{array}$ & $\begin{array}{l}\quad \begin{array}{l}359.2 \\
855.1\end{array}-1 \\
\end{array}$ & $\begin{array}{l}42.30 \\
19.59\end{array}$ \\
\hline $\begin{array}{l}60 \\
67\end{array}$ & Niigata-Ken Chuetsu & 10/23/2004 & $\begin{array}{l}8.45600 \\
8: 56: 00\end{array}$ & 6.60 & Mw & $\begin{array}{l}50.005 \\
37.229\end{array}$ & $\begin{array}{l}14.1082 \\
138.773\end{array}$ & $\begin{array}{l}11 \\
15.8\end{array}$ & 2 & NIGHO1 NAGAOKA & $\begin{array}{l}39.0222 \\
37.4242\end{array}$ & $\begin{array}{c}14.5801 \\
138.87\end{array}$ & $c$ & $\begin{array}{l}390.0 \\
-1\end{array}$ & $\begin{array}{l}853.1 \\
855.0\end{array}$ & $\begin{array}{l}19.59 \\
69.77\end{array}$ \\
\hline 68 & $\begin{array}{l}\text { Southern Honshu } \\
\text { Soutan }\end{array}$ & $\begin{array}{r}1 / 23 / 2004 \\
3 / 24 / 2001\end{array}$ & $\begin{array}{l}8.560 .00 \\
6: 27: 54\end{array}$ & $\begin{array}{l}0.00 \\
6.40\end{array}$ & Mw & $\begin{array}{l}37.229 \\
34.12\end{array}$ & $\begin{array}{l}138.708 \\
132.708\end{array}$ & $\begin{array}{c}15.8 \\
51\end{array}$ & 6 & $\begin{array}{l}\text { HRSO09 Yuki } \\
\text { HRAOA }\end{array}$ & $\begin{array}{l}31.442 \\
34.4926\end{array}$ & $\begin{array}{l}138.81 \\
132.2794\end{array}$ & c & $\begin{array}{c}-1 \\
473\end{array}$ & $\begin{array}{l}855.0 \\
851.2\end{array}$ & 31.23 \\
\hline 69 & $\begin{array}{l}\text { Kashiwazaki, Nigata, } \\
\text { Japan }\end{array}$ & $7 / 16 / 2007$ & $1: 13: 28$ & 6.60 & Mw & 37.5 & 138.6 & 10 & 2 & NIG018 Kashiwazaki & 37.3724 & 138.5579 & D & 180 & 849.5 & 152.11 \\
\hline 70 & Miyagi-Oki & $5 / 26 / 2003$ & 9:24:33 & 7.00 & Mw & 38.805 & 141.682 & 71 & 7 & IWTH21 Yamada & 39.4706 & 141.9372 & c & 527.0 & 848.6 & 24.22 \\
\hline
\end{tabular}




\begin{tabular}{|c|c|c|c|c|c|c|c|c|c|c|c|c|c|c|c|c|}
\hline Rank & Earthquake Name & Date & Time & Magnitude & $\begin{array}{c}\text { Magnitude } \\
\text { Type }\end{array}$ & $\begin{array}{c}\text { Earthquake } \\
\text { Loatitude }\end{array}$ & $\begin{array}{c}\text { Earthquake } \\
\text { Longitude }\end{array}$ & $\begin{array}{l}\text { Depth } \\
(\mathrm{km})\end{array}$ & Mechanism & Station & $\begin{array}{l}\text { Station } \\
\text { Latitude }\end{array}$ & $\begin{array}{c}\text { Station } \\
\text { Longitude }\end{array}$ & $\begin{array}{c}\text { Preferred } \\
\text { NEHRP } \\
\text { Vs30 }\end{array}$ & $\begin{array}{l}\text { Preferred } \\
\mathrm{V}_{\mathrm{s} 30}(\mathrm{~m} / \mathrm{s})\end{array}$ & $\begin{array}{c}\text { PGA } \\
\text { 3D-Vec. } \\
\left.\text { (cm/s } / \mathrm{s}^{2}\right)\end{array}$ & $\begin{array}{c}\text { PGV } \\
\text { 3D-Vec. } \\
\text { (cm/s) }\end{array}$ \\
\hline 71 & Western Tottori & $10 / 6 / 2000$ & 4:30:19 & 7.10 & Mw & 35.275 & 133.3937 & 11 & 0 & SMNH01 Hakuta & 35.2931 & 133.263 & C & 464 & 843.1 & 43.63 \\
\hline 72 & $\begin{array}{l}\text { South Iceland } \\
\text { Aftershock }\end{array}$ & $6 / 21 / 2000$ & 0:51:48 & 6.49 & MW & 63.97 & -20.71 & & 0 & 006349 Thjorsarbru & 63.931 & -20.649 & & -1 & 833.7 & 104.09 \\
\hline 73 & Northridge & 1/177/1994 & 12:30:55 & 6.70 & Mw & 34.2057 & -118.5539 & 17.5 & 2 & $\begin{array}{l}\text { Sylmar County } \\
\text { Hospital (Olive View) }\end{array}$ & 34.326 & -118.444 & c & 440.54 & 827.4 & 131.19 \\
\hline 74 & $\begin{array}{l}\text { Niigata-Ken Chuetsu } \\
\text { aftershock } 3\end{array}$ & 10/23/2004 & 9:34:07 & 6.30 & Mw & 37.28 & 138.787 & 22.2 & 2 & $\begin{array}{l}\text { NIG019 Ojiya } \\
\text { Nill }\end{array}$ & 37.3027 & 138.793 & D & 292 & 826.5 & 71.61 \\
\hline 75 & $\begin{array}{l}\text { Nigata-Ken Chuetsu } \\
\text { aftershock } 1\end{array}$ & 10/23/2004 & 9:03:00 & 6.30 & Mjma & 37.35 & 138.985 & 9 & 2 & NIGH01 Nagaoka & 37.4242 & 138.87 & & -1 & 826.3 & 41.86 \\
\hline 76 & Valapraiso & $3 / 3 / 1985$ & 22:47:07 & 7.80 & Mw & -33.135 & -71.871 & 33 & 7 & San Isidro & & & & -1 & 823.0 & 45.80 \\
\hline 77 & Chi-Chi & 9/20/1999 & $17: 47: 16$ & 7.60 & Mw & 23.8603 & 120.7995 & 33 & 3 & TCU071 & 23.9855 & 120.7883 & c & 624.9 & 820.4 & 71.43 \\
\hline 78 & Northridge & 1/117/1994 & $12: 30: 55$ & 6.70 & Mw & 34.2057 & -118.5539 & 17.5 & 2 & 17645 Saticoy St., & 34.2089 & -118.5172 & D & 280.9 & 812.7 & 62.72 \\
\hline 79 & Chi-Chi & 9/20/1999 & $17: 47: 16$ & 7.60 & Mw & 23.8603 & 120.7995 & 33 & 3 & CHY028 & 23.632 & 120.6052 & c & 542.6 & 812.1 & 80.17 \\
\hline 80 & Tokachi-Oki & 9/25/2003 & $19: 50: 07$ & 8.00 & Mw & 41.778 & 144.078 & 42 & 7 & HKD086 Chokubetsu & 42.8526 & 143.8636 & D & 201 & 810.8 & 80.87 \\
\hline 81 & Duzce Aftershock 2 & $11 / 12 / 19999$ & 17:17:56 & 5.50 & mbGS & 40.78 & 31.12 & 10 & -1 & IRIGM 496 & 40.742 & 30.873 & & -1 & 810.2 & 33.88 \\
\hline 82 & Landers & 6/28/1992 & $11: 57: 34$ & 7.30 & Mw & 34.201 & -116.436 & 7 & 0 & Lucerne & 34.5675 & -116.6122 & c & 684.9 & 807.5 & 147.49 \\
\hline 83 & Northridge aftershock & 1/29/1994 & 11:20:35 & 5.10 & Mw & 34.31 & -118.58 & & -1 & Brown's Canyon & 34.307 & -118.603 & & -1 & 803.9 & 39.59 \\
\hline 84 & Western Tottori & $10 / 6 / 2000$ & 4:30:19 & 7.10 & Mw & 35.275 & 133.3937 & 11 & 0 & TTR007 Kohfu & 35.2826 & 133.4876 & C & 404 & 797.8 & 42.45 \\
\hline 85 & Northridge & 1/17/1994 & $12: 30: 55$ & 6.70 & Mw & 34.2057 & -118.5539 & 17.5 & 2 & Simi Valley & 34.264 & -118.666 & C & 557.4 & 796.2 & 68.31 \\
\hline 86 & Chi-Chi & 9/20/1999 & $17: 47: 16$ & 7.60 & Mw & 23.8603 & 120.7995 & 33 & 3 & TCU065 & 24.0588 & 120.6912 & D & 305.9 & 795.8 & 151.42 \\
\hline 87 & Northridge & 1/17/1994 & 12:30:55 & 6.70 & Mw & 34.2057 & -118.5539 & 17.5 & 2 & $\begin{array}{l}\text { Sylmar Converter Stn } \\
\text { Valve Group } 7\end{array}$ & 34.311 & -118.49 & D & 251.24 & 786.2 & 134.93 \\
\hline 88 & Parkfield 2004 & 9/28/2004 & 17:15:24 & 6.00 & Mw & 35.815 & -120.374 & 7.9 & 0 & Joaquin Canyon & 35.9397 & -120.4319 & & -1 & 781.9 & 32.82 \\
\hline 89 & Off Southern Honshu & $4 / 15 / 2007$ & 3:19:00 & 5.40 & Mjma & 34.787 & 136.41 & 16 & -1 & MIE004 & 34.8569 & 136.4493 & c & 404 & 781.8 & 35.19 \\
\hline 90 & Imperial Valley 1979 & 10/15/1979 & $23: 16: 53$ & 6.50 & Mw & 32.6435 & -115.3088 & 9.96 & 0 & Bonds Corner & 32.6932 & -115.3382 & D & 223.0 & 781.1 & 53.13 \\
\hline 91 & North Palm Springs & $7 / 8 / 1986$ & 9:20:44 & 6.20 & Mw & 34 & -116.6117 & 11 & 3 & $\begin{array}{l}\text { North Palm Springs } \\
\text { Post Office }\end{array}$ & 33.924 & -116.543 & D & 345.4 & 769.0 & 74.27 \\
\hline 92 & Kyushu & $5 / 13 / 1997$ & 5:38:30 & 6.20 & Mw & 32 & 130.3 & 8 & 0 & KGSO02 Izumi & 32.0909 & 130.3532 & c & 442 & 763.4 & 23.05 \\
\hline 93 & Manili, Iran & $6 / 20 / 1990$ & 9:00:10 & 7.40 & Mw & 36.95 & 49.52 & 18 & 0 & Abbar & 36.92 & 48.97 & $\mathrm{c}$ & 724.0 & 762.8 & 101.55 \\
\hline 94 & $\begin{array}{l}\text { Niigata-Ken Chuetsu } \\
\text { aftershock } 3\end{array}$ & 10/23/2004 & 9:34:07 & 6.30 & Mw & 37.28 & 138.787 & 22.2 & 2 & NIGH11 Kawanishi & 37.1697 & 138.7472 & c & 375 & 761.6 & 47.36 \\
\hline 95 & Kobe & 1/16/1995 & 20:46:52 & 6.90 & Mw & 34.5948 & 135.0121 & 17.9 & 0 & Takarazuka & 34.809 & 135.344 & D & 312.0 & 756.5 & 89.50 \\
\hline 96 & Western Tottori & $10 / 6 / 2000$ & 4:30:19 & 7.10 & Mw & 35.275 & 133.3937 & 11 & 0 & TTR009 Nichinan & 35.1629 & 133.3063 & $\mathrm{c}$ & 423 & 745.7 & 41.59 \\
\hline 97 & Imperial Valley 1979 & $10 / 15 / 1979$ & $23: 16: 53$ & 6.50 & Mw & 32.6435 & -115.3088 & 9.96 & 0 & Differential Array & 32.796 & -115.535 & D & 202.3 & 742.7 & 74.39 \\
\hline 98 & Parkfield 2004 & 9/28/2004 & $17: 15: 24$ & 6.00 & Mw & 35.815 & -120.374 & 7.9 & 0 & Cholame 3E & 35.77 & -120.247 & & -1 & 741.6 & 34.77 \\
\hline 99 & Umbria Marche, Italy & 9/26/1997 & 9:40:33 & 6.04 & Mw & 43.031 & 12.862 & 6 & 1 & 0594 Nocera Umbra & 43.113 & 12.785 & & -1 & 737.0 & 40.73 \\
\hline 100 & Michoacan Aftershock & $\begin{array}{l}9 / 21 / 1985 \\
9\end{array}$ & $\begin{array}{l}3.437: 13 \\
1: 30\end{array}$ & 7.50 & Mw & $\begin{array}{l}4.051 \\
17.8\end{array}$ & $\begin{array}{l}-101.65 \\
-\end{array}$ & 30 & 7 & Paraiso & 17.343 & -100.225 & & -1 & 736.1 & 12.43 \\
\hline
\end{tabular}

\section{B. Top 100 velocities}

\begin{tabular}{|c|c|c|c|c|c|c|c|c|c|c|c|c|c|c|c|c|}
\hline Rank & Earthquake Name & Date & Time & Magnitude & $\begin{array}{c}\text { Magnitude } \\
\text { Type }\end{array}$ & $\begin{array}{l}\text { Earthquake } \\
\text { Loatitude }\end{array}$ & $\begin{array}{l}\text { Earthquake } \\
\text { Longitude }\end{array}$ & $\begin{array}{l}\text { Depth } \\
(\mathrm{km})\end{array}$ & Mechanism & Station & $\begin{array}{l}\text { Station } \\
\text { Latitude }\end{array}$ & $\begin{array}{c}\text { Station } \\
\text { Longitude }\end{array}$ & $\begin{array}{l}\text { Preferred } \\
\text { NEHRP } \\
\text { Vs30 }\end{array}$ & $\begin{array}{l}\text { Preferred } \\
\mathrm{V}_{\mathrm{s}} 30(\mathrm{~m} / \mathrm{s})\end{array}$ & $\begin{array}{c}\text { PGA } \\
\text { 3D-Vec. } \\
\left(\mathrm{cm} / \mathrm{s}^{2}\right)\end{array}$ & $\begin{array}{c}\text { PGV } \\
\text { 3D-Vec. } \\
\text { (cm/s) }\end{array}$ \\
\hline 1 & Chi-Chi & 9/20/1999 & 17:47:16 & 7.60 & Mw & 23.8603 & 120.7995 & 33 & 3 & TCU068 & 24.2772 & 120.7658 & $\mathrm{C}$ & 487.3 & 583.5 & 317.57 \\
\hline 2 & Chi-Chi & 9/20/1999 & $17: 47: 16$ & 7.60 & $\mathrm{Mw}$ & 23.8603 & 120.7995 & 33 & 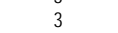 & TCU052 & 24.198 & 120.7393 & C & 393.2 & 502.2 & 200.45 \\
\hline 3 & Kobe & 1/16/1995 & 20:46:52 & $\begin{array}{l}1.900 \\
6.90\end{array}$ & Mw & $\begin{array}{l}34.50948 \\
34.5948\end{array}$ & 135.0121 & 17.9 & 0 & Takatori & 34.649 & 135.139 & D & $\begin{array}{l}250.2 \\
256.0\end{array}$ & 688.1 & 169.72 \\
\hline 4 & Northridge & 1/117/1994 & $12: 30: 55$ & 6.70 & Mw & 34.2057 & -118.5539 & 17.5 & 2 & $\begin{array}{l}\text { Rinaldi Receiving } \\
\text { Station }\end{array}$ & 34.281 & -118.478 & D & 282.3 & 1035.5 & 160.48 \\
\hline 5 & $\begin{array}{l}\text { Kashiwazaki, Niigata, } \\
\text { Japan }\end{array}$ & $7 / 16 / 2007$ & 1:13:28 & 6.60 & Mw & 37.5 & 138.6 & 10 & 2 & NIG018 Kashiwazaki & 37.3724 & 138.5579 & D & 180 & 849.5 & 152.11 \\
\hline 6 & Chi-Chi & 9/20/1999 & 17:47:16 & 7.60 & Mw & 23.8603 & 120.7995 & 33 & 3 & TCU065 & 24.0588 & 120.6912 & 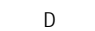 & 305.9 & 795.8 & 151.42 \\
\hline 7 & Landers & $6 / 2$ & 11:57:34 & 7. & Mw & 34.201 & -116.436 & 7 & 0 & Lucerne & 34.5675 & -116.6122 & 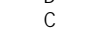 & 684.9 & 807.5 & 147.49 \\
\hline 8 & $\begin{array}{l}\text { Lanuers } \\
\text { Nigata-Ken }\end{array}$ & $\begin{array}{l}0 / 281 / 924 \\
10 / 23 / 2004\end{array}$ & $8: 5$ & 6. & Mw & $\begin{array}{l}34 \\
37 \\
\end{array}$ & & $\begin{array}{l}1 \\
15.8\end{array}$ & 2 & Kawaguchi & & & & -1 & 1839.3 & 144.63 \\
\hline 9 & Cane Mendocino & $4 / 25 / 1992$ & 18.06 .04 & 7.00 & Mw & 40.3338 & -124.2294 & 21 & 2 & Cane Mendocino. & 40,348 & -124.352 & D & 311.8 & 18435 & 138.15 \\
\hline
\end{tabular}




\begin{tabular}{|c|c|c|c|c|c|c|c|c|c|c|c|c|c|c|c|c|}
\hline Rank & Earthquake Name & Date & Time & Magnitude & $\begin{array}{c}\text { Magnitude } \\
\text { Type }\end{array}$ & $\begin{array}{l}\text { Earthquake } \\
\text { Loatitude }\end{array}$ & $\begin{array}{l}\text { Earthquake } \\
\text { Longitude }\end{array}$ & $\begin{array}{l}\text { Depth } \\
(\mathrm{km})\end{array}$ & Mechanism & Station & $\begin{array}{c}\text { Station } \\
\text { Latitude }\end{array}$ & $\begin{array}{c}\text { Station } \\
\text { Longitude }\end{array}$ & $\begin{array}{c}\text { Preferred } \\
\text { NEHRP } \\
\text { Vs30 }\end{array}$ & $\begin{array}{l}\text { Preferred } \\
\mathrm{V}_{\mathrm{s}} 30(\mathrm{~m} / \mathrm{s}) \\
\end{array}$ & $\begin{array}{l}\text { PGA } \\
\text { 3D-Vec. } \\
\text { (cm/st) }\end{array}$ & $\begin{array}{l}\text { PGV } \\
\text { 3D-Vec. } \\
(\mathrm{cm} / \mathrm{s})\end{array}$ \\
\hline 10 & & 10/23/2004 & $8: 56: 00$ & 6.60 & $M w$ & 37.229 & 138.773 & 158 & 2 & $\begin{array}{l}\text { Petrolia } \\
\text { LIG019 }\end{array}$ & & & $D$ & & & \\
\hline 11 & $\begin{array}{l}\text { Niligata-ken Chuelsu } \\
\text { Northridge }\end{array}$ & $1 / 17 / 1994$ & $12: 30: 55$ & 6.70 & Mw & 34.2057 & $\begin{array}{l}1388.7 / 3 \\
-118.5539\end{array}$ & $\begin{array}{l}15.8 \\
17.5\end{array}$ & $\begin{array}{l}2 \\
2\end{array}$ & $\begin{array}{l}\text { NIG0191 OJjya } \\
\text { Sylmar Converter Stn }\end{array}$ & $\begin{array}{l}37.3021 \\
34.311\end{array}$ & $\begin{array}{l}138.193 \\
-118.49\end{array}$ & $\begin{array}{l}D \\
D\end{array}$ & $\begin{array}{l}292 \\
251.24\end{array}$ & $\begin{array}{l}1533.3 \\
786.2\end{array}$ & $\begin{array}{l}133.60 \\
134.93\end{array}$ \\
\hline 12 & Northridge & 1/17/1994 & 12:30:55 & 6.70 & Mw & 34.2057 & -118.5539 & 17.5 & 2 & $\begin{array}{l}\text { Valve Group } 7 \\
\text { Sylmar County } \\
\text { Hospital (Olive View) }\end{array}$ & 34.326 & -118.444 & c & 440.54 & 827.4 & 131.19 \\
\hline 13 & Chi-Chi & 9/20/1999 & 17:47:16 & 7.60 & Mw & 23.8603 & 120.7995 & 33 & 3 & CHY080 & 23.5972 & 120.6777 & c & 553.4 & 1254.2 & 128.06 \\
\hline 14 & Western Tottori & 10/6/2000 & 4:30:19 & 7.10 & Mw & 35.275 & 133.3937 & 11 & 0 & TTRH02 Hino & 35.2281 & 133.3937 & D & 310 & 1104.5 & 125.36 \\
\hline 15 & San Fernando & 2/9/1971 & 14:00:41 & 6.60 & Mw & 34.44 & -118.41 & 13 & 2 & Pacoima Dam & 34.334 & -118.396 & A & 2016.1 & 1389.6 & 125.10 \\
\hline 16 & Chi-Chi & 9/20/1999 & 17:47:16 & 7.60 & Mw & 23.8603 & 120.7995 & 33 & 3 & TCU084 & 23.883 & 120.8998 & c & 553.4 & 1034.0 & 124.10 \\
\hline 17 & Northridge & 1/17/19994 & $12: 30: 55$ & 6.70 & Mw & 34.2057 & -118.5539 & 17.5 & 2 & $\begin{array}{l}\text { Sylmar Converter Stn } \\
\text { Valve Group 1-6 }\end{array}$ & 34.312 & -118.481 & c & 370.52 & 684.9 & 123.74 \\
\hline 18 & Northridge & 1/17/1994 & 12:30:55 & 6.70 & Mw & 34.2057 & -118.5539 & 17.5 & 2 & $\begin{array}{l}\text { Sylmar Valve Hall } \\
\text { Floor - Converter } \\
\text { Station East }\end{array}$ & 34.312 & -118.481 & c & 370.5 & 872.2 & 122.56 \\
\hline 19 & Bam & 12/26/2003 & 1:56:56 & 6.70 & Mw & 29.09 & 58.35 & 7 & 0 & Bam & 29.09 & 58.35 & & -1 & 1133.6 & 122.46 \\
\hline 20 & Northridge & 1/17/1994 & 12:30:55 & 6.70 & Mw & 34.2057 & -118.5539 & 17.5 & 2 & Newhall F.S. & 34.39 & -118.53 & D & 269.1 & 878.6 & 121.71 \\
\hline 21 & Loma Prieta & 10/18/1989 & 0:04:15 & 7.00 & Mw & 37.0407 & -121.8829 & 17.48 & 3 & $\begin{array}{l}\text { Los Gatos Lexington } \\
\text { Dam }\end{array}$ & 37.202 & -121.949 & B & 1070.3 & 462.5 & 121.50 \\
\hline 22 & Superstition Hills & 11/24/1987 & 13:16:00 & 6.70 & MLbrk & 33.01 & -115.84 & 2 & 0 & $\begin{array}{l}\text { Superstition Mtn. } \\
\text { Camera }\end{array}$ & 32.955 & -115.823 & c & 362.4 & 206.6 & 120.79 \\
\hline 23 & Northridge & 1/17/1994 & 12:30:55 & 6.70 & Mw & 34.2057 & -118.5539 & 17.5 & 2 & $\begin{array}{l}\text { West Pico Canyon } \\
\text { Road }\end{array}$ & 34.391 & -118.621 & D & 285.9 & 414.1 & 118.49 \\
\hline 24 & Loma Prieta & 10/18/1989 & $0: 04: 15$ & 7.00 & Mw & 37.0407 & -121.8829 & 17.48 & 3 & LGPC & & & c & 477.7 & 1134.3 & 117.89 \\
\hline 25 & Northridge & 1/17/19994 & 12:30:55 & 6.70 & Mw & 34.2057 & -118.5539 & 17.5 & 2 & $\begin{array}{l}\text { Jensen F.P. } \\
\text { Administration Bldg }\end{array}$ & 34.312 & -118.496 & c & 373.1 & 621.9 & 116.86 \\
\hline 26 & Chi-Chi & 9/20/1999 & 17:47:16 & 7.60 & Mw & 23.8603 & 120.7995 & 33 & 3 & TCU102 & 24.2493 & 120.7208 & c & 714.3 & 308.2 & 115.47 \\
\hline 27 & Superstition Hills & 11/24/1987 & 13:15:56 & 6.70 & MLbrk & 33.01 & -115.84 & 2 & 0 & Parachute Test Site & 32.93 & -115.7 & D & 348.7 & 556.3 & 114.67 \\
\hline 28 & Chi-Chi & 9/20/1999 & $17: 47: 16$ & 7.60 & $\mathrm{Mw}$ & 23.8603 & 120.7995 & 33 & 3 & TCU075 & 23.9827 & 120.6778 & c & 549.4 & 331.5 & 113.01 \\
\hline 29 & Victoria & $6 / 9 / 1980$ & $3: 28: 19$ & 6.40 & Mw & 32.185 & -115.076 & 11 & 0 & Victoria & 32.29 & -115.1 & D & 274.5 & 1280.0 & 111.95 \\
\hline 30 & Imperial Valley 1979 & $10 / 15 / 1979$ & 23:16:53 & 6.50 & Mw & 32.6435 & -115.3088 & 9.96 & 0 & El Centro Array \#6 & 32.839 & -115.49 & D & 203.2 & 1777.9 & 111.09 \\
\hline 31 & Northridge & $1 / 17 / 1994$ & $12: 30: 55$ & 6.70 & Mw & 34.2057 & -118.5539 & 17.5 & 2 & Pacoima Dam & 34.334 & -118.396 & A & 2016.1 & 1743.4 & 111.05 \\
\hline 32 & Northridge & 1/17/1994 & $12: 30: 55$ & 6.70 & Mw & 34.2057 & -118.5539 & 17.5 & 2 & Tarzana & 34.16 & -118.534 & D & 257.21 & 1970.7 & 109.88 \\
\hline 33 & Chi-Chi & 9/20/1999 & 17:47:16 & 7.60 & Mw & 23.8603 & 120.7995 & 33 & 3 & CHY101 & 23.6862 & 120.5622 & D & 258.9 & 508.9 & 109.87 \\
\hline 34 & North Palm Springs & $7 / 8 / 1986$ & $9: 20: 44$ & 6.20 & Mw & 34 & -116.6117 & 11 & 3 & Devers Substation & 33.932 & -116.579 & & -1 & 1269.0 & 107.43 \\
\hline 35 & $\begin{array}{l}\text { South Iceland } \\
\text { Aftershock }\end{array}$ & $6 / 21 / 2000$ & 0:51:48 & 6.49 & MW & 63.97 & -20.71 & & 0 & 006334 Solheimar & 64.065 & -20.642 & & -1 & 727.9 & 107.03 \\
\hline 36 & Imperial Valley 1979 & 10/15/1979 & 23:16:53 & 6.50 & Mw & 32.6435 & -115.3088 & 9.96 & 0 & $\begin{array}{l}\text { EC Meloland } \\
\text { Overpass }\end{array}$ & 32.773 & -115.448 & D & 186.2 & 434.3 & 104.26 \\
\hline 37 & $\begin{array}{l}\text { South Iceland } \\
\text { Aftershock }\end{array}$ & $6 / 21 / 2000$ & 0:51:48 & 6.49 & MW & 63.97 & -20.71 & & 0 & 006349 Thjorsarbru & 63.931 & -20.649 & & -1 & 833.7 & 104.09 \\
\hline 38 & Denali, Alaska & $11 / 3 / 2002$ & 22:13:00 & 7.90 & Ms & 63.23 & -144.89 & 15 & 0 & $\begin{array}{l}\text { Taps Pump Station } \\
\# 10\end{array}$ & 63.4239 & -145.7658 & D & 329.4 & 399.0 & 103.93 \\
\hline 39 & $\begin{array}{l}\text { Southern Honshu } \\
\text { (-Fukui) }\end{array}$ & $3 / 25 / 2007$ & 0:42:00 & 6.90 & Mjma & 37.22 & 136.685 & 11 & 2 & ISK005 & 37.2307 & 136.9039 & $\mathrm{D}+$ & 323 & 945.5 & 102.53 \\
\hline 40 & Manjil, Iran & 6/20/1990 & 9:00:10 & 7.40 & Mw & 36.95 & 49.52 & 18 & 0 & Abbar & 36.92 & 48.97 & c & 724.0 & 762.8 & 101.55 \\
\hline 41 & Kobe & 1/16/1995 & $20: 46: 52$ & 6.90 & Mw & 34.5948 & 135.0121 & 17.9 & 0 & KJMA & 34.6833 & 135.18 & D & 312.0 & 884.0 & 99.78 \\
\hline 42 & Northridge & 1/17/1994 & 12:30:55 & 6.70 & Mw & 34.2057 & -118.5539 & 17.5 & 2 & $\begin{array}{l}\text { Jensen F.P. } \\
\text { Generator }\end{array}$ & 34.313 & -118.498 & c & 525.8 & 1114.9 & 98.91 \\
\hline 43 & Cape Mendocino & 4/25/1992 & 18:06:14 & 7.00 & Mw & 40.3338 & -124.2294 & 9.6 & 2 & Petrolia Gen Store 1 & 40.325 & -124.287 & c & 712.8 & 697.2 & 98.79 \\
\hline 44 & Erzican & $3 / 13 / 1992$ & 17:18:40 & 6.90 & MSbrk & 39.705 & 39.587 & 9 & 0 & Erzincan & & & D & 274.5 & 540.8 & 95.54 \\
\hline 45 & Chi-Chi & 9/20/1999 & $17: 47: 16$ & 7.60 & $\mathrm{Mw}$ & 23.8603 & 120.7995 & 33 & 3 & TCU067 & 24.0912 & 120.72 & c & 433.6 & 560.2 & 93.67 \\
\hline 46 & Chi-Chi & 9/20/1999 & 17:47:16 & 7.60 & Mw & 23.8603 & 120.7995 & 33 & 3 & TCU103 & 24.3098 & 120.7072 & $\mathrm{c}$ & 494.1 & 1927 & 90.64 \\
\hline 47 & Kobe & $1 / 16 / 1995$ & $20: 46: 52$ & 6.90 & Mw & 34.5948 & 135.0121 & 17.9 & 0 & Takarazuka & 34.809 & 135.344 & D & 312.0 & 756.5 & 89.50 \\
\hline 48 & Imperial Valley 1979 & $10 / 15 / 1979$ & $23: 16: 53$ & 6.50 & Mw & 32.6435 & -115.3088 & 9.96 & 0 & El Centro Array \#5 & 32.855 & -115.47 & D & 205.6 & 570.5 & 88.89 \\
\hline 49 & Parkfield 2004 & 9/28/2004 & $17: 15: 24$ & 6.00 & Mw & 35.815 & -120.374 & 7.9 & 0 & Fault Zone 14 & 35.908 & -120.458 & & -1 & 1287.1 & 88.50 \\
\hline 50 & Northridge & $1 / 17 / 1994$ & 12:30:55 & 6.70 & Mw & 34.2057 & -118.5539 & 17.5 & 2 & holand Dr. & 34.132 & -118.439 & D & 355.8 & 532.2 & 87.72 \\
\hline 51 & Imperial Valley 1979 & 10/15/1979 & $23: 16: 53$ & 6.50 & Mw & 32.6435 & -115.3088 & 9.96 & 0 & El Centro Array \#7 & 32.829 & -115.5 & D & 210.5 & 623.9 & 87.48 \\
\hline
\end{tabular}

ORD-FY06-022 Subtask 2: Final Technical Report 


\begin{tabular}{|c|c|c|c|c|c|c|c|c|c|c|c|c|c|c|c|c|}
\hline Rank & Earthquake Name & Date & Time & Magnitude & $\begin{array}{c}\text { Magnitude } \\
\text { Type }\end{array}$ & $\begin{array}{c}\text { Earthquake } \\
\text { Loatitude }\end{array}$ & $\begin{array}{l}\text { Earthquake } \\
\text { Longitude }\end{array}$ & $\begin{array}{l}\text { Depth } \\
(\mathrm{km})\end{array}$ & Mechanism & Station & $\begin{array}{c}\text { Station } \\
\text { Latitude }\end{array}$ & $\begin{array}{c}\text { Station } \\
\text { Longitude }\end{array}$ & $\begin{array}{l}\text { Preferred } \\
\text { NEHRP } \\
\text { Vs } 30\end{array}$ & $\begin{array}{l}\text { Preferred } \\
\mathrm{V}_{\mathrm{s} 30}(\mathrm{~m} / \mathrm{s})\end{array}$ & $\begin{array}{l}\text { PGA } \\
\text { 3D-Vec. } \\
\left(\mathrm{cm} / \mathrm{s}^{2}\right)\end{array}$ & $\begin{array}{c}\text { PGV } \\
\text { 3D-Vec. } \\
(\mathrm{cm} / \mathrm{s})\end{array}$ \\
\hline 52 & Kocaeli, Turkey & 8/17/1999 & 0:01:40 & 7.60 & Mw-hrv & 40.702 & 29.987 & 17 & 0 & Yarimca & 40.7639 & 29.762 & $\mathrm{D}$ & 297.0 & 377.1 & 87.30 \\
\hline 53 & Duzce & 11/1/2/1999 & 16:57:27 & 7.10 & MW & 40.93 & 31.25 & 18 & 0 & Duzce & 40.843 & 31.151 & D & 276.0 & 534.8 & 86.86 \\
\hline 54 & Chi-Chi & 9/20/1999 & $17: 47: 16$ & 7.60 & Mw & 23.8603 & 120.7995 & 33 & 3 & TCU063 & 24.1083 & 120.6158 & D & 272.6 & 200.0 & 86.37 \\
\hline 55 & $\begin{array}{l}\text { South Iceland } \\
\text { Aftershock }\end{array}$ & $6 / 21 / 2000$ & 0:51:48 & 6.49 & MW & 63.97 & -20.71 & & 0 & 006332 Thjorsartun & 63.928 & -20.648 & & -1 & 704.1 & 86.27 \\
\hline 56 & Kobe & 1/16/1995 & 20:46:52 & 6.90 & Mw & 34.5948 & 135.0121 & 17.9 & 0 & Port Island, Kobe & 34.67 & 135.201 & D & 198.0 & 552.5 & 85.63 \\
\hline 57 & Chi-Chi & 9/20/1999 & $17: 47: 16$ & 7.60 & Mw & 23.8603 & 120.7995 & 33 & 3 & TCU101 & 24.242 & 120.7092 & D & 272.6 & 266.3 & 85.61 \\
\hline 58 & Chi-Chi & 9/20/1999 & $17: 47: 16$ & 7.60 & Mw & 23.8603 & 120.7995 & 33 & 3 & TCU076 & 23.9077 & 120.6757 & c & 573.0 & 461.8 & 82.76 \\
\hline 59 & Chi-Chi & 9/20/1999 & $17: 47: 16$ & 7.60 & Mw & 23.8603 & 120.7995 & 33 & 3 & WGK & 23.6862 & 120.5622 & D & 258.9 & 500.2 & 82.74 \\
\hline 60 & Parkfield 2004 & 9/28/2004 & $17: 15: 24$ & 6.00 & Mw & 35.815 & -120.374 & 7.9 & 0 & Fault Zone 1 & 35.758 & -120.307 & & -1 & 861.3 & 82.30 \\
\hline 61 & Tokachi-Oki & 9/25/2003 & 19:50:07 & 8.00 & Mw & 41.778 & 144.078 & 42 & 7 & HKD086 Chokubetsu & 42.8526 & 143.8636 & D & 201 & 810.8 & 80.87 \\
\hline 62 & Northridge & 1/1/7/1994 & $12: 30: 55$ & 6.70 & Mw & 34.2057 & -118.5539 & 17.5 & 2 & $\begin{array}{l}\text { Sepulvelda VA } \\
\text { Hospital }\end{array}$ & 34.249 & -118.478 & c & 380.1 & 949.6 & 80.26 \\
\hline 63 & Chi-Chi & 9/20/1999 & 17:47:16 & 7.60 & Mw & 23.8603 & 120.7995 & 33 & 3 & CHYO28 & 23.632 & 120.6052 & c & 542.6 & 812.1 & 80.17 \\
\hline 64 & Chi-Chi & 9/20/1999 & 17:47:16 & 7.60 & Mw & 23.8603 & 120.7995 & 33 & 3 & TCU128 & 24.4162 & 120.7607 & c & 599.6 & 199.7 & 80.13 \\
\hline 65 & Chi-Chi & 9/20/1999 & 17:47:16 & 7.60 & Mw & 23.8603 & 120.7995 & 33 & 3 & TCU039 & 24.04917 & 120.7837 & c & 540.7 & 220.2 & 79.73 \\
\hline 66 & Chi-Chi & 9/20/1999 & $17: 47: 16$ & 7.60 & Mw & 23.8603 & 120.7995 & 33 & 3 & TCU074 & 23.9622 & 120.9618 & c & 468.1 & 608.4 & 79.06 \\
\hline 67 & Imperial Valley 1979 & 10/15/1979 & 23:16:53 & 6.50 & Mw & 32.6435 & -115.3088 & 9.96 & 0 & El Centro Array \#4 & 32.864 & -115.5 & $\mathrm{D}$ & 208.9 & 546.0 & 77.83 \\
\hline 68 & Tokachi-Oki & $9 / 25 / 2003$ & 19:50:07 & 8.00 & Mw & 41.778 & 144.078 & 42 & 7 & HKD066 Shibetsu & 43.6619 & 145.1307 & E & 126 & 578.0 & 77.73 \\
\hline 69 & Morgan Hill & 4/24/1984 & 21:15:18 & 6.10 & Mw & 37.306 & -121.695 & 8.5 & 0 & Coyote Lake Dam & 37.118 & -121.55 & c & 597.1 & 1193.5 & 77.25 \\
\hline 70 & Gazli & $5 / 17 / 1976$ & 2:58:40 & 6.80 & & 40.465 & 63.462 & 18.2 & 2 & Karakyr & 40.35 & 63.47 & c & 659.6 & 1429.5 & 76.86 \\
\hline 71 & Imperial Valley 1979 & 10/15/1979 & $23: 16: 53$ & 6.50 & Mw & 32.6435 & -115.3088 & 9.96 & 0 & El Centro Array \#8 & 32.811 & -115.53 & D & 206.1 & 635.0 & 76.14 \\
\hline 72 & Northridge & 1/17/1994 & $12: 30: 55$ & 6.70 & Mw & 34.2057 & -118.5539 & 17.5 & 2 & Pardee & & & D & 345.4 & 703.5 & 75.60 \\
\hline 73 & Parkfield & $6 / 28 / 1966$ & 4:26:14 & 6.10 & Mw & 36 & -120.5 & 10 & 0 & Cholome 2wa & 35.733 & -120.29 & D & 184.8 & 473.4 & 75.34 \\
\hline 74 & Northridge & $1 / 17 / 1994$ & 12:30:55 & 6.70 & Mw & 34.2057 & -118.5539 & 17.5 & 2 & $\begin{array}{l}\text { LA Dam } \\
\text { lat }\end{array}$ & 34.294 & -118.483 & $\mathrm{c}$ & 629.0 & 337.7 & 75.06 \\
\hline 75 & Loma Prieta & $10 / 18 / 1989$ & $0: 05: 00$ & 7.00 & Mw & 37.0407 & -121.8829 & 17.48 & 3 & Saratoga & 37.255 & -122.031 & $\mathrm{c}$ & 370.8 & 408.2 & 74.66 \\
\hline 76 & Coalinga & $5 / 2 / 1983$ & $23: 42: 38$ & 6.50 & Mw & 36.233 & -120.31 & 4.6 & 2 & $\begin{array}{l}\text { Pleasant Valley P.P. } \\
\text { yard }\end{array}$ & 36.308 & -120.249 & D & 257.4 & $\begin{array}{l}40.2 \\
608.4\end{array}$ & 74.58 \\
\hline 77 & Imperial Valley 1979 & 10/15/1979 & 23:16:53 & 6.50 & Mw & 32.6435 & -115.3088 & 9.96 & 0 & Differential Array & 32.796 & -115.535 & D & 202.3 & 742.7 & 74.39 \\
\hline 78 & North Palm Springs & $7 / 8 / 1986$ & 9:20:44 & 6.20 & Mw & 34 & -116.6117 & 11 & 3 & $\begin{array}{l}\text { North Palm Springs } \\
\text { Post Office }\end{array}$ & 33.924 & -116.543 & D & 345.4 & 769.0 & 74.27 \\
\hline 79 & Niigata-Ken Chuetsu & 10/23/2004 & 8:56:00 & 6.60 & Mw & 37.229 & 138.773 & 15.8 & 2 & NIG021 Tohkamachi & 37.125 & 138.75 & c & 419 & 1765.7 & 74.10 \\
\hline 80 & Chi-Chi & 9/20/1999 & $17: 47: 16$ & 7.60 & Mw & 23.8603 & 120.7995 & 33 & 3 & TCU072 & 20.0407 & 120.8488 & c & 468.1 & 476.0 & 73.27 \\
\hline 81 & $\begin{array}{l}\text { Niigata-Ken Chuetsu } \\
\text { aftershock } 3\end{array}$ & 10/23/2004 & $9: 34: 07$ & 6.30 & Mw & 37.28 & 138.787 & 22.2 & 2 & NIG019 Ojiya & 37.3027 & 138.793 & D & 292 & 826.5 & 71.61 \\
\hline 82 & Chi-Chi & 9/20/1999 & 17:47:16 & 7.60 & Mw & 23.8603 & 120.7995 & 33 & 3 & TCU129 & 23.8783 & 120.6843 & c & 664.4 & 1002.9 & 71.43 \\
\hline 83 & Chi-Chi & 9/20/1999 & 17:47:16 & 7.60 & Mw & 23.8603 & 120.7995 & 33 & 3 & TCU071 & 23.9855 & 120.7883 & C & 624.9 & 820.4 & 71.43 \\
\hline 84 & Hokkaido & $12 / 14 / 2004$ & $5: 56: 09$ & 5.80 & Mw & 44.108 & 141.753 & 10 & 2 & Minatomachi & 44.1463 & 141.668 & & -1 & 1206.8 & 70.86 \\
\hline 85 & Niigata-Ken Chuetsu & 10/23/2004 & 8:56:00 & 6.60 & Mw & 37.229 & 138.773 & 15.8 & 2 & NIGH01 NAGAOKA & 37.4242 & 138.87 & & -1 & 855.0 & 69.77 \\
\hline 86 & Kocaeli, Turkey & $8 / 17 / 1999$ & 0:01:40 & 7.60 & Mw-hrv & 40.702 & 29.987 & 17 & 0 & Sakarya & 40.7639 & 29.762 & c & 471.0 & 436.6 & 68.68 \\
\hline 87 & Nigata-Ken Chuetsu & 10/23/2004 & $8: 56: 00$ & 6.60 & $\mathrm{Mw}$ & 37.229 & 138.773 & 15.8 & 2 & NIGH11 Kawanishi & 37.1697 & 138.7472 & c & 375 & 647.5 & 68.50 \\
\hline 88 & Northridge & 1/17/19994 & $12: 30: 55$ & 6.70 & Mw & 34.2057 & -118.5539 & 17.5 & 2 & Simi Valley & 34.264 & -118.666 & C & 557.4 & 796.2 & 68.31 \\
\hline 89 & Chi-Chi & 9/20/1999 & 17:47:16 & 7.60 & Mw & 23.8603 & 120.7995 & 33 & 3 & TCU055 & 24.1392 & 120.6643 & D & 272.6 & 294.7 & 68.06 \\
\hline 90 & Chi-Chi & 9/20/1999 & $17: 47: 16$ & 7.60 & Mw & 23.8603 & 120.7995 & 33 & 3 & CHY006 & 23.5815 & 120.552 & c & 438.2 & 424.8 & 67.77 \\
\hline 91 & Chi-Chi & 9/20/1999 & $17: 47: 16$ & 7.60 & Mw & 23.8603 & 120.7995 & 33 & 3 & TCU049 & 24.179 & 120.6902 & c & 487.3 & 325.6 & 67.76 \\
\hline 92 & Niligata-Ken Chuetsu & $10 / 23 / 2004$ & 8:56:00 & 6.60 & Mw & 37.229 & 138.773 & 15.8 & 2 & $\begin{array}{l}\text { NIG028 Nagaoka- } \\
\text { Shisho }\end{array}$ & 37.4231 & 138.8894 & & -1 & 913.2 & 67.22 \\
\hline 93 & Chi-Chi & 9/20/1999 & 17:47:16 & 7.60 & Mw & 23.8603 & 120.7995 & 33 & 3 & TCU036 & 24.4488 & 120.6963 & D & 272.6 & 141.7 & 67.16 \\
\hline 94 & Chi-Chi & 9/20/1999 & $17: 47: 16$ & 7.60 & Mw & 23.8603 & 120.7995 & 33 & 3 & TCU087 & 24.3482 & 120.7733 & c & 473.9 & 140.5 & 66.99 \\
\hline 95 & Chi-Chi & 9/20/1999 & 17:47:16 & 7.60 & Mw & 23.8603 & 120.7995 & 33 & 3 & WNT & 23.8783 & 120.6843 & c & 664.4 & 946.7 & 66.45 \\
\hline 96 & Chi-Chi & 9/20/1999 & 17:47:16 & 7.60 & Mw & 23.8603 & 120.7995 & 33 & 3 & CHY024 & 23.757 & 120.6062 & $\mathrm{c}$ & 427.7 & 310.7 & 66.44 \\
\hline 97 & Coalinga & $7 / 22 / 1983$ & $2: 39: 54$ & 6.00 & Mw & 36.241 & -120.409 & 7.4 & 2 & Transmitter Hill & 36.249 & -120.343 & c & 376.1 & 1250.1 & 65.81 \\
\hline 98 & El Salvador & $1 / 13 / 2001$ & $17: 33: 32$ & 7.60 & Mw & 13.049 & -88.66 & 60 & 6 & Armenia, Sonsonate & 13.744 & -89.501 & & -1 & 611.2 & 65.14 \\
\hline 99 & Northridge & $1 / 177 / 1994$ & $12: 30: 55$ & 6.70 & Mw & 34.2057 & -118.5539 & 17.5 & 2 & Canoga Park & 34.2119 & -118.6056 & D & 267.5 & 473.6 & 65.08 \\
\hline 100 & Parkfield 2004 & 9/28/2004 & $17: 15: 24$ & 6.00 & Mw & 35.815 & -120.374 & 7.9 & 0 & CHOLAME 2WA & 35.733 & -120.29 & & -1 & 598.5 & 64.73 \\
\hline
\end{tabular}


Table 4. Estimate of Level of Instrumentation Effort for Selected Accelerograph Networks

\begin{tabular}{|c|c|c|c|c|c|c|}
\hline $\begin{array}{l}\text { Strong Motion } \\
\text { Network }\end{array}$ & $\begin{array}{l}\text { Number of } \\
\text { Instruments }\end{array}$ & $\begin{array}{l}\text { Year } \\
\text { Installed }\end{array}$ & Present & Years & Inst-Years & Assumptions \\
\hline USGS & 700 & 1980 & 2007.5 & 27.5 & 19250 & assumed built on timetable similar to CSMIP \\
\hline USGS & 300 & 2000 & 2007.5 & 7.5 & 2250 & estimate last 300 in ANSS \\
\hline CSMIP & 650 & 1980 & 2007.5 & 27.5 & 17875 & established 1972, assumed complete 1990 \\
\hline Guerrero & 30 & 1986 & 2007.5 & 21.5 & 645 & $\begin{array}{l}\text { Some instruments installed } 1985 \text { - use } \\
\text { average installation date }\end{array}$ \\
\hline K-Net & 1000 & 1996.5 & 2007.5 & 11 & 11000 & $\begin{array}{l}\text { Estimated start date from earliest records on } \\
\text { web }\end{array}$ \\
\hline Kik-Net & 680 & 2000.5 & 2007.5 & 7 & 4276 & Precise calculation \\
\hline Taiwan & 708 & 1994 & 2007.5 & 13.5 & 9558 & $\begin{array}{l}\text { Estimated start date, from dates of early } \\
\text { earthquakes }\end{array}$ \\
\hline Iran & 1094 & 1982 & 2007.5 & 25.5 & 27897 & start in 1973 , assume complete in 1990 \\
\hline Turkey & 114 & 1973 & 2007.5 & 34.5 & 3933 & $\begin{array}{l}\text { From info in web site: } \\
\text { http://angora deprem. gov.tr/TKYHAKKen.htm, } \\
\text { July } 2007\end{array}$ \\
\hline Turkey & 20 & 2001 & 2007.5 & 6.5 & 130 & ditto \\
\hline Total & & & & & 96814 & \\
\hline
\end{tabular}

\subsection{Figures}

\section{Figure 1. Earthquake Locations}

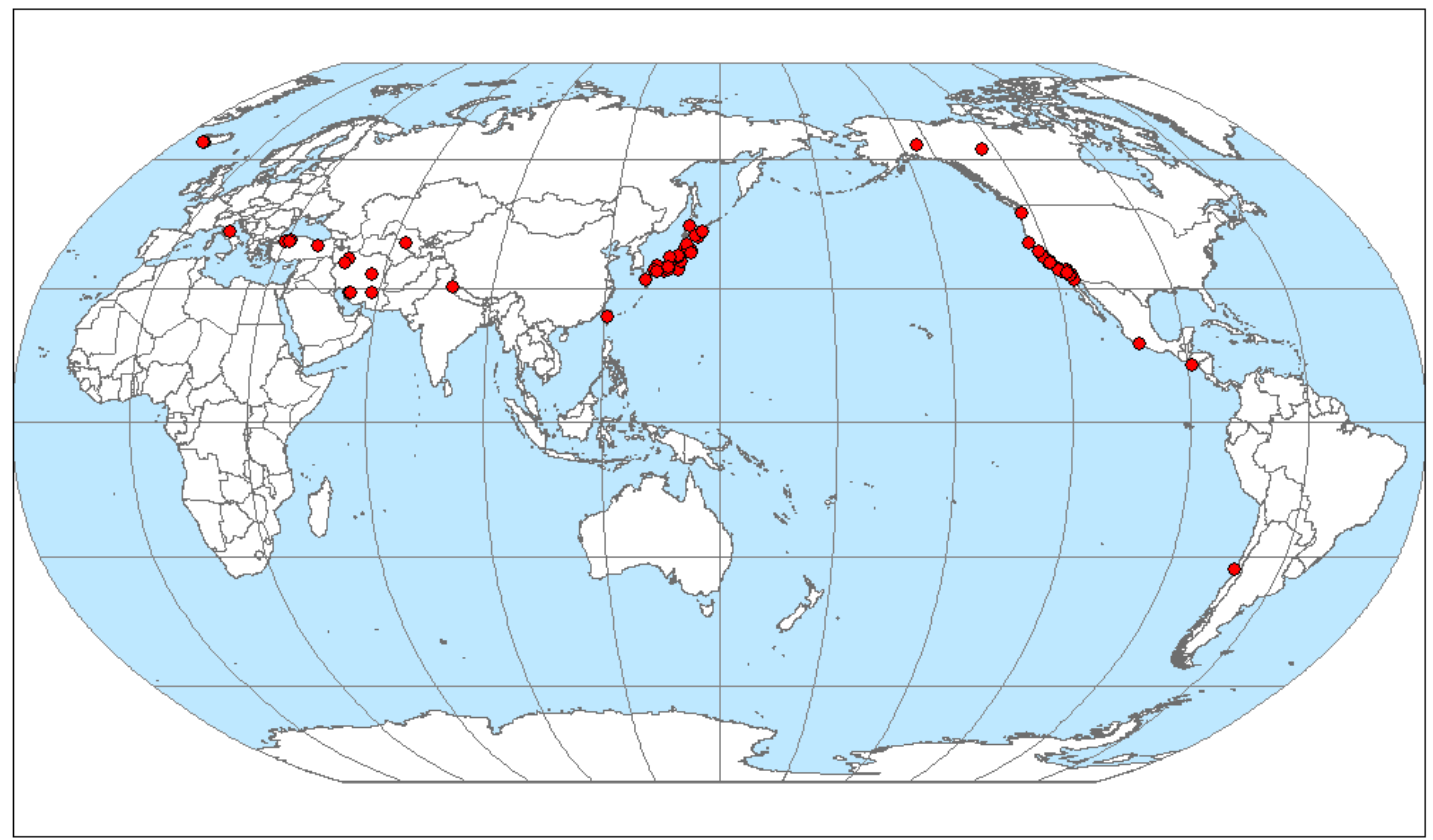

Figure 1. Locations of earthquakes represented in the data set of exceptional accelerograms. The earthquakes are listed in Table 1. 


\section{Figure 2. Distribution of Ratios among Various Peak Acceleration Intensity Measures}

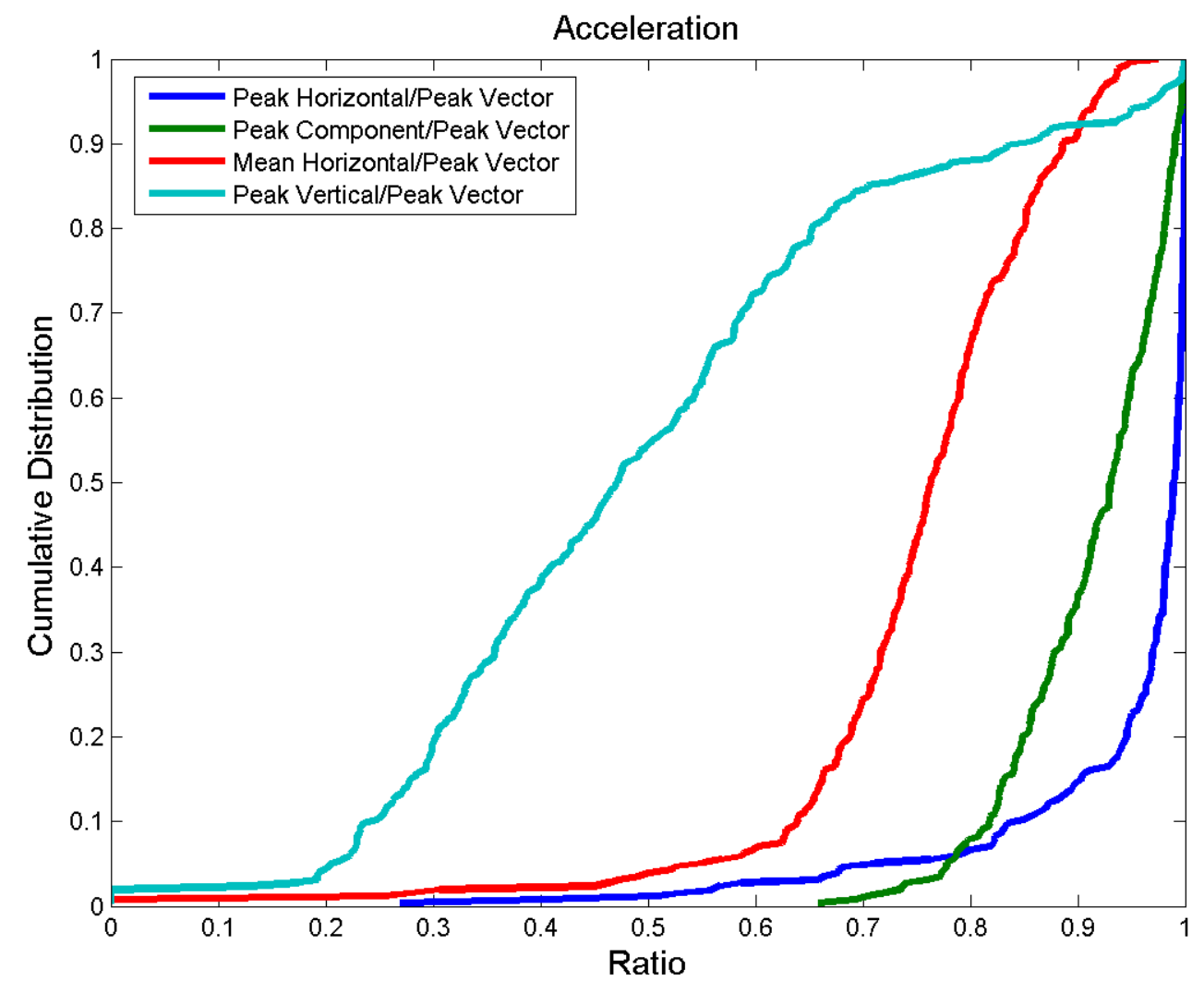

Figure 2. Distribution of ratios among various peak acceleration intensity measures. The denominator ("Peak Vector") in all cases is the peak magnitude of the 3-component acceleration vector. "Peak Horizontal" is the peak magnitude of the 2-component horizontal acceleration vector. "Peak Component" is the peak acceleration on the largest of the three individual components as recorded. "Mean Horizontal" is the geometrical mean of the peak accelerations of the two horizontal components as recorded. "Peak Vertical" is the peak acceleration on the vertical component. All 255 accelerograms in Table 1 are used to develop this distribution. For records where one of the horizontal components is missing, the peak on that component is treated as equal to zero. The figure is generated by the script j10s1.m in directory C:|Task_22\Analysis|Statistics-1. The file name is C:ITask_22\Analysis|Statistics-1|J4_4.png. 


\section{Figure 3. Distribution of Ratios among Various Peak Velocity Intensity Measures}

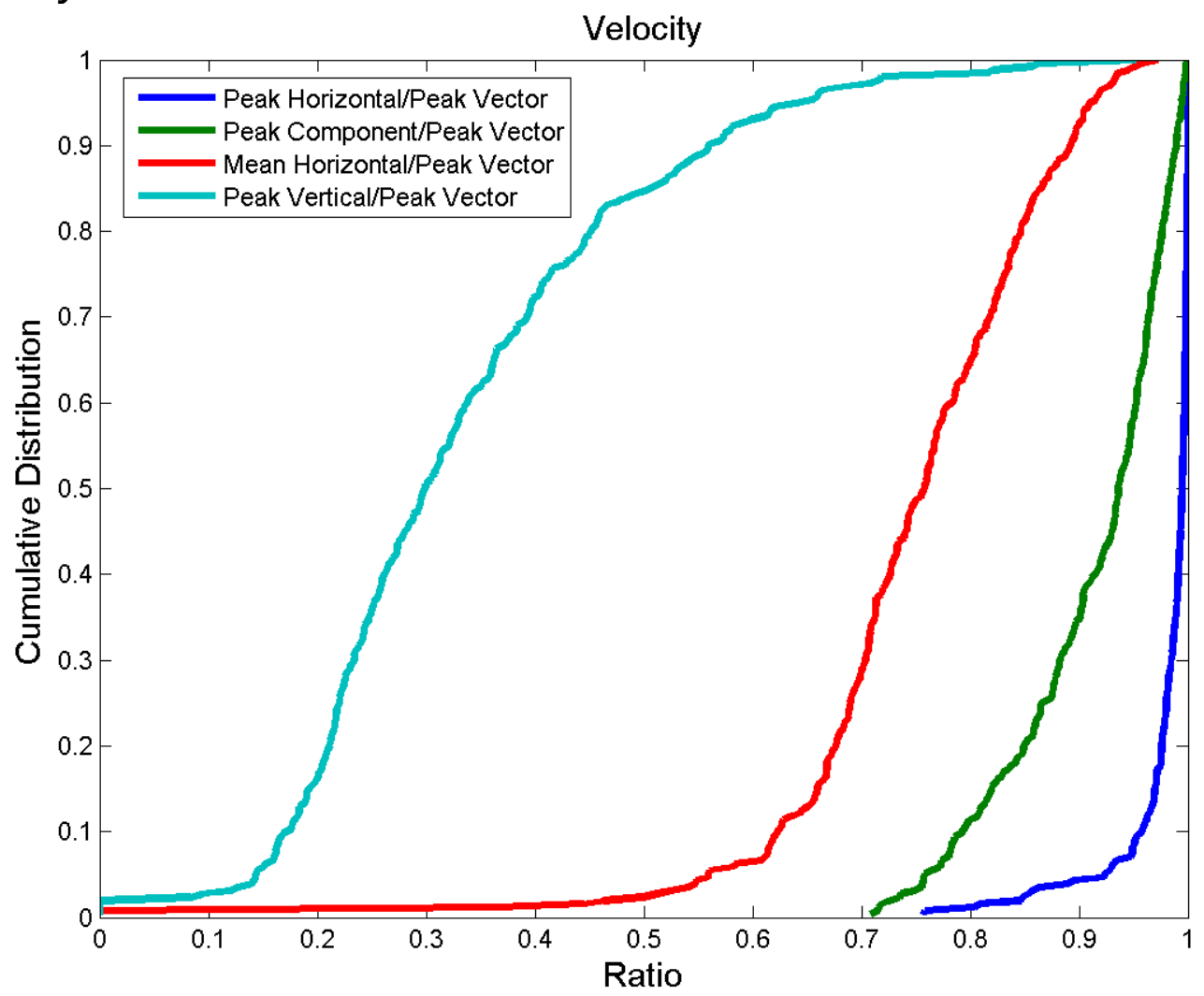

Figure 3. Distribution of ratios among various peak velocity intensity measures. See the caption for an explanation of the variables, which are applied to the velocity rather than acceleration in this figure. The figure is generated by the script j10s1.m in directory C:ITask_22\Analysis|Statistics-1. The file name is C:|Task_22\Analysis|Statistics1\J4_5.png. 
Figure 4. Distribution of Angles between the Peak 3-Component Vectors and Horizontal

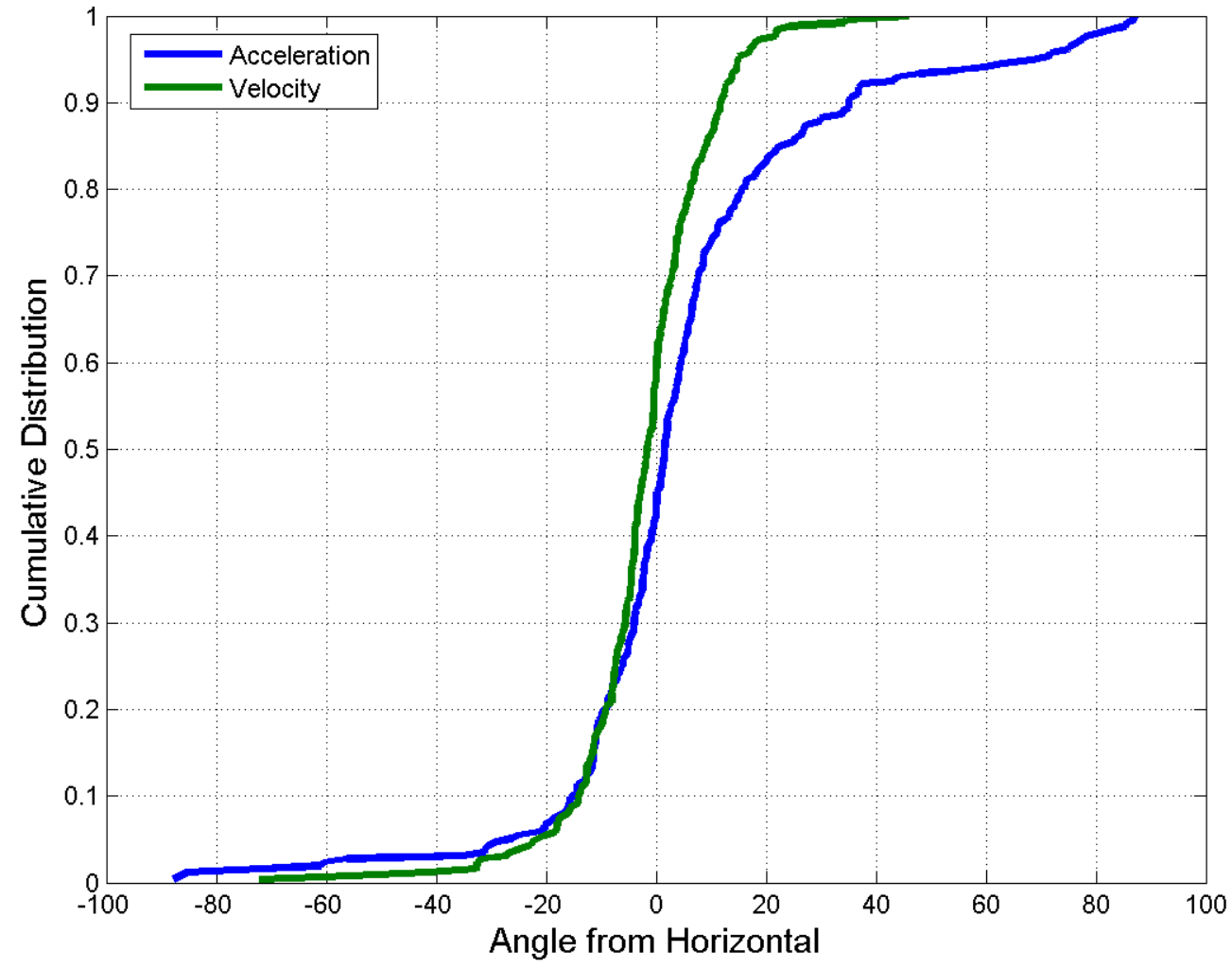

Figure 4. Distribution of angles between the peak 3-component vectors and horizontal. For each 3-component accelerogram, the angle between the acceleration vector and the horizontal is measured at the time when the magnitude of the 3-component acceleration is maximum. The algorithm for velocity is the same. All 255 accelerograms in Table 1 are used to develop this distribution. The figure is generated by the script j10s1.m in directory C:|Task_22|Analysis|Statistics-1. The file name is C:|Task_22\Analysis|Statistics-1|J4_7.png. 
Figure 5. Distribution of Ratio of the Two Observed Horizontal Components
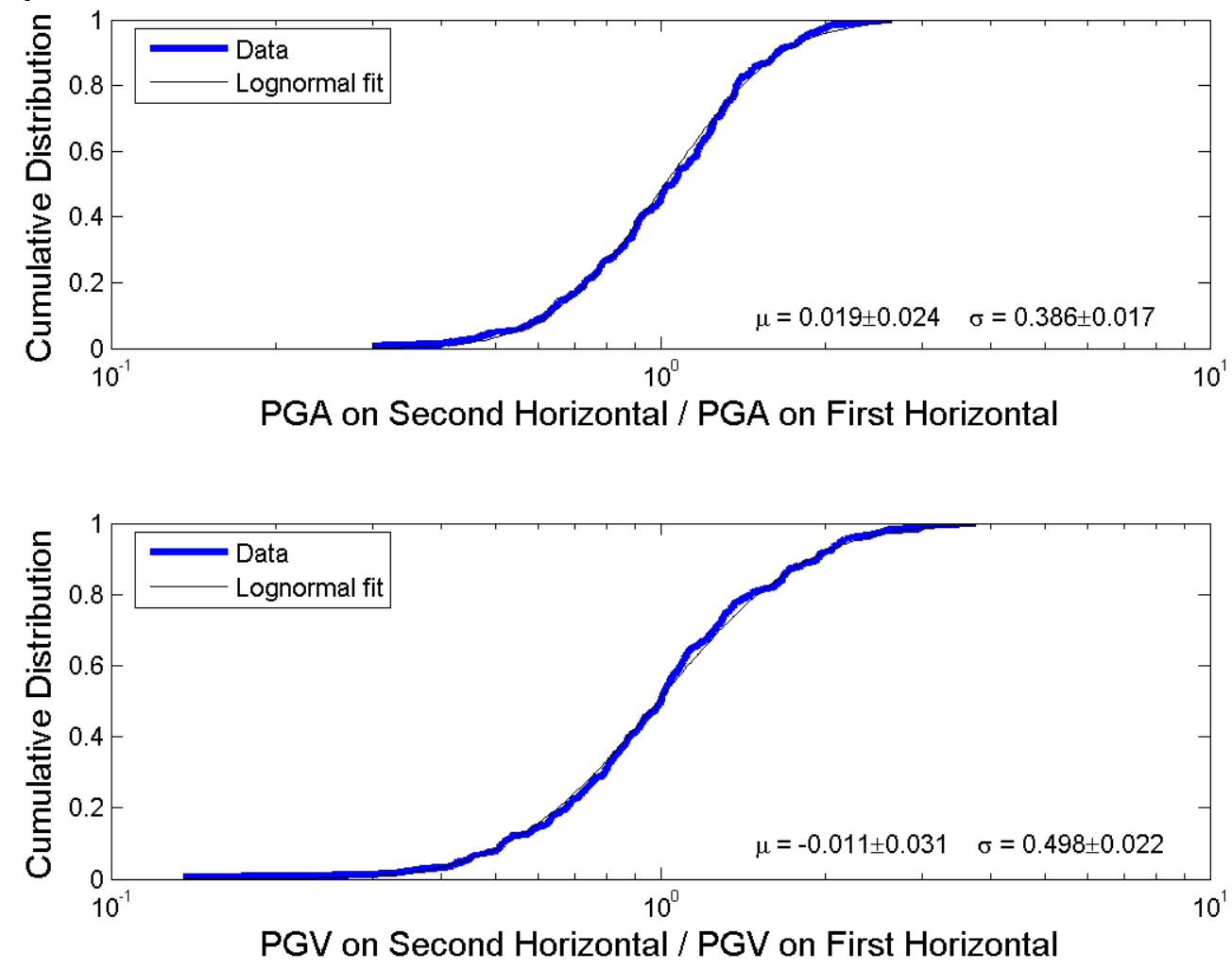

Figure 5. Distribution of the ratio of the peak value of the second (generally more northerly) observed horizontal component to the first (generally more easterly) component. The upper figure is for peak acceleration, and the lower is for peak velocity. The pale black line is the best-fitting lognormal distribution for these ratios; the mean $(\mu)$ and standard deviation $(\sigma)$ of the distribution are given in the figure. The figure is generated by the script j10s1.m in directory C:|Task_22|Analysis|Statistics-1. The file name is C:|Task_22|Analysis|Statistics-1|J4_10.png. 
Figure 6. Distribution of Peak Acceleration and Peak Velocity in the Selected Data

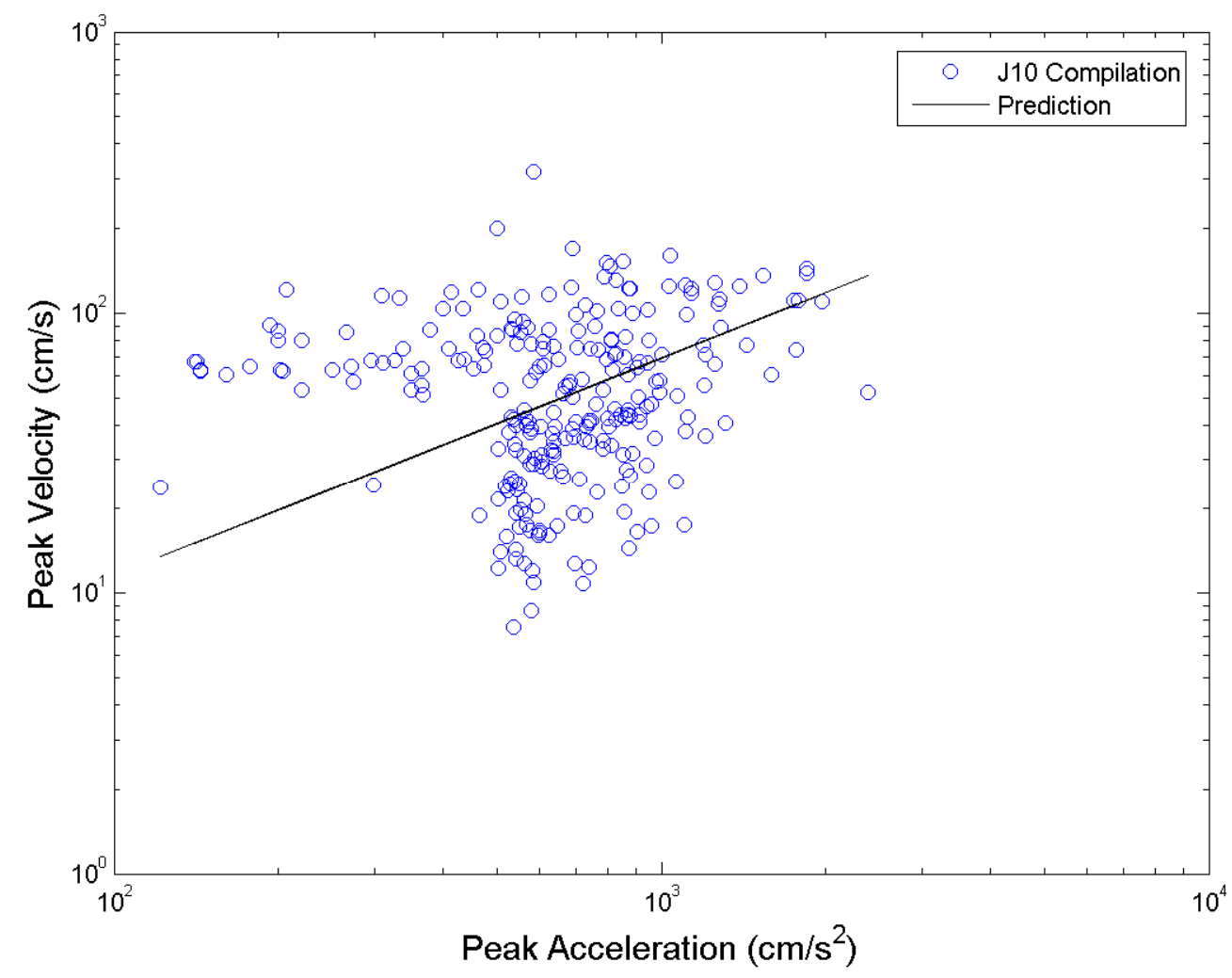

Figure 6. Distribution of peak acceleration and peak velocity for the accelerograms listed in Table 1. PGA and PGV are the vector peak values. The "predicted" line is the relationship: $\ln (P G V)=4.22+0.776 \ln (P G A)$, where the units of $P G A$ are fraction of the acceleration of gravity, and the units of $P G V$ are $\mathrm{cm} / \mathrm{s}$. This relationship was developed for the PEGASOS project (Abrahamson et al, 2002). The points in this figure represent only the upper-right tip of other compilations of strong-motion data. Figure 6 is generated by the script j10s1.m in directory C:|Task_22|Analysis|Statistics-1. The file name is C:ITask_22\Analysis|Statistics-1\J4_5.png. 
Figure 7. Exceptional ground motions over time
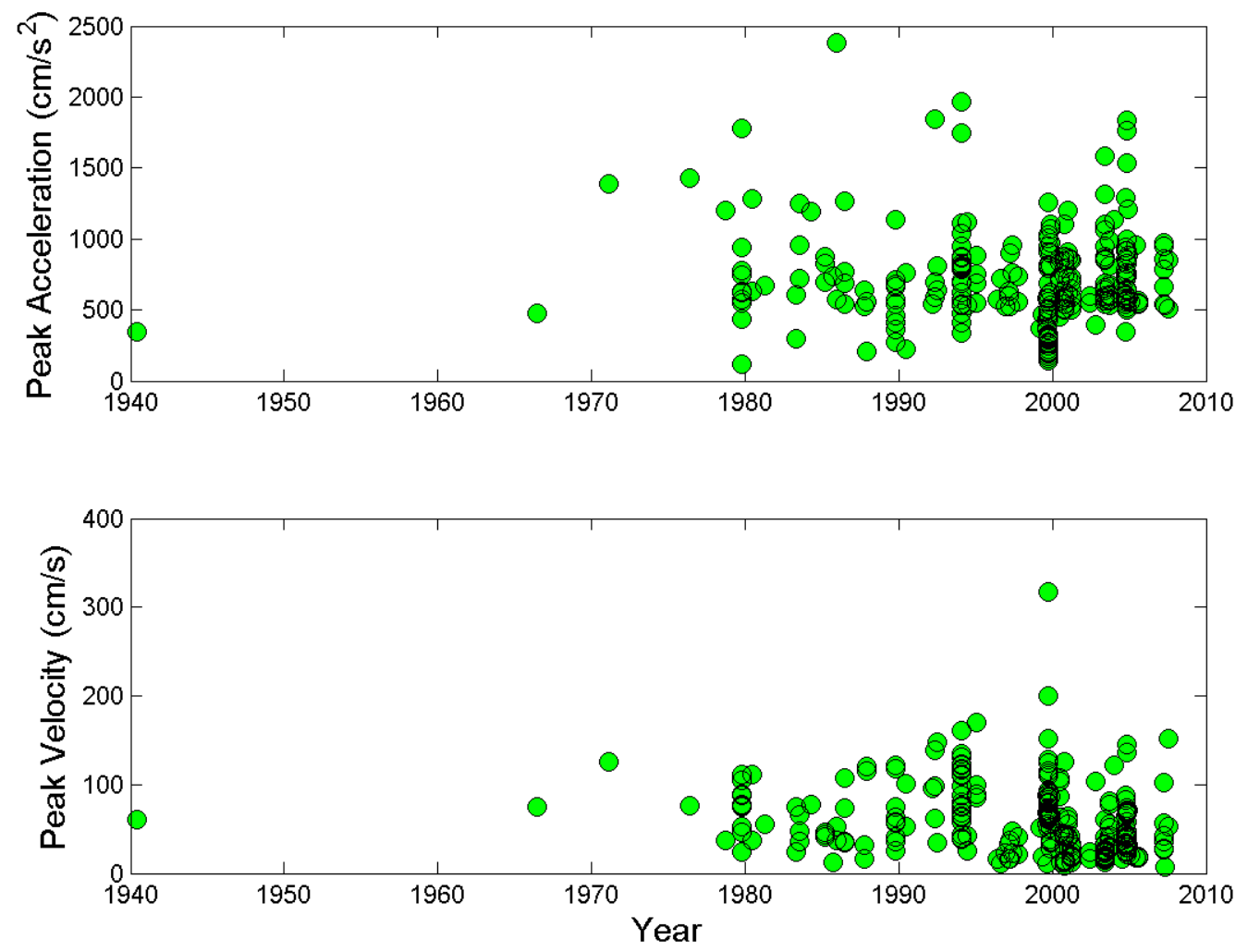

Figure 7. Exceptional ground motions over time. Peak acceleration and peak velocity of the records in Table 1, shown as a function of the time that they were recorded. This figure is generated by the script j10s1.m in directory C:|Task_22\Analysis|Statistics-1. The file name is C:ITask_22\Analysis|Statistics-1|J4_1.png. 
Figure 8. Exceptional Ground Motions vs Moment Magnitude
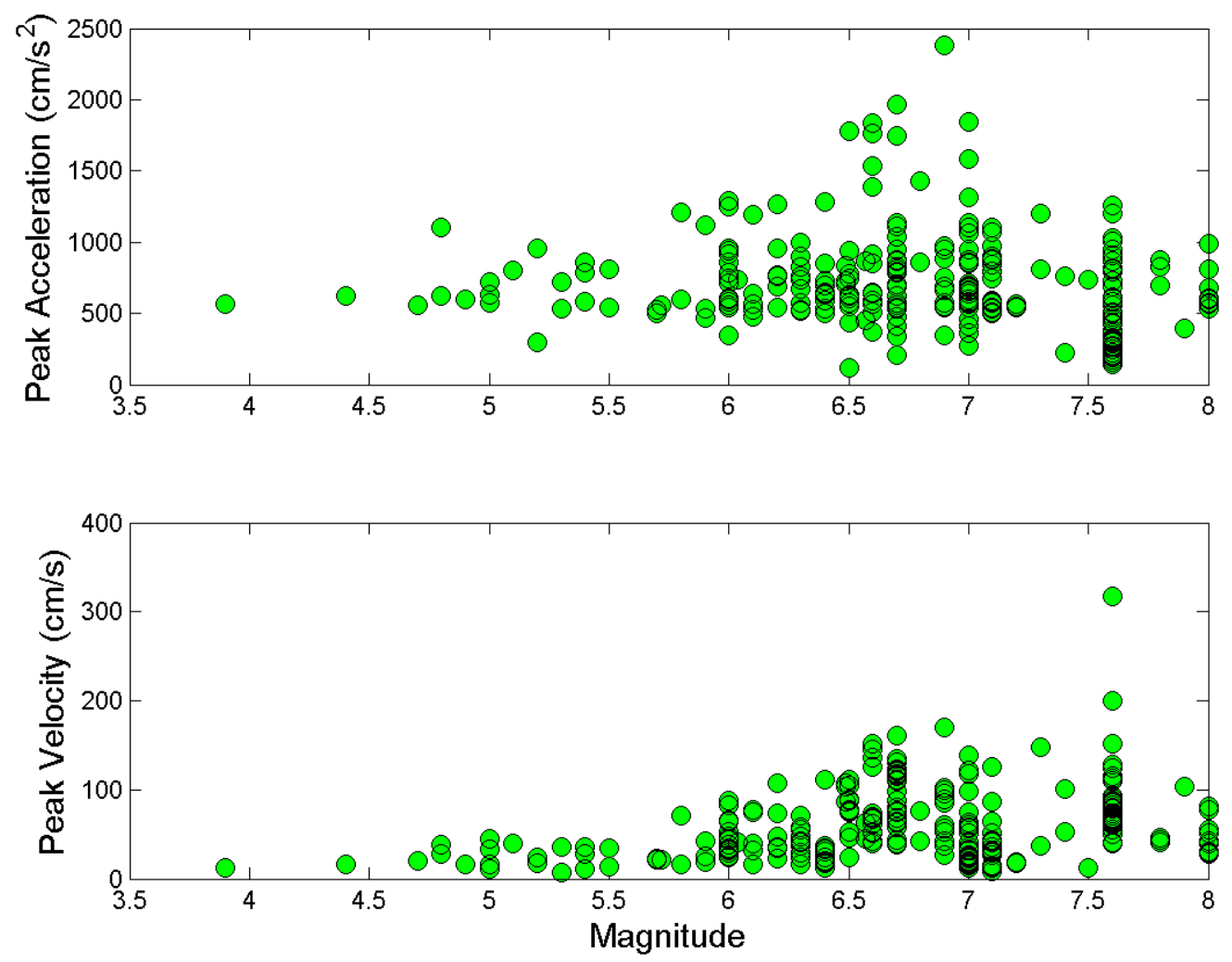

Figure 8. Exceptional ground motions vs moment magnitude. Peak acceleration and peak velocity for all events in Table 1, shown as a function of the magnitude of the earthquake. This figure is generated by the script j10s1.m in directory C:|Task_22\Analysis|Statistics1. The file name is C:|Task_22\Analysis|Statistics-1|J4_5.png. 
Figure 9. Rank of Peak Acceleration, Displayed as a Power Law

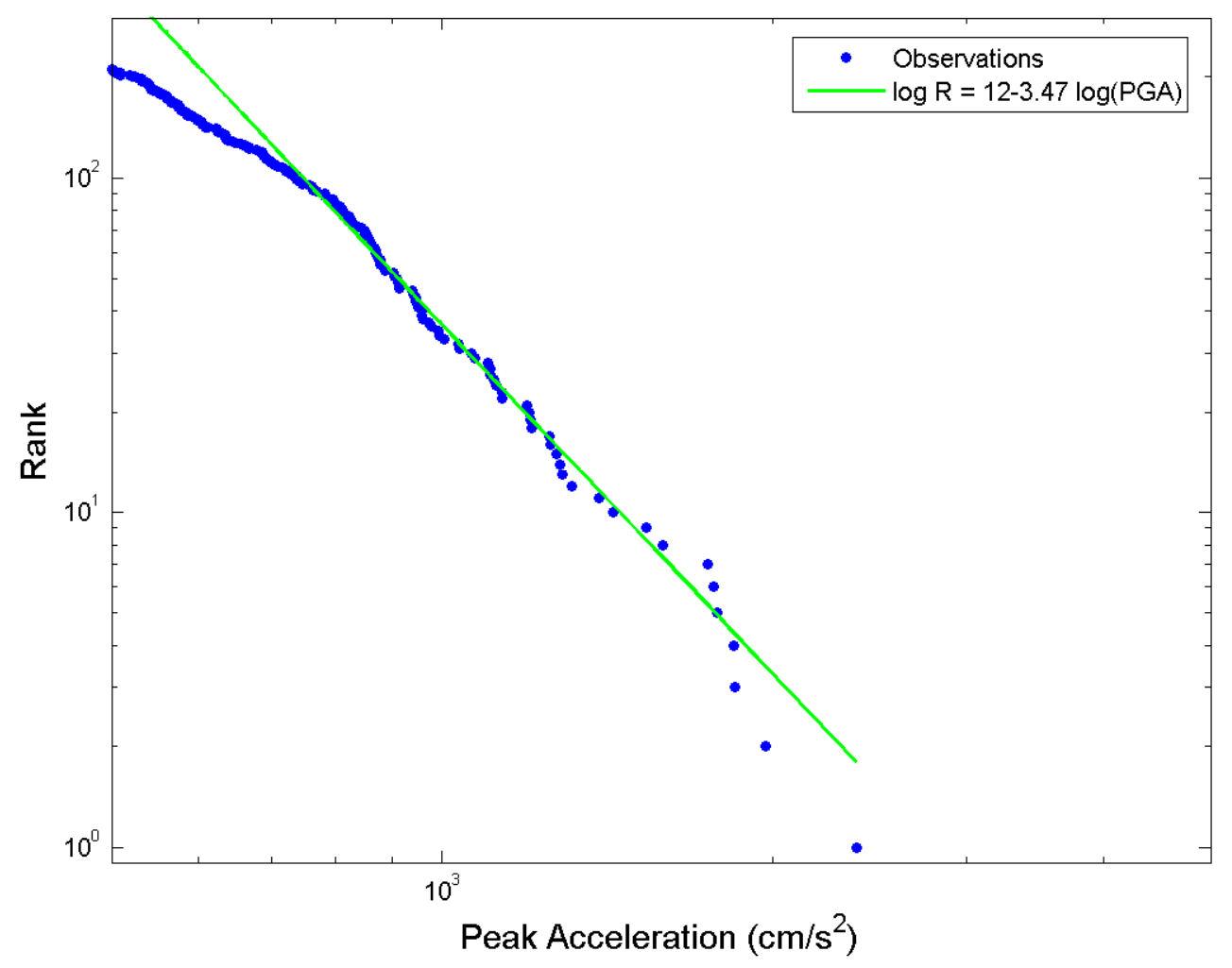

Figure 9. Ranking of exceptional records as a function of peak accelerations. The observations are shown as points. The axes are chosen such that data consistent with a power law distribution (Equation 1) of exceptional values would fall on a straight line. The green line, with parameters given in the figure, is the best power-law fit, using an L2 norm, to the data with ranks of 6 to 100 . This figure is generated by the Matlab script j10s2.m in directory C:|Task_22\Analysis|Statistics-1. The file name is C:|Task_22\Analysis|Statistics-1|J5_01.png. 


\section{Figure 10. Rank of Peak Velocity, Displayed as a Power Law}

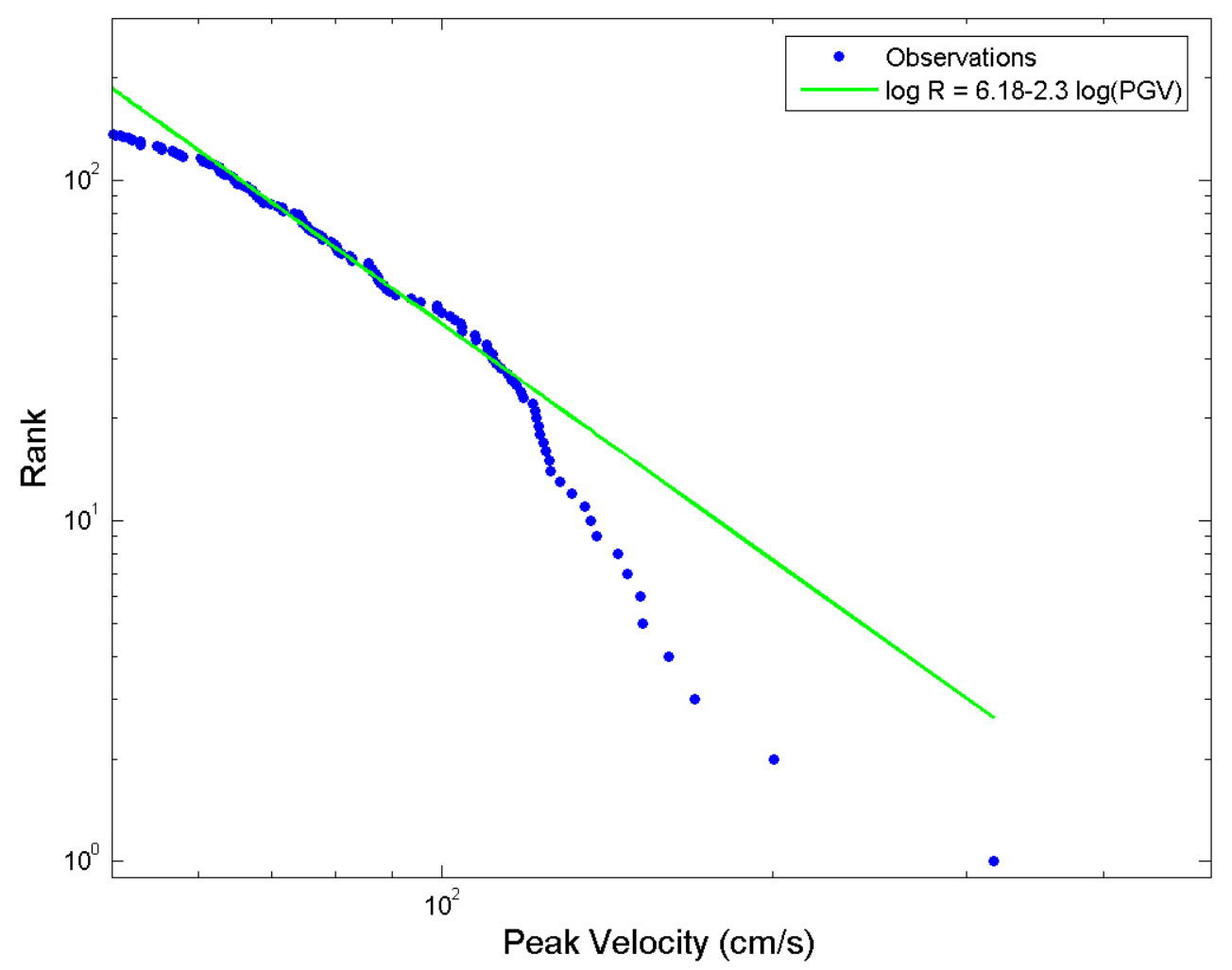

Figure 10. Ranking of exceptional records as a function of peak velocities. The observations are shown as points. The axes are chosen such that data consistent with a power law distribution (Equation 1) of exceptional values would fall on a straight line. The green line, with parameters given in the figure, is the best power law fit, using an L2 norm, to the data with ranks of 20 to 100 . This figure is generated by the script j10s2.m in directory C:ITask_22\Analysis|Statistics-1. The file name is C:|Task_22\Analysis|Statistics-1|J5_02.png. 
Figure 11. Rank of Peak Acceleration, Displayed as an Exponential Law

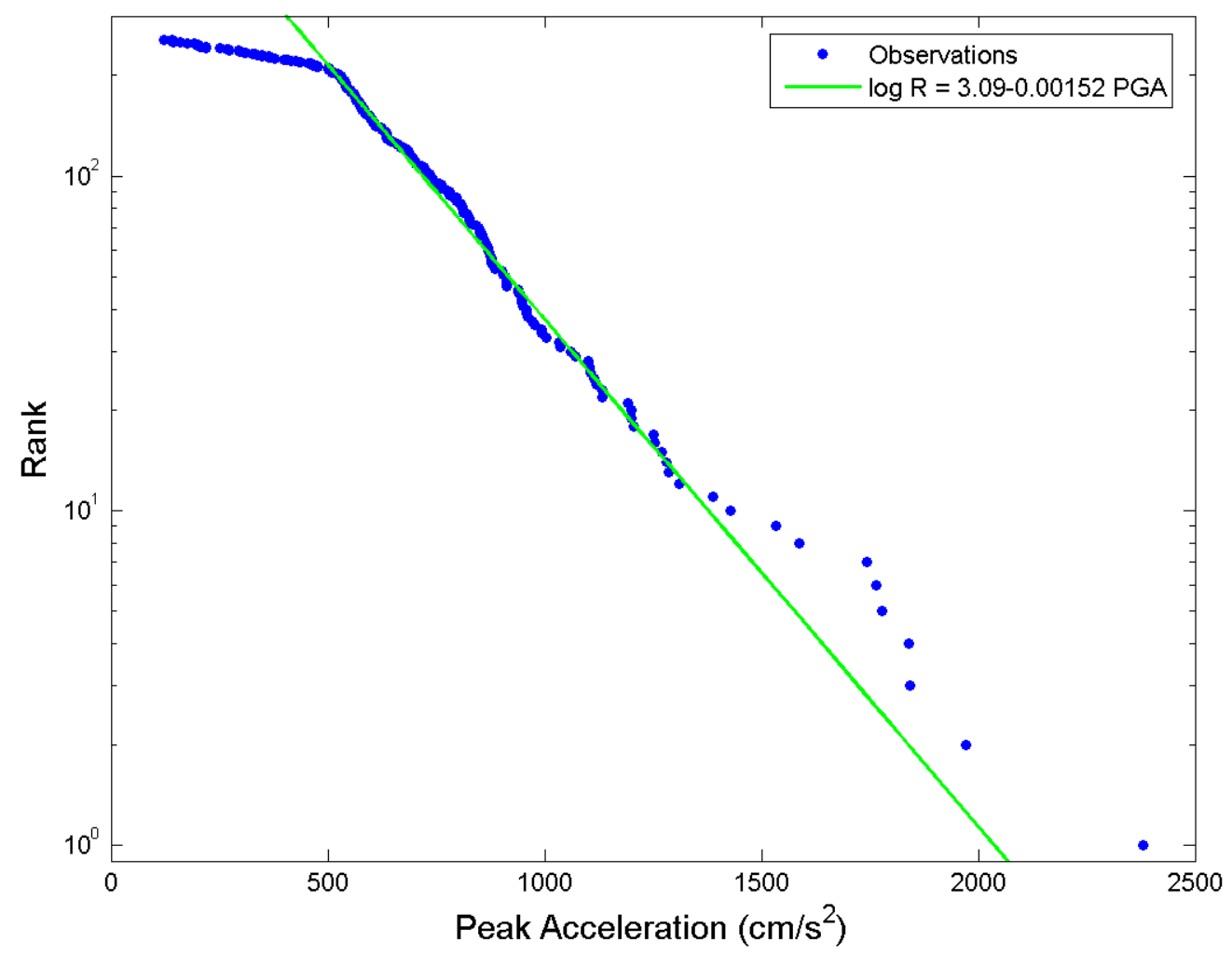

Figure 11. Ranking of exceptional records as a function of peak accelerations. The observations are shown as points. The axes are chosen such that data consistent with an exponential distribution (Equation 2) of exceptional values would fall on a straight line. The green line, with parameters given in the figure, is the best fitting exponential distribution, using an L2 norm, to the data with ranks of 10 to 80 . This figure is generated by the script j10s2.m in directory C:|Task_22|Analysis|Statistics-1. The file name is C:|Task_22\Analysis|Statistics-1|J5_03.png. 


\section{Figure 12. Rank of Peak Velocity, Displayed as an Exponential Law}

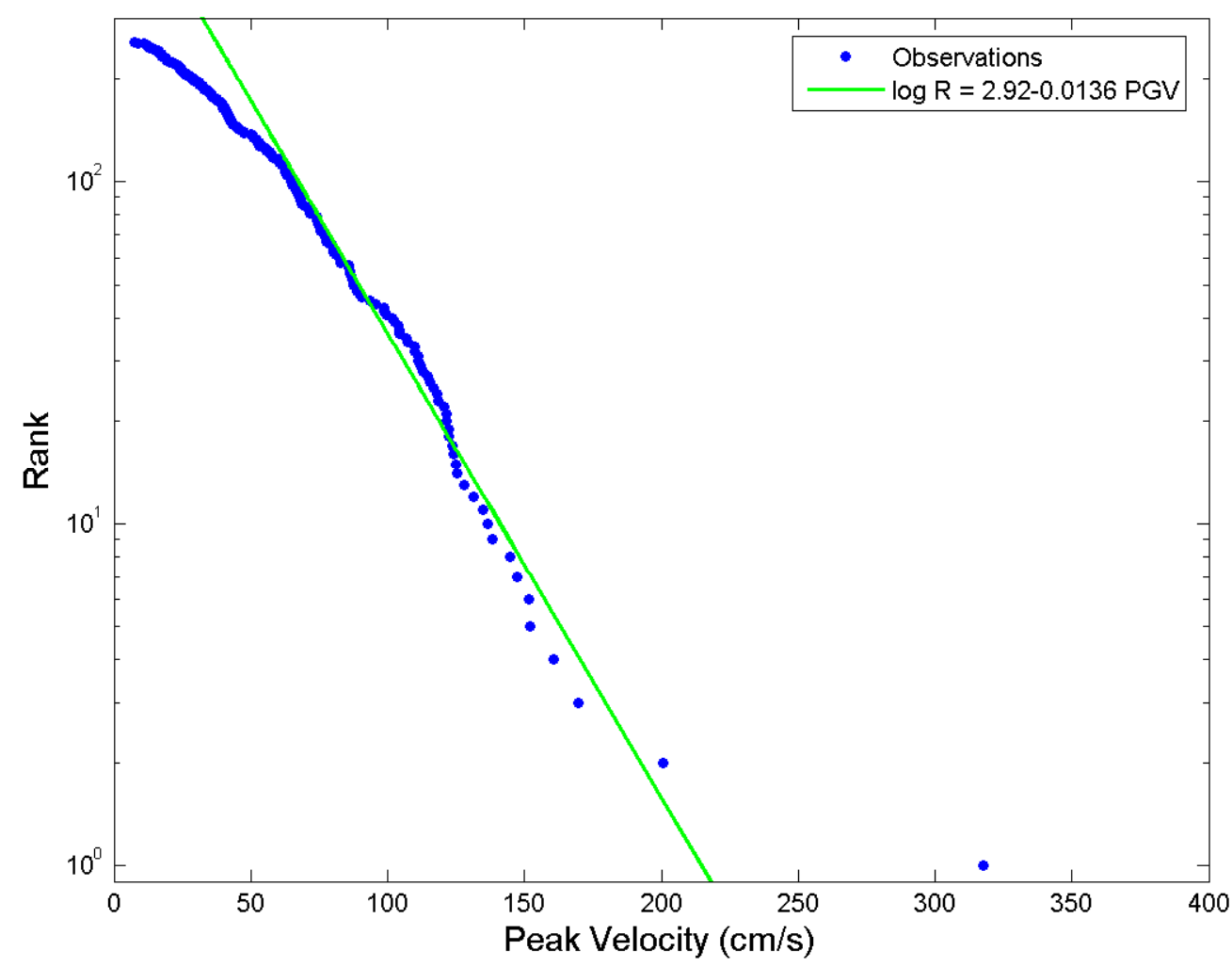

Figure 12. Ranking of exceptional records as a function of peak velocities. The observations are shown as points. The axes are chosen such that data consistent with an exponential distribution (Equation 2) of exceptional values would fall on a straight line. The green line, with parameters given in the figure, is the best fitting exponential distribution, using an L2 norm, to the data with ranks of 5 to 80 . This figure is generated by the script j10s2.m in directory C:ITask_22|Analysis|Statistics-1. The file name is C:|Task_22\Analysis|Statistics-1|J5_04.png. 


\section{Figure 13. Rank of Peak Acceleration, Displayed as an Extreme Value Distribution}

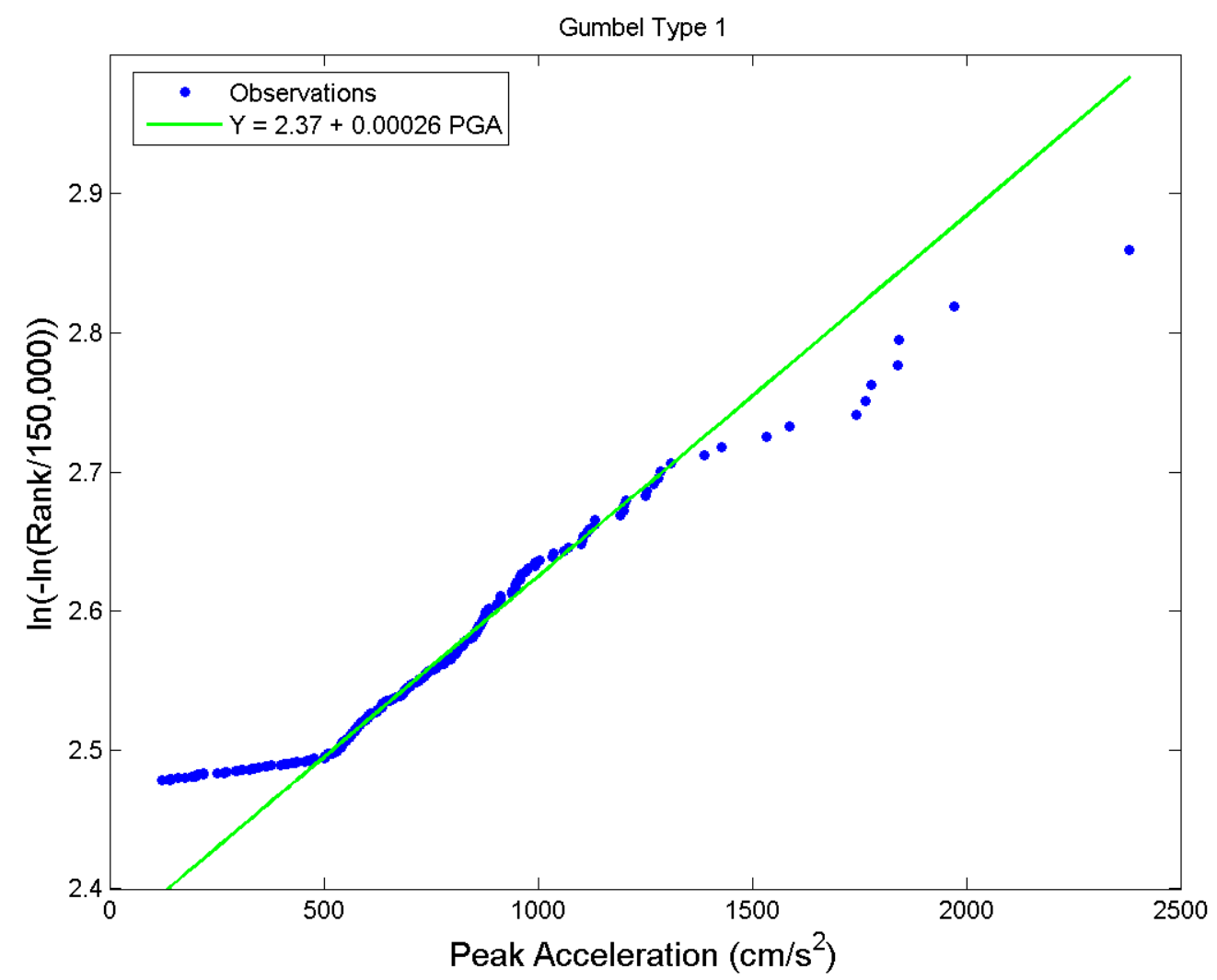

Figure 13. Ranking of exceptional records as a function of peak accelerations. The observations are shown as points. The axes are chosen such that data consistent with an extreme value distribution (Equation 3) of exceptional values would fall on a straight line. The green line, with parameters given in the figure, is the best fitting exponential distribution, using an L2 norm, to the data with ranks of 10 to 100. This figure is generated by the script j10s2.m in directory C:ITask_22\Analysis|Statistics-1. The file name is C:ITask_22\Analysis|Statistics-1|J5_05.png. 


\section{Figure 14. Rank of Peak Velocity, Displayed as an Extreme Value Distribution}

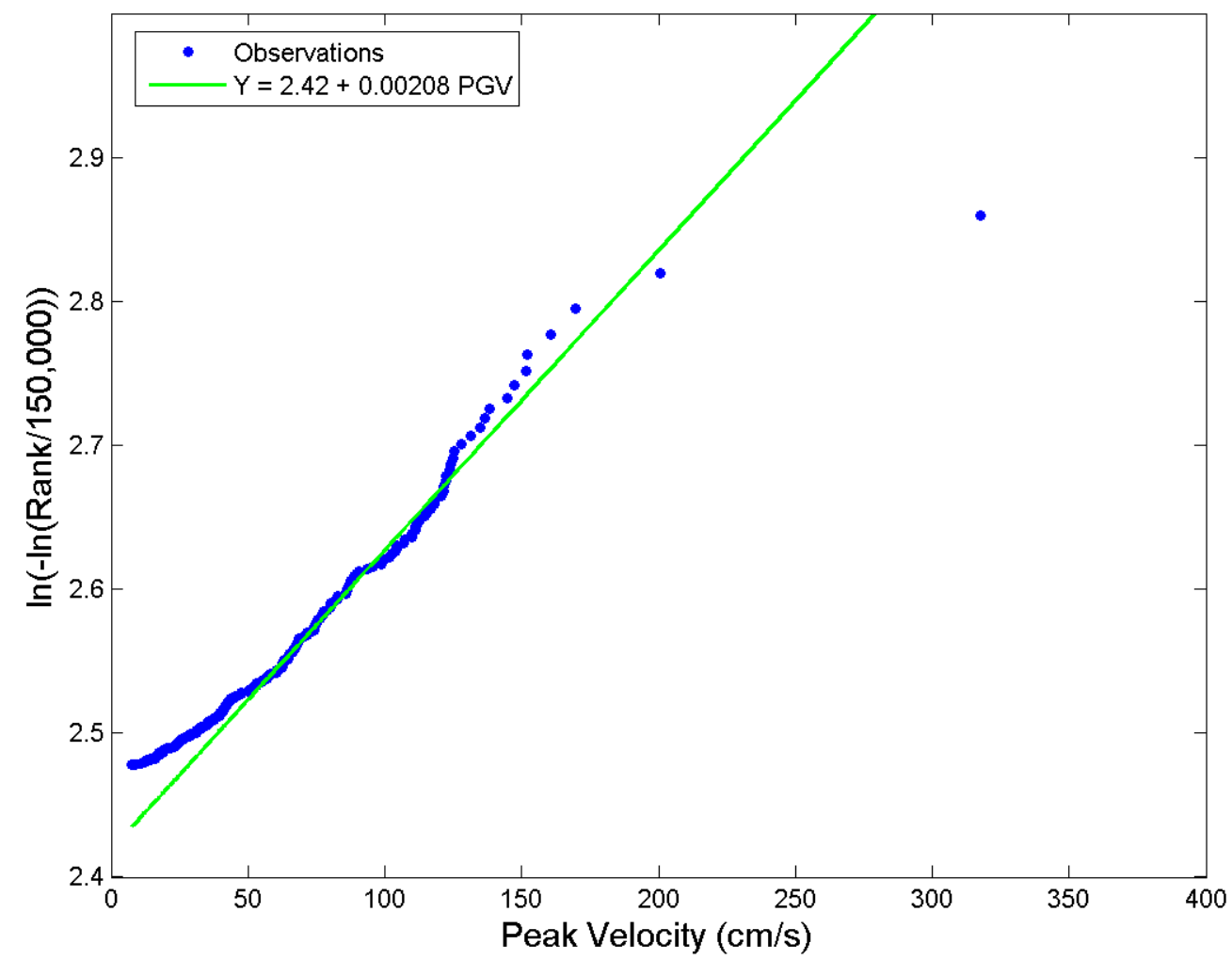

Figure 14. Ranking of exceptional records as a function of peak velocities. The observations are shown as points. The axes are chosen such that data consistent with an extreme value distribution (Equation 3) of exceptional values would fall on a straight line. The green line, with parameters given in the figure, is the best fitting exponential distribution, using an L2 norm, to the data with ranks of 10 to 100 . This figure is generated by the script j10s2.m in directory C:|Task_22|Analysis|Statistics-1. The file name is C:|Task_22\Analysis|Statistics-1|J5_06.png. 


\section{Figure 15. Estimated Exceedance Rate of Peak Acceleration Per}

Instrument Year

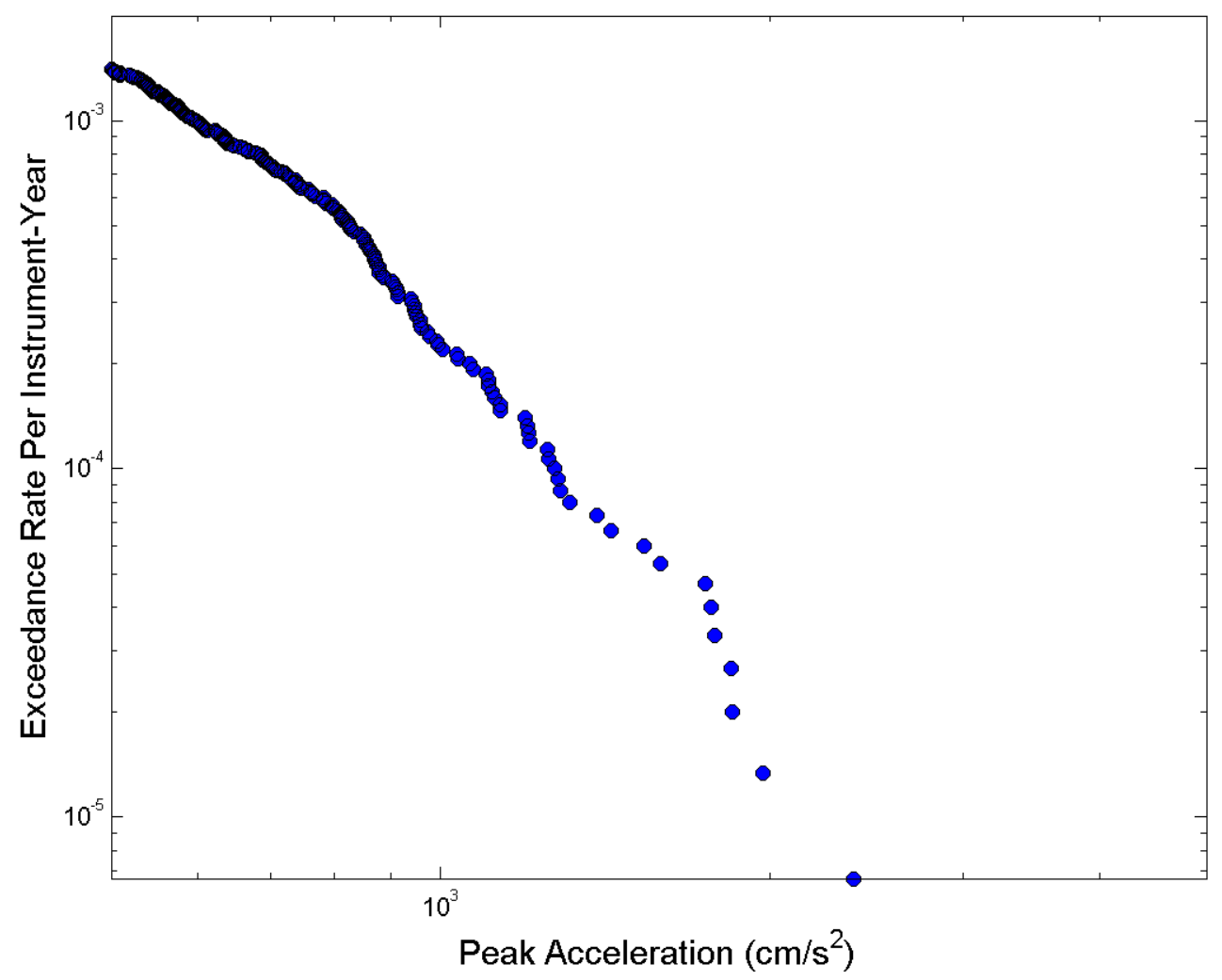

Figure 15. Estimated exceedance rate of peak acceleration per instrument year. The points are obtained by dividing the rank in Figure 9 by the estimate that these data represent about 150,000 instrument-years of data collection effort. This figure is generated by the script j10s2.m in directory C:ITask_22।Analysis|Statistics-1. The file name is C:|Task_22\Analysis|Statistics-1|J5_07.png. 


\section{Figure 16. Estimated Exceedance Rate of Peak Velocity Per}

Instrument Year

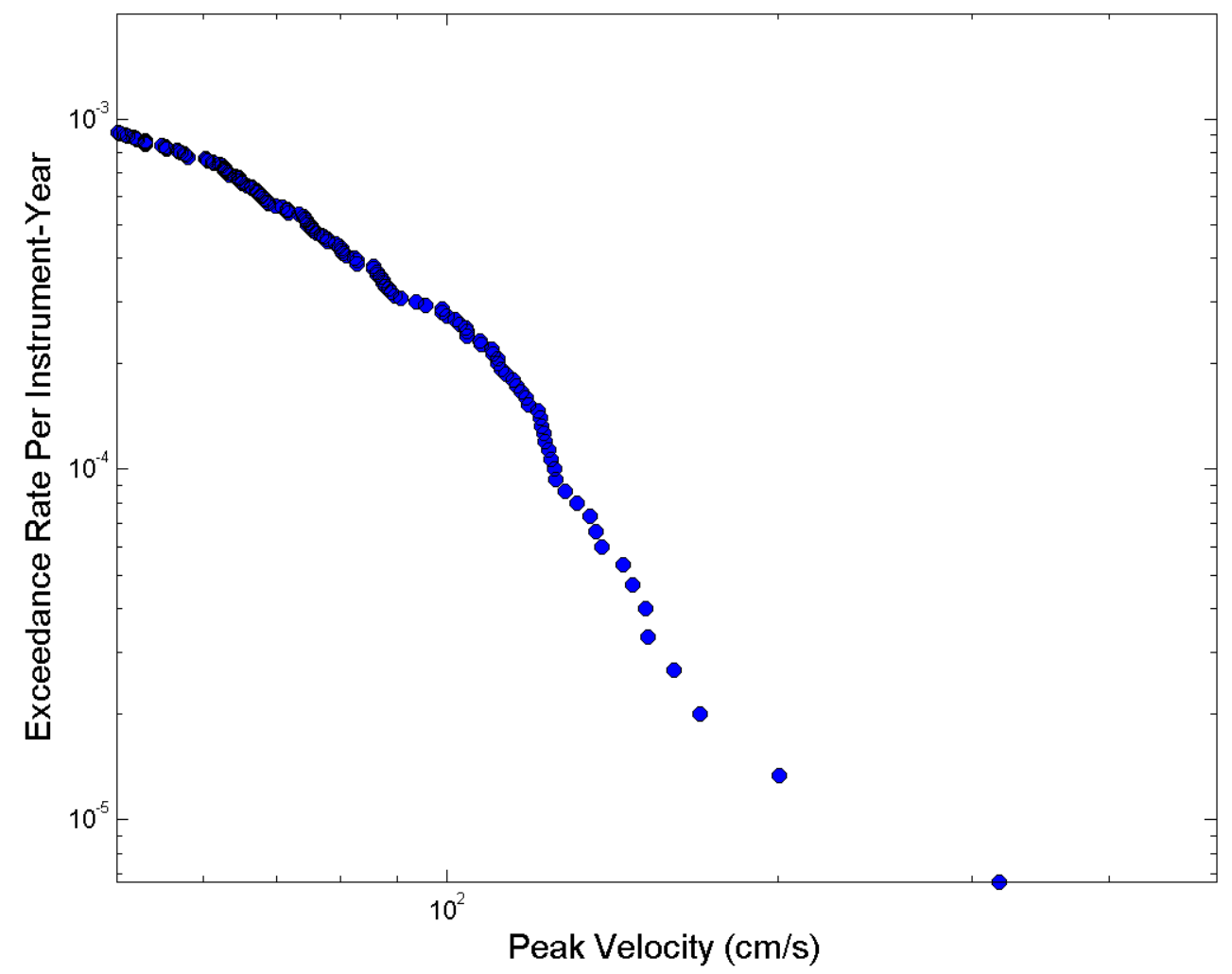

Figure 16. Estimated exceedance rate of peak velocity per instrument year. The points are obtained by dividing the rank in Figure 9 by the estimate that these data represent about 150,000 instrument-years of data collection effort. This figure is generated by the script j10s2.m in directory C:ITask_22\Analysis|Statistics-1. The file name is C:|Task_22\Analysis|Statistics-1|J5_08.png. 
Figure 17. Distribution of Magnitudes for All Included Earthquakes

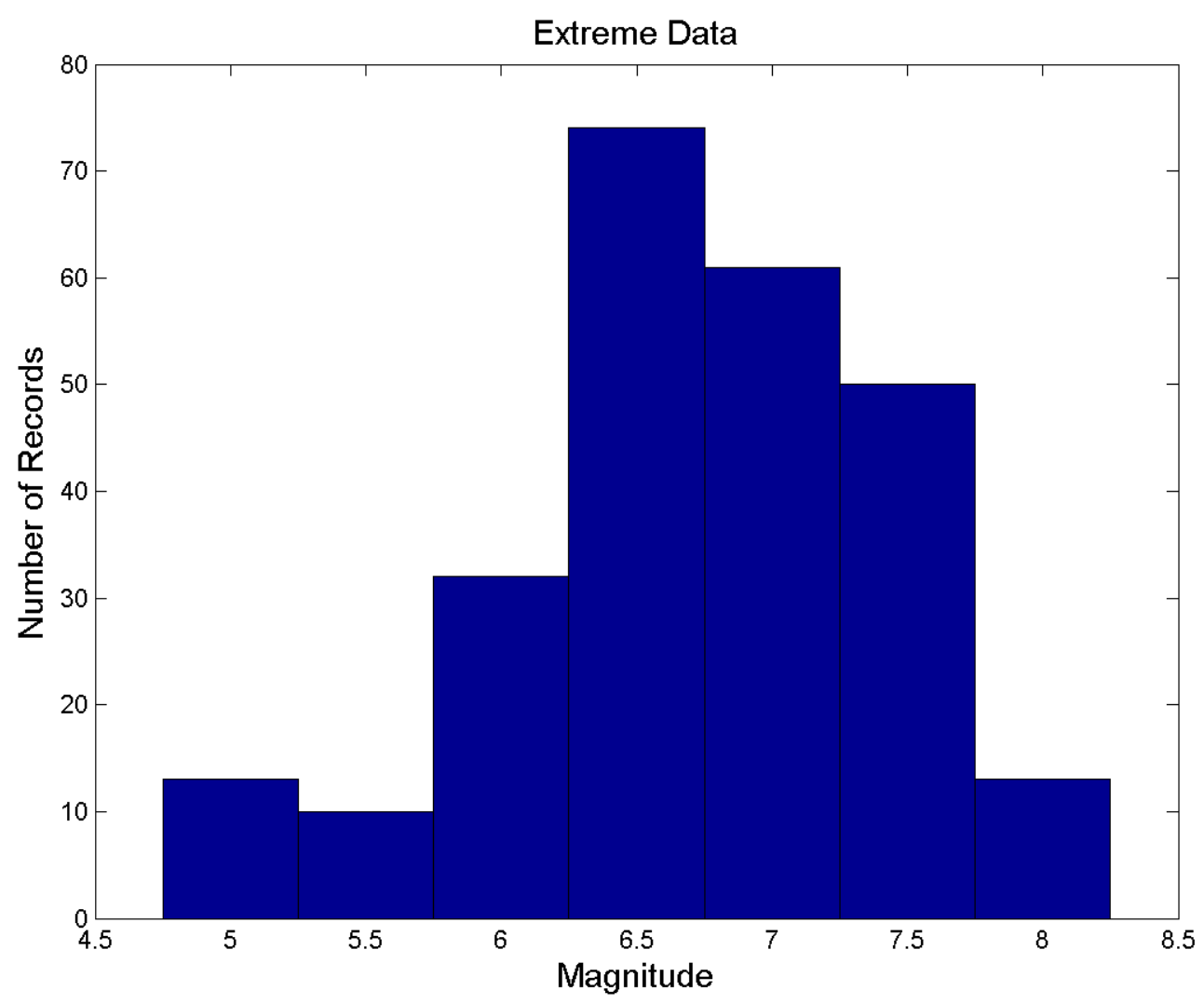

Figure 17. Magnitudes of the earthquakes for all of the records included in Table 1. Earthquakes that generated more than one exceptional ground motion record are counted once for each record. This figure is generated by the Matlab script j11sa.m in directory C:|Task_22\Analysis|Statistics-2. The file name of this figure is

C:|Task_22\Analysis|Statistics-2\J11sa_08.png. 
Figure 18. Magnitude Distribution of Earthquakes Causing the Top 100 Accelerations, Compared With the Distribution of Magnitude in the NGA Database

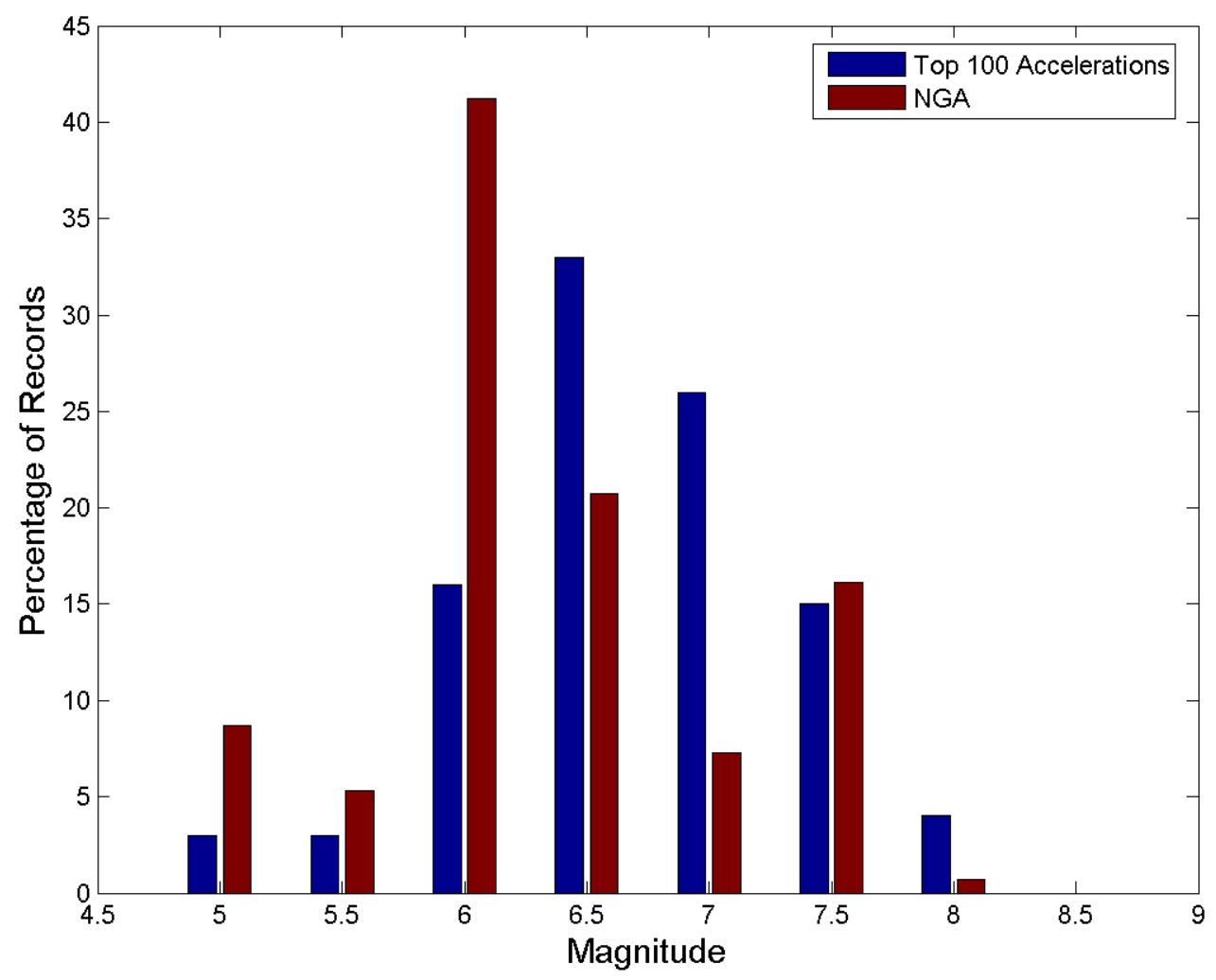

Figure 18. Magnitude distribution of earthquakes causing the top 100 acceleration records, compared with the distribution of magnitudes in the NGA database. Earthquakes that generated more than one of the top 100 ground motion records are counted once for each record. This figure is generated by the Matlab script j11sa.m in directory C:|Task_22\Analysis|Statistics-2. The file name of this figure is C:ITask_22\Analysis|Statistics-2|J11sa_08a.png. 
Figure 19. Magnitude Distribution of Earthquakes Causing the Top 100 Velocities, Compared With the Distribution of Magnitude in the NGA Database

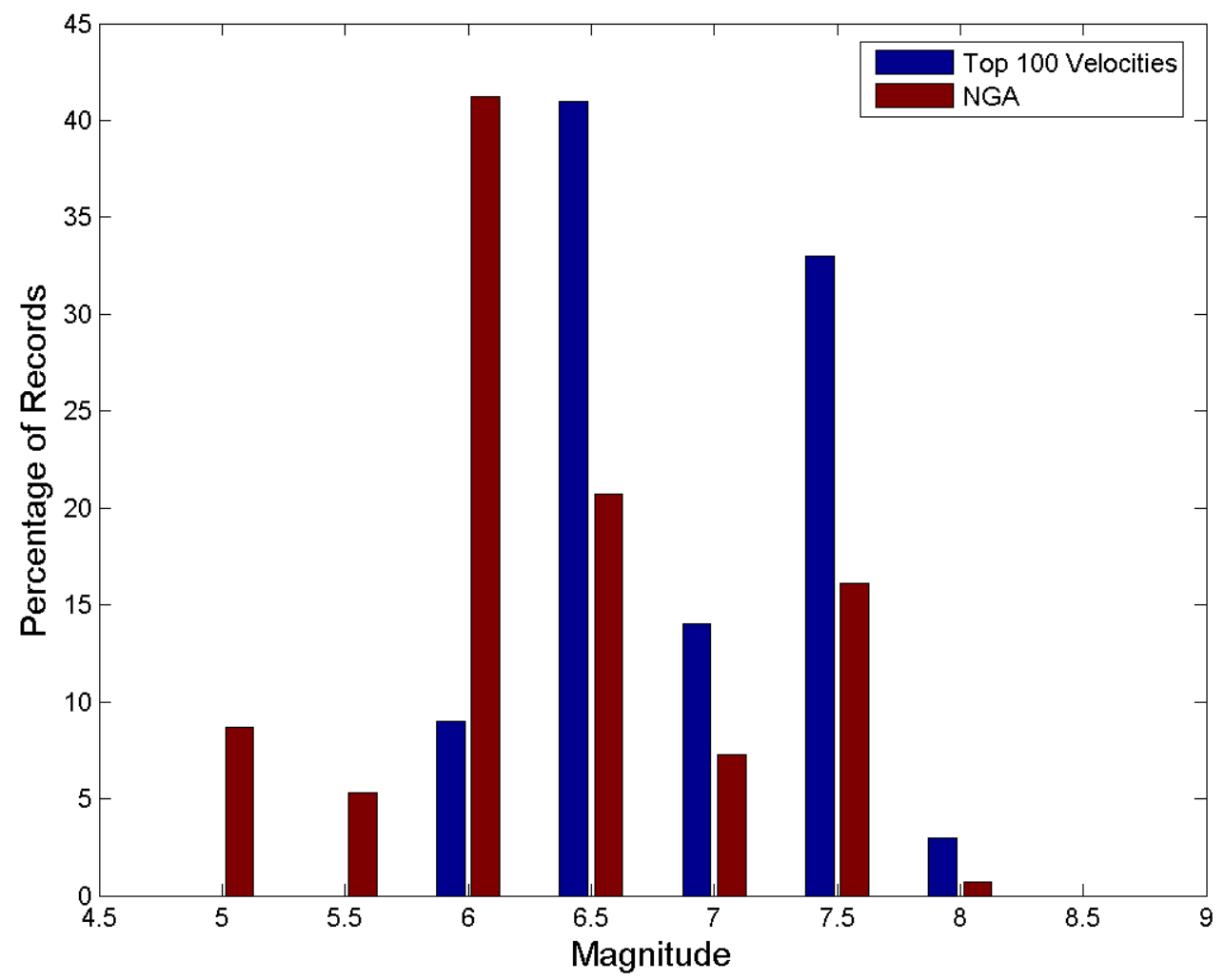

Figure 19. Magnitude distribution of earthquakes causing the top 100 velocity records, compared with the distribution of magnitudes in the NGA database. Earthquakes that generated more than one of the top 100 ground motion records are counted once for each record. Figure 19 is generated by the Matlab script j11sv.m in directory

C:|Task_22\Analysis|Statistics-2. The file name of this figure is

C:|Task_22\Analysis|Statistics-2|J11sv_08a.png. 
Figure 20. Magnitudes of Earthquakes Causing the Top 100 Accelerations, Displayed by Quartile

Top 100 Acceleration
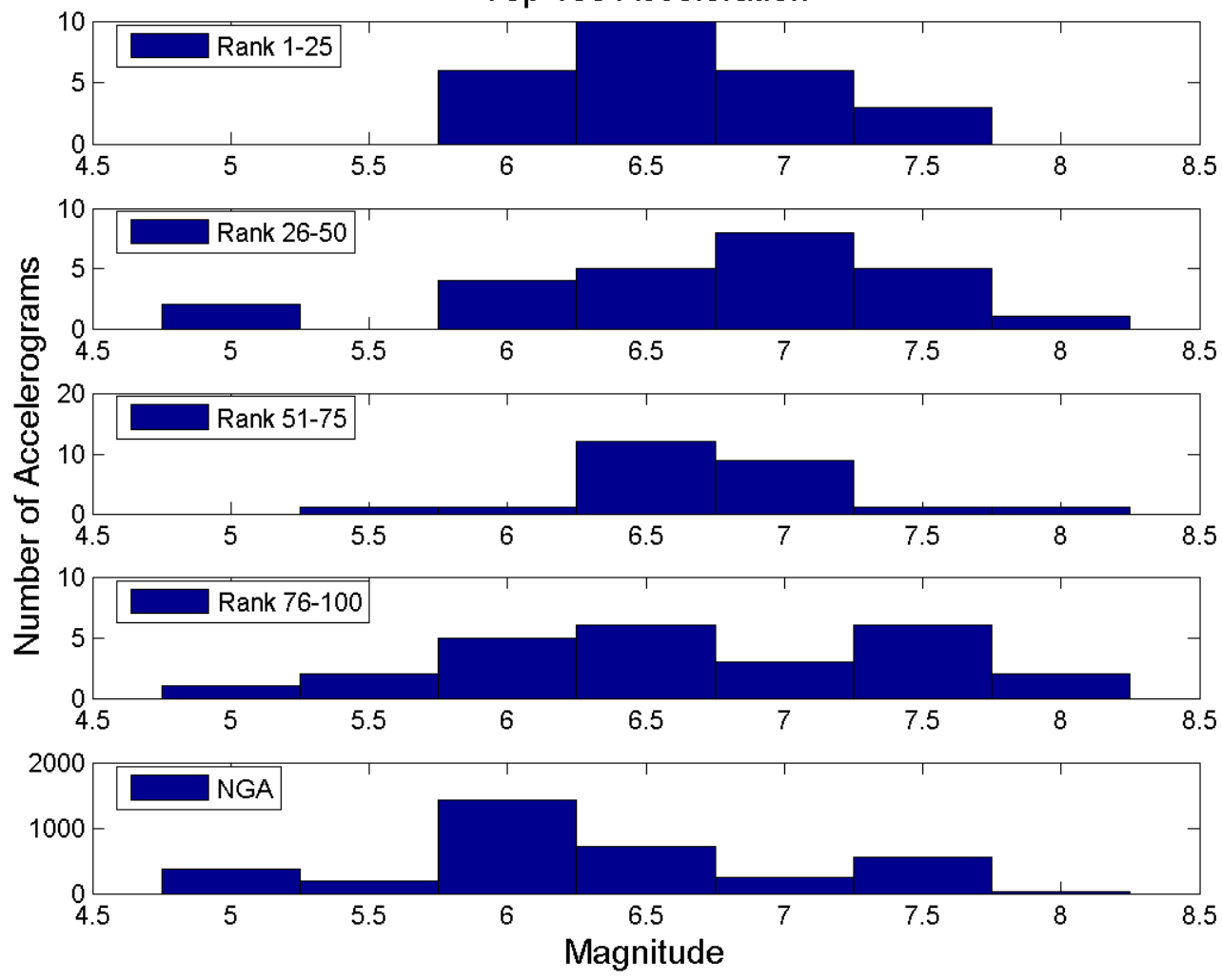

Figure 20. Magnitudes of earthquakes causing the top 100 accelerations, displayed by quartile. Earthquakes that generated more than one of the top 100 ground motion records are counted once for each record. This figure is generated by the Matlab script j11sa.m in directory C: $\mid$ Task_22\Analysis|Statistics-2. The file name of this figure is C:ITask_22\Analysis|Statistics-2|J11sa_10.png. 
Figure 21. Magnitudes of Earthquakes Causing the Top 100 Velocities, Displayed by Quartile

Top 100 Velocities
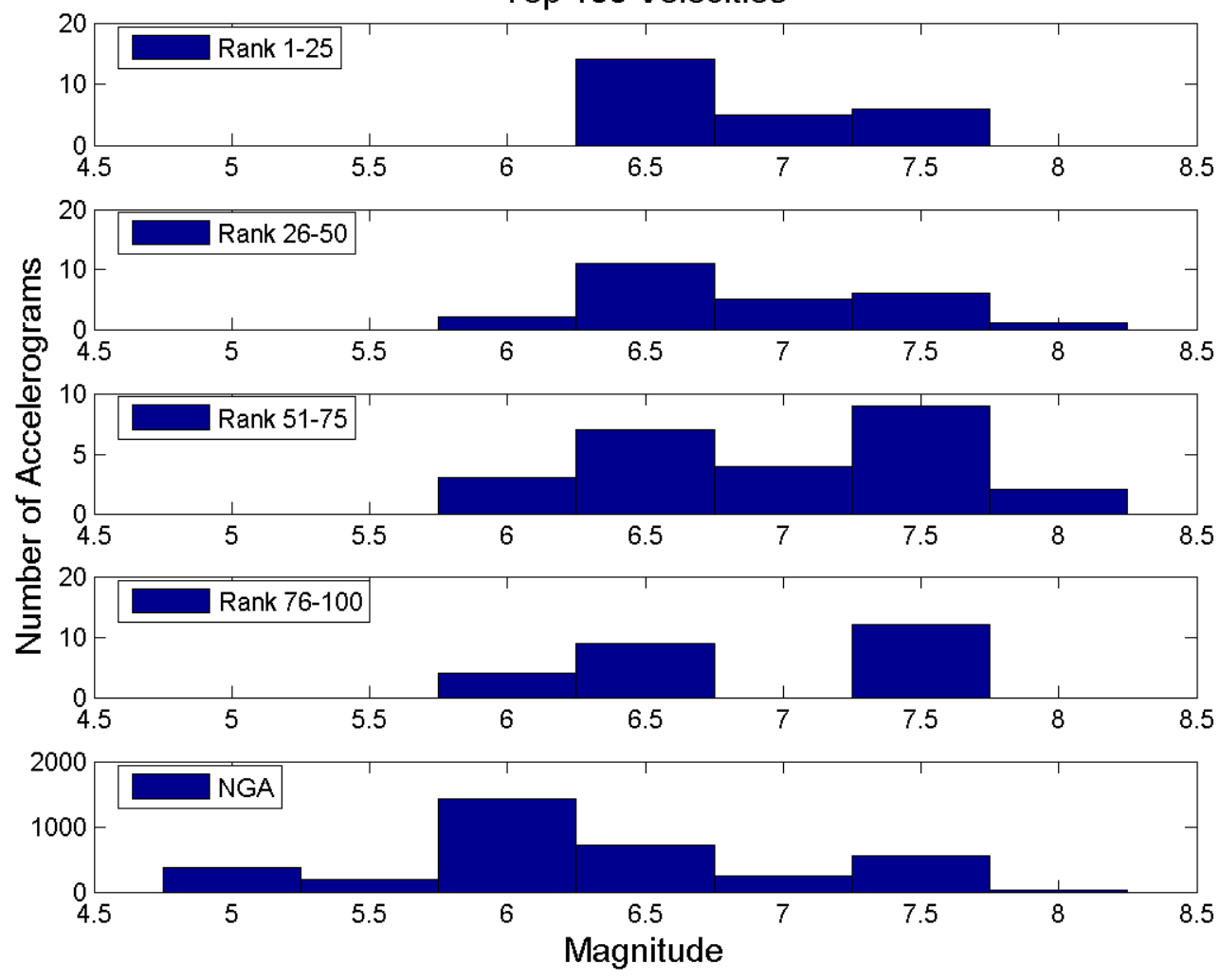

Figure 21. Magnitudes of earthquakes causing the top 100 velocities, displayed by quartile. Earthquakes that generated more than one of the top 100 ground motion records are counted once for each record. This figure is generated by the Matlab script j11sv.m in directory C: $\mid$ Task_22\Analysis|Statistics-2. The file name of this figure is C:ITask_22\Analysis|Statistics-2|J11sv_10.png. 
Figure 22. Distribution of Focal Mechanisms for All Included Earthquakes

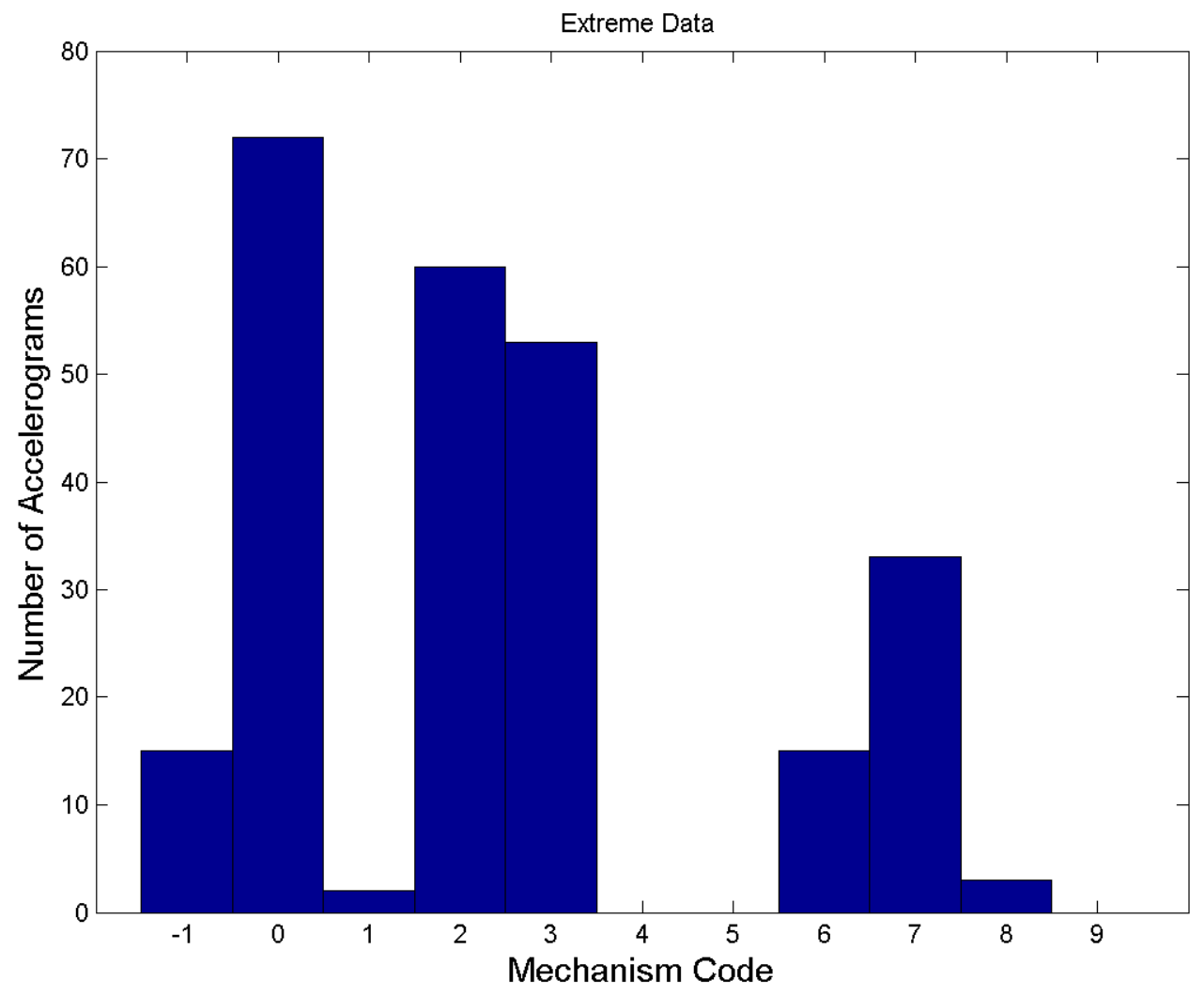

Figure 22. Distribution of focal mechanisms for the earthquake generating each record in Table 1. The mechanism code is as follows: 0 ) strike-slip faulting in continental crust; 1) normal faulting in continental crust; 2) thrust faulting in continental crust; 3) oblique thrust faulting in continental crust; 4) oblique normal faulting in continental crust; 6) normal faulting associated with the downgoing slab in a subduction zone; 7) thrust faulting in an oceanic subduction zone; and 8) oblique thrust faulting in an oceanic subduction zone. A code of -1 indicates that the mechanism for that record was not available. For earthquakes causing more than one record in Table 1, the earthquake is counted once for each record. This is generated by the Matlab script j11sa.m in directory

C:ITask_22\Analysis|Statistics-2. The file name of this figure is

C:|Task_22\Analysis|Statistics-2|J11sa_01.png. 
Figure 23. Distribution of Focal Mechanism for the Top 100 Acceleration Records, Compared With the Distribution of Focal Mechanism in the NGA Database

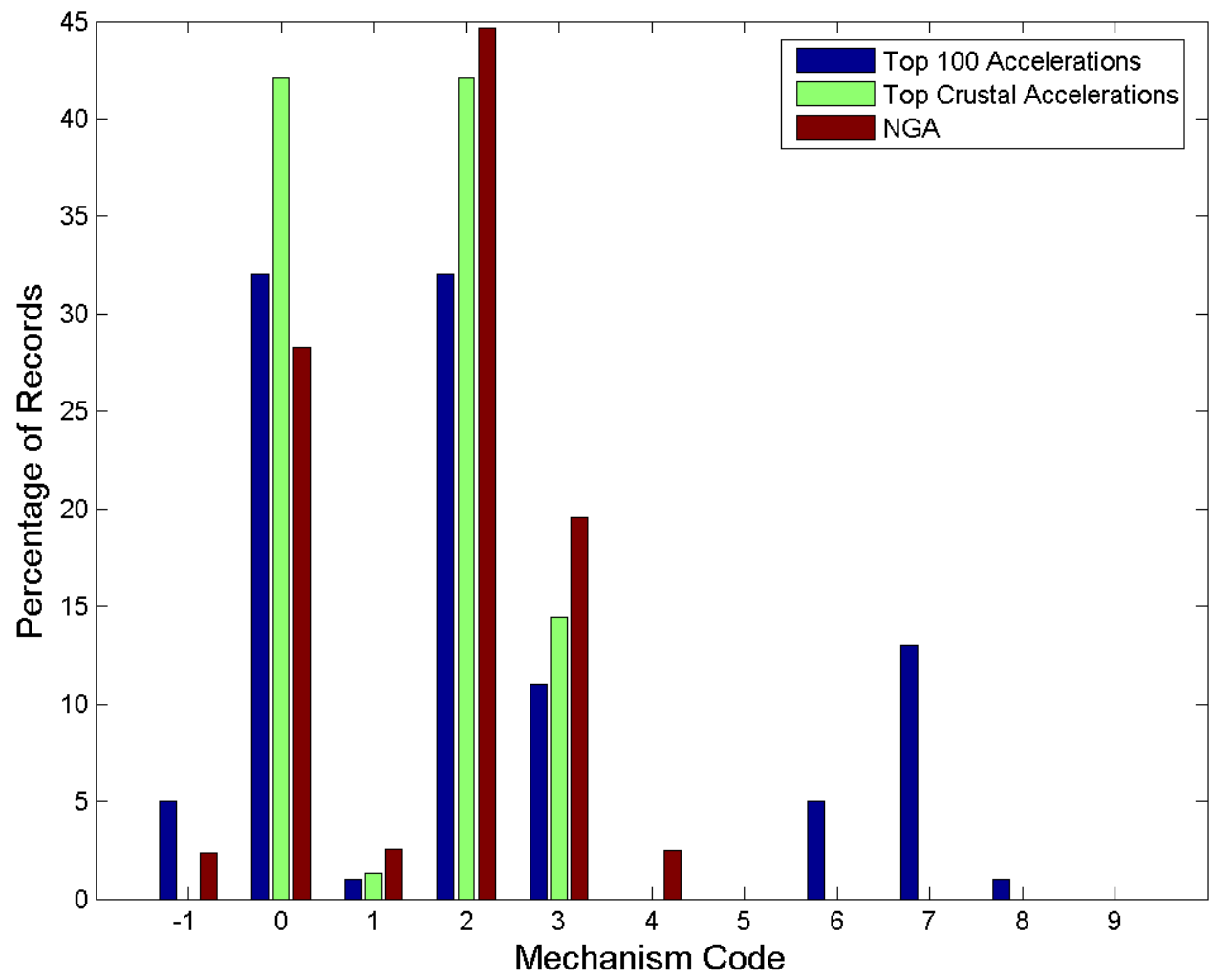

Figure 23. Distribution of focal mechanisms of earthquakes causing the top 100 acceleration records, compared with the distribution of focal mechanism in the NGA database. The NGA database does not include subduction zone earthquakes. Therefore, the bars giving the percentage of "Top Crustal Accelerations" is generated for comparison with NGA by renormalizing those top 100 records with mechanisms $0,1,2$, 3 , or 4 to a total of $100 \%$. Mechanism codes are given in the caption to Figure 22. For earthquakes causing more than one record in Table 1, the earthquake is counted once for each record. This figure is generated by the Matlab script j11sa.m in directory C:|Task_22\Analysis|Statistics-2. The file name of this figure is C:|Task_22\Analysis|Statistics-2|J11sa_01a.png. 
Figure 24. Distribution of Focal Mechanism for the Top 100 Velocities, Compared With the Distribution of Focal Mechanism in the NGA Database

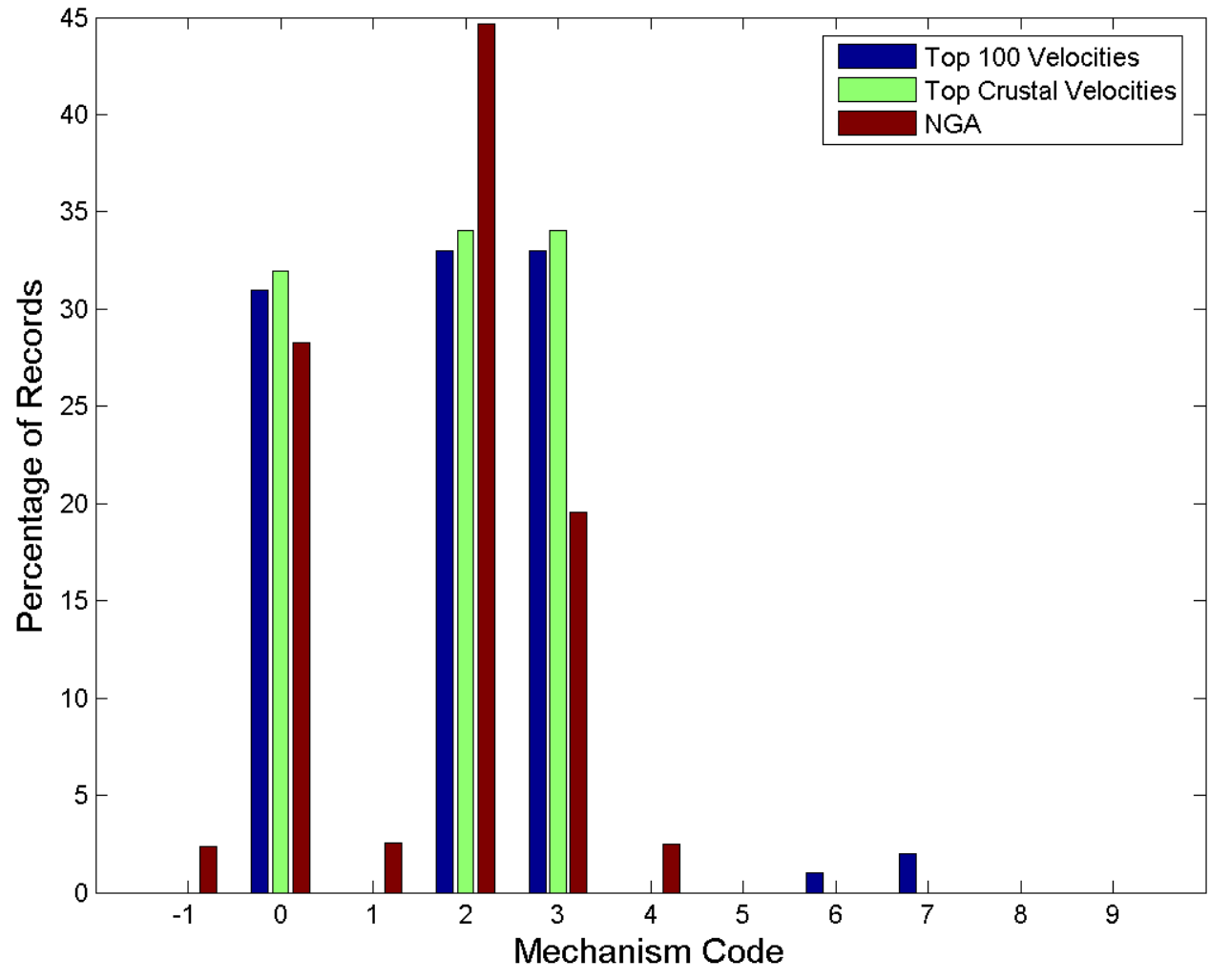

Figure 24. Distribution of focal mechanisms of earthquakes causing the top 100 velocity records, compared with the distribution of focal mechanism in the NGA database. See Figure 23 for a detailed explanation. This figure is generated by the Matlab script j11sv.m in directory C:ITask_22\Analysis|Statistics-2. The file name of this figure is C:|Task_22\Analysis|Statistics-2|J11sv_01a.png. 
Figure 25. Focal Mechanisms of Earthquakes Causing the Top 100 Acceleration Records, Displayed by Quartile

Top 100 Acceleration
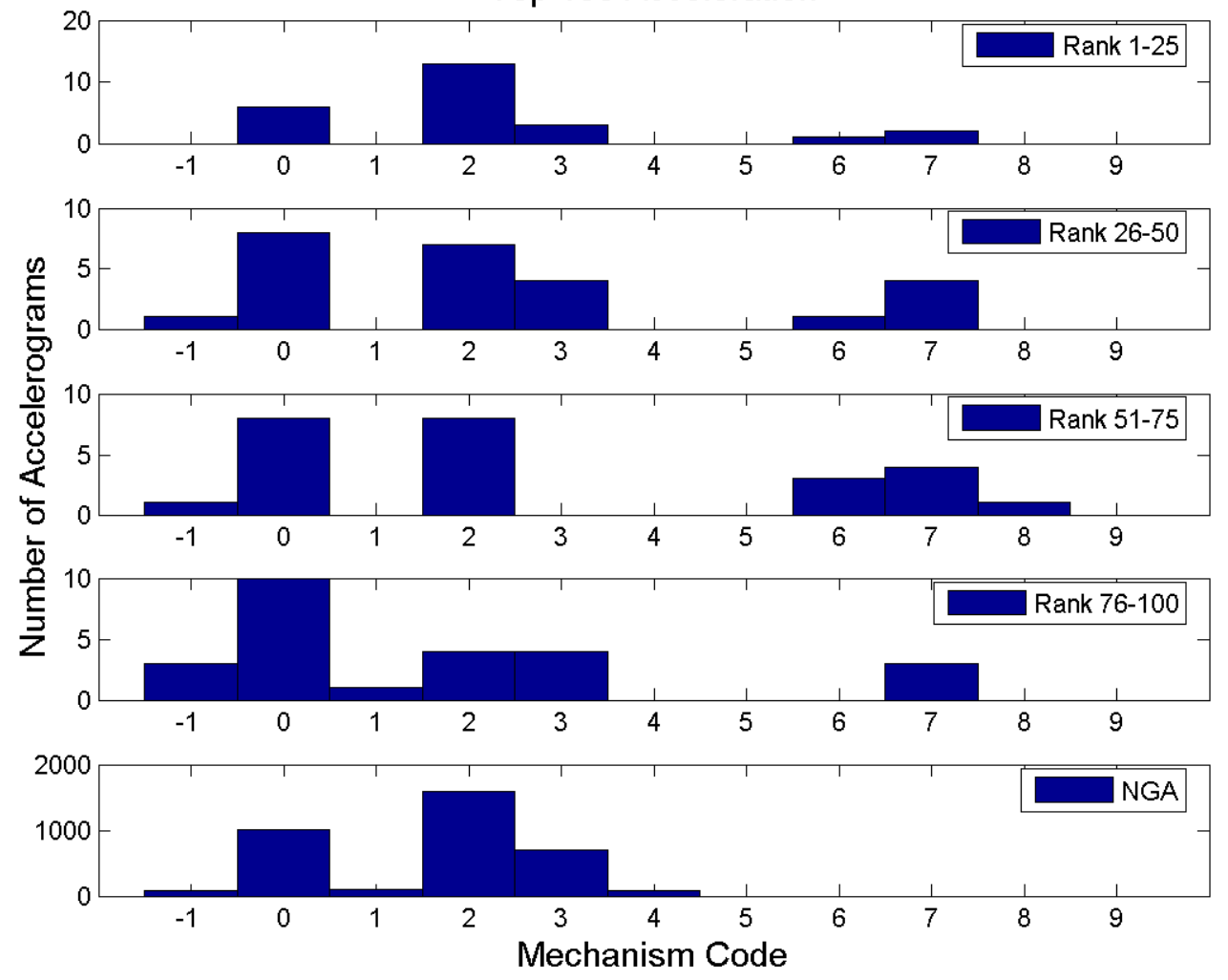

Figure 25. Focal mechanisms of earthquakes causing the top 100 acceleration records, displayed by quartile. See Figure 22 for mechanism codes. For earthquakes causing more than one record in Table 1, the earthquake is counted once for each record. This figure is generated by the Matlab script j11sa.m in directory

C:ITask_22\Analysis|Statistics-2. The file name of this figure is

C:|Task_22\Analysis|Statistics-2|J11sa_03.png. 
Figure 26. Focal Mechanisms of Earthquakes Causing the Top 100 Velocity Records, Displayed by Quartile

Top 100 Velocities
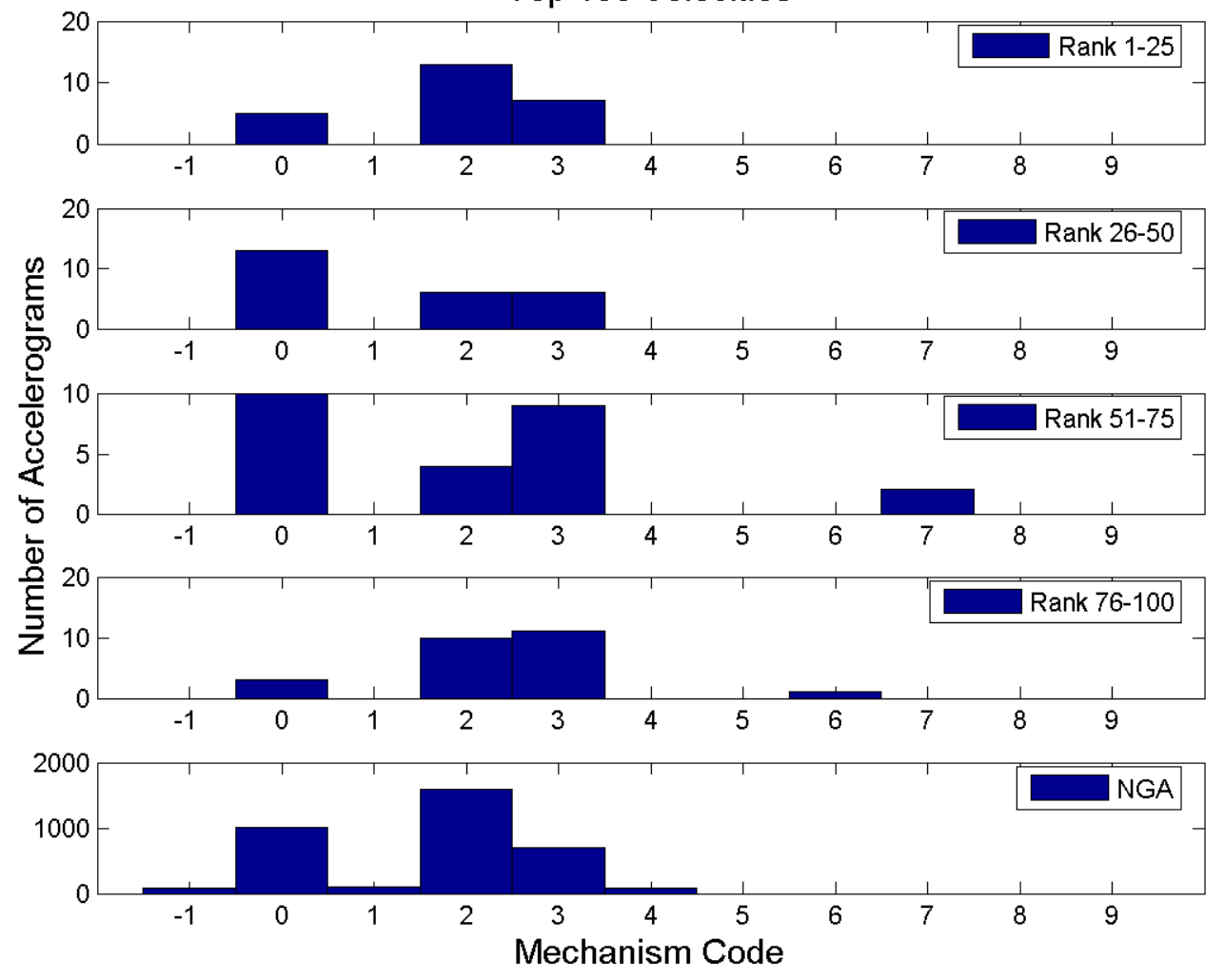

Figure 26. Focal mechanisms of earthquakes causing the top 100 velocity records, displayed by quartile. See Figure 25 for additional details. This figure is generated by the Matlab script j11sv.m in directory C: $\mid$ Task_22\Analysis|Statistics-2. The file name of this figure is C:|Task_22\Analysis|Statistics-2|J11sv_03.png. 
Figure 27. Distribution of Site Categories for All Included Records.

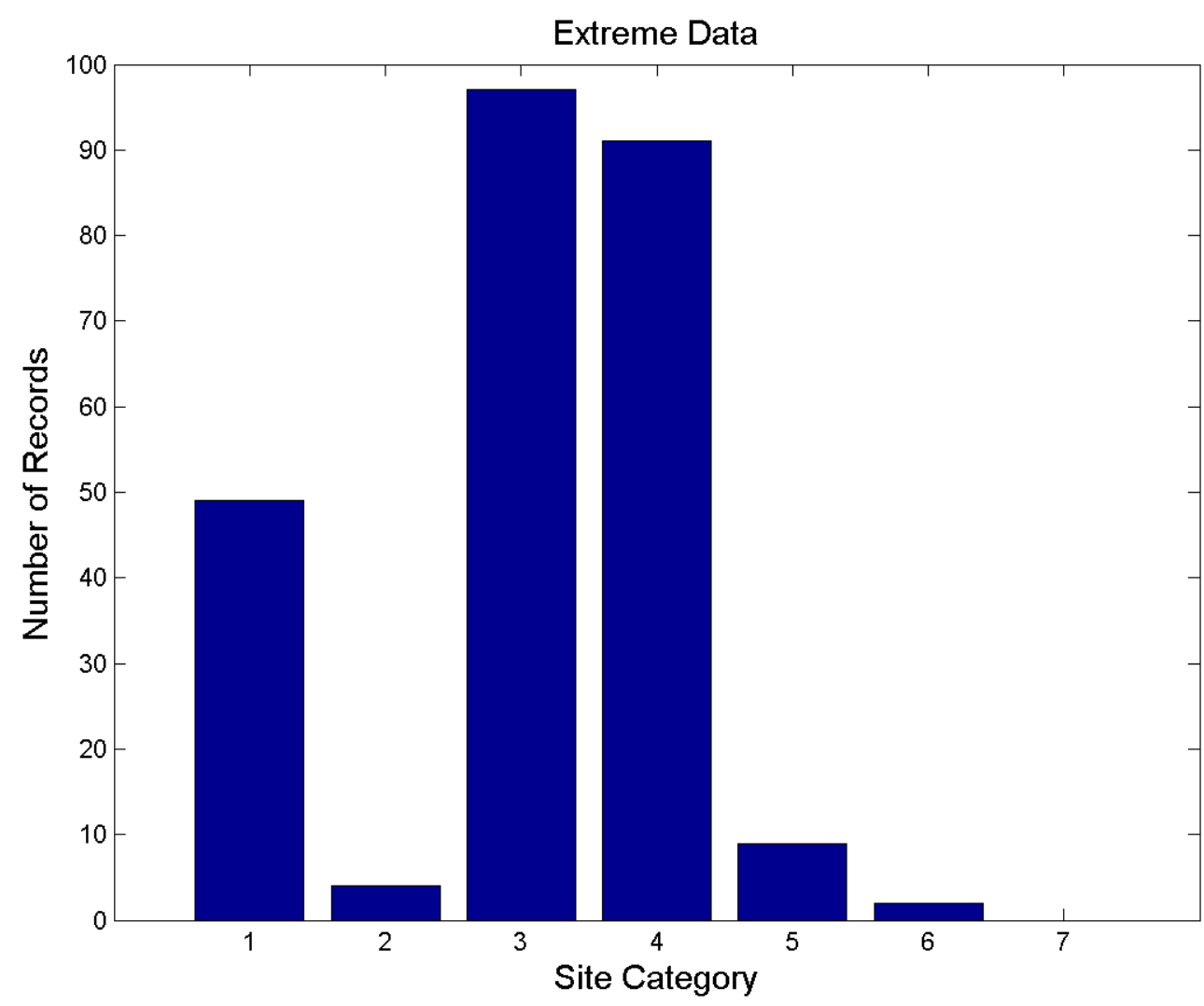

Figure 27. Distribution of site categories for all records in Table 1 . Site category $1=$ not available, 2=NEHRP E, 3=NEHRP D, 4=NEHRP C, 5-NEHRP B, 6-NEHRP A.

Earthquakes causing more than one record are displayed once for each record. This figure is generated by the Matlab script j11sa.m in directory C:ITask_22\Analysis|Statistics-2. The file name of this figure is C:|Task_22\Analysis|Statistics-2|J11sa_04.png. 
Figure 28. Distribution of Site Categories for the Top 100 Acceleration Records, Compared with the Distribution of Site Categories in the NGA Database.

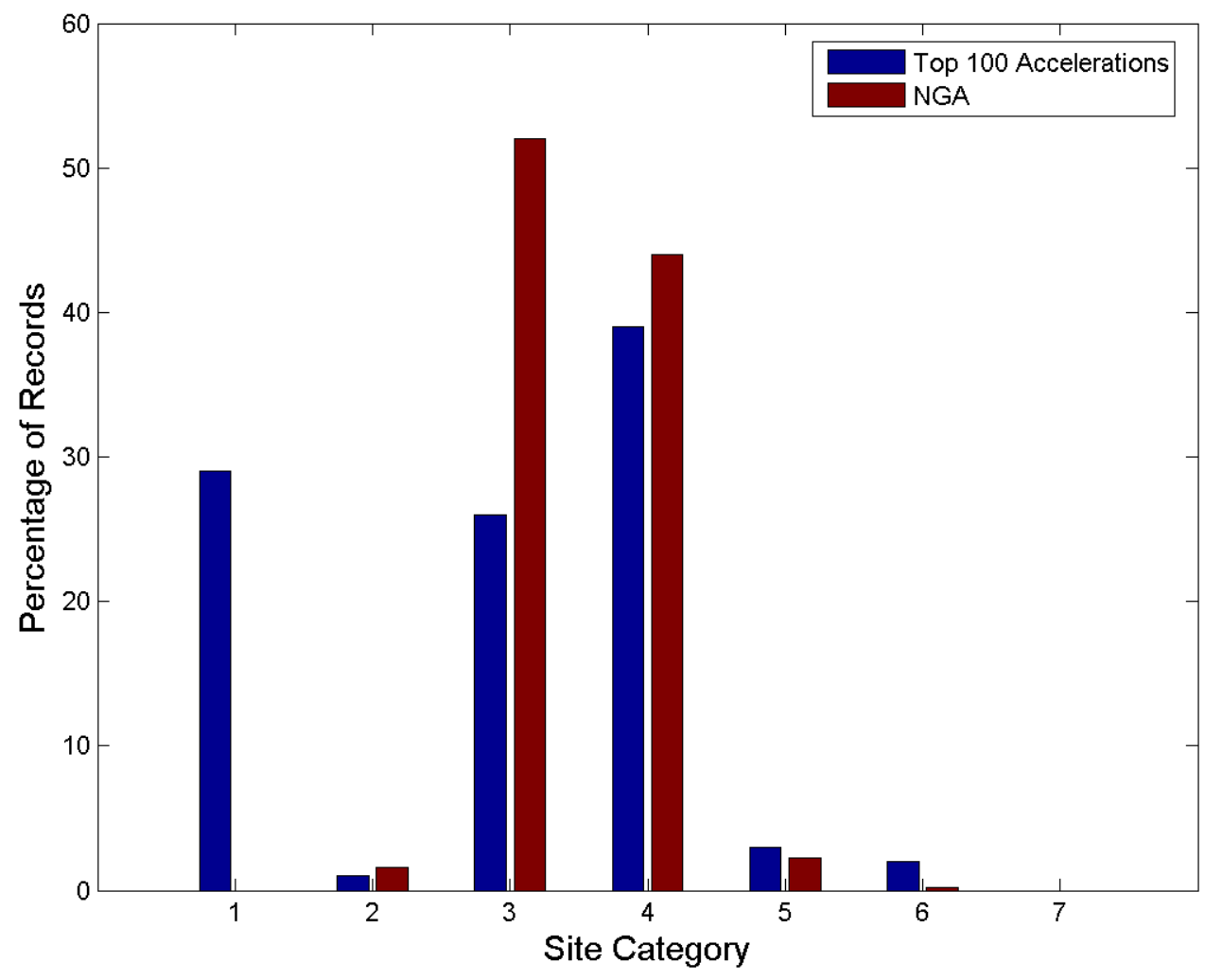

Figure 28. Distribution of site categories for the top 100 acceleration records, compared with the distribution of site categories in the NGA database. See the caption to Figure 27 for a definition of Site Category. This figure is generated by the Matlab script j11sa.m in directory C:ITask_22|Analysis|Statistics-2. The file name of this figure is C:|Task_22\Analysis|Statistics-2\J11sa_04a.png. 
Figure 29. Distribution of Site Categories for the Top 100 Velocity Records, Compared with the Distribution of Site Categories in the NGA Database.

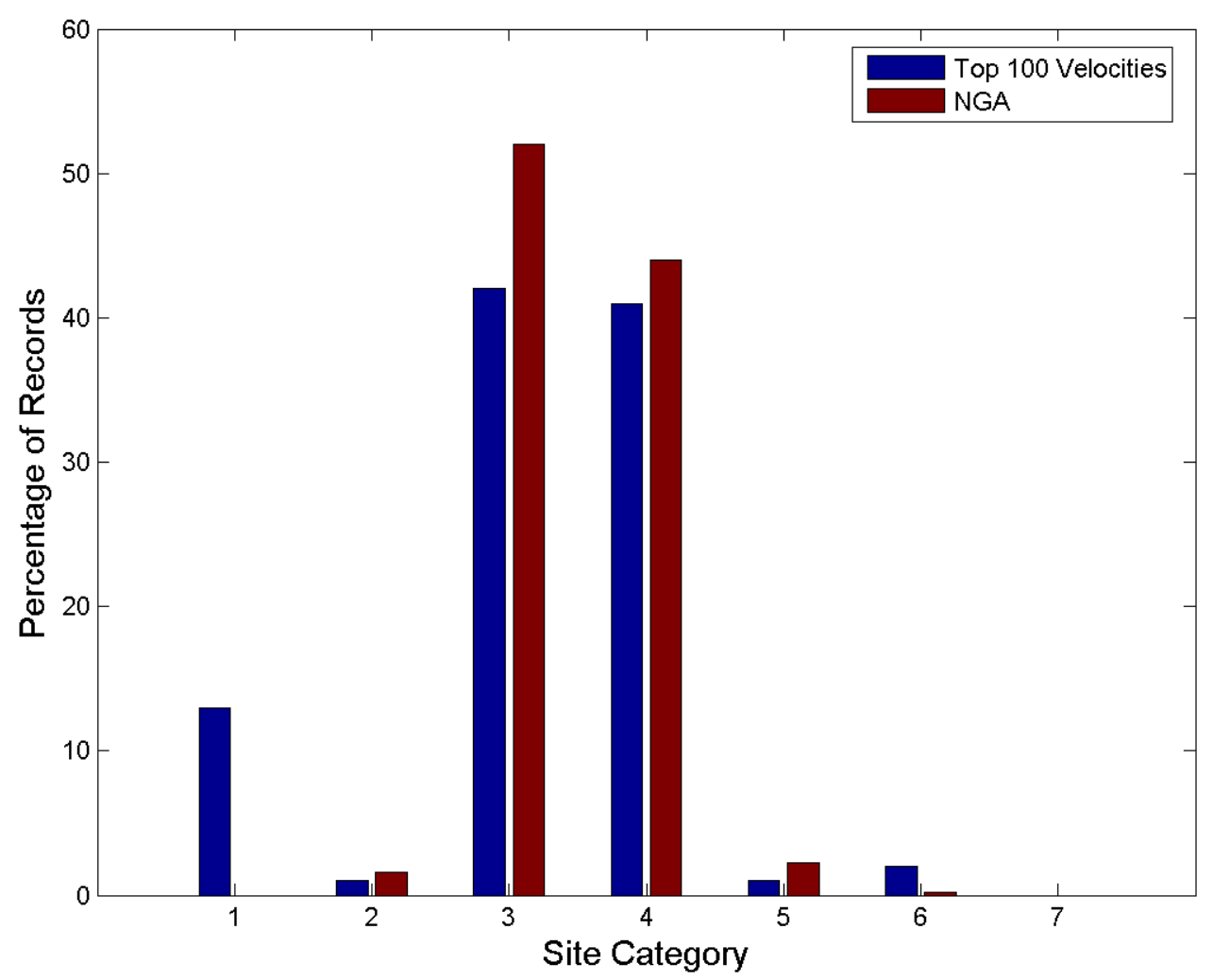

Figure 29. Distribution of site categories for the top 100 velocity records, compared with the distribution of site categories in the NGA database. See the caption to Figure 27 for a definition of Site Category. This figure is generated by the Matlab script j11sv.m in directory C: $\mid$ Task_22|Analysis|Statistics-2. The file name of this figure is C:|Task_22\Analysis|Statistics-2\J11sv_04a.png. 
Figure 30. Peak Acceleration and Peak Velocity for all Included Data, as a Function of Estimated V30
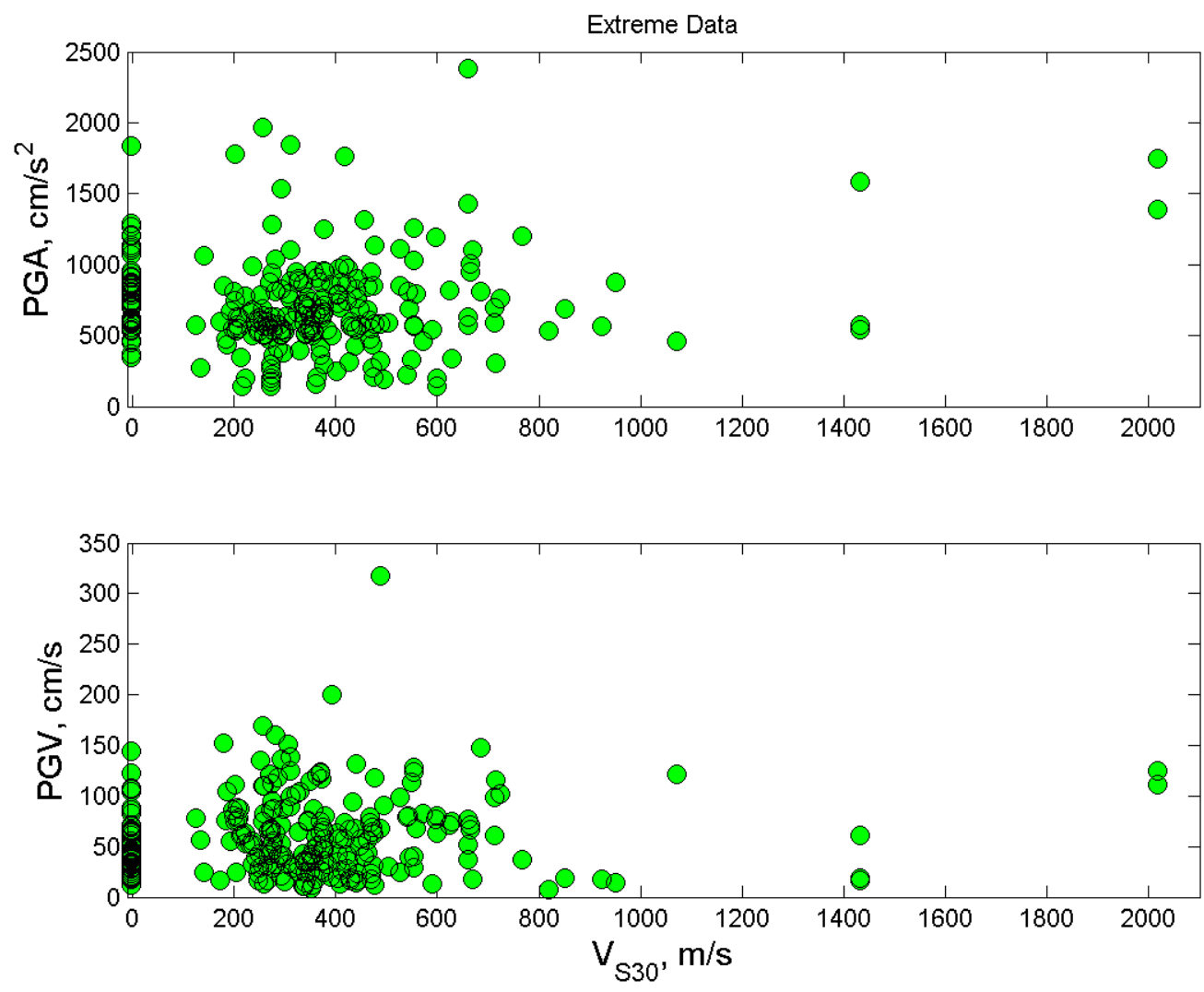

Figure 30. Peak acceleration and peak velocity for all records in Table 1, as a function of estimated $\mathrm{V}_{\mathrm{S}} 30$. Records for which the value of $\mathrm{V}_{\mathrm{S}} 30$ is not available are plotted at $\mathrm{V}_{\mathrm{S}} 30=0$. This figure is generated by the Matlab script j11sa.m in directory

C:ITask_22\Analysis|Statistics-2. The file name of this figure is

C:|Task_22\Analysis|Statistics-2|J11sa_07.png. 
Figure 31. Distribution of Average Horizontal Kappa for All Records in Table 1.

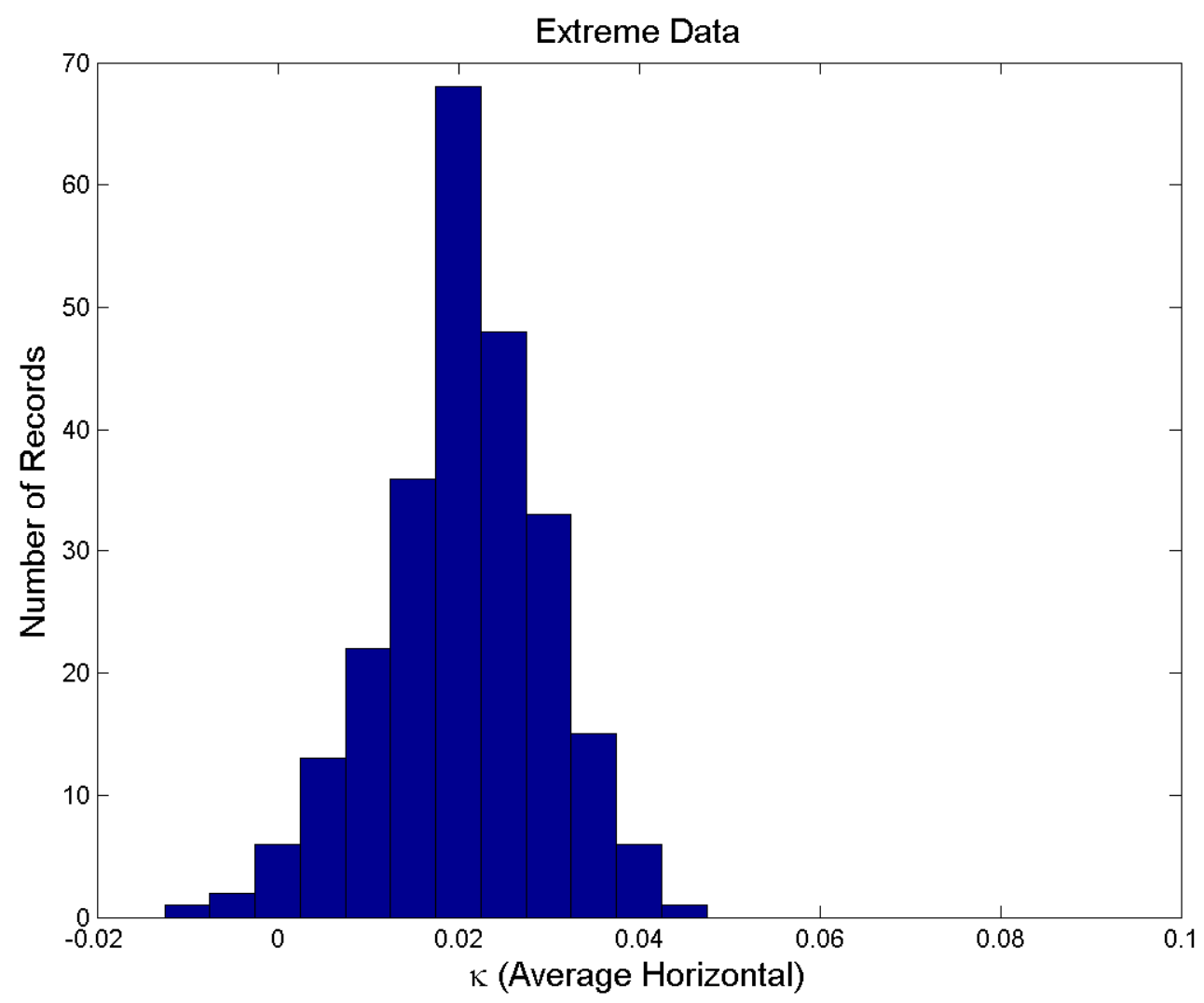

Figure 31. Distribution of average horizontal kappa for all records in Table 1. For each component, $\kappa$ was calculated as described in the text, and then the average of the horizontal components used to create this histogram. Units of $\kappa$ are seconds. This figure is generated by the Matlab script j11sa.m in directory C:ITask_22\Analysis|Statistics-2. The file name of this figure is C:|Task_22\Analysis|Statistics-2|J11sa_13.png. 
Figure 32. Distribution of Average Horizontal Kappa for the Top 100 Acceleration Records, by Quartile.

Top 100 Acceleration
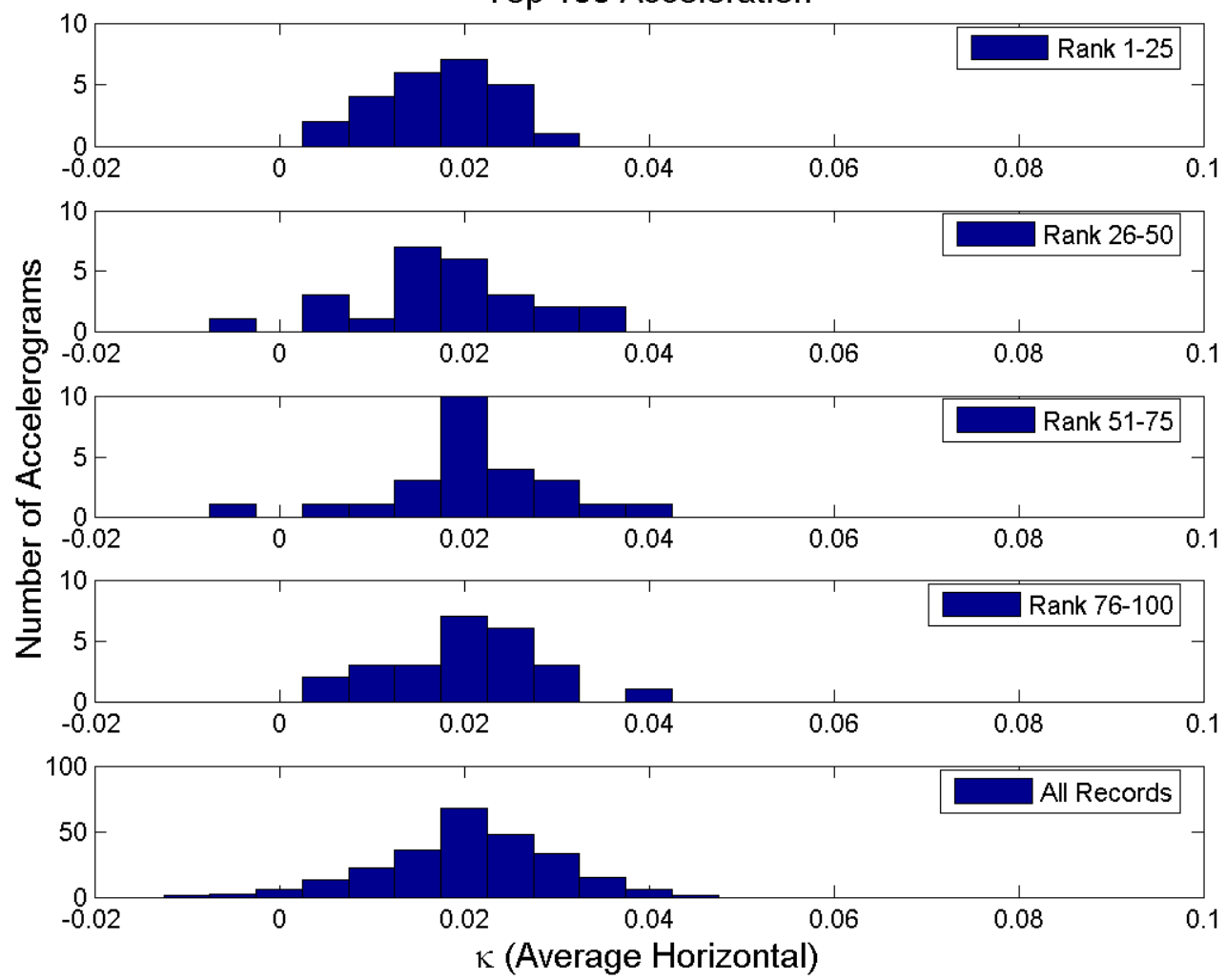

Figure 32. Distribution of average horizontal kappa for the top 100 acceleration records, by quartile. Units of $\kappa$ are seconds. This figure is generated by the Matlab script j11sa.m in directory C:ITask_22\Analysis $\mid$ Statistics-2. The file name of this figure is C:ITask_22\Analysis|Statistics-2|J11sa_14.png. 
Figure 33. Distribution of Average Horizontal Kappa for the Top 100 Velocitie Records, by Quartile.

Top 100 Velocities
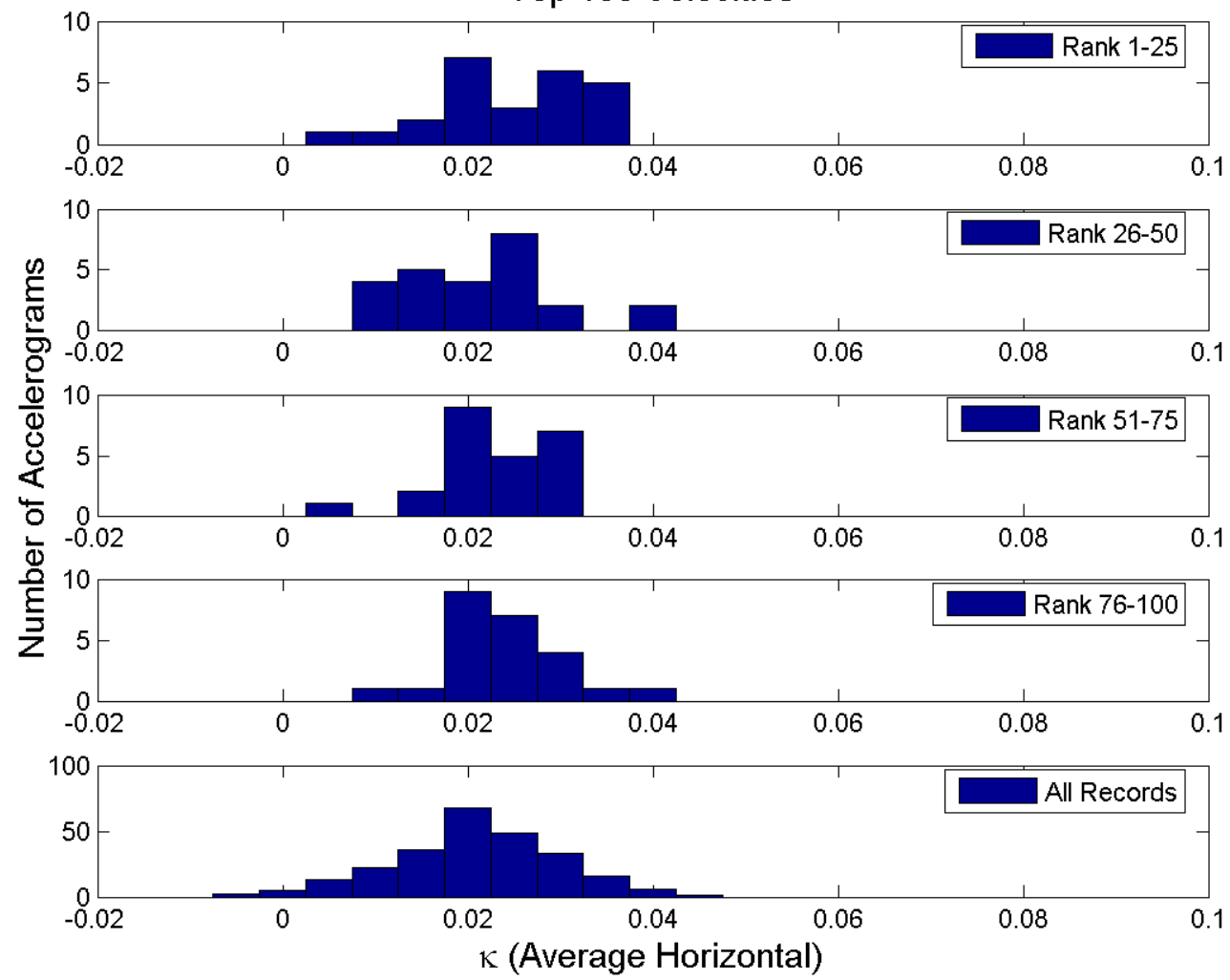

Figure 33. Distribution of average horizontal kappa for the top 100 velocity records, by quartile. Units of $\kappa$ are seconds. This figure is generated by the Matlab script j11sv.m in directory C:|Task_22\Analysis|Statistics-2. The file name of this figure is C:|Task_22\Analysis|Statistics-2|J11sv_14.png. 


\section{Appendix A. Earthquake Maps}

Figure A1. Imperial Valley, May 19, 1940, 04:36:41, $M_{W} 6.90$ Imperial Valley 1940

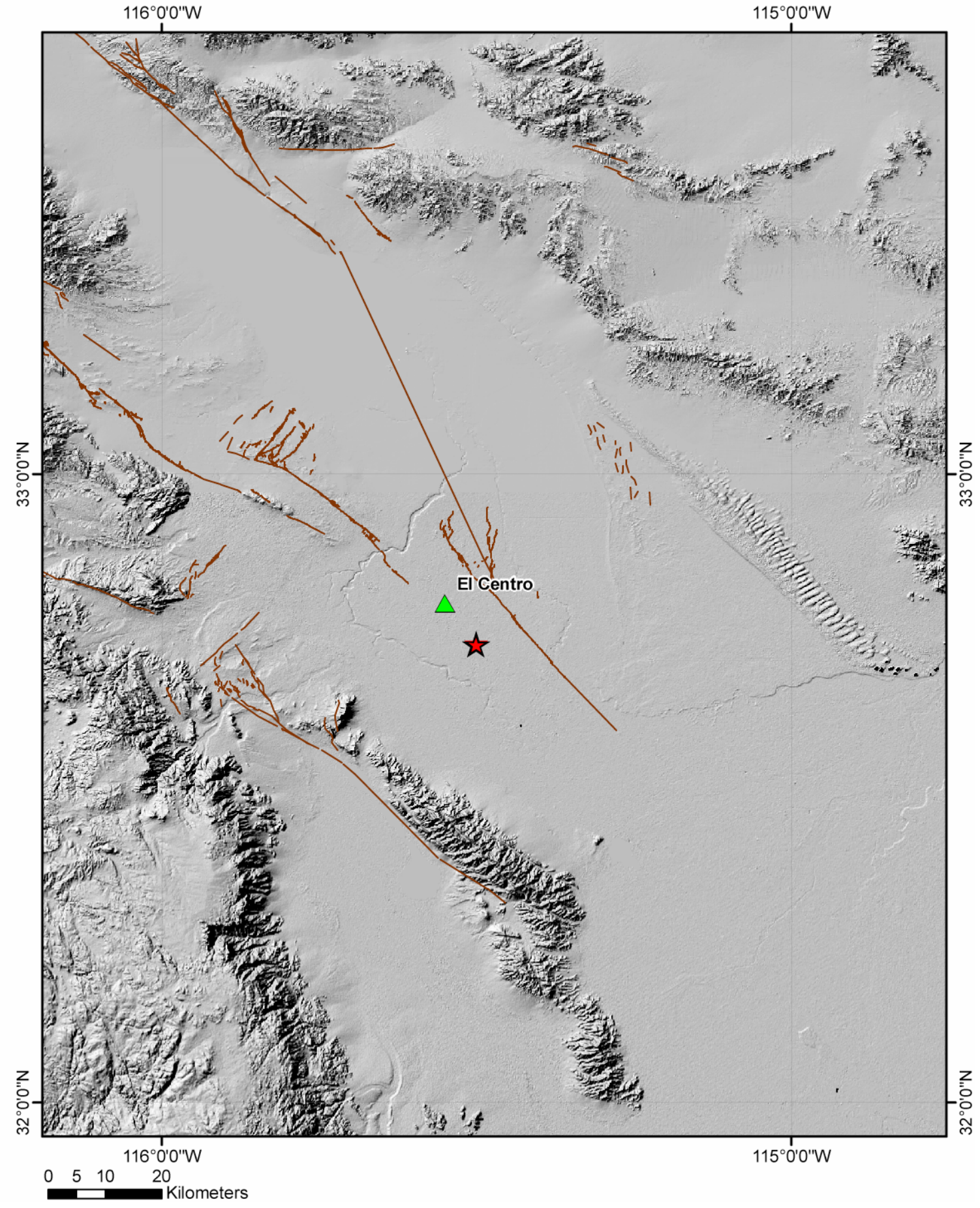


Figure A2. Parkfield, June 28, 1966, 04:26:14, $M_{W} 6.10$

\section{Parkfield 1966}

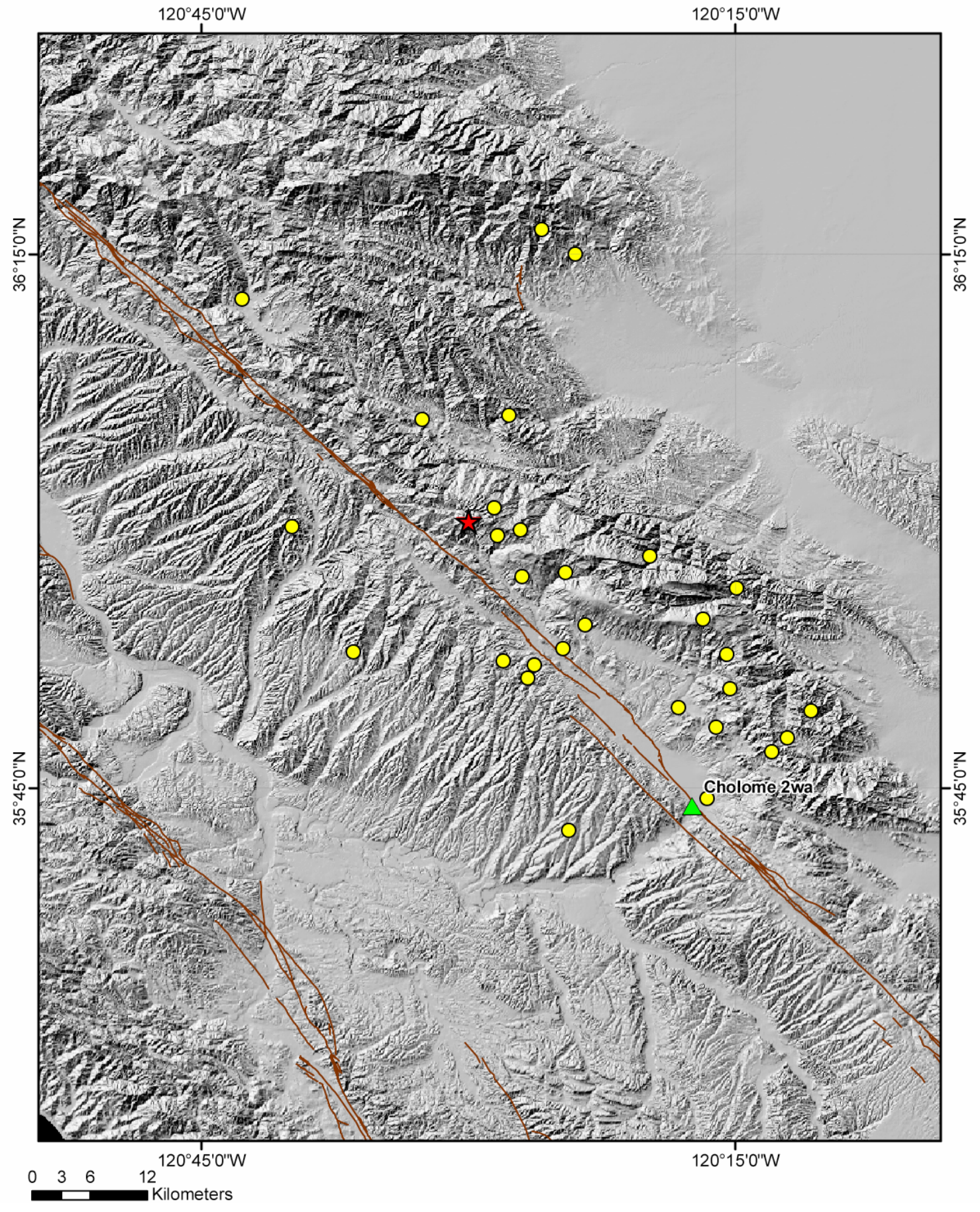

ORD-FY06-022 Subtask 2: Final Technical Report. 
Figure A3. San Fernando, February 9, 1971, 14:00:41, $M_{W} 6.60$ San Fernando 1971

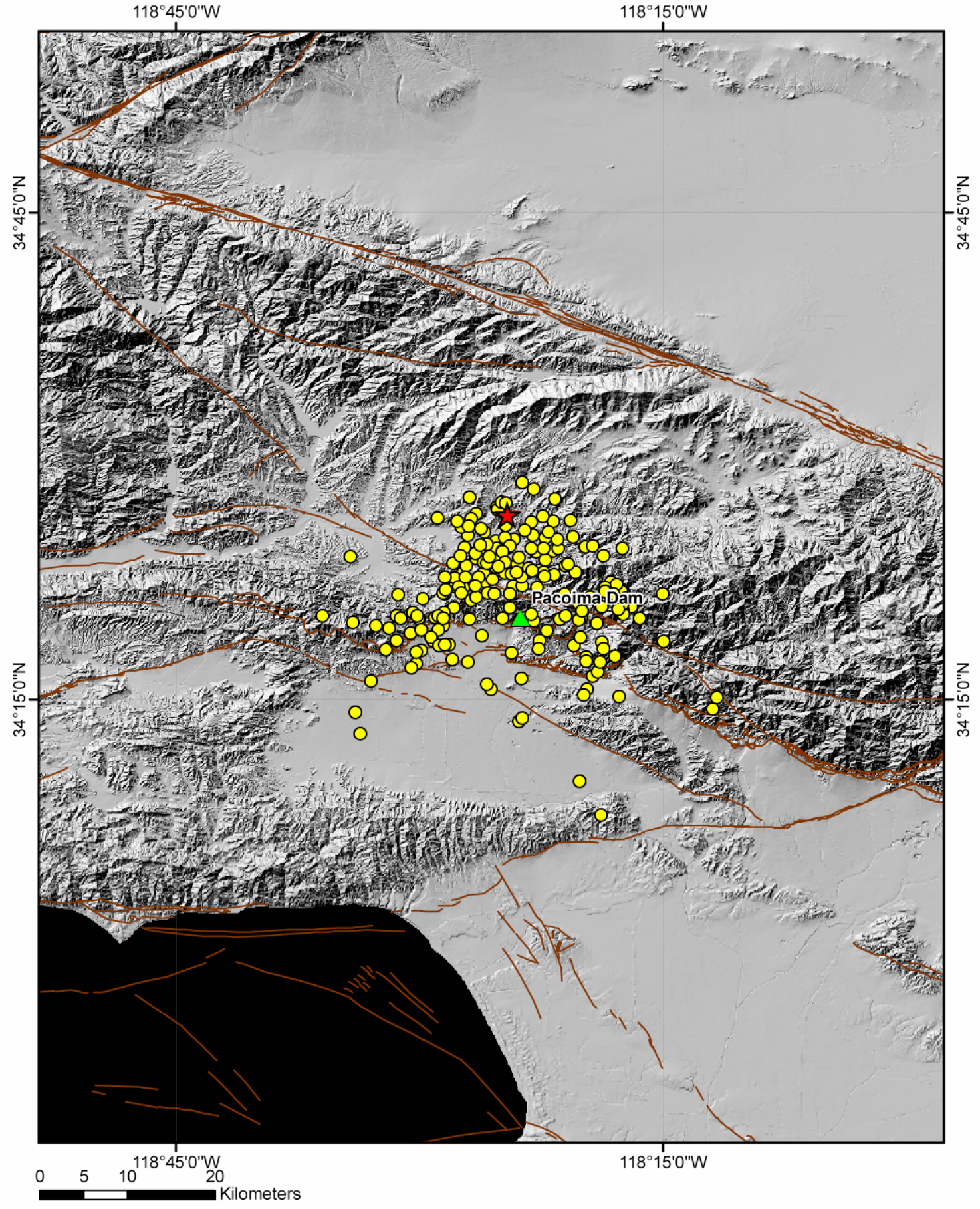


Figure A4. Gazli, May 17, 1976, 02:58:40, M 6.80

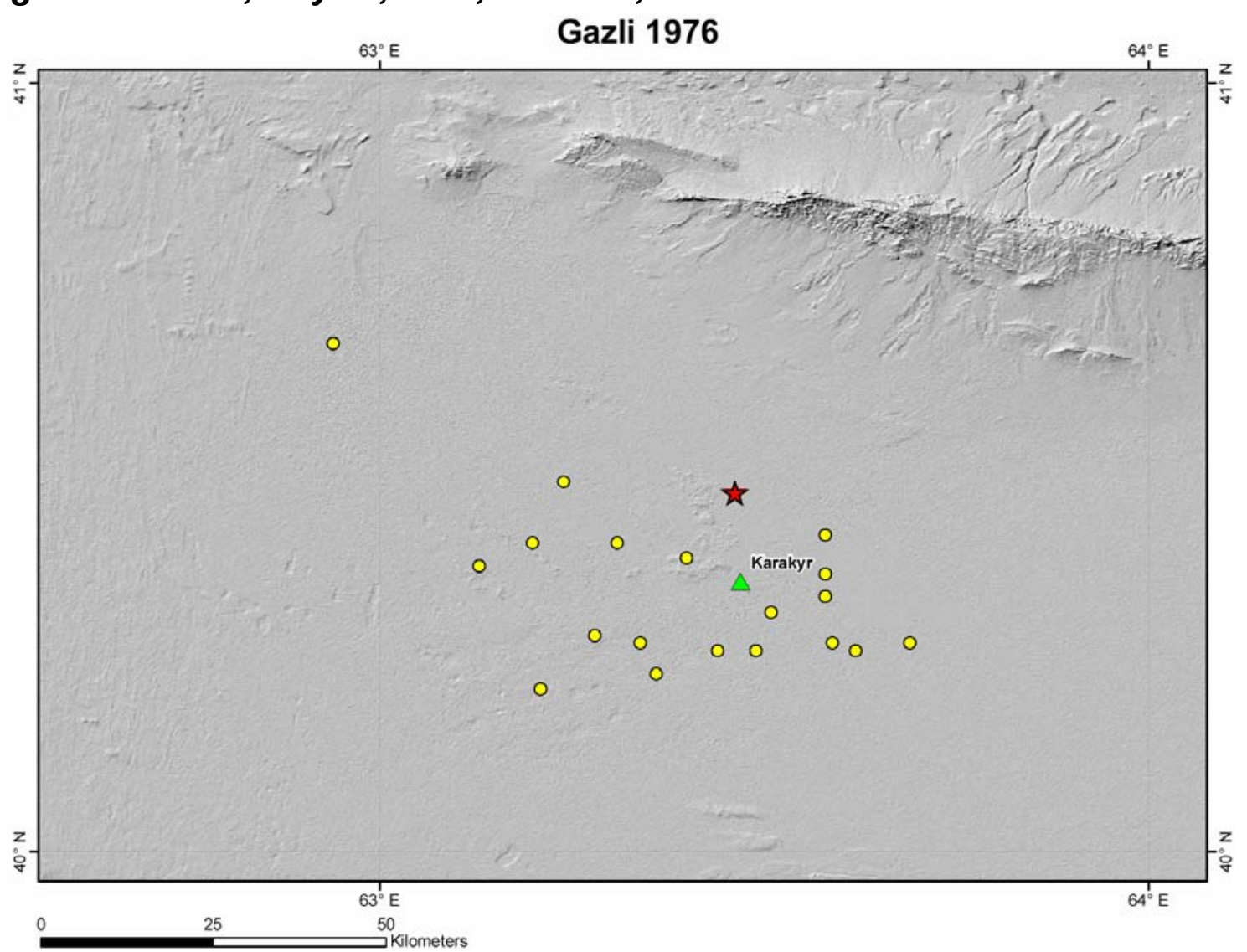


Figure A5. Tabas, Iran, September 16, 1978, 15:35:56, $M_{W} 7.30$

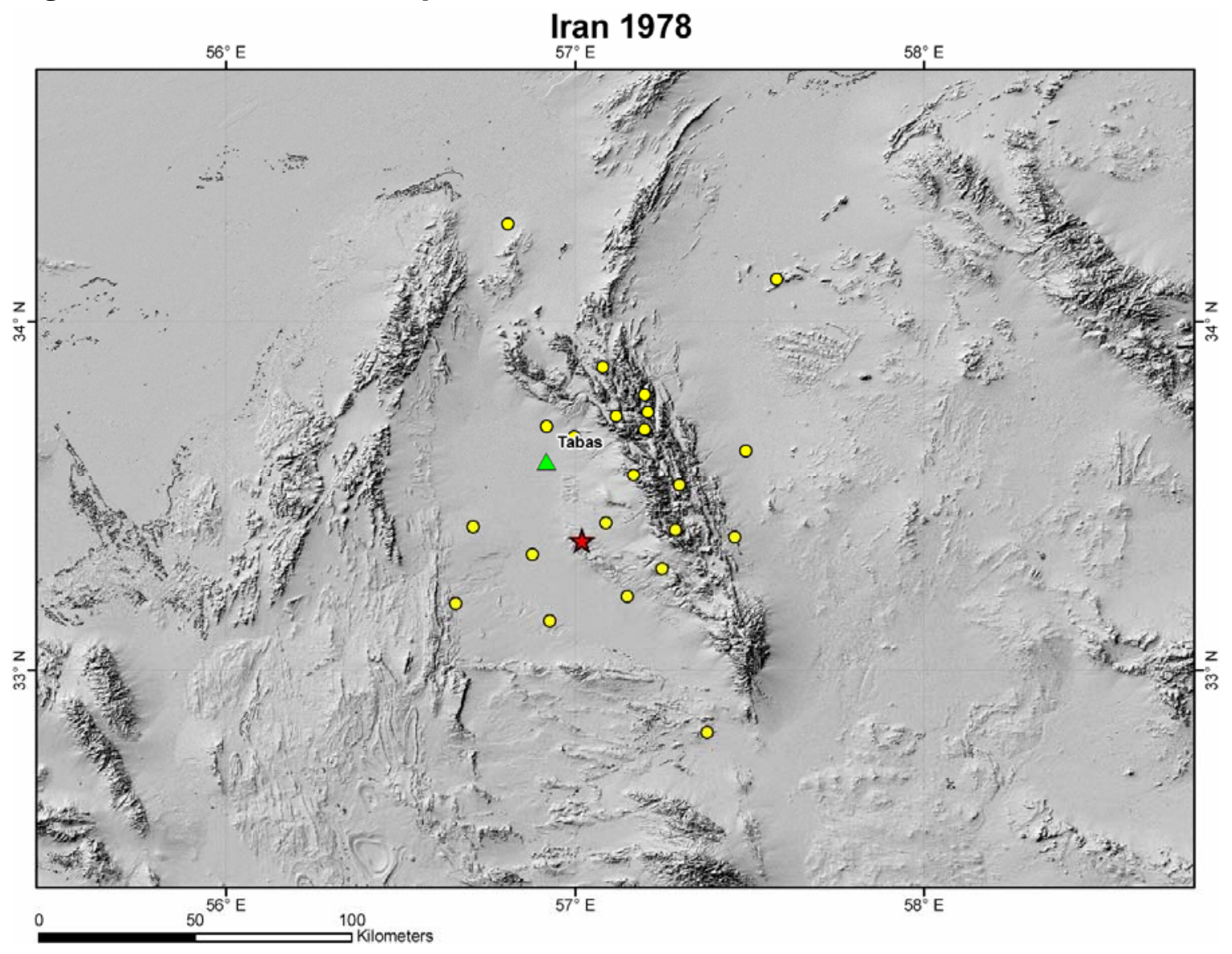


Figure A6. Imperial Valley, October 15, 1979, 23:16:53, $M_{W} 6.50$

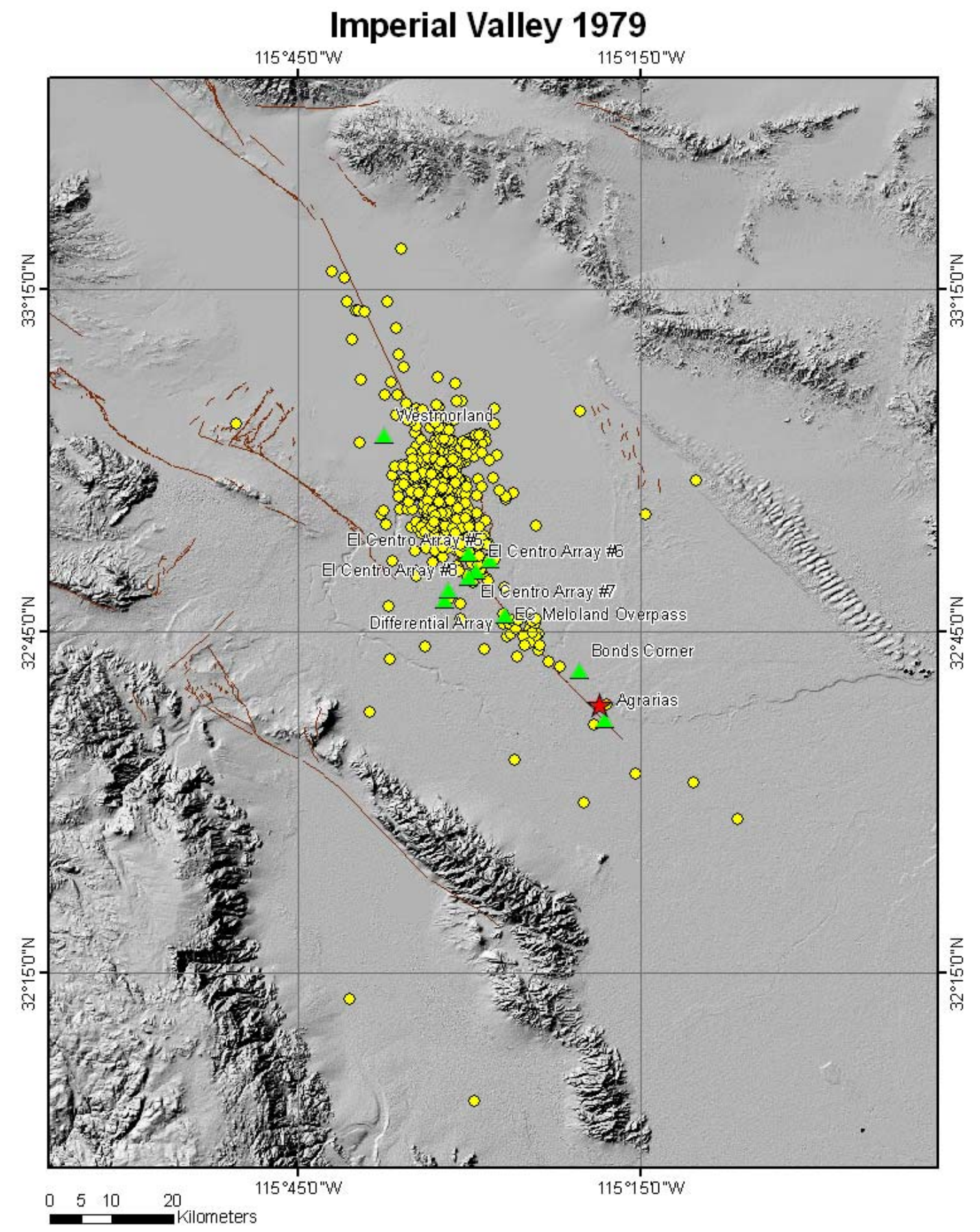


Figure A7. Victoria, June 9, 1980, 03:28:19, $M_{w} 6.40$

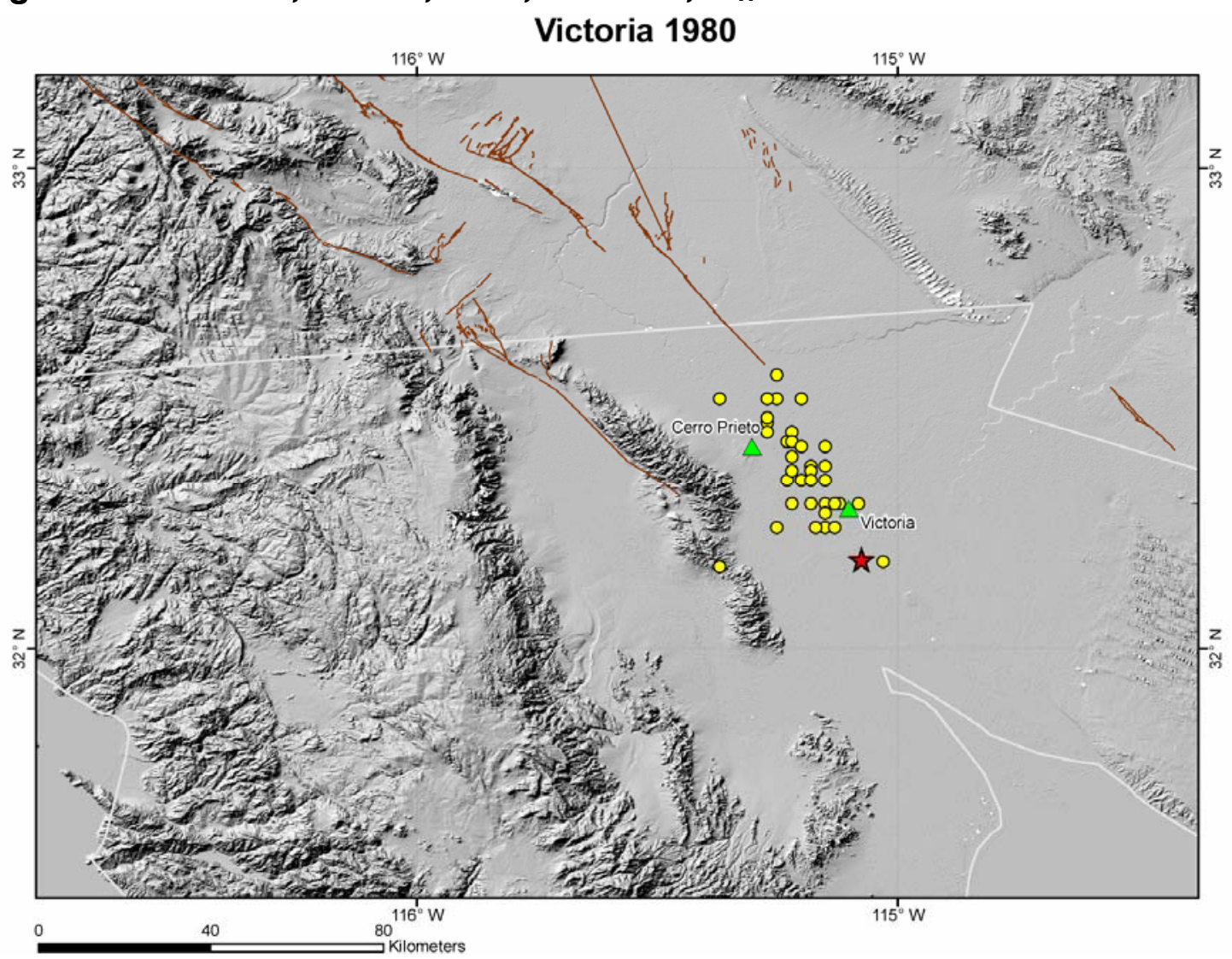


Figure A8. Westmorland, April 26, 1981, 12:09:28, $M_{L}$ brk 6.30

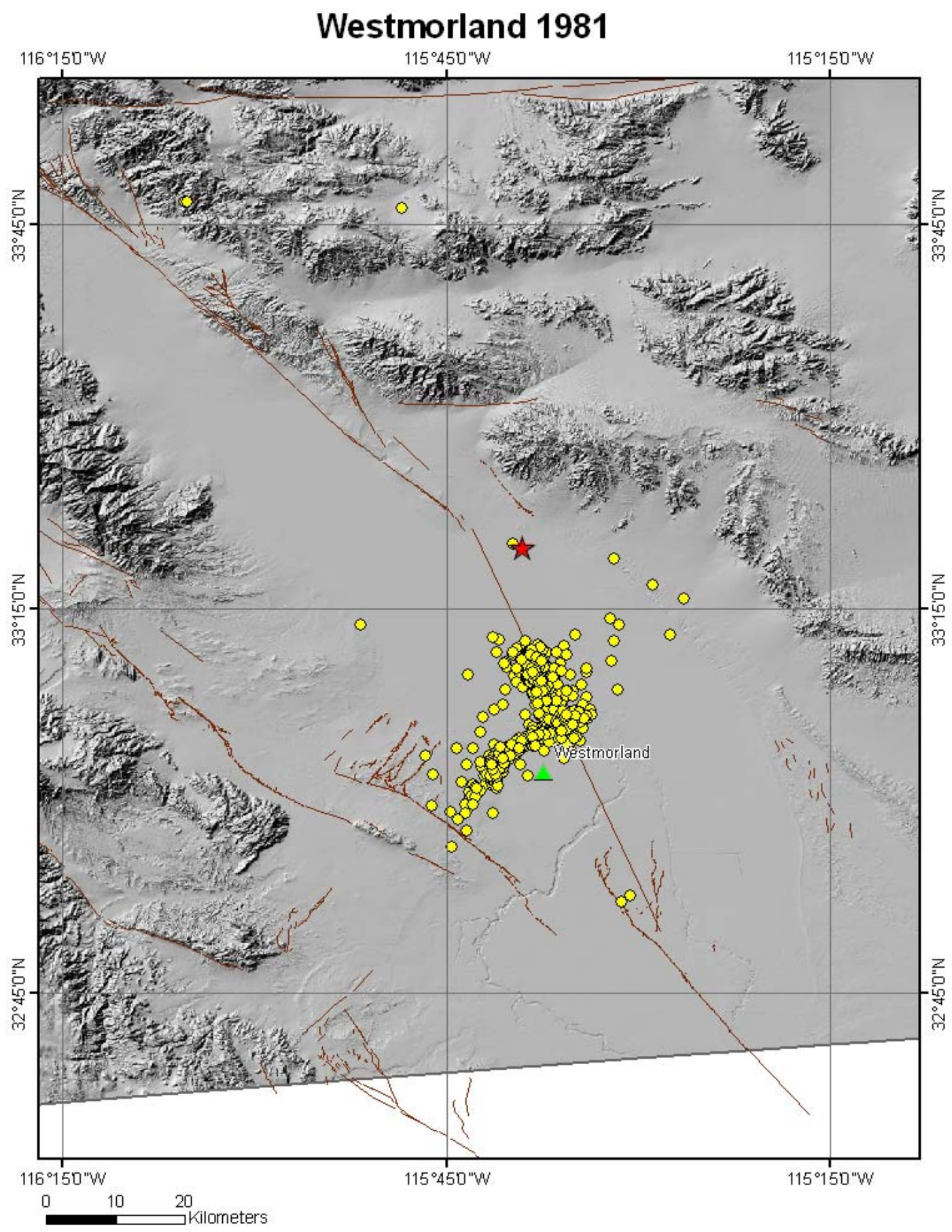

Figure A9. Coalinga, May 2, 1983, 23:42:38, $M_{W} 6.50$ 


\section{Coalinga 1983 (1)}

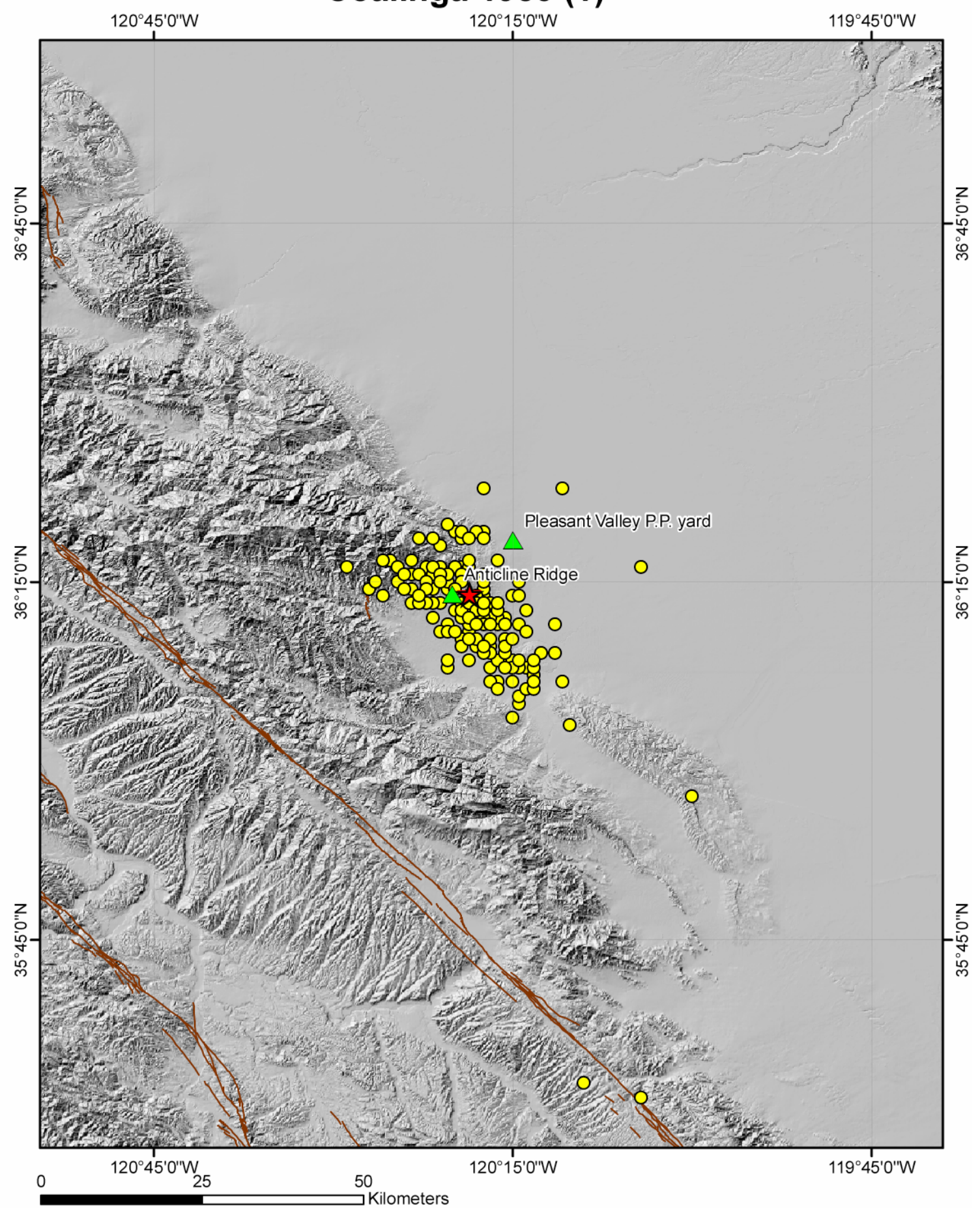


Figure A10. Coalinga, July 22, 1983, 02:39:54, $M_{W} 6.00$

\section{Coalinga $1983(2)$}

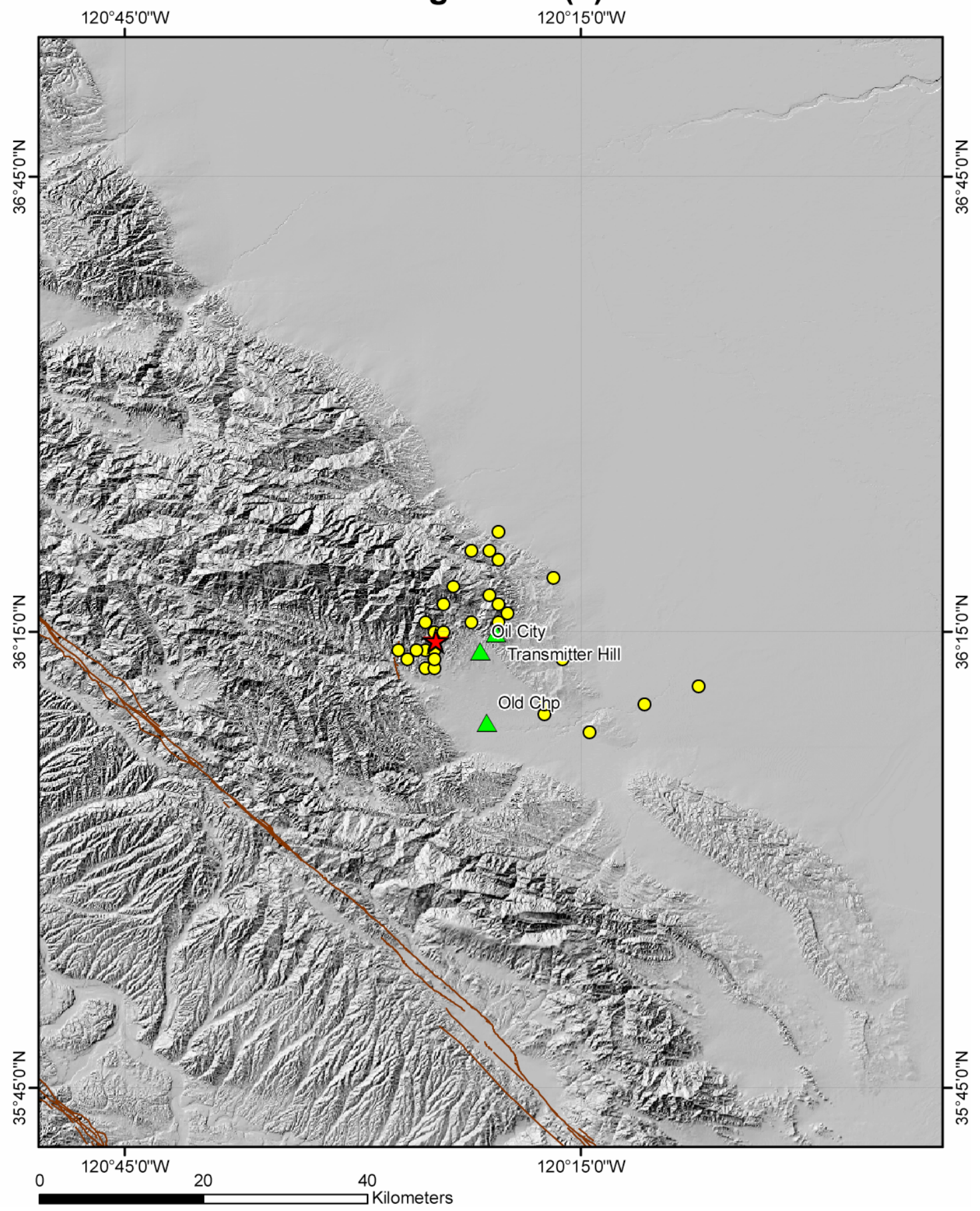


Figure A11. Morgan Hill, April 24, 1984, 21:15:18, $M_{W} 6.10$

\section{Morgan Hill 1984}

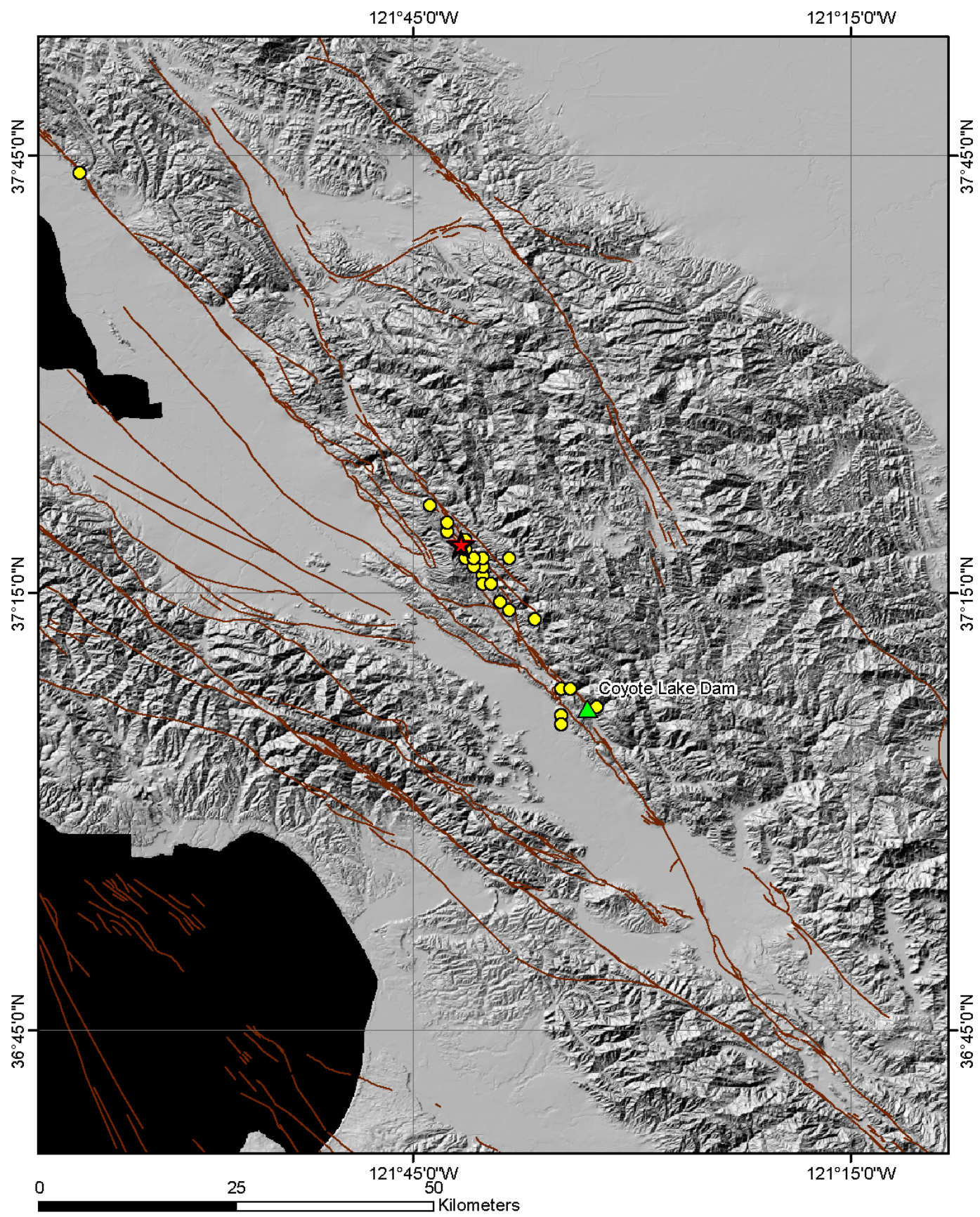


Figure A12. Valapraiso, March 3, 1985, 22:47:07, $M_{W} 7.80$

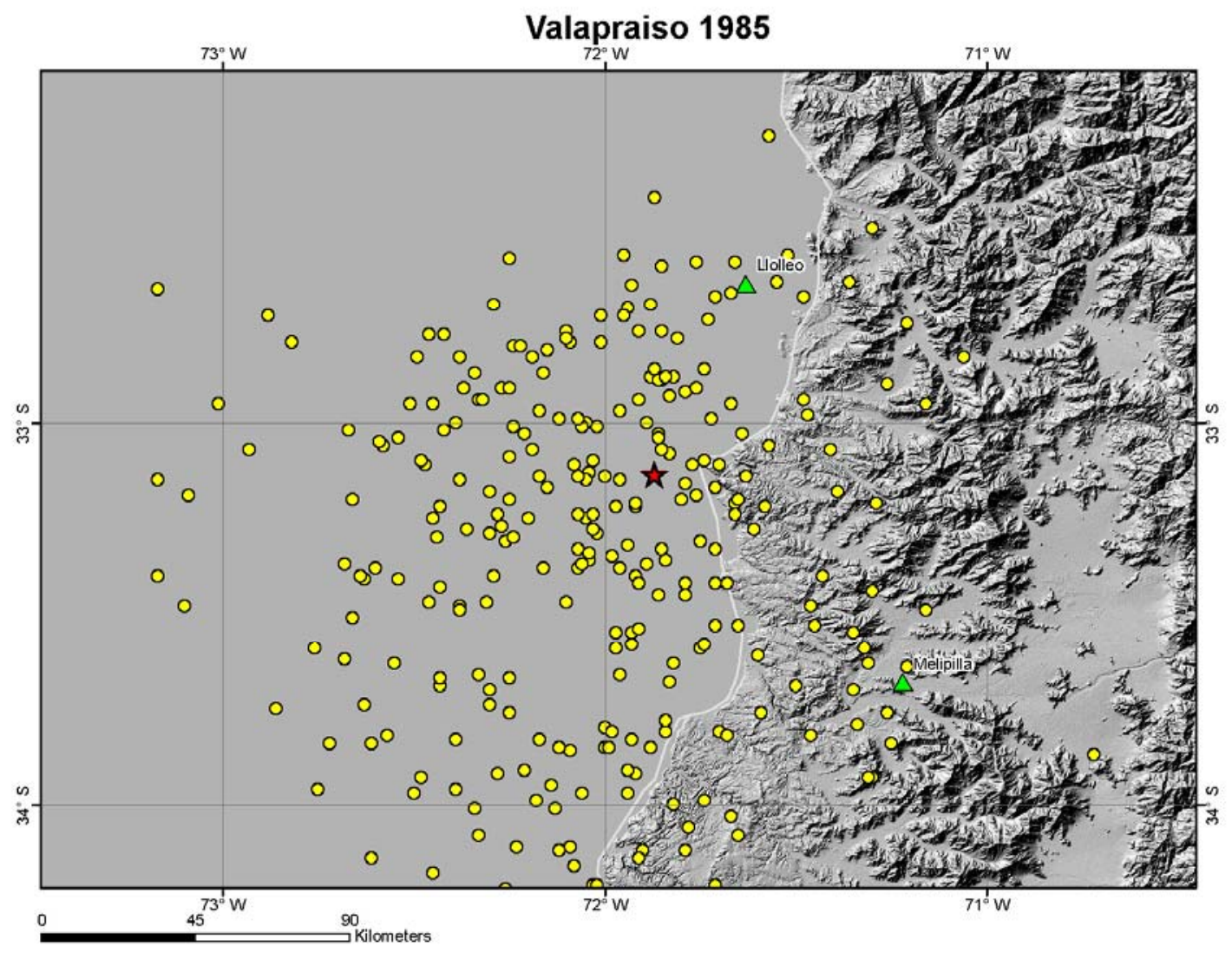


Figure A13. Michoacan Aftershock, September 21, 1985, 01:37:13, $M_{W} 7.50$

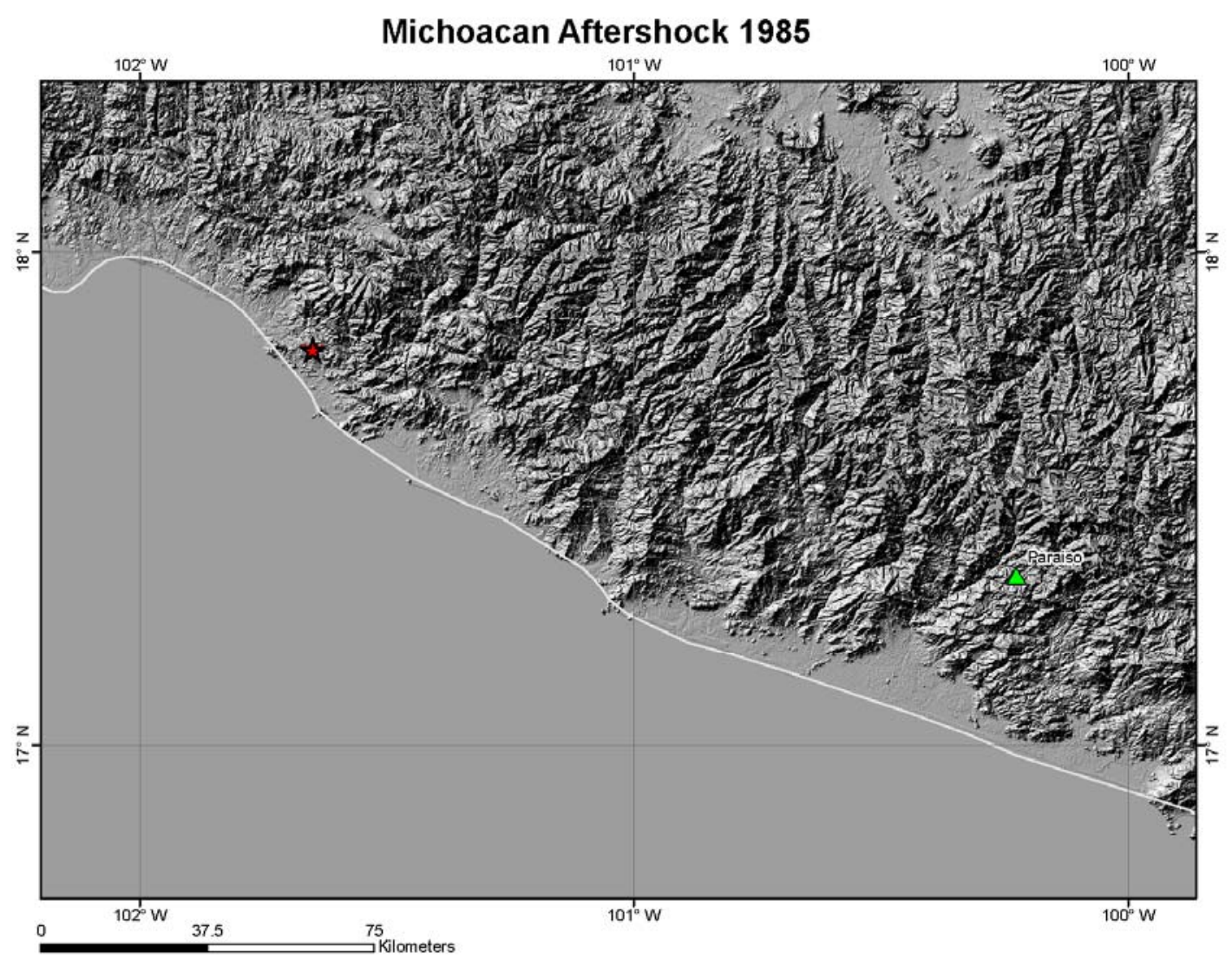


Figure A14. Nahanni, December 23, 1985, 05:16:00, $M_{s} 6.90$

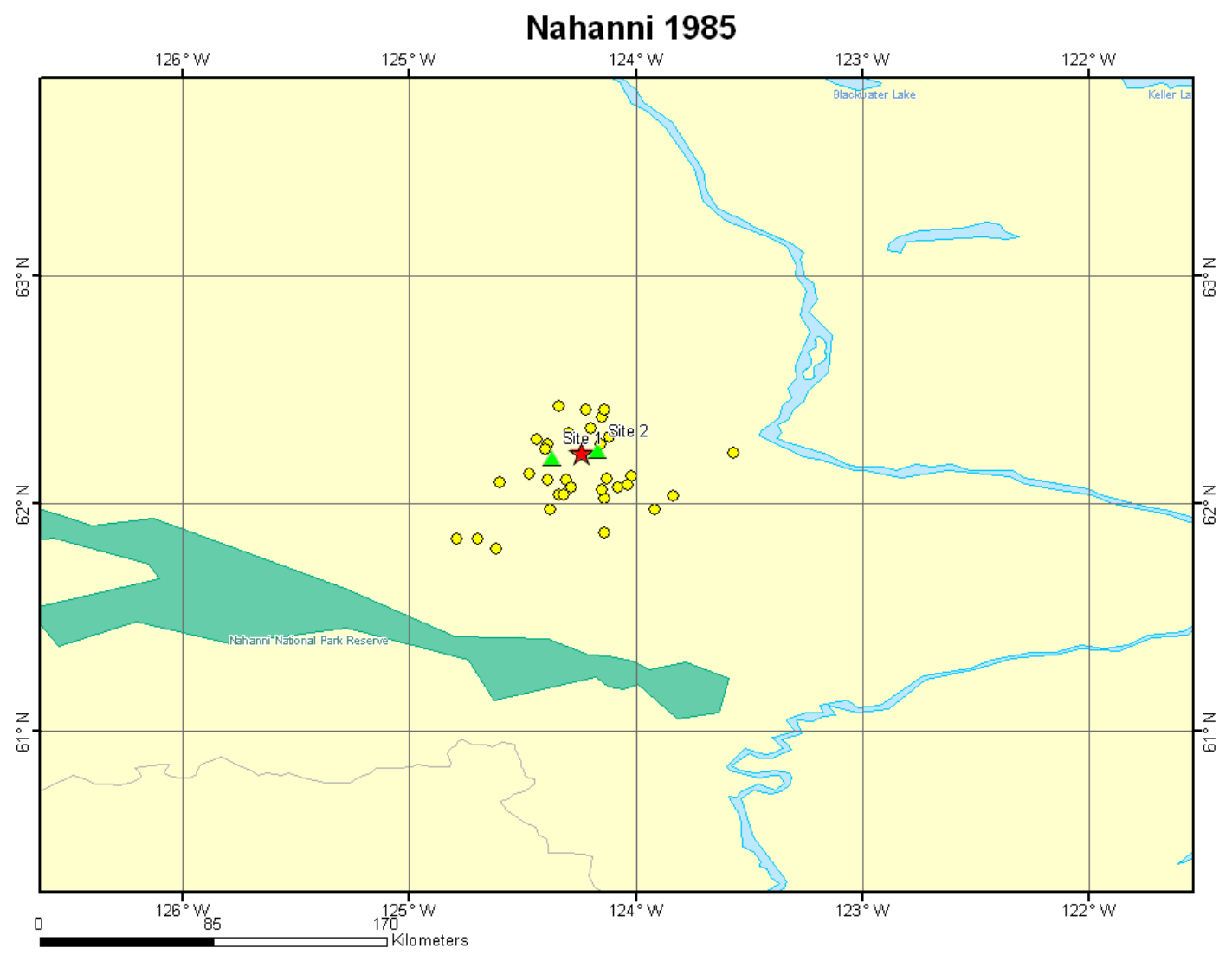


Figure A15. North Palm Springs, July 8, 1986, 09:20:44, $M_{W} 6.20$

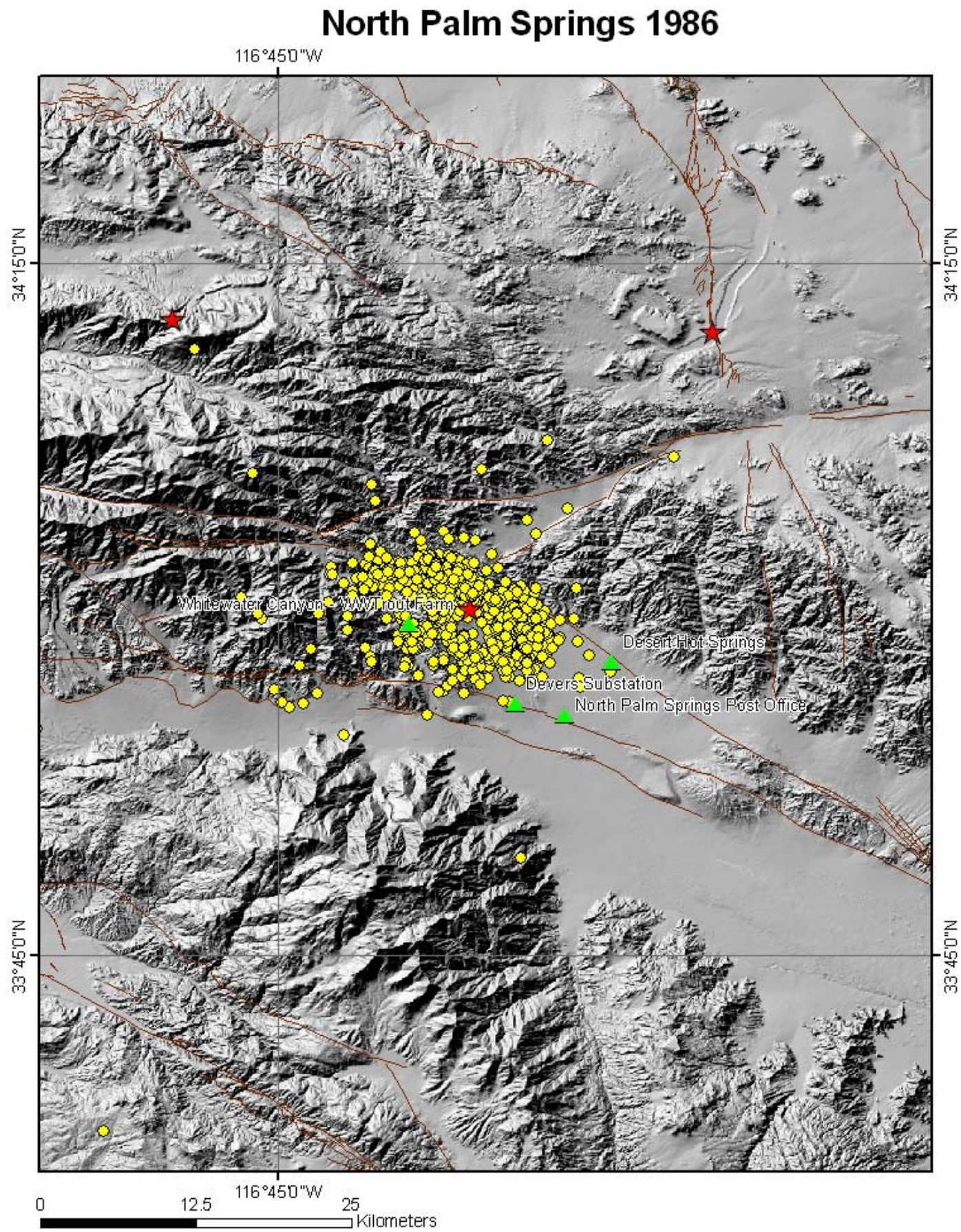


Figure A16. Whittier Narrows, October 1, 1987, 14:42:20, $M_{W} 6.10$

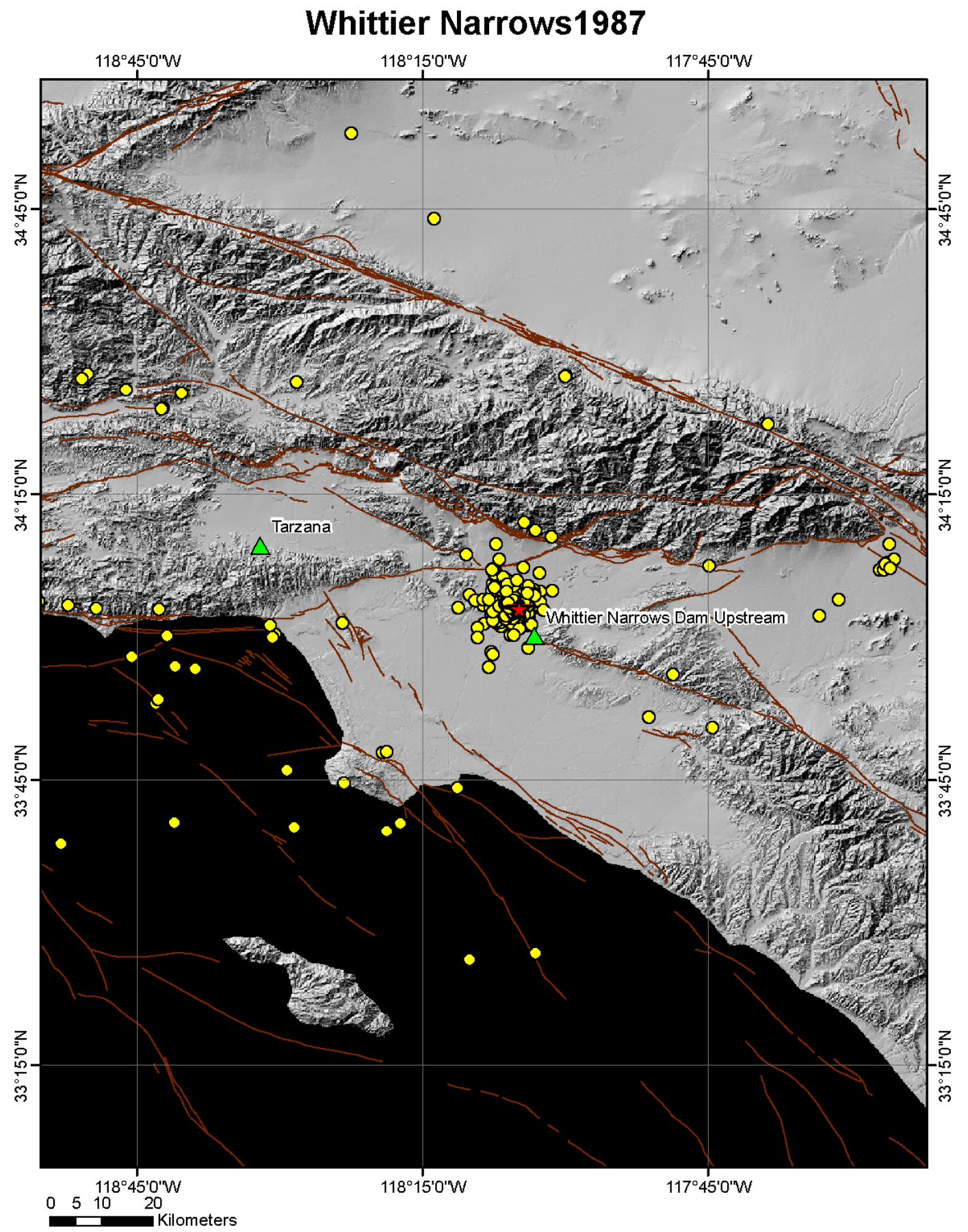


Figure A17. Superstition Hills, November 24, 1987, 13:15:56, $M_{L}$ brk 6.70

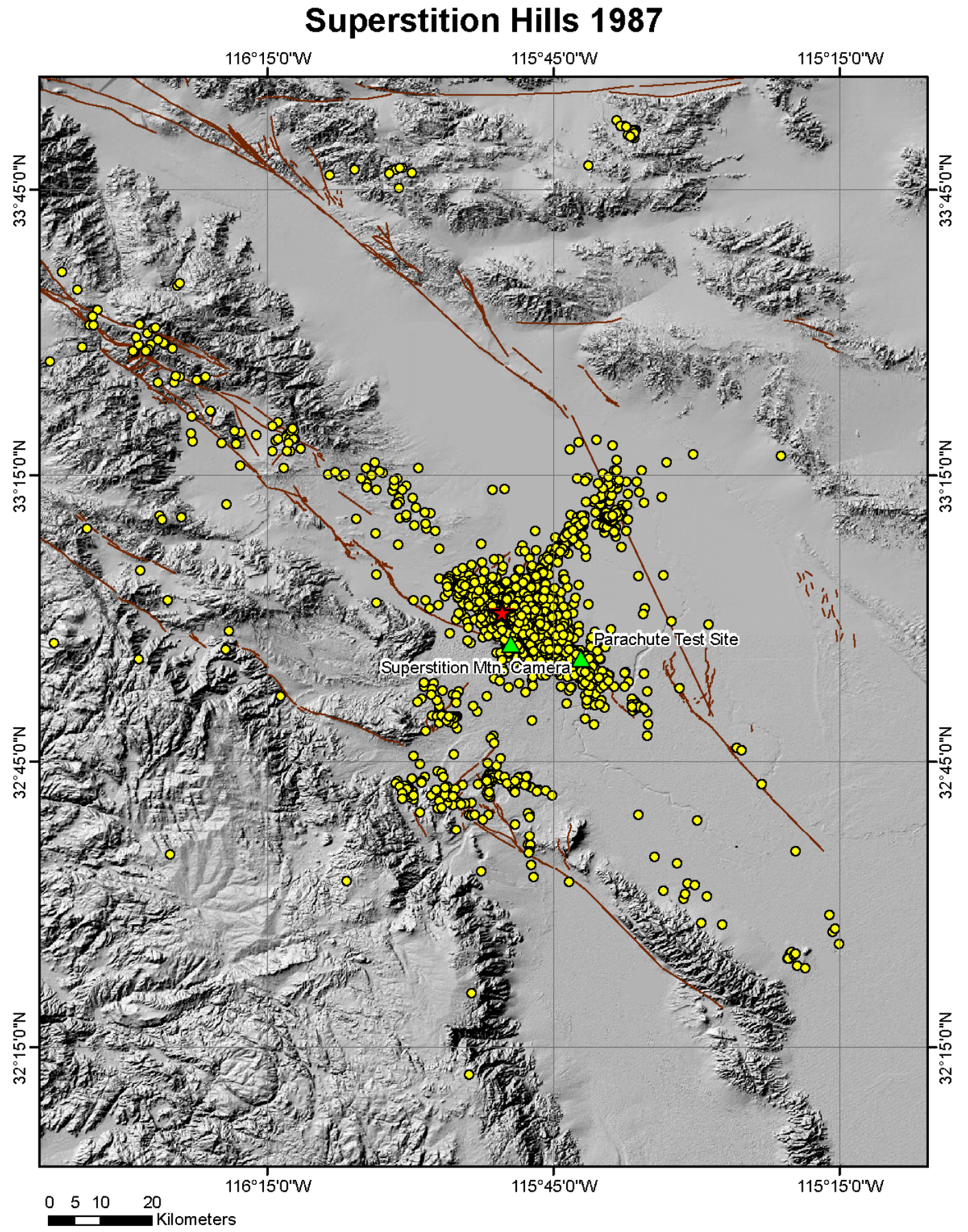


Figure A18. Loma Prieta, October 18, 1989, 00:04:15, $M_{W} 7.00$

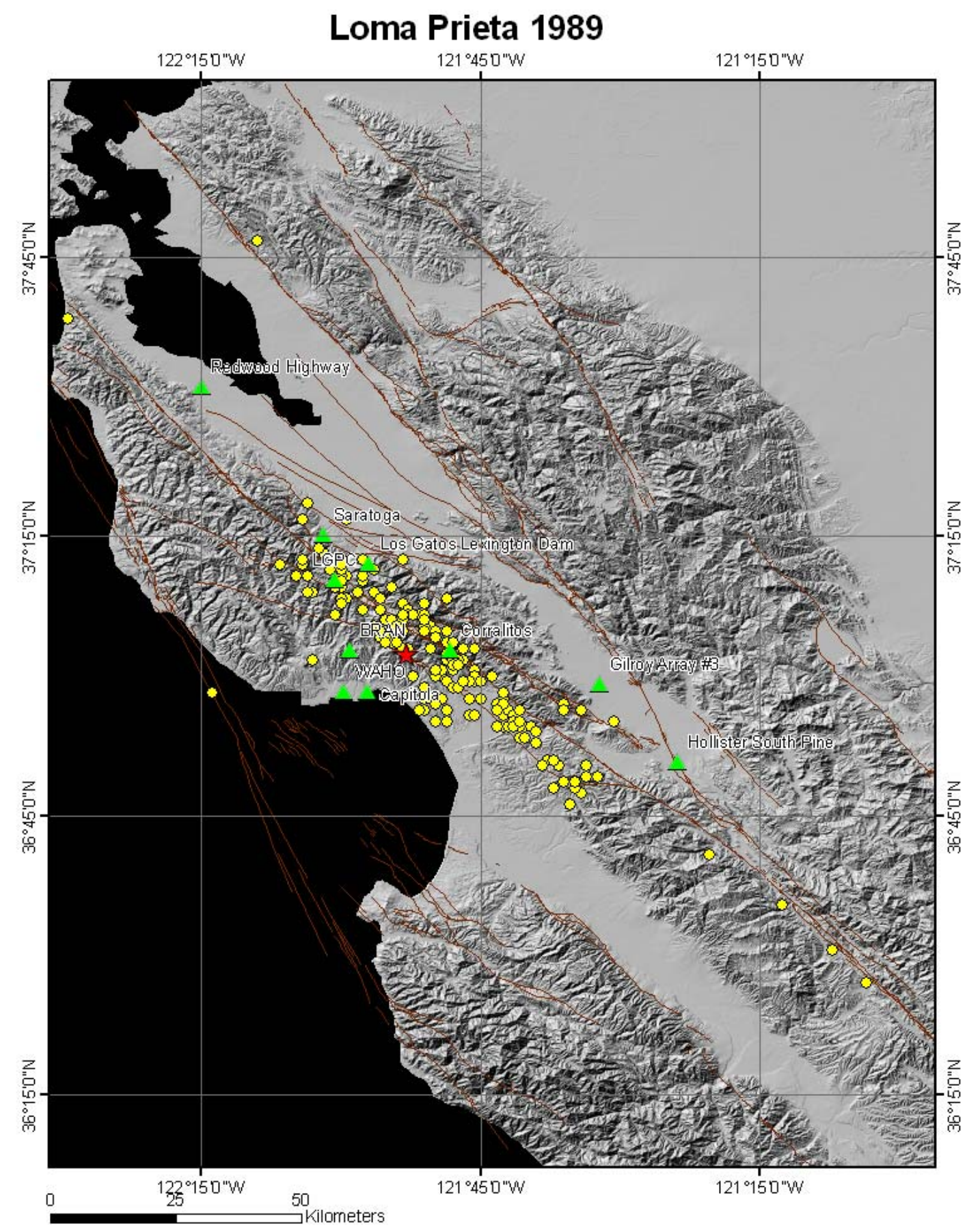


Figure A19. Manjil, Iran, June 20, 1990, 09:00:10, $M_{W} 7.40$

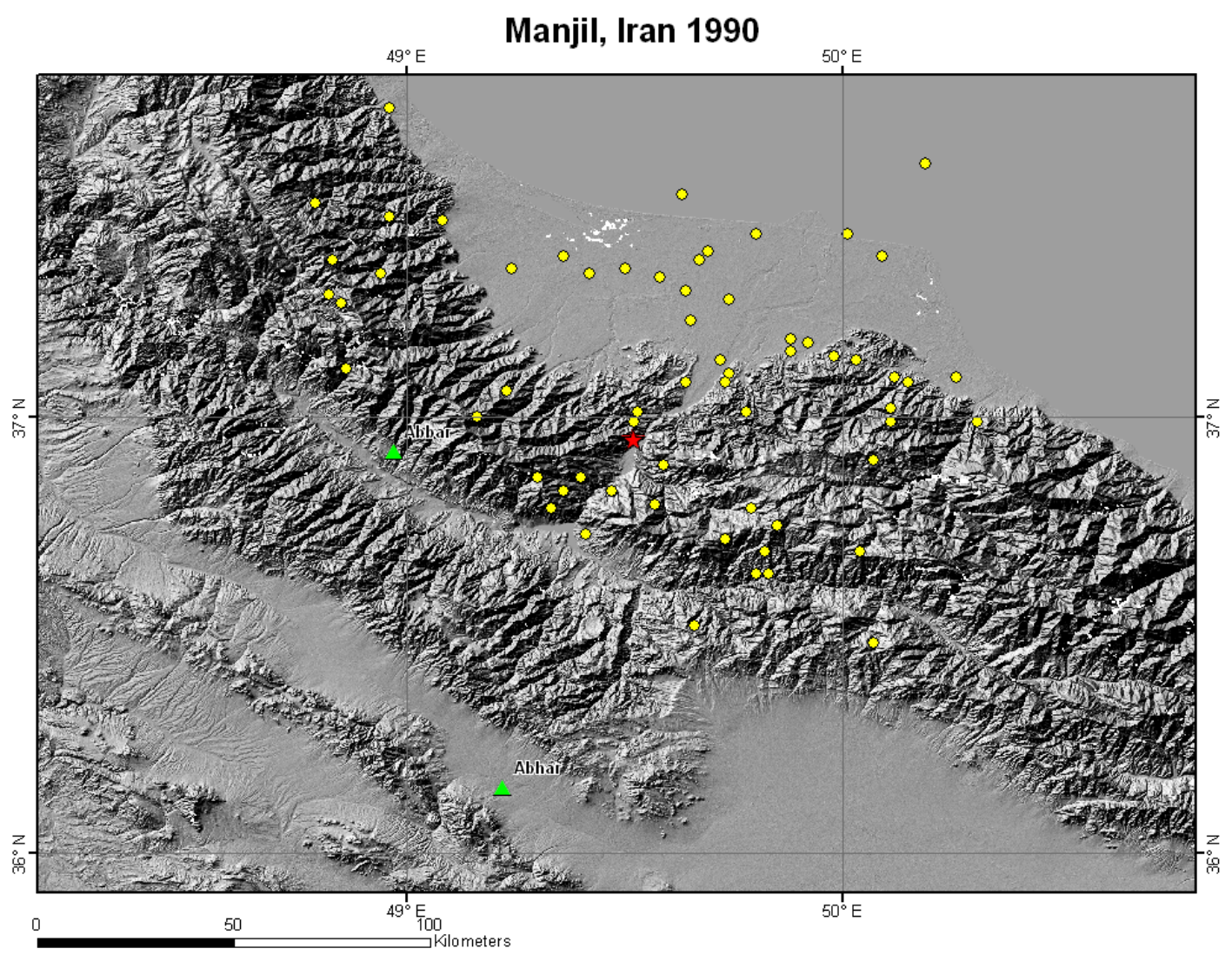


Figure A20. Erzican, March 13, 1992, 17:18:40, Msbrk 6.90

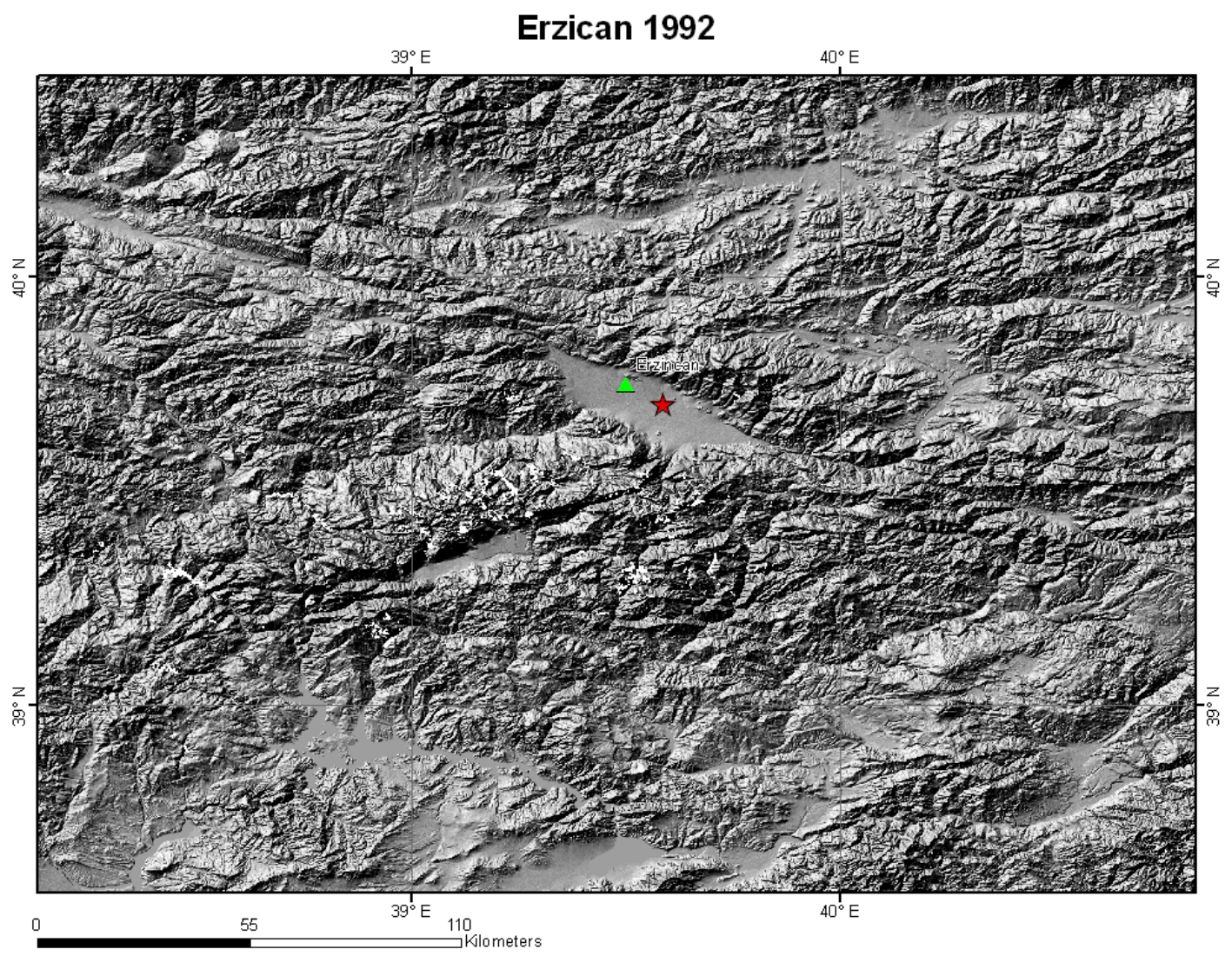

ORD-FY06-022 Subtask 2: Final Technical Report. 
Figure A21. Cape Mendocino, April 25, 1992, 18:06:04, $M_{W} 7.00$

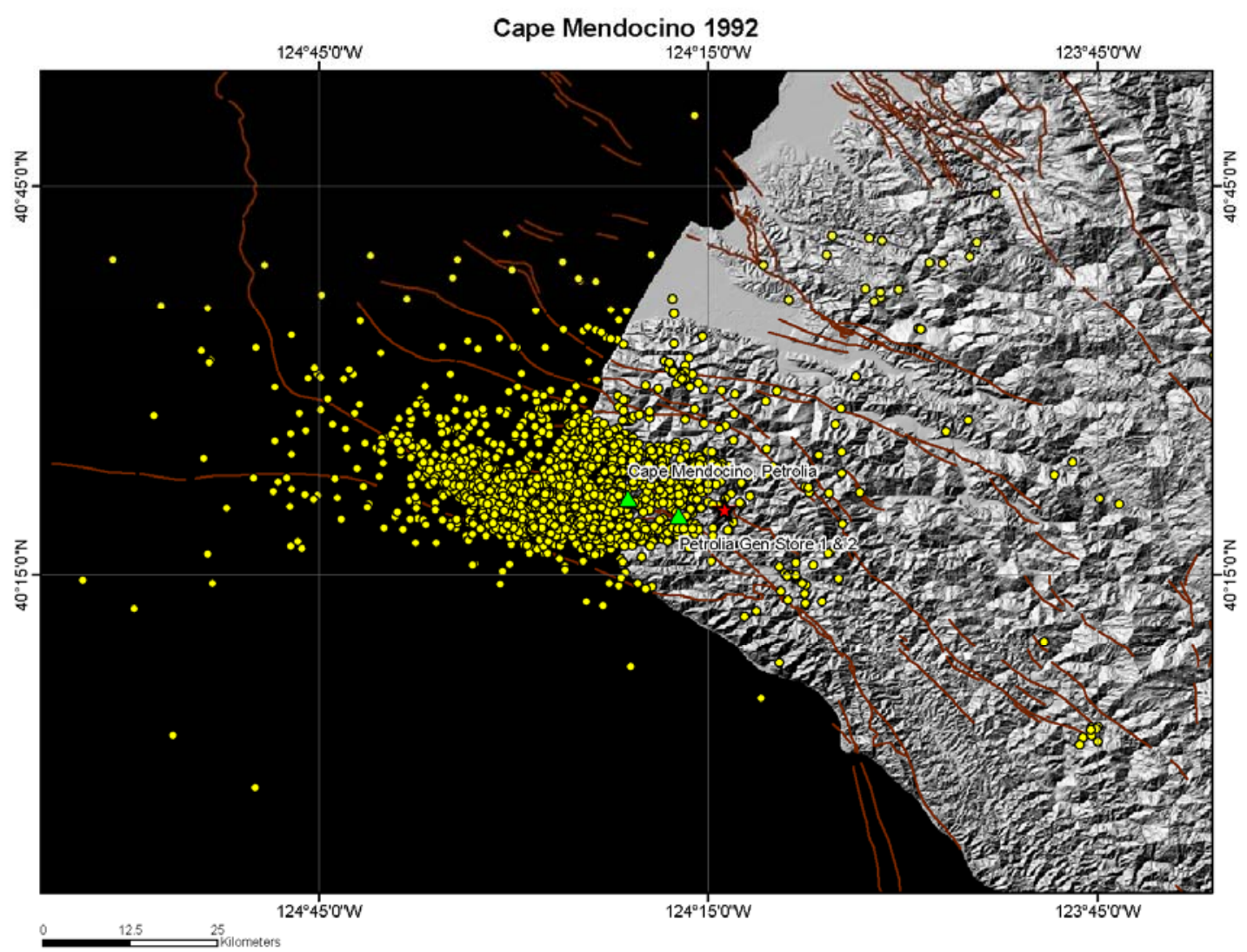


Figure A22. Landers, June 28, 1992, 11:57:34, $M_{W} 7.30$

\section{Landers 1992}

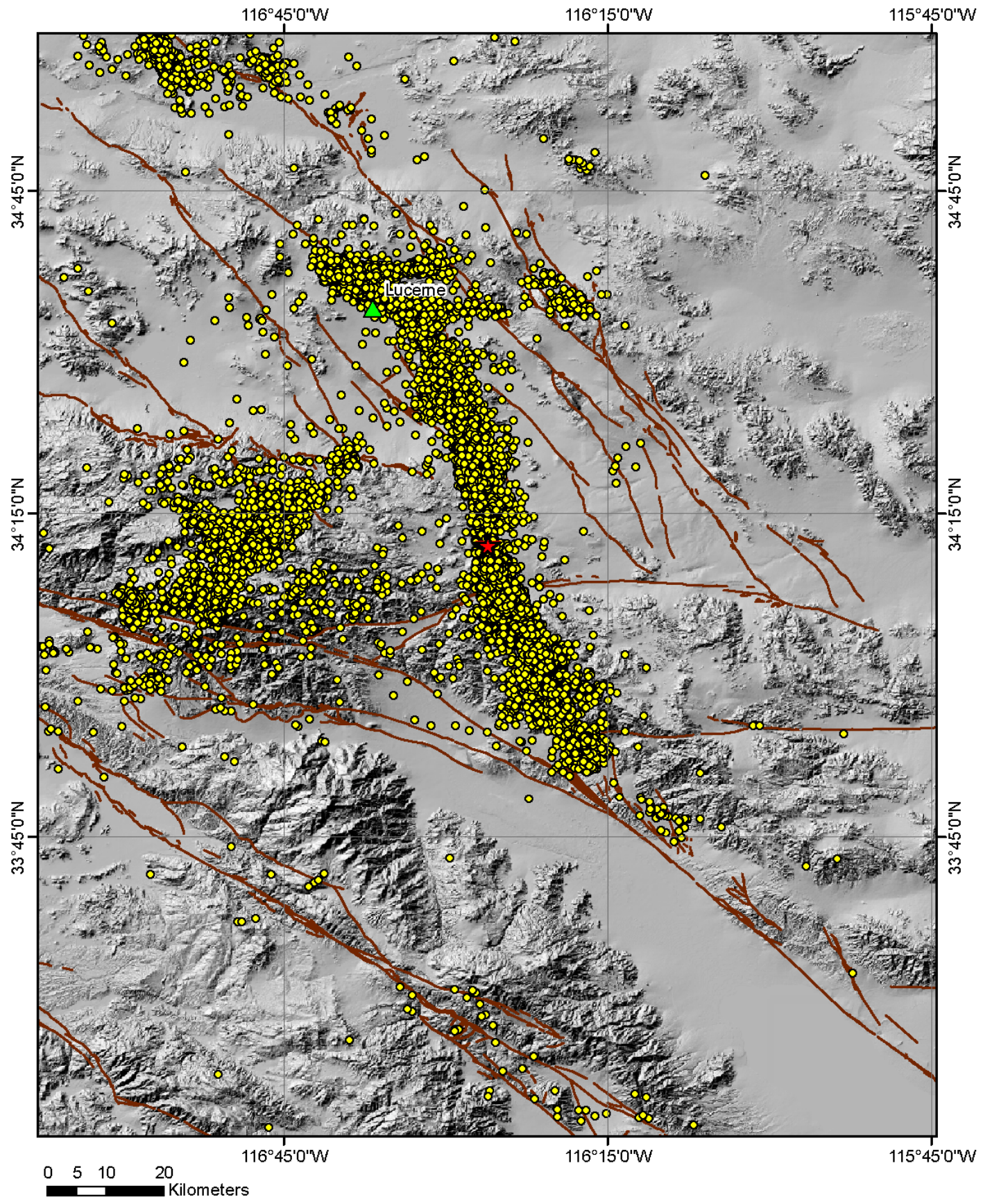


Figure A23. Northridge, January 17, 1994, 12:30:55, $M_{W} 6.70$

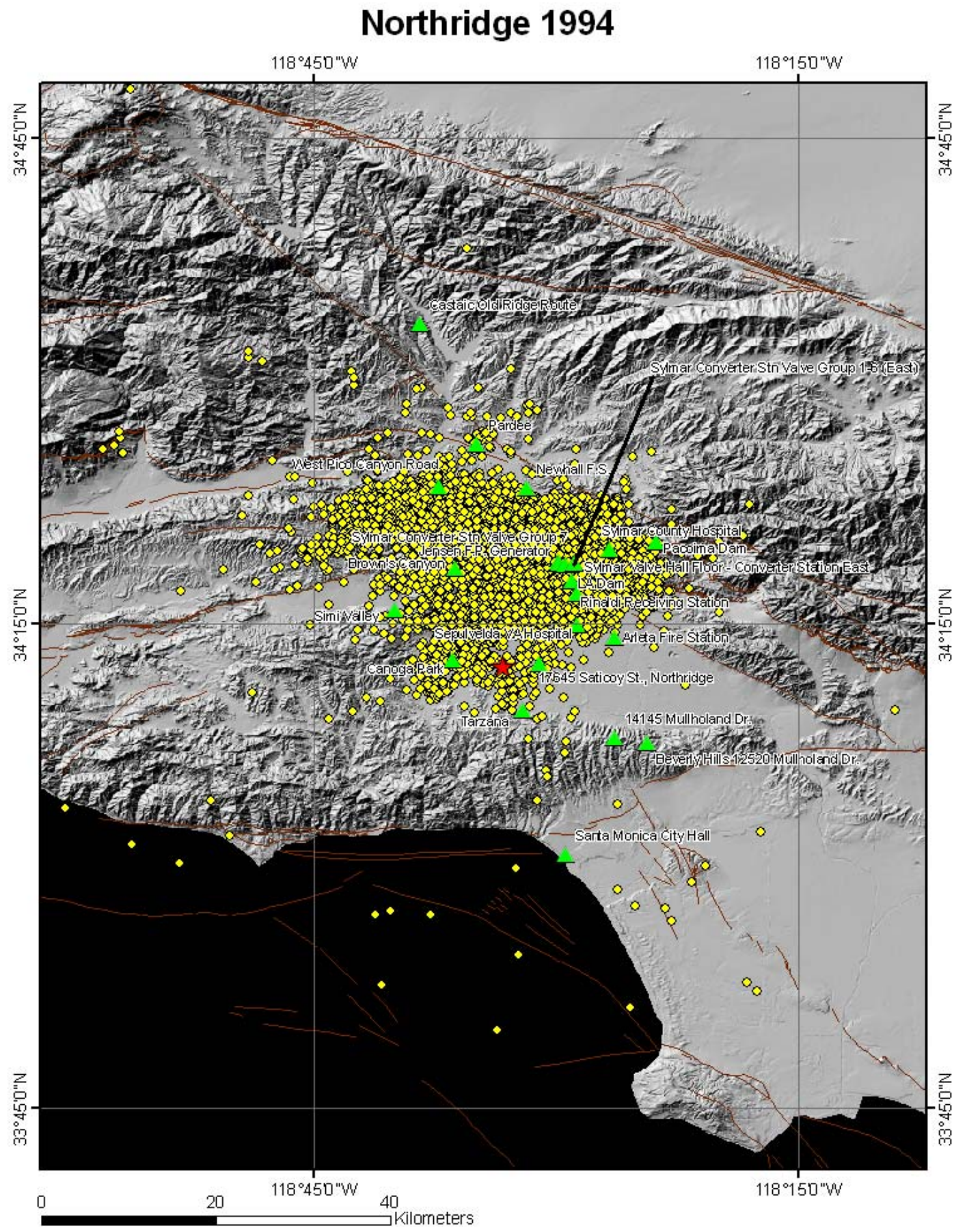


Figure A24. Zanjiran, June 20, 1994, 09:09:02, $M_{W} 5.90$

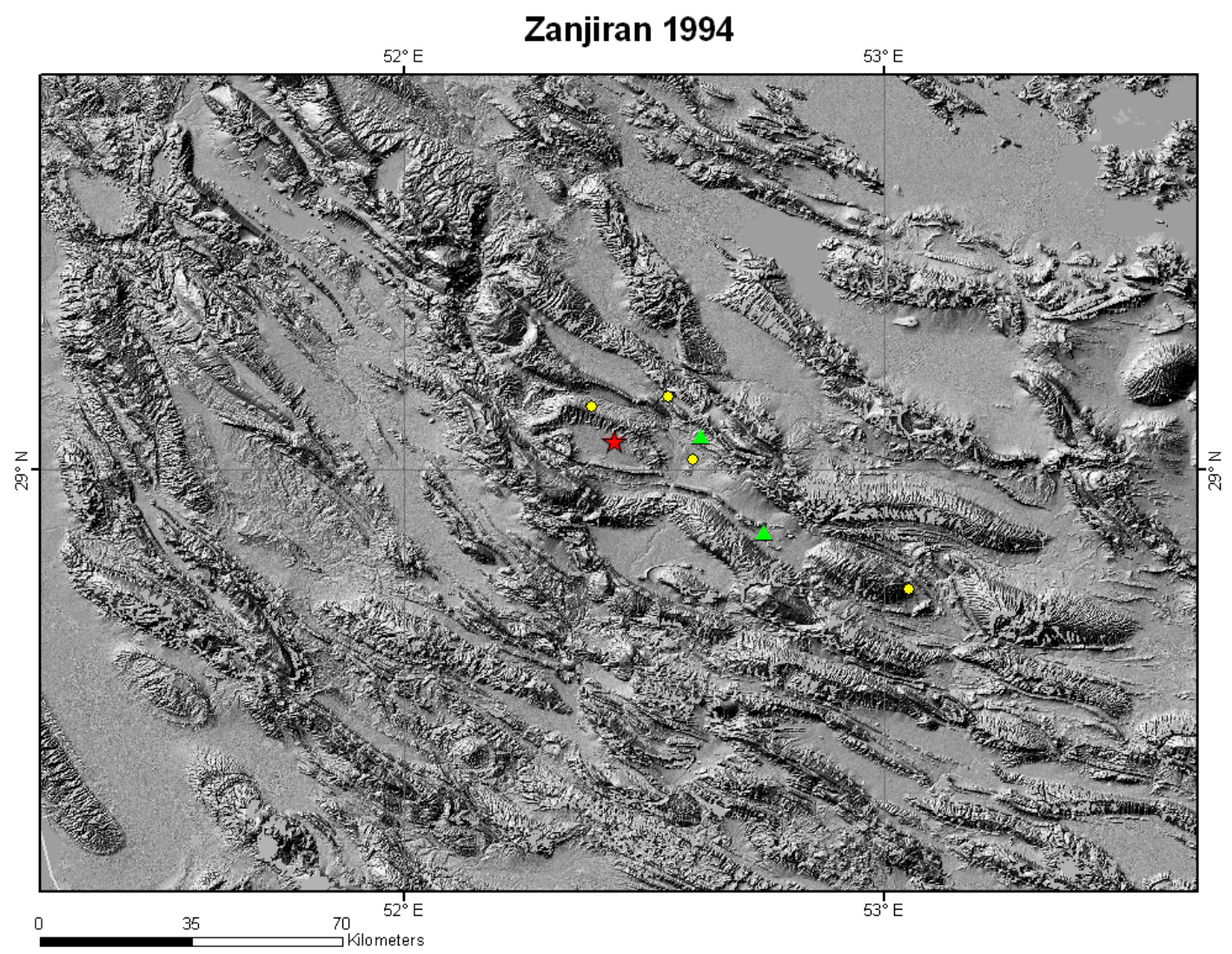


Figure A25. Kobe, January 16, 1995, 20:46:52, $M_{W} 6.90$

\section{Kobe 1995}

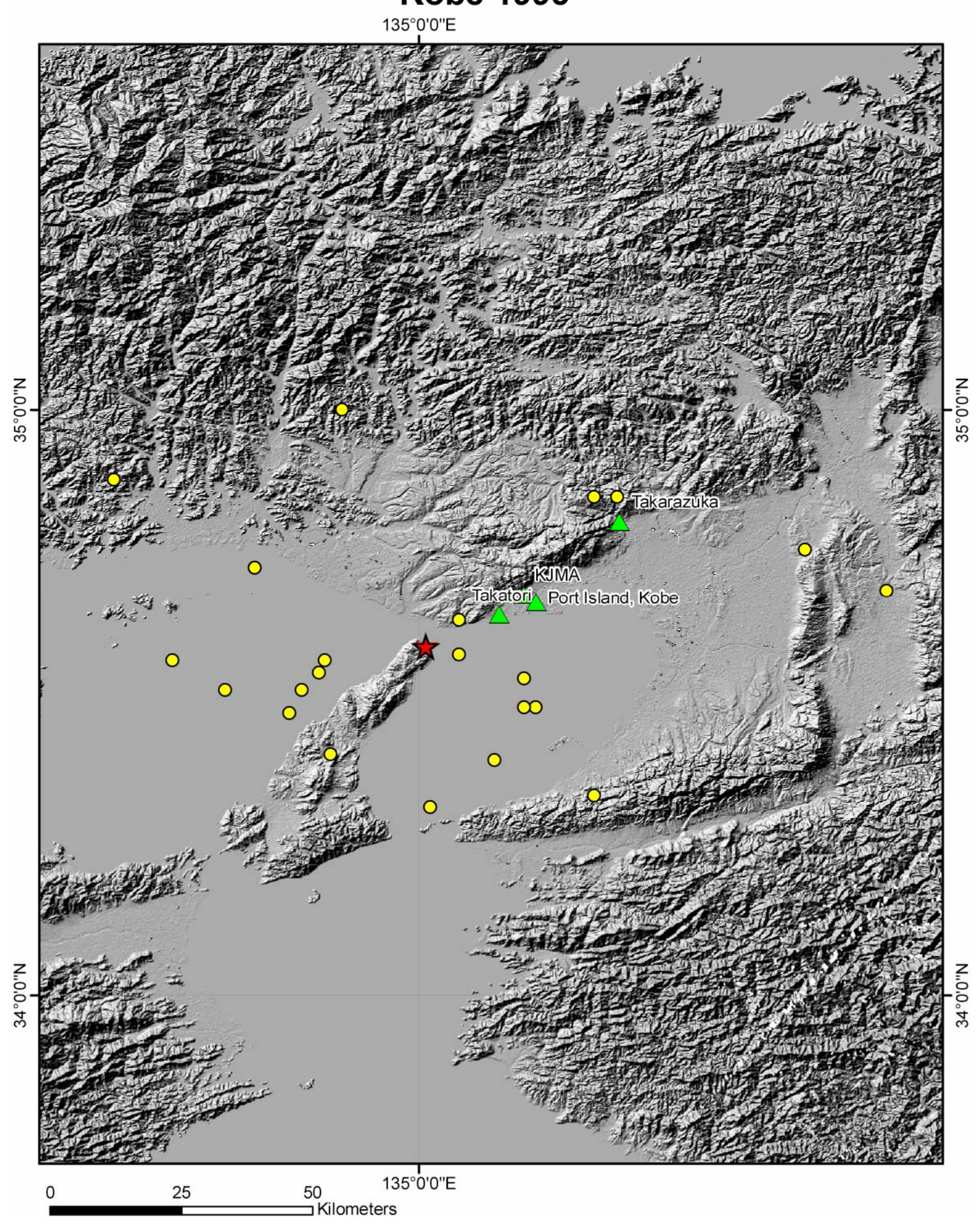

ORD-FY06-022 Subtask 2: Final Technical Report. 
Figure A26. East Coast Honshu, May 23, 1996, 09:36:31, $M_{W} 5.00$

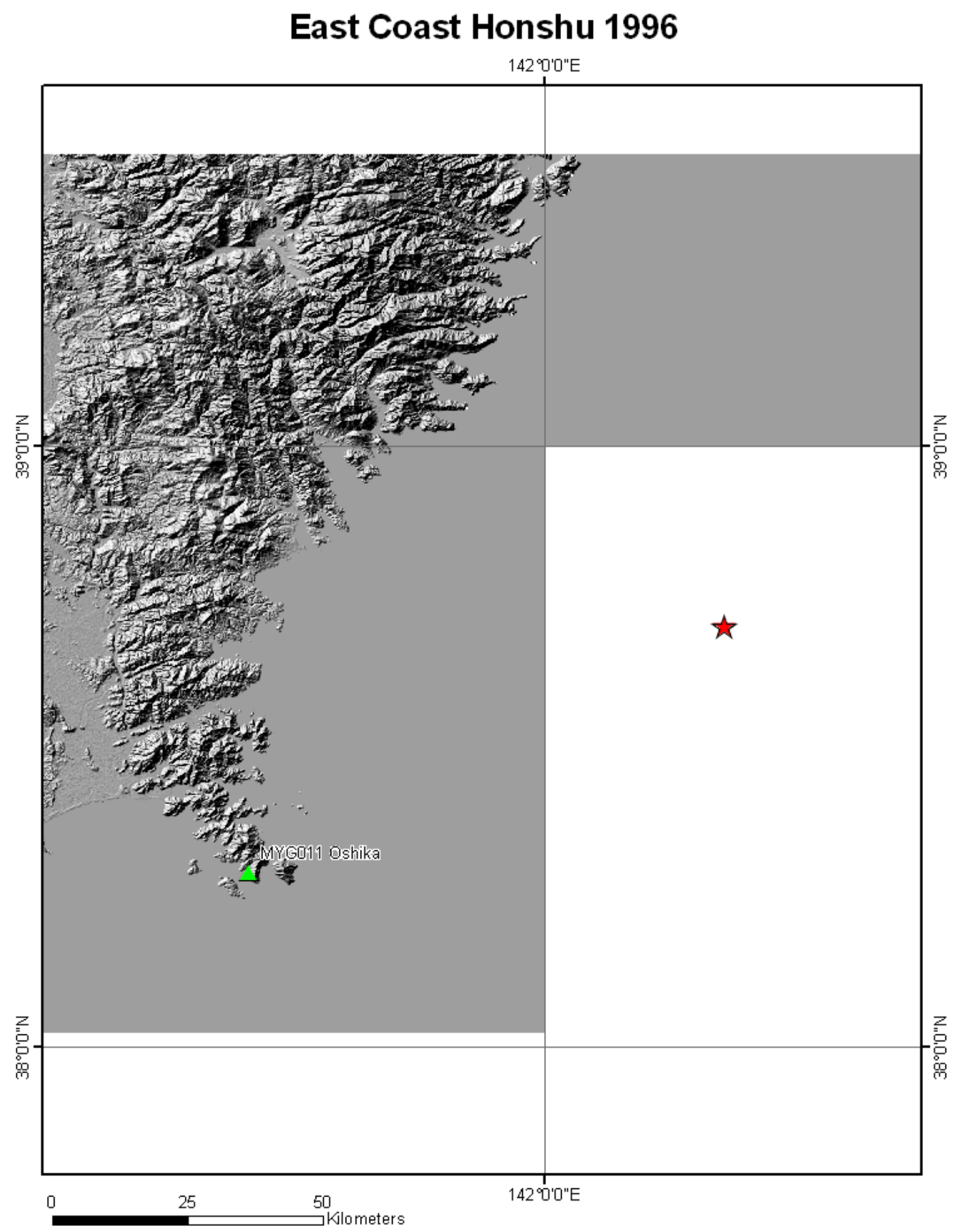


Figure A27. Central Honshu, August 13, 1996, 02:13:00, Mjma 5.00

\section{Central Honshu 1996}

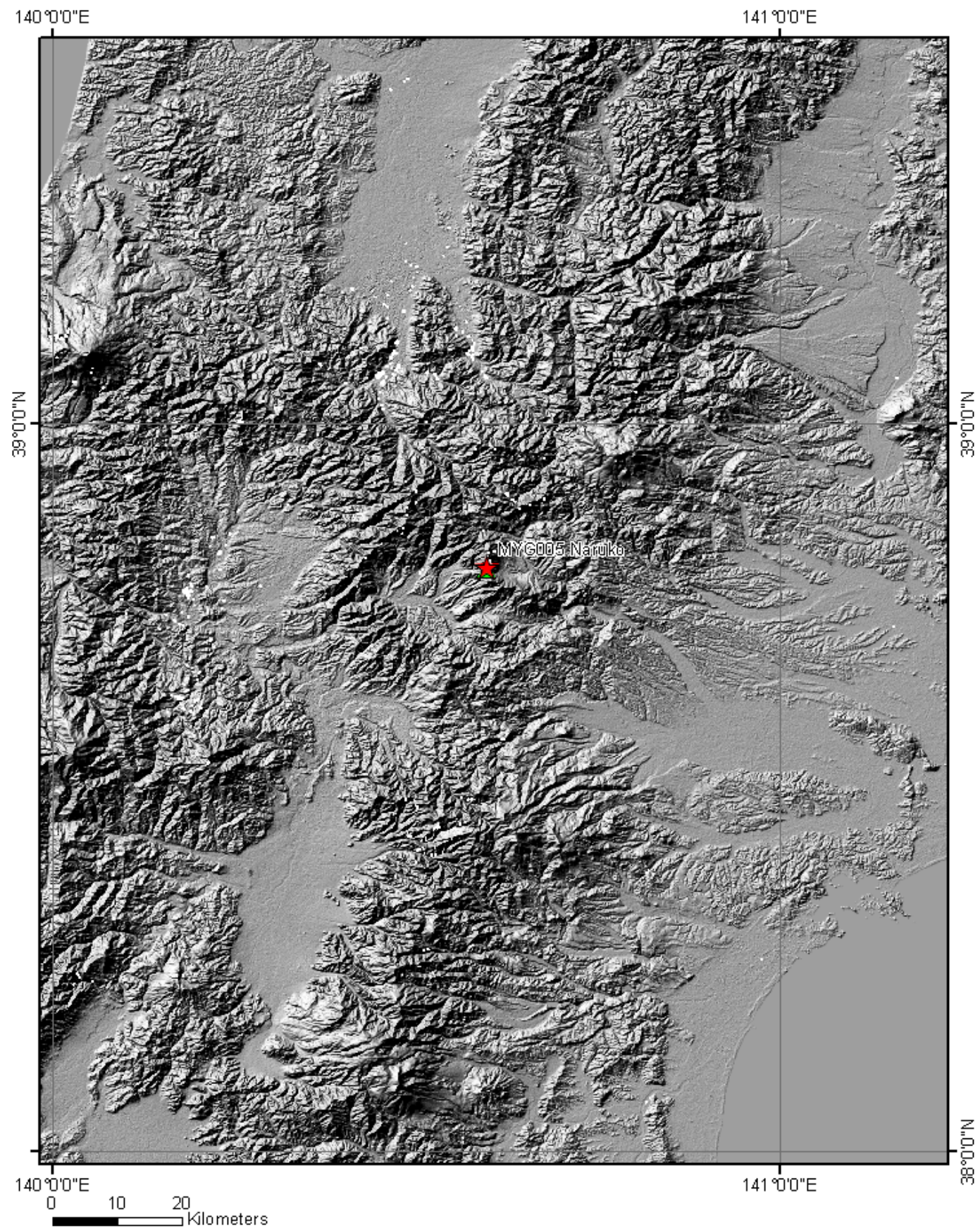


Figure A28. Honshu, December 21, 1996, 01:28:51, mb-GS 5.70

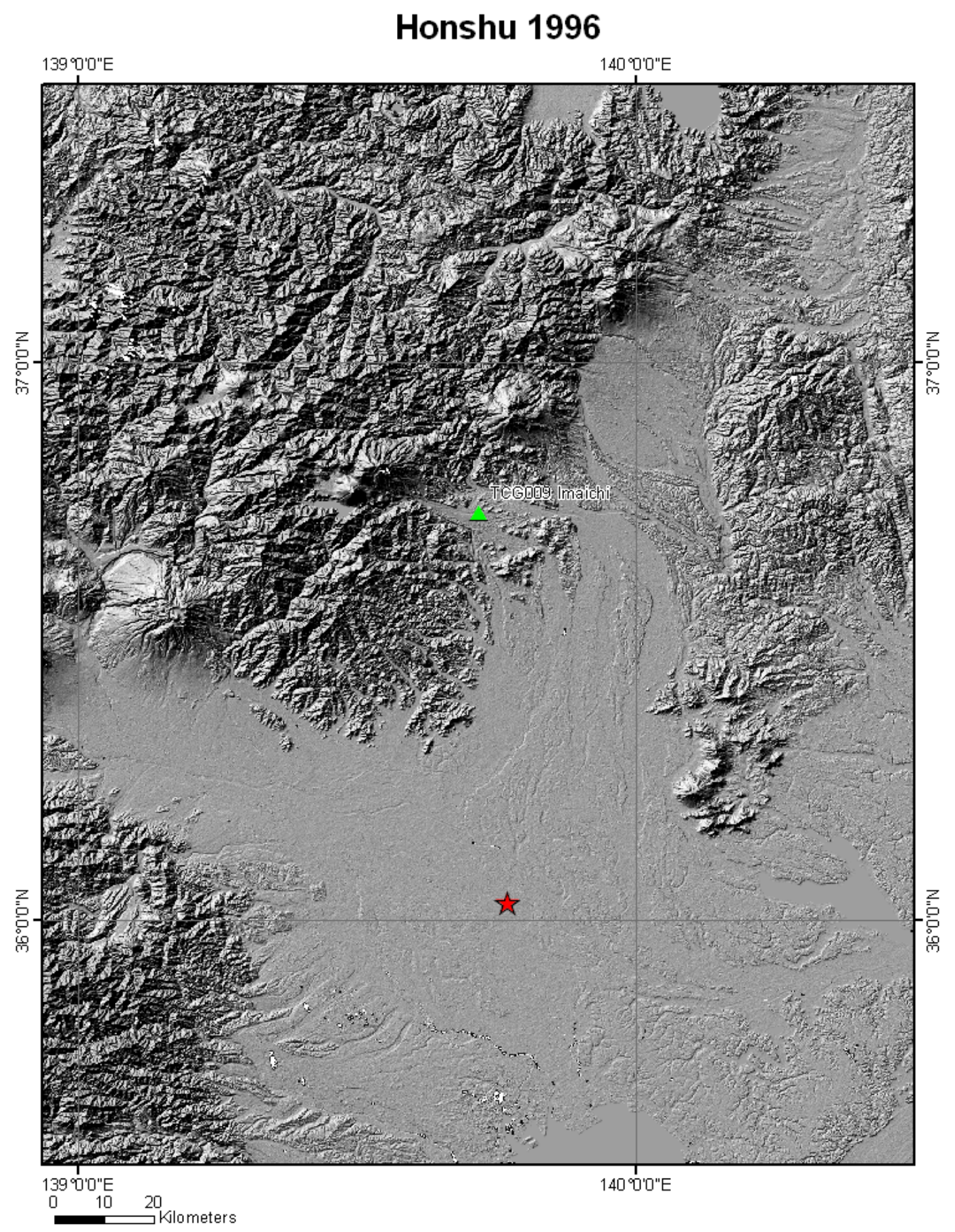

ORD-FY06-022 Subtask 2: Final Technical Report. 
Figure A29. South Coast Honshu, March 3, 1997, 14:09:43, $M_{W} 5.00$

\section{South Coast Honshu 1997}

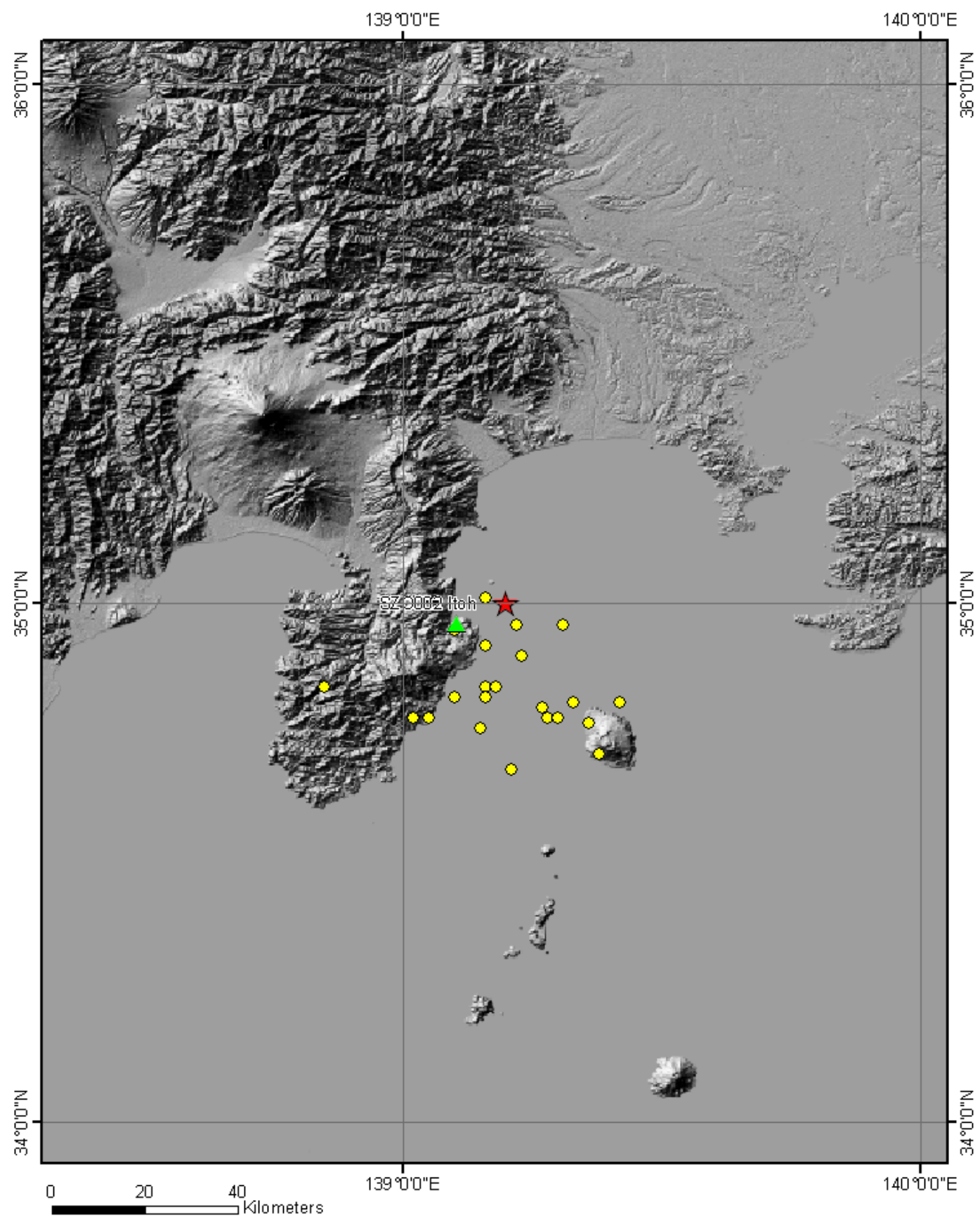


Figure A30. South Coast Honshu, March 16, 1997, 05:51:37, $M_{W} 5.80$

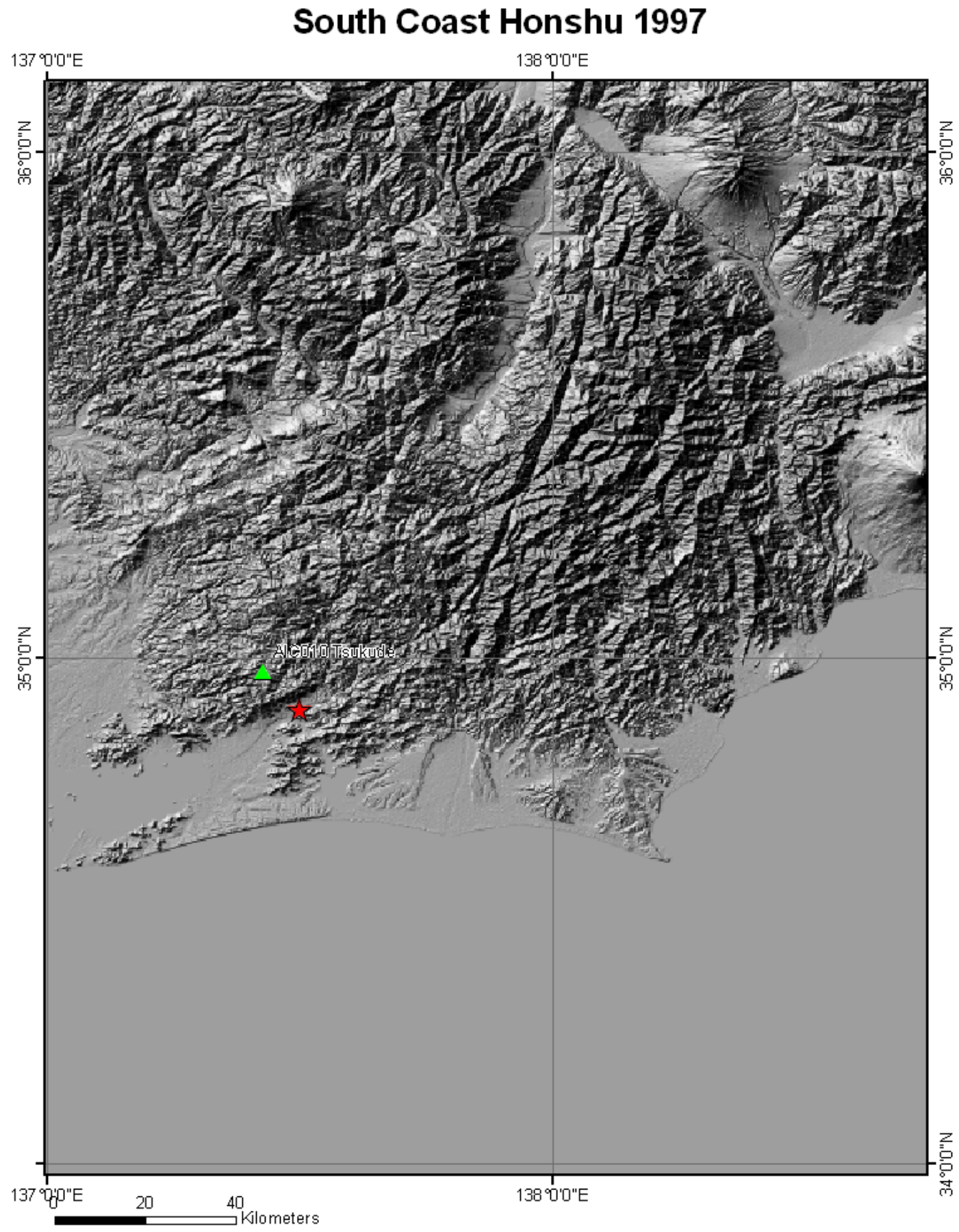


Figure A31. Kyushu, March 26, 1997, 08:31:47, $M_{W} 6.30$

\section{Kyushu 1997 March}

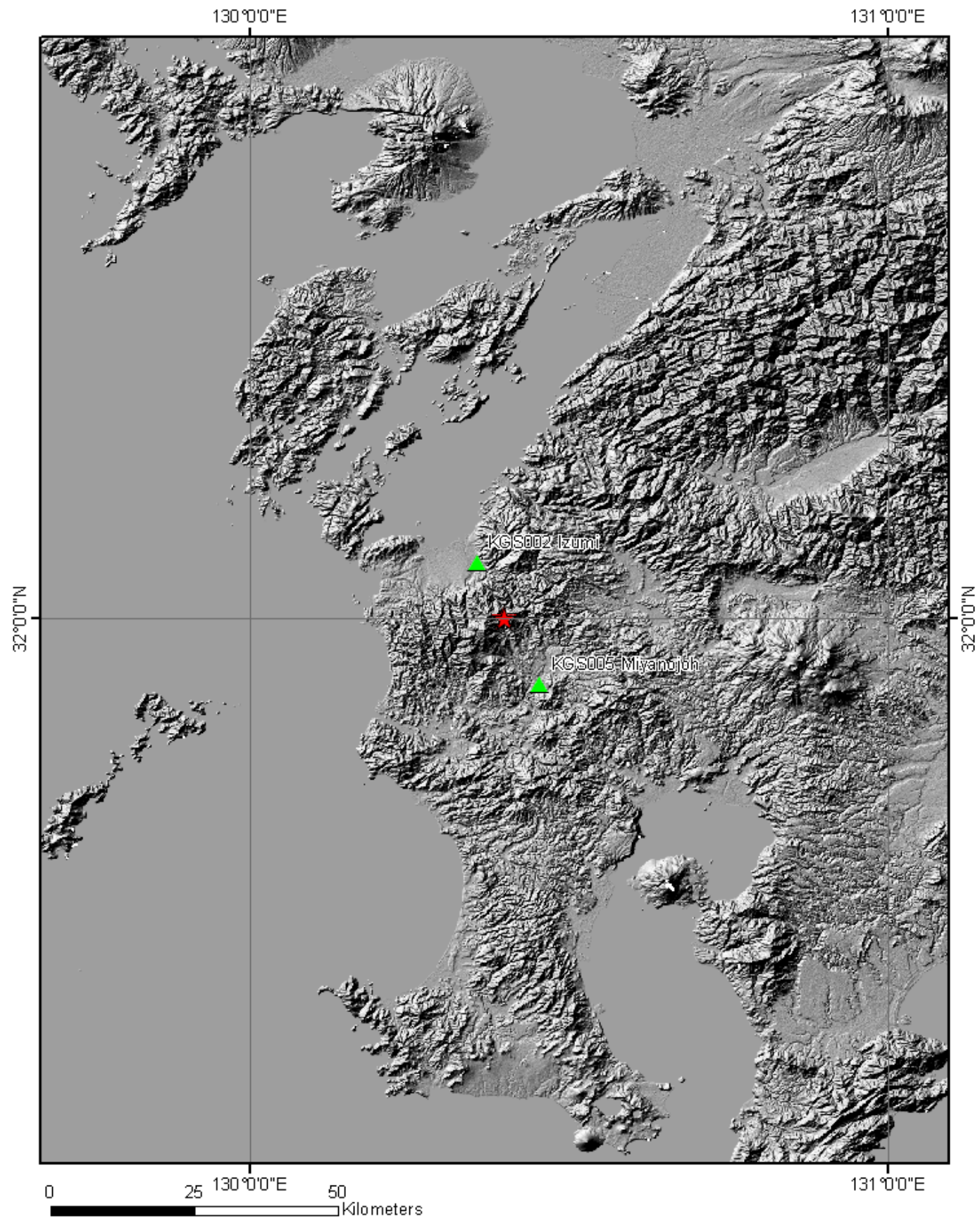


Figure A32. Kyushu, May 13, 1997, 05:38:30, $M_{W} 6.20$

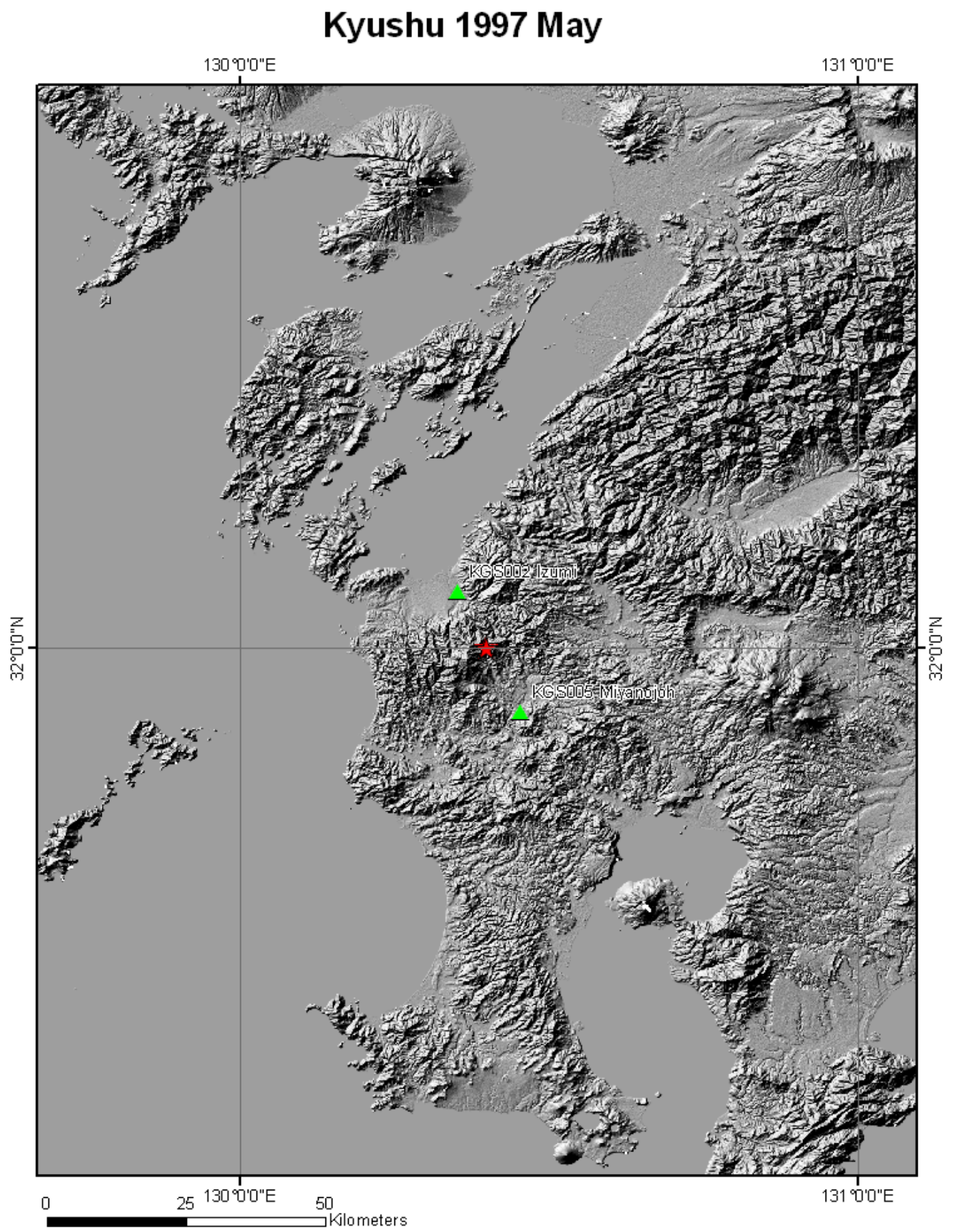


Figure A33. Umbria Marche, Italy foreshock, September 26, 1997, 00:33:16, Mw 5.72 and 09:40:33, Mw 6.04

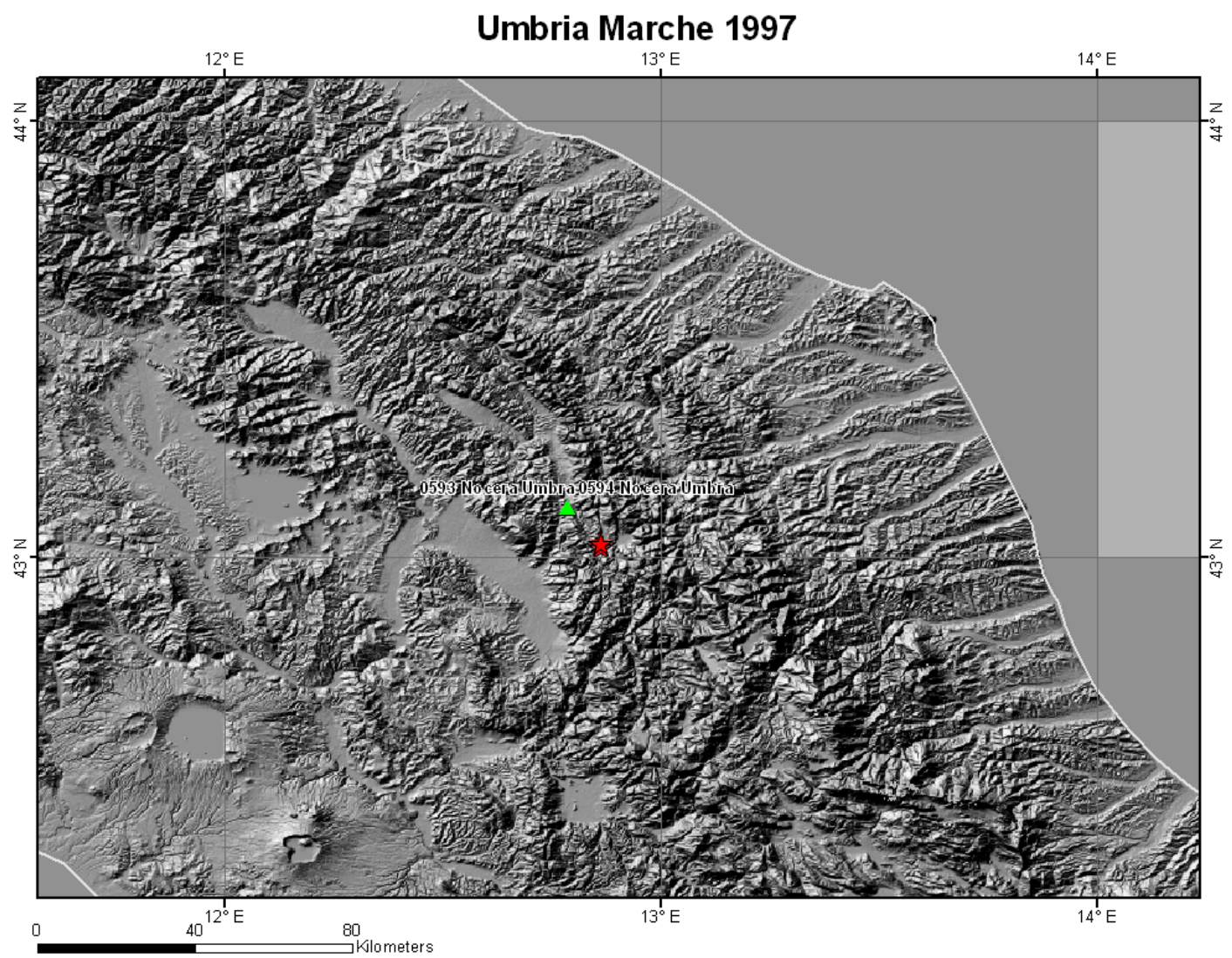


Figure A34. Chamoli, March 28, 1999, 19:05:11, $M_{W} 6.60$

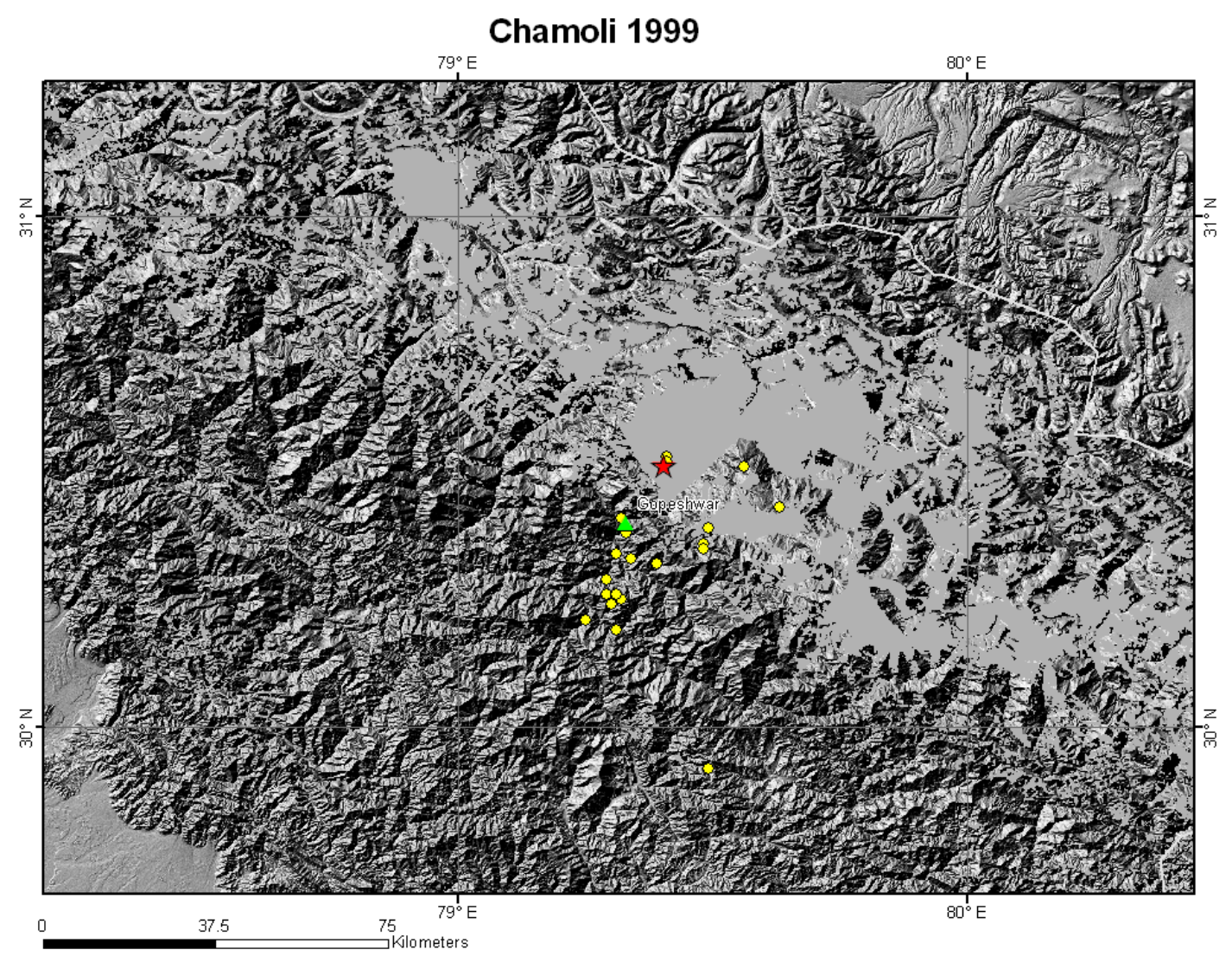


Figure A35. Karehbas, May 6, 1999, 23:00:53, $M_{W} 5.90$

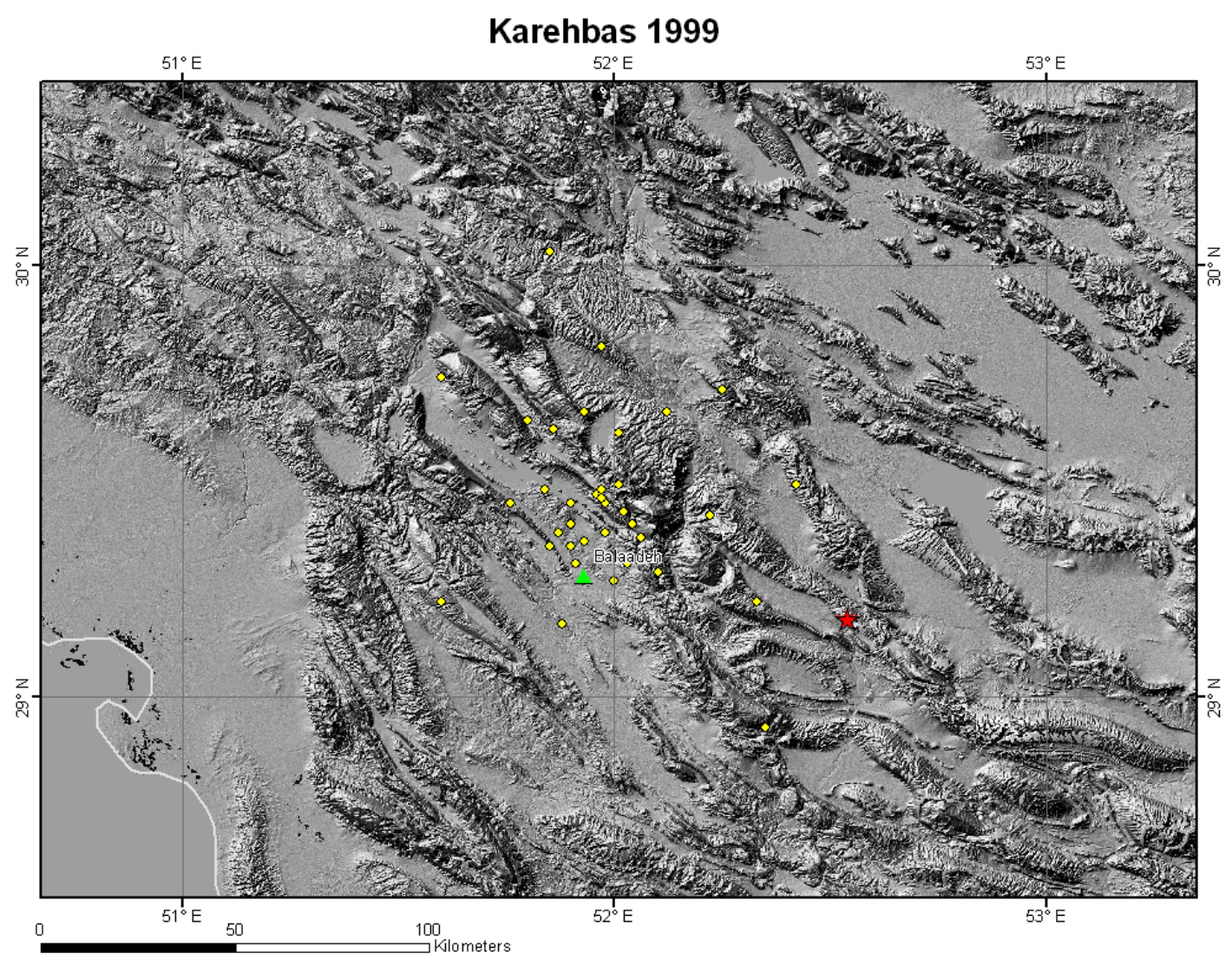


Figure A36. Kocaeli, Turkey, August 17, 1999, 00:01:40, $M_{w}$-hrv 7.60

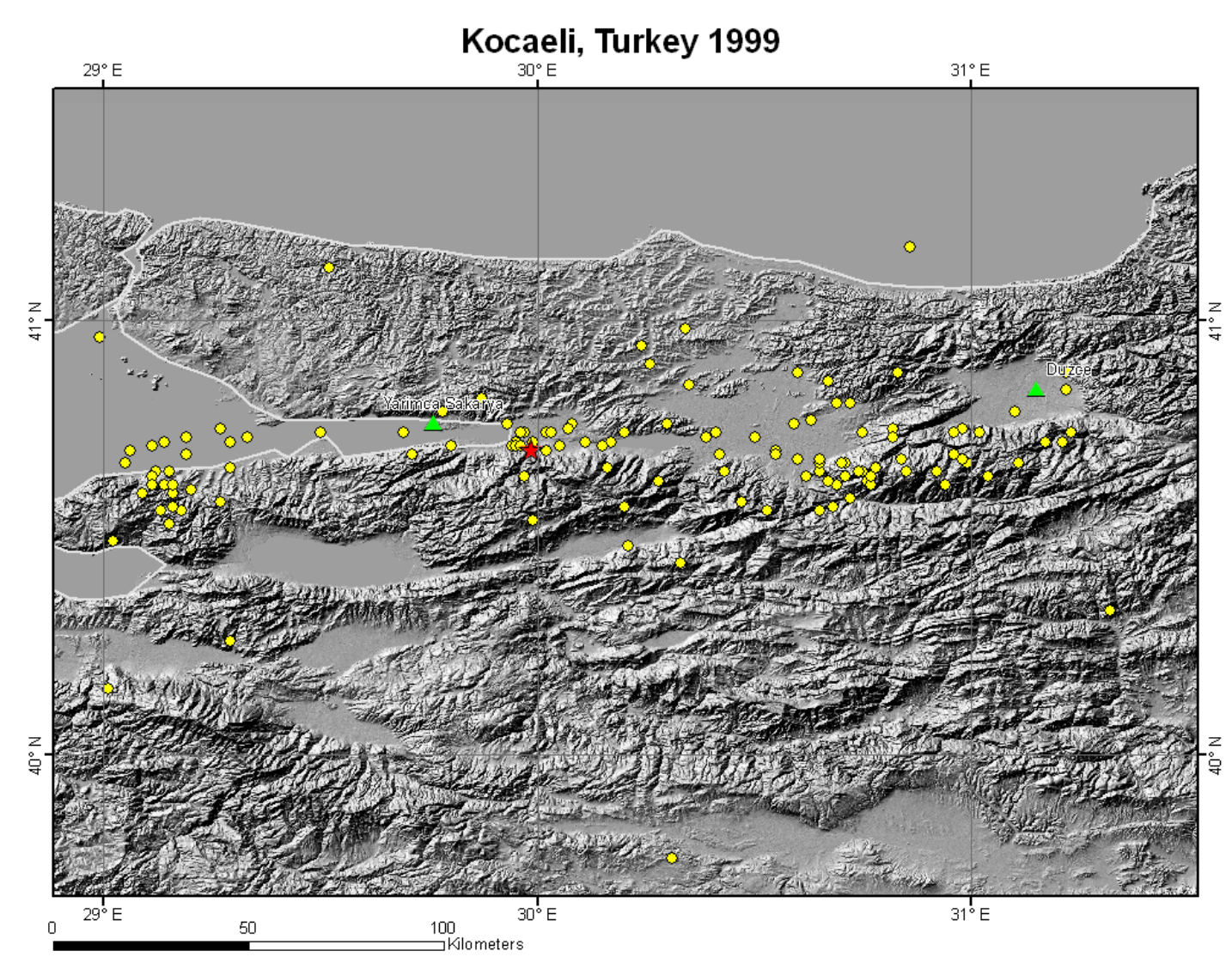


Figure A37. Southern Honshu, August 20, 1999, 20:33:00, Mjma 5.40

\section{Southern Honshu 1999}

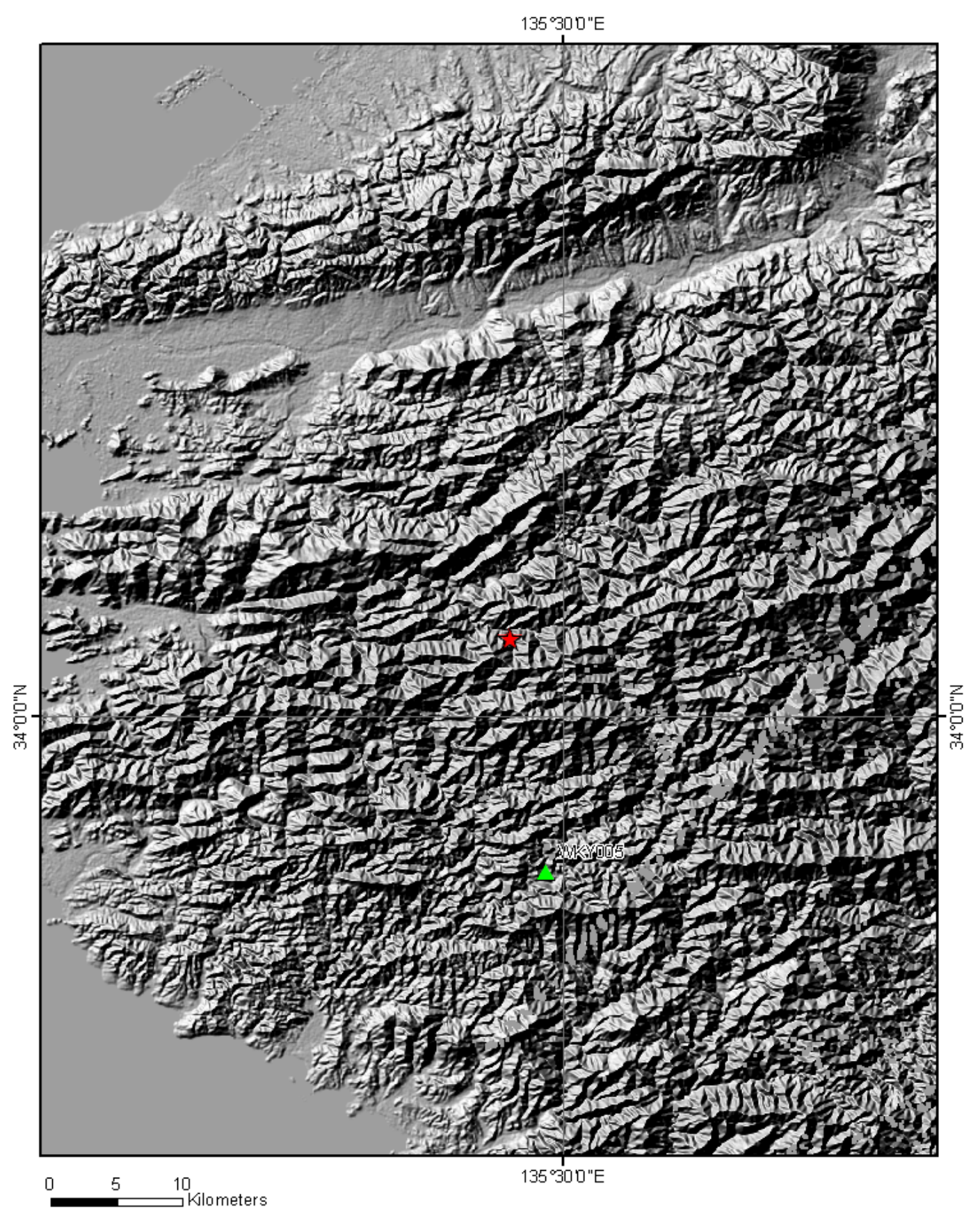

ORD-FY06-022 Subtask 2: Final Technical Report. 
Figure A38. Chi-Chi, September 20, 1999, 17:47:16, $M_{W} 7.60$

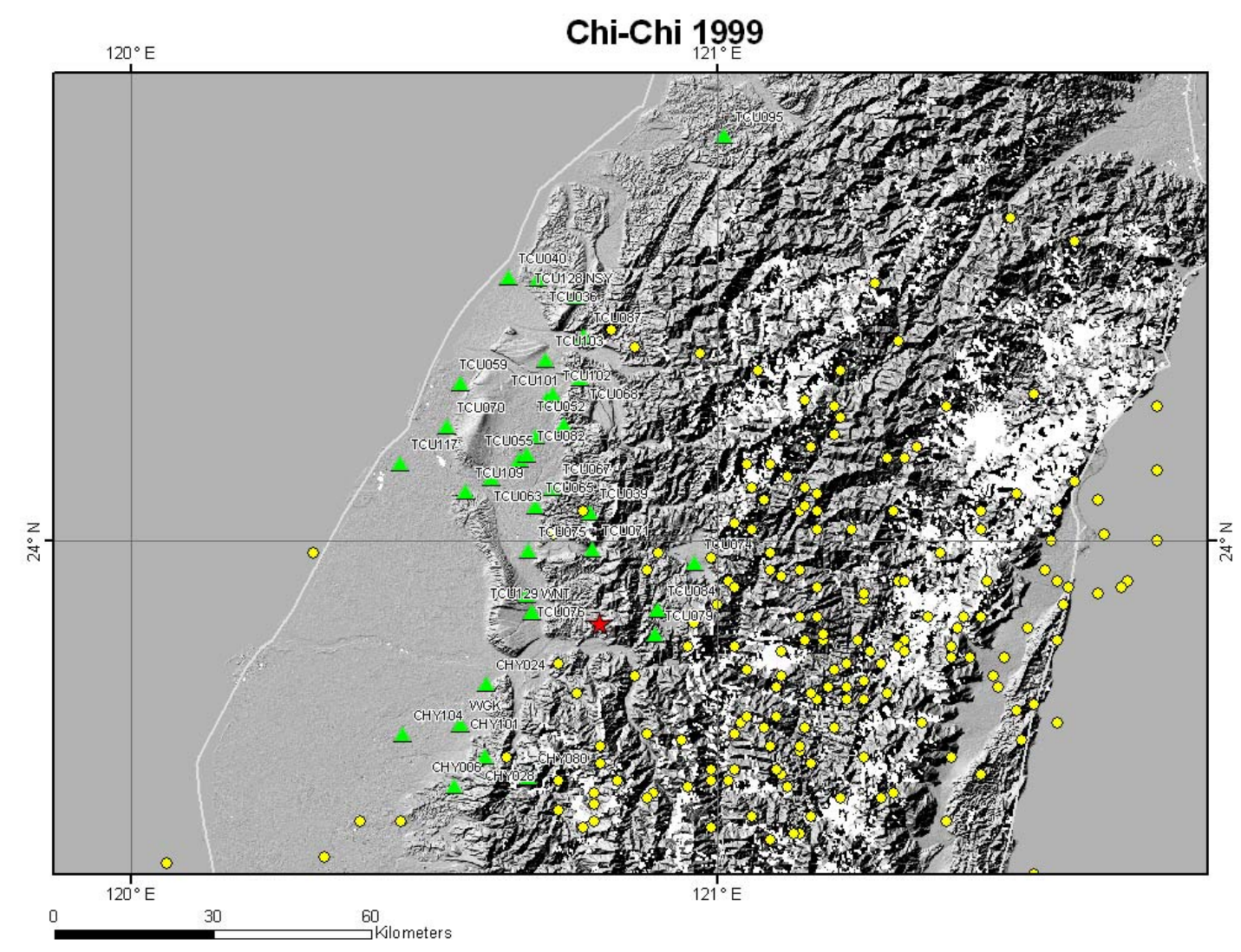


Figure A39. Duzce, November 12, 1999, 16:57:27, $M_{W} 7.10$

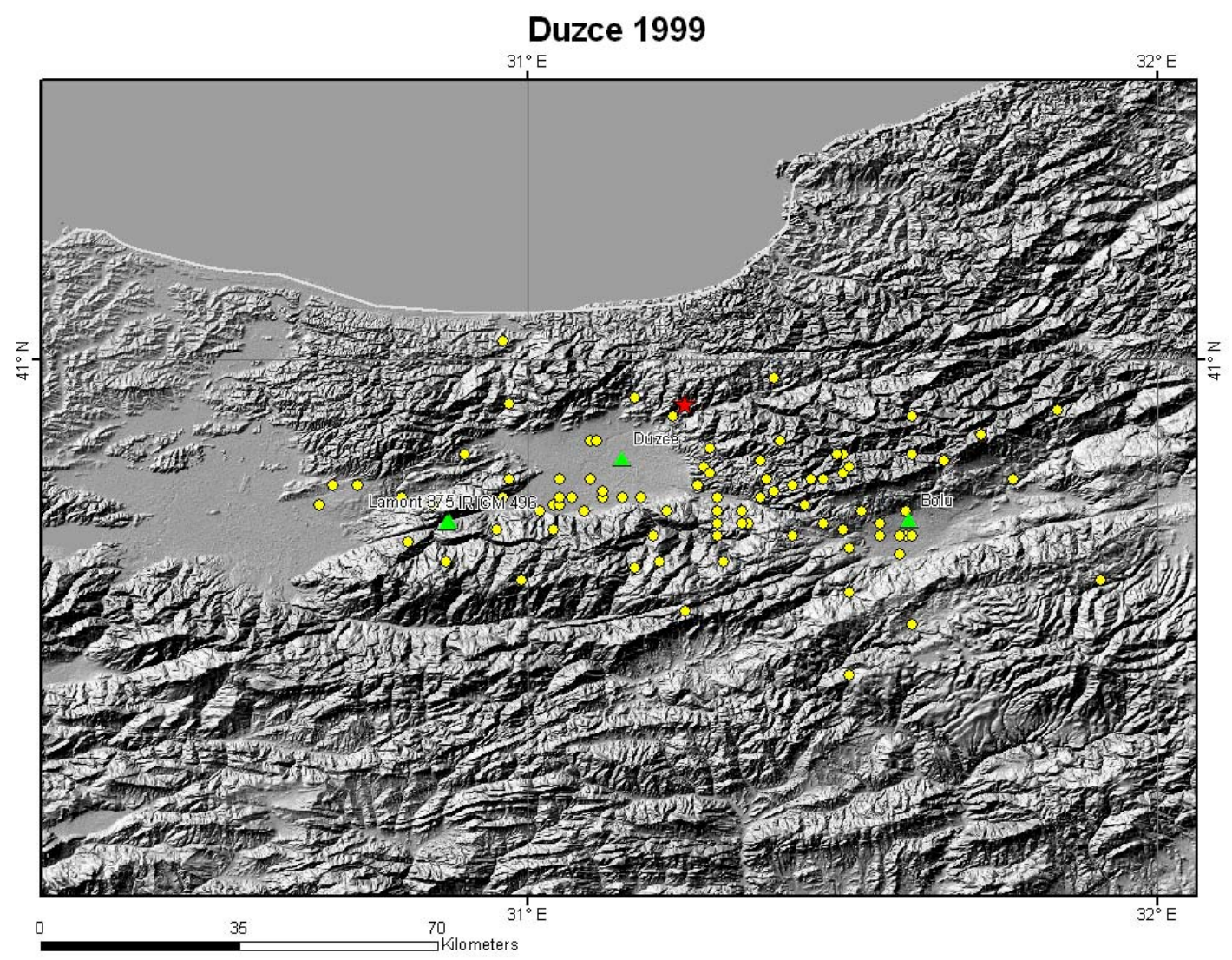

ORD-FY06-022 Subtask 2: Final Technical Report. 
Figure A40. South Iceland, June 17, 2000, 15:40:41, $M_{W} 6.57$ and 00:51:48, $M_{W} 6.49$

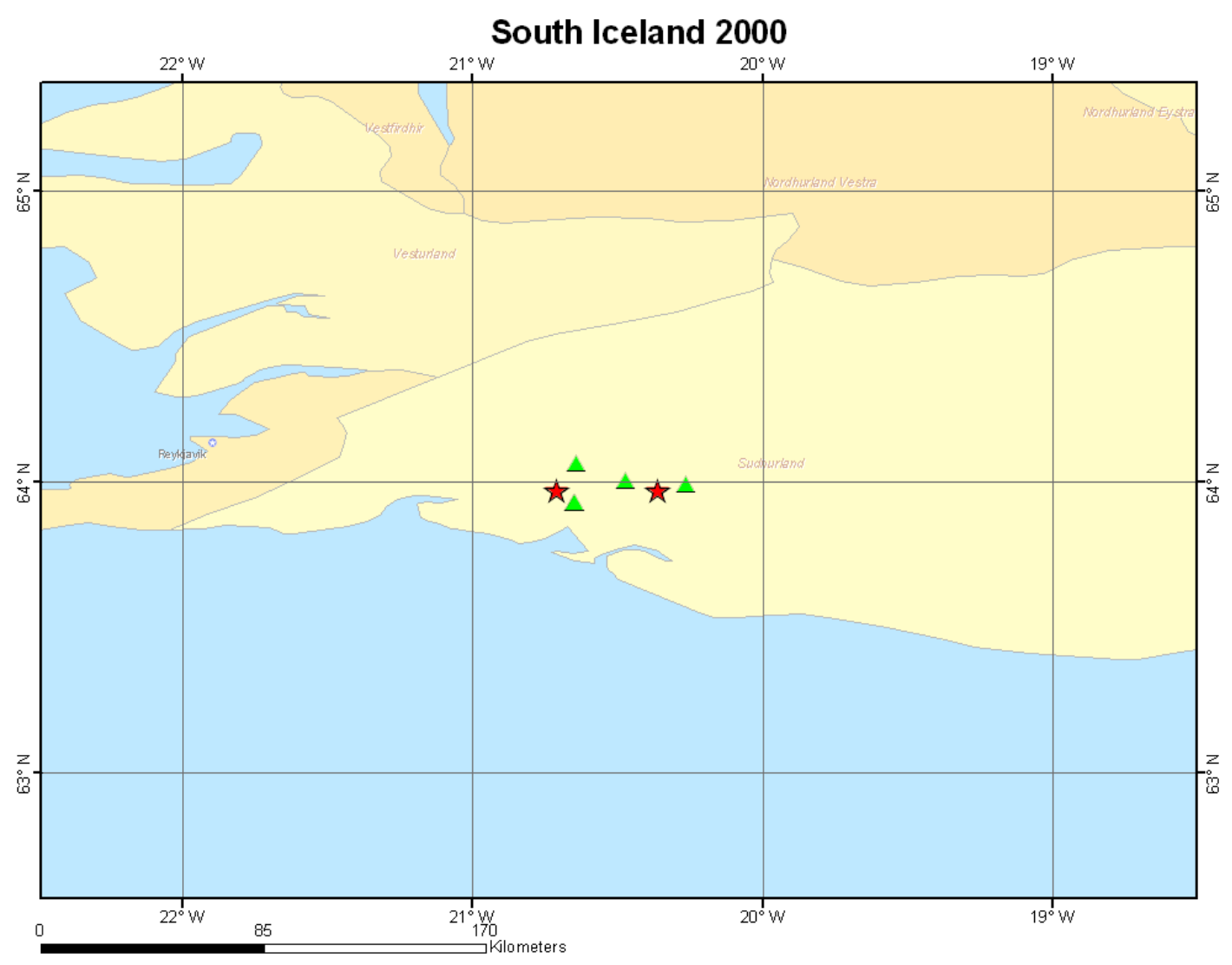


Figure A41. Japan, July 14, 2000, 16:18:00, Mjma 3.90

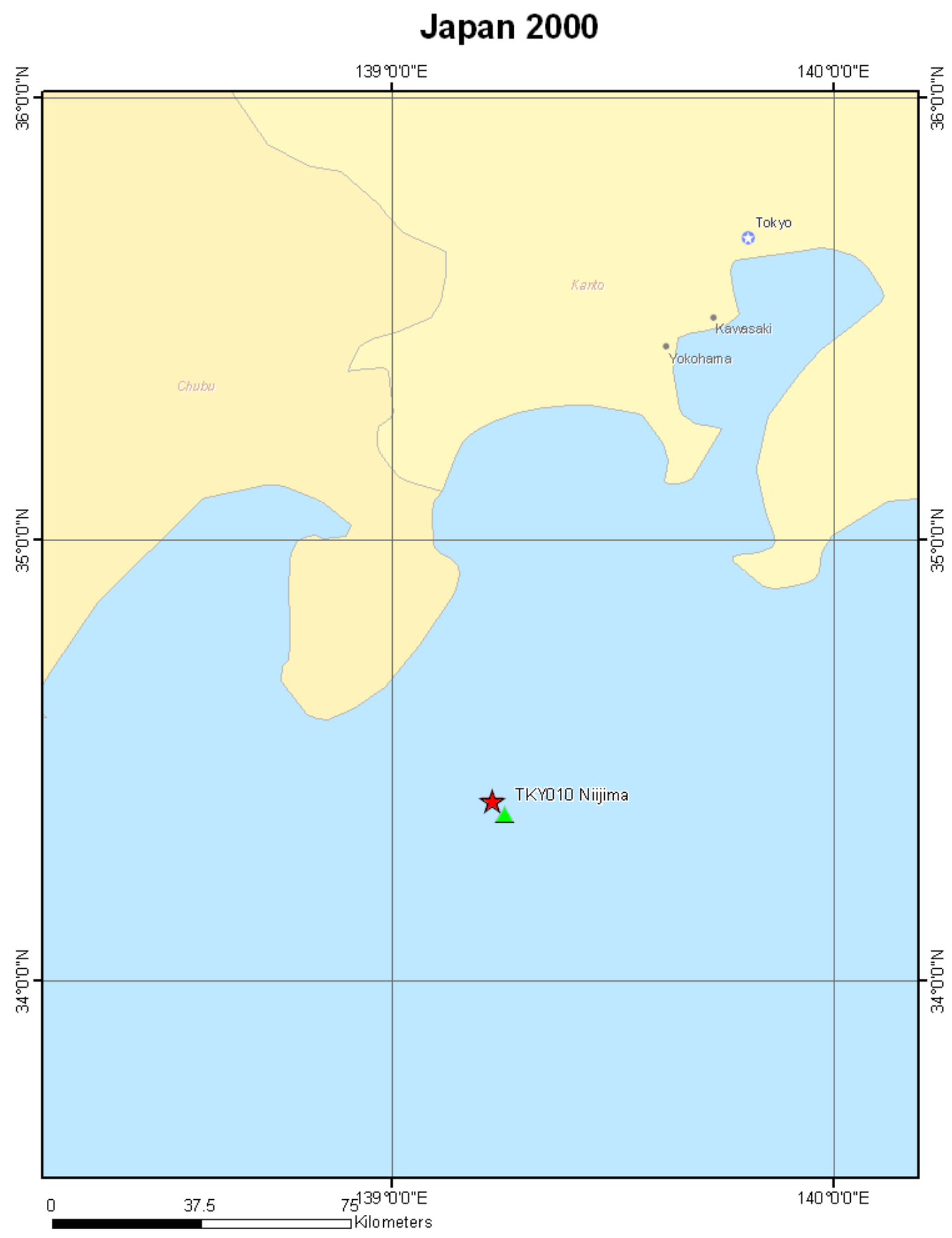


Figure A42. Yountville, September 3, 2000, 08:36:30, $M_{W} 5.00$

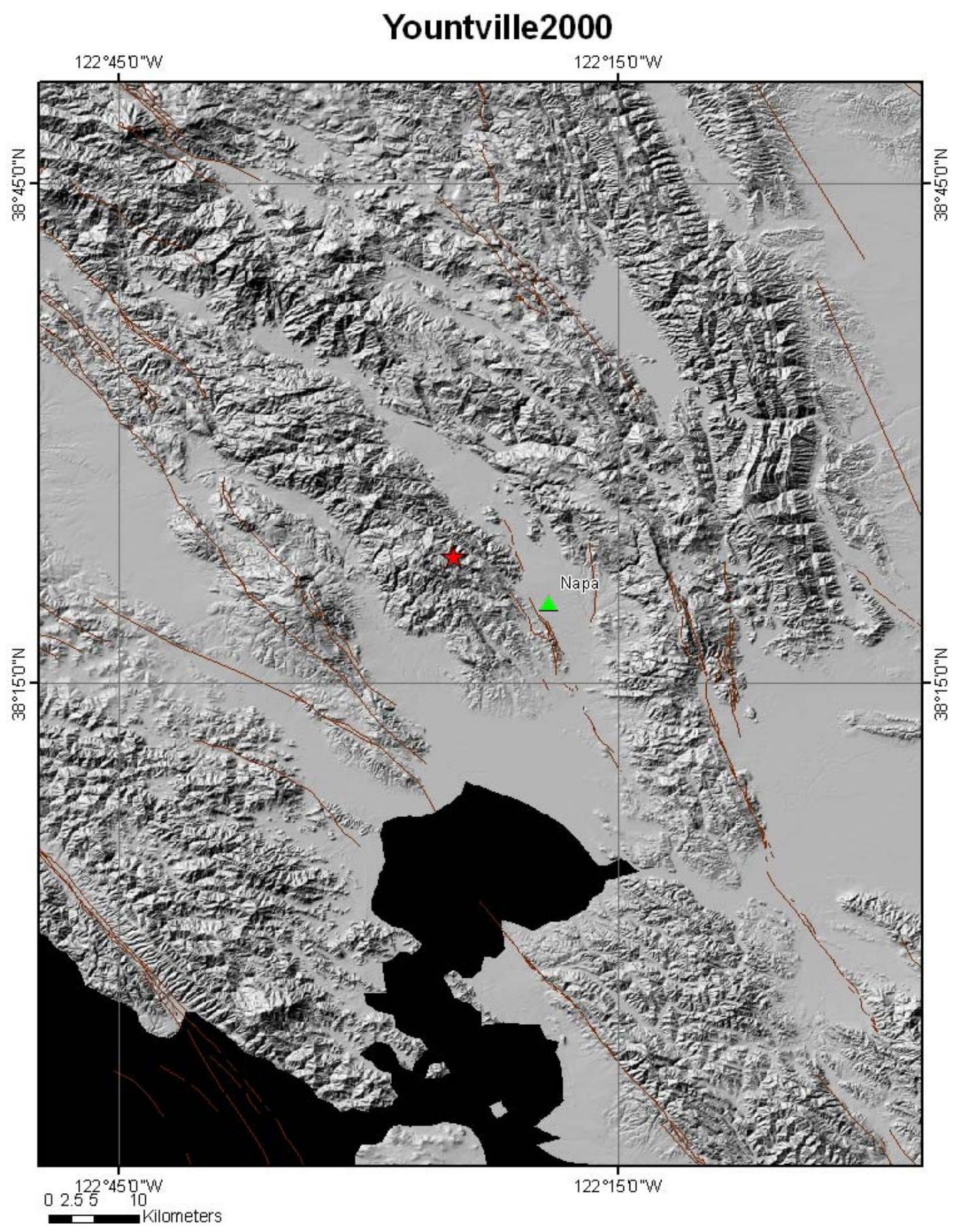


Figure A43. Western Tottori, October 6, 2000, 04:30:19, $M_{W} 7.10$

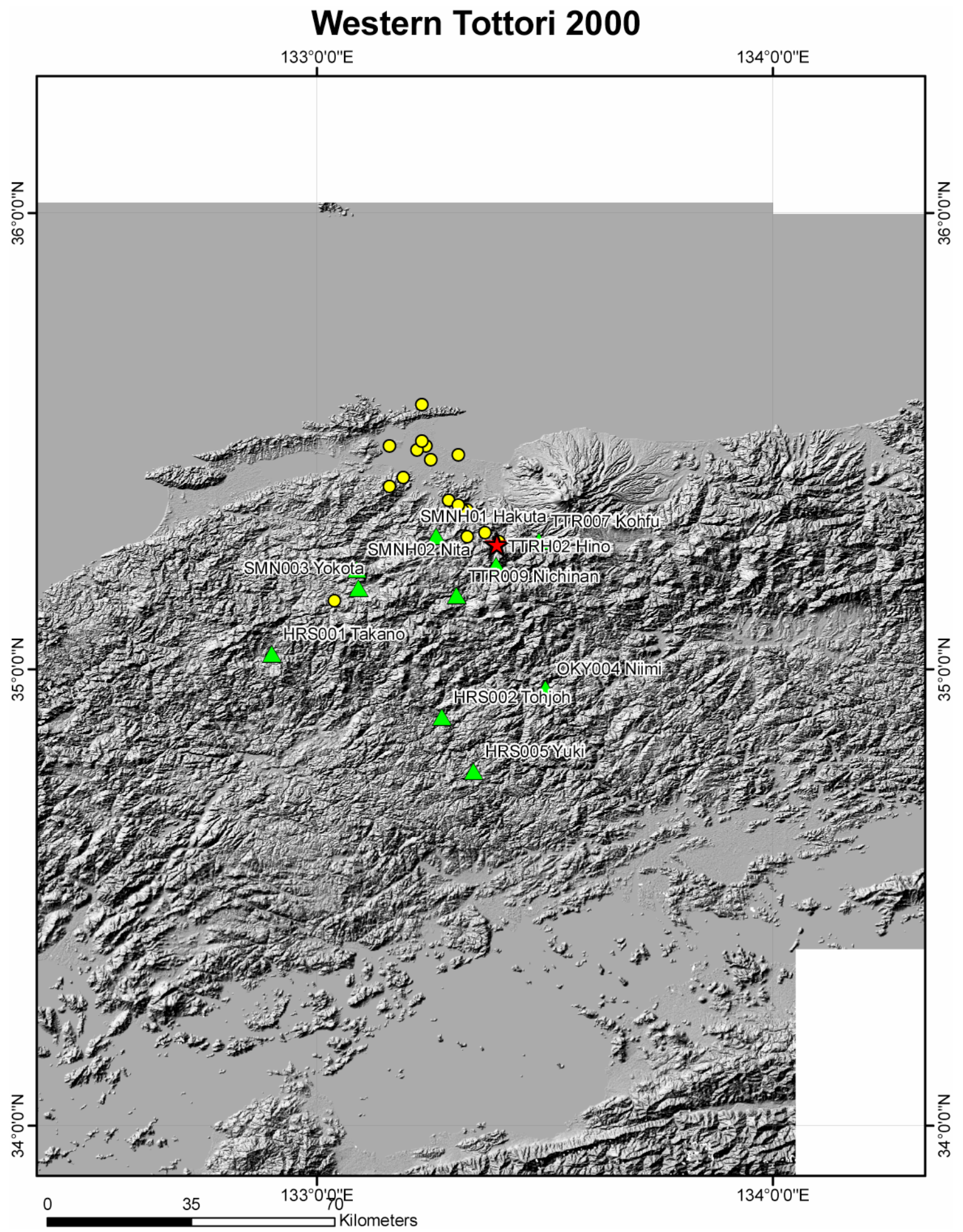


Figure A44. Honshu, October 30, 2000, 16:42:52, Mjma 5.50

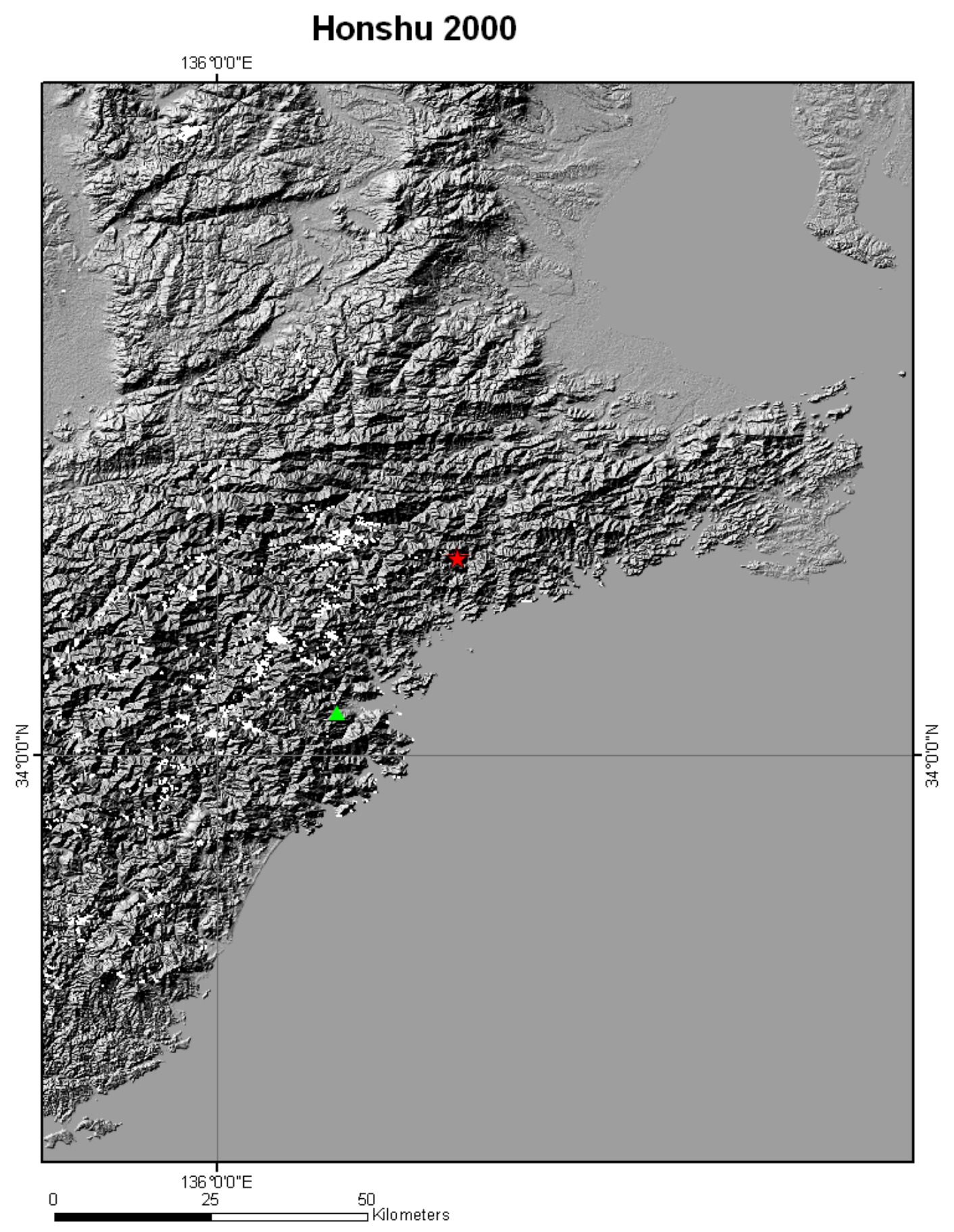

ORD-FY06-022 Subtask 2: Final Technical Report. 
Figure A45. El Salvador, January 13, 2001, 17:33:32, $M_{W} 7.60$

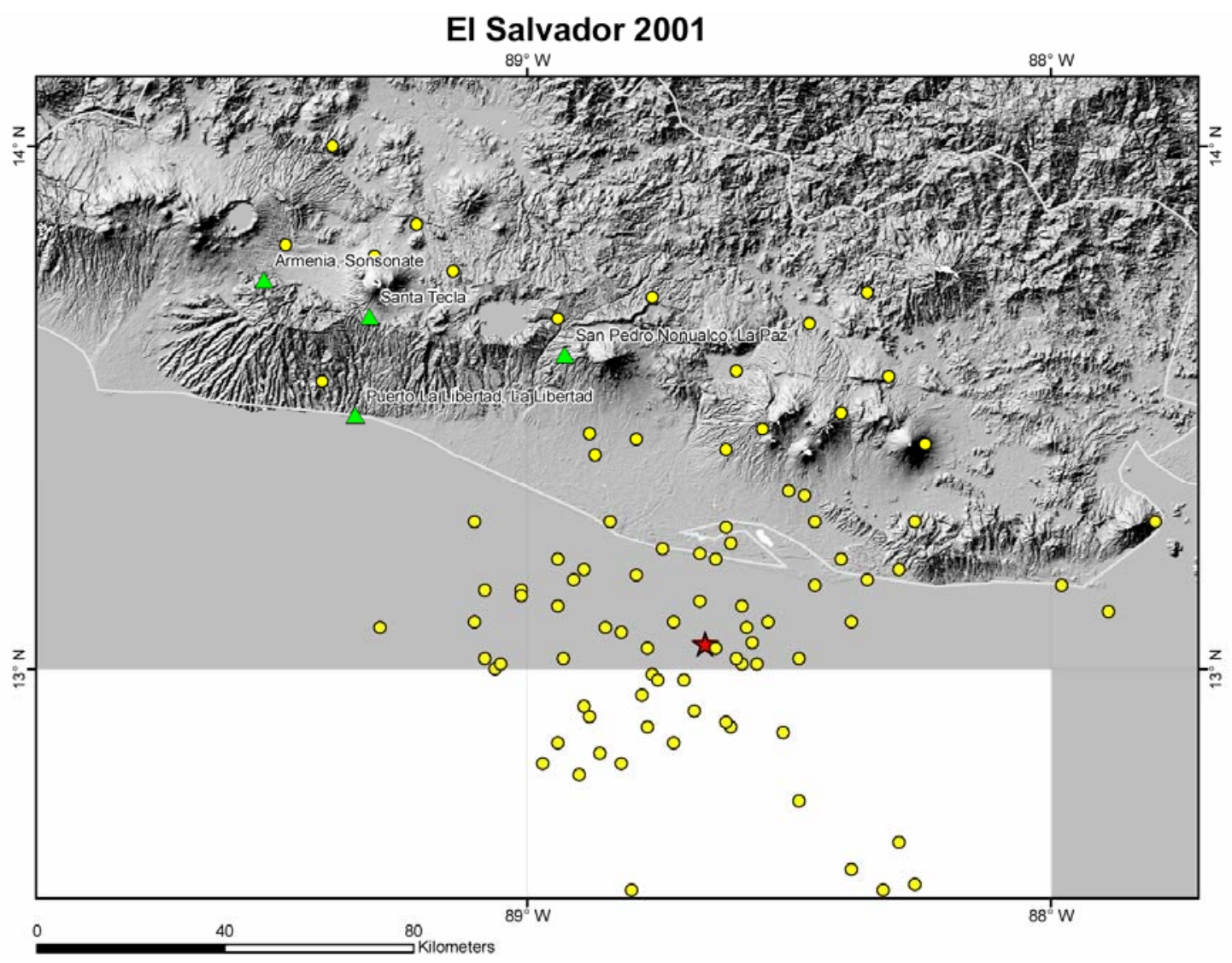


Figure A46. Nisqually, February 28, 2001, 18:54:31, $M_{W} 6.80$

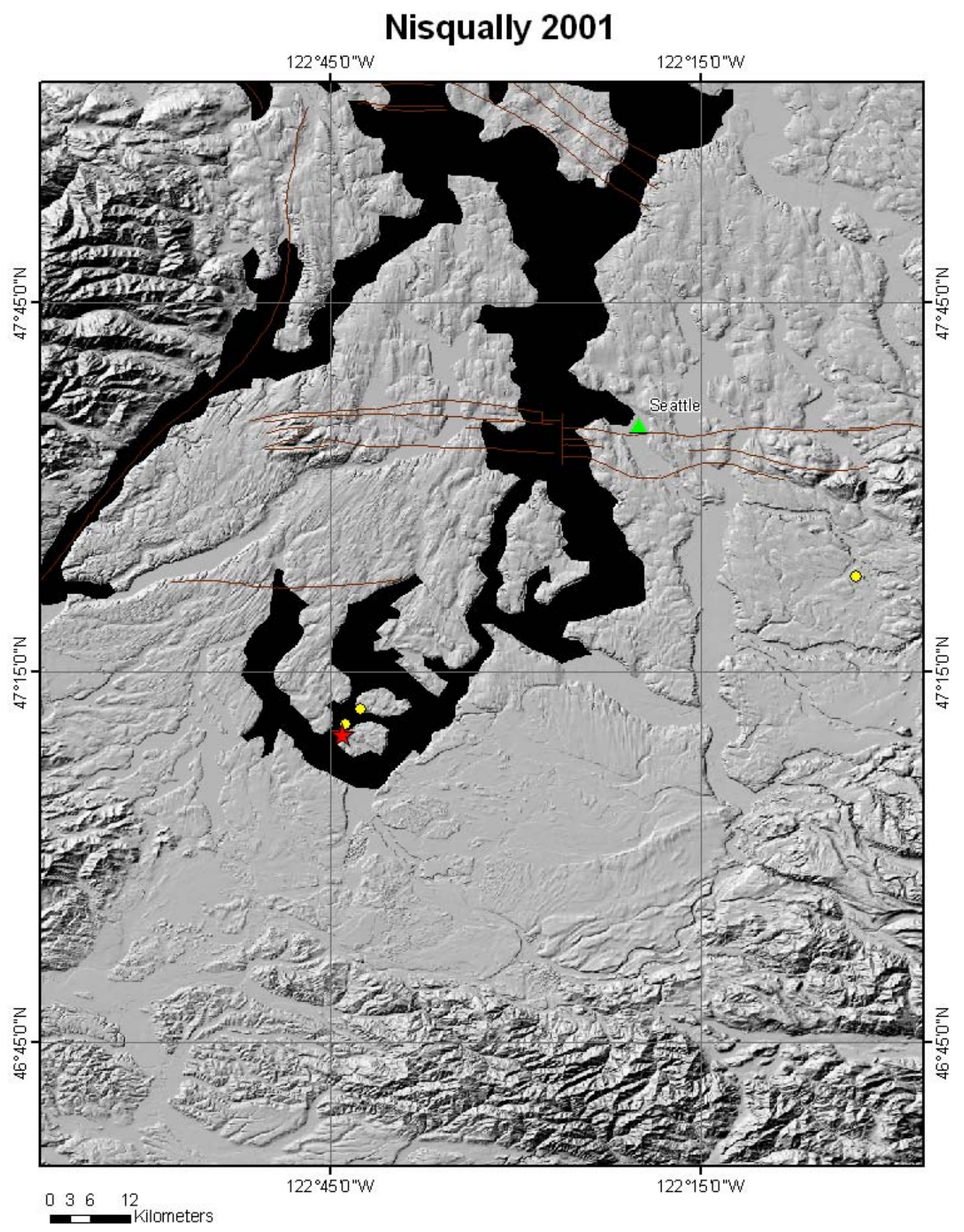


Figure A47. Southern Honshu, March 24, 2001, 06:27:54, $M_{W} 6.40$

\section{Southern Honshu 2001}

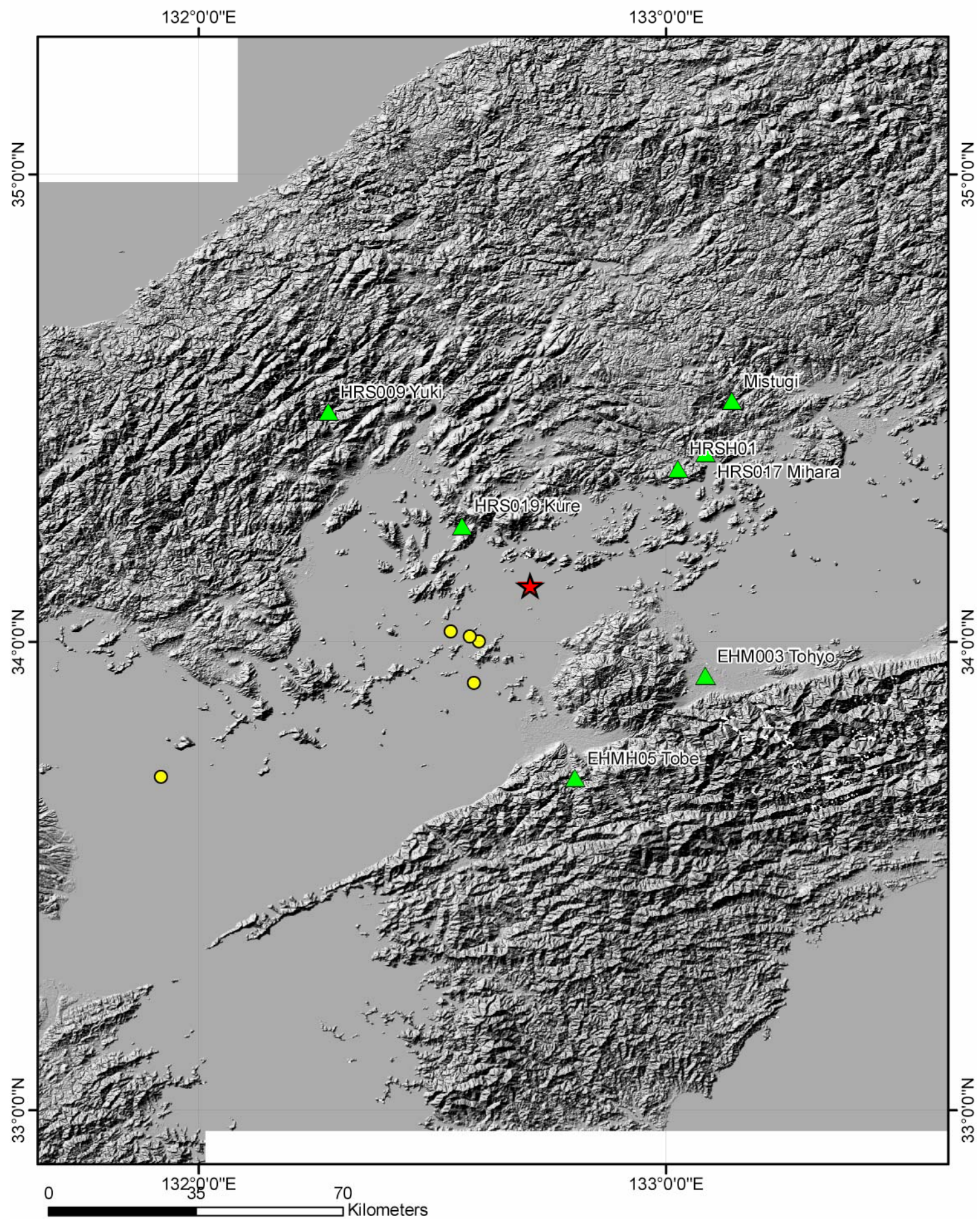


Figure A48. Japan, June 14, 2002, 02:42:00, Mjma 4.90

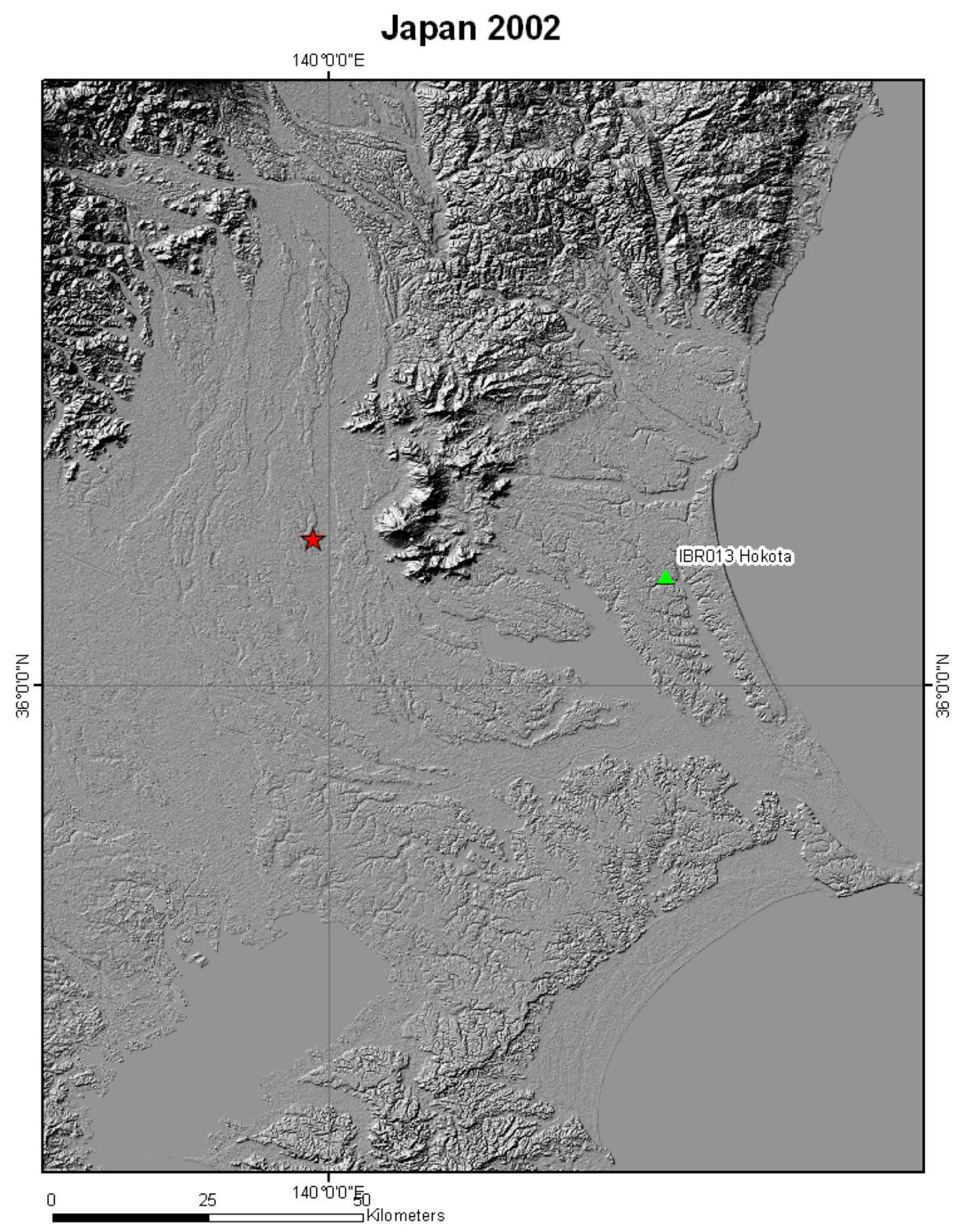

ORD-FY06-022 Subtask 2: Final Technical Report. 
Figure A49. Avaj, Iran, June 22, 2002, 02:58:20, $M_{W} 6.50$

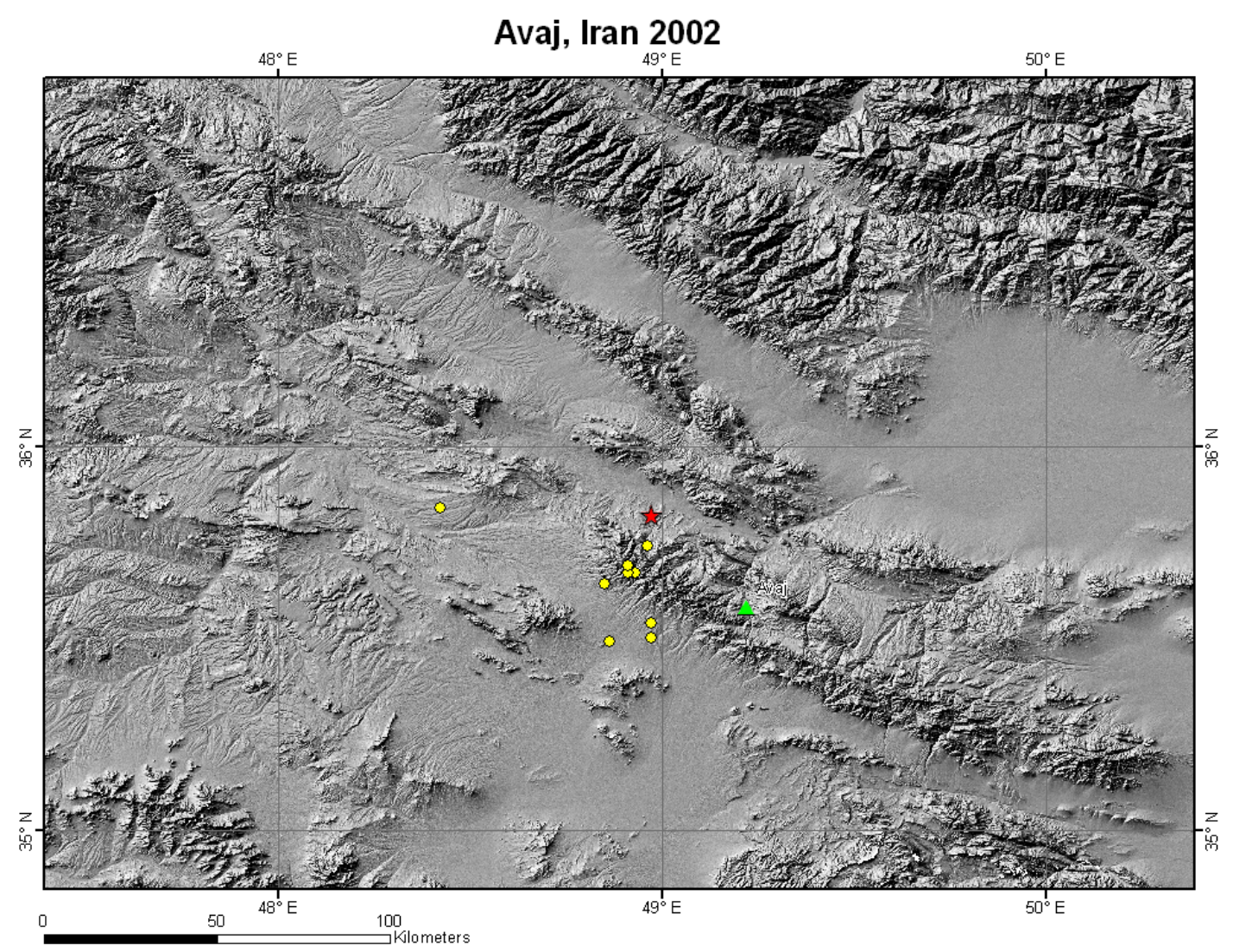


Figure A50. Denali, Alaska, November 3, 2002, 22:13:00, $M_{s} 7.90$

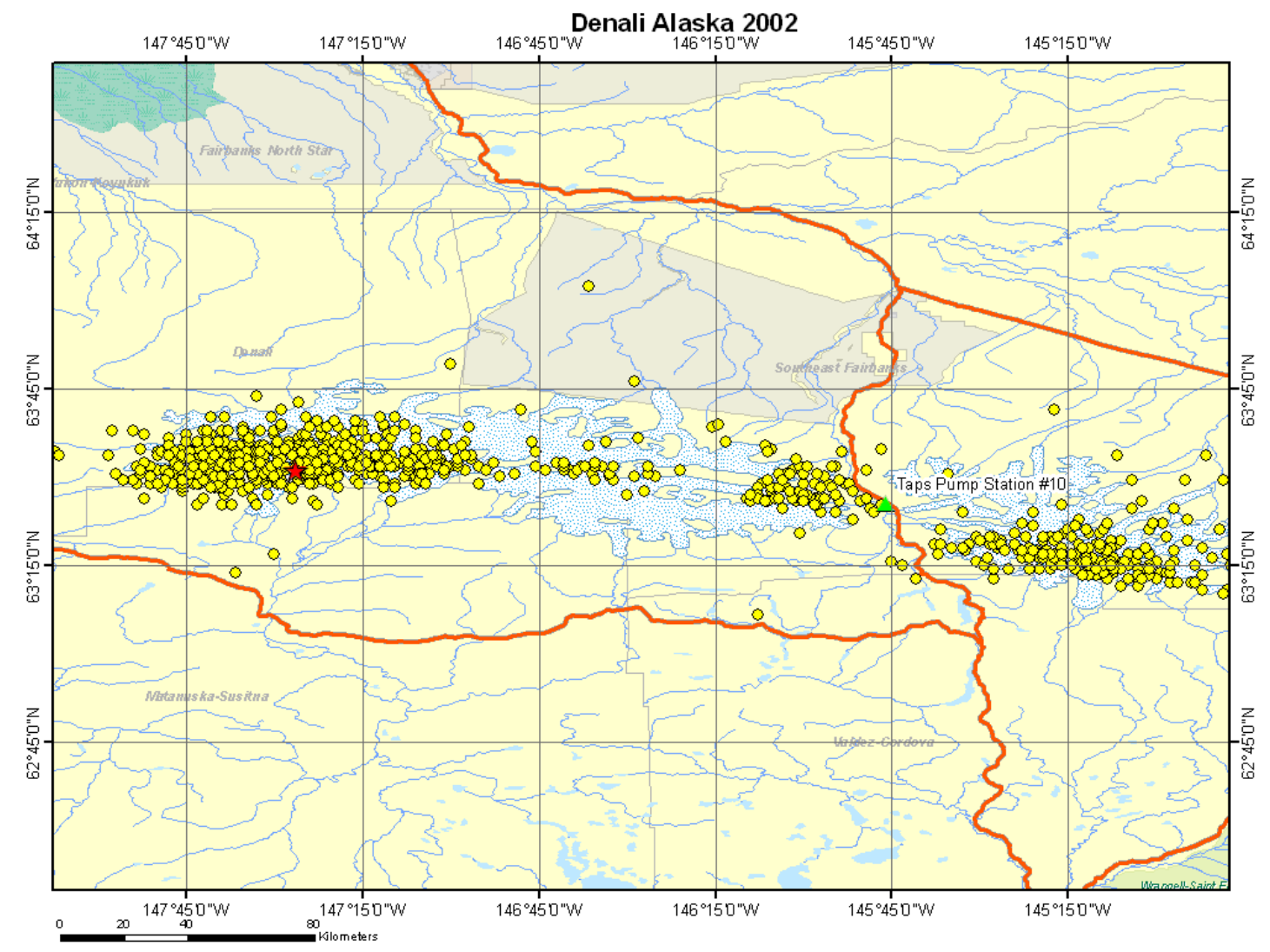


Figure A51. Miyagi-Oki, May 26, 2003, 09:24:33, $M_{W} 7.00$

Miyagi-Oki 2003

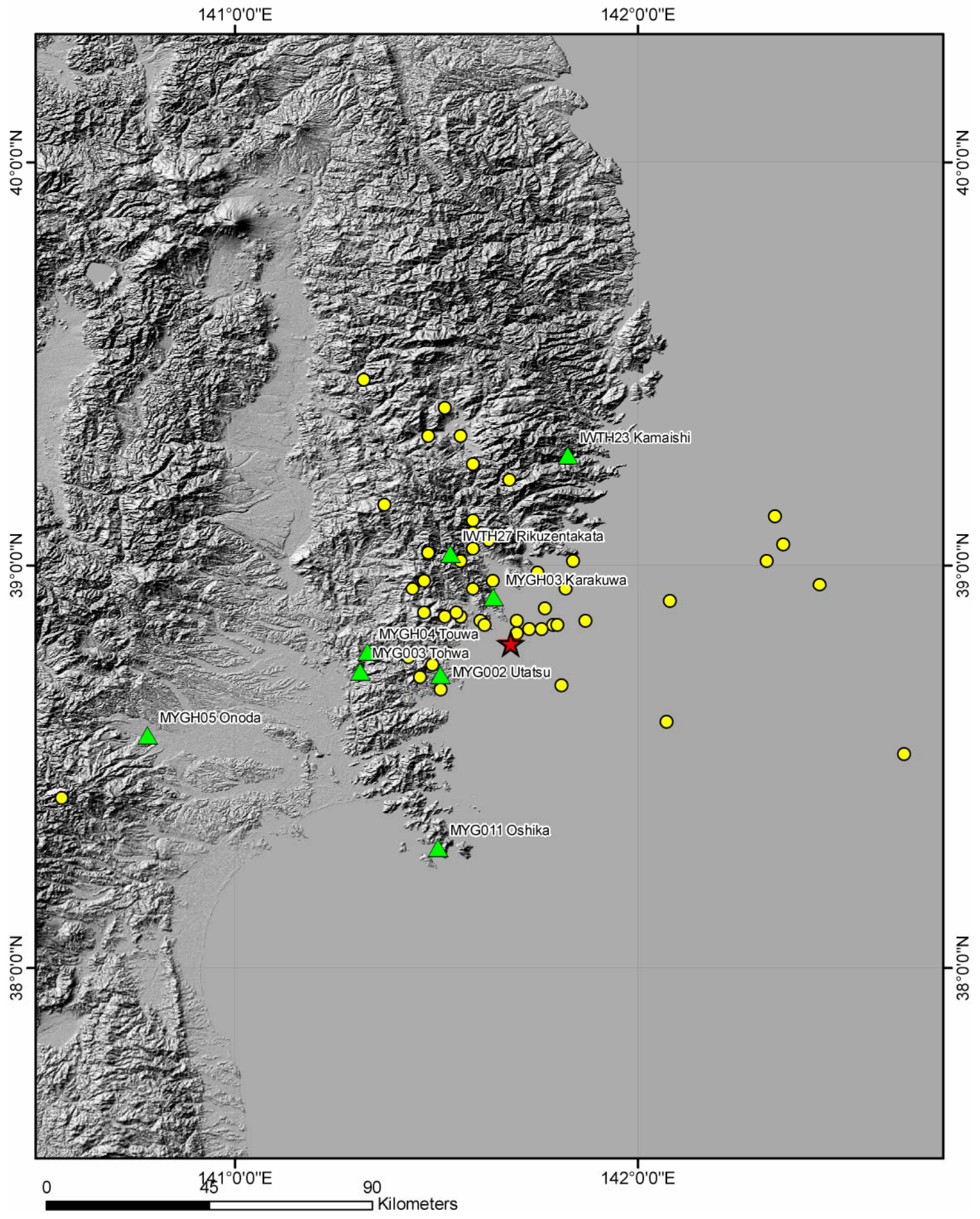


Figure A52. Tokachi-Oki, September 25, 2003, 19:50:07, $M_{W} 8.00$

\section{Tokachi-Oki 2003}

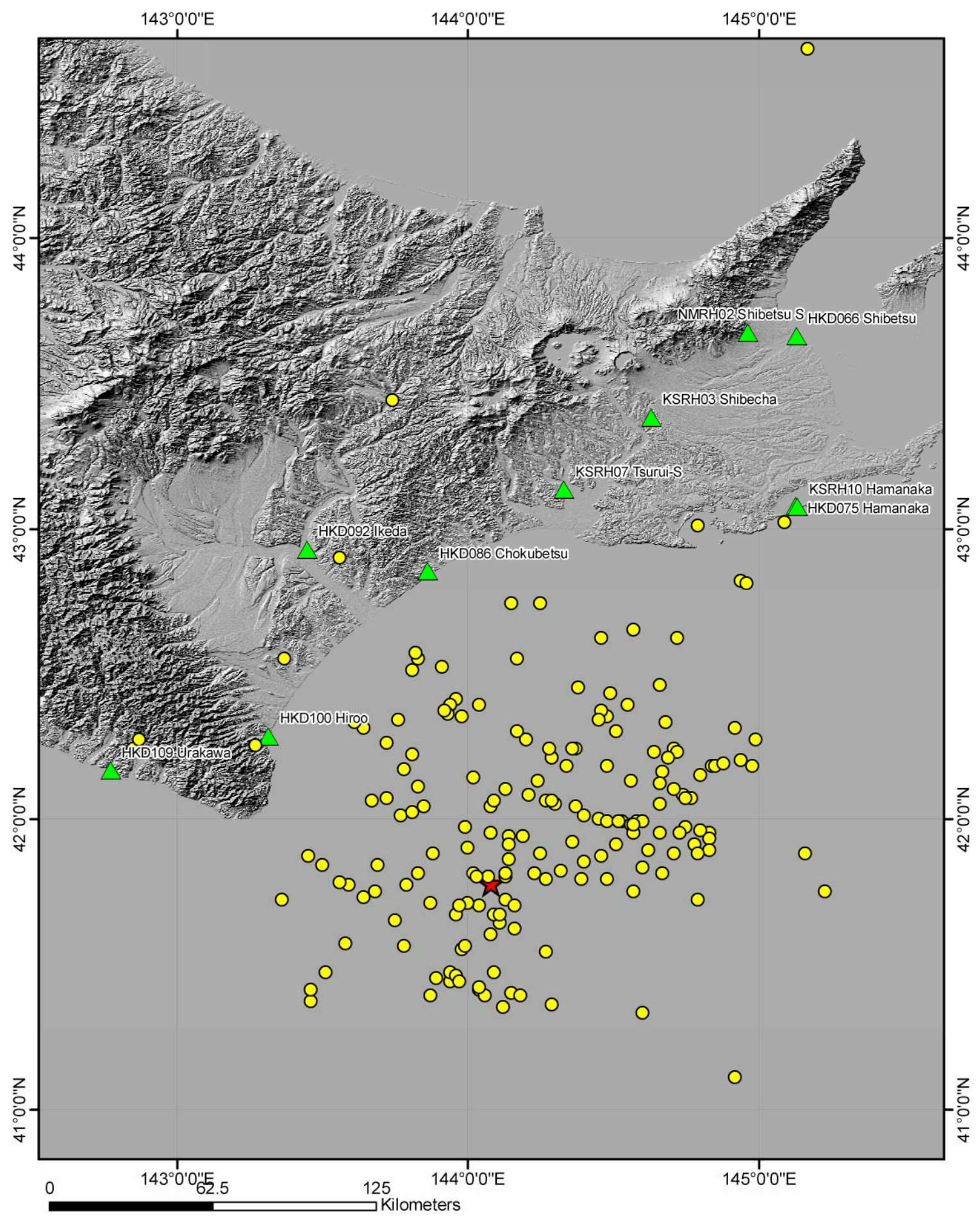


Figure A53. Bam, December 26, 2003, 01:56:56, $M_{w} 6.70$

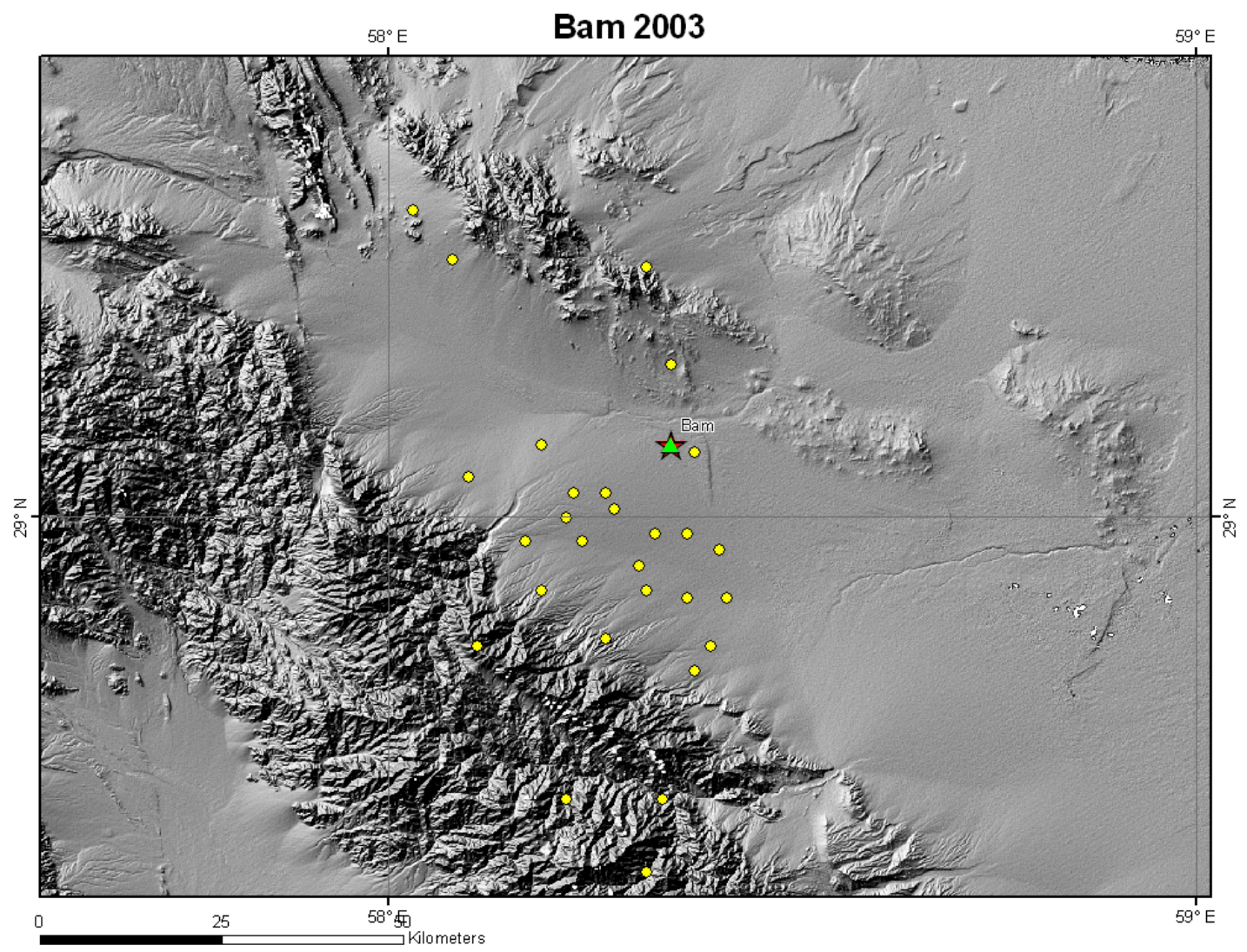

ORD-FY06-022 Subtask 2: Final Technical Report. 
Figure A54. Honshu, July 9, 2004, 10:54:00, Mjma 4.40

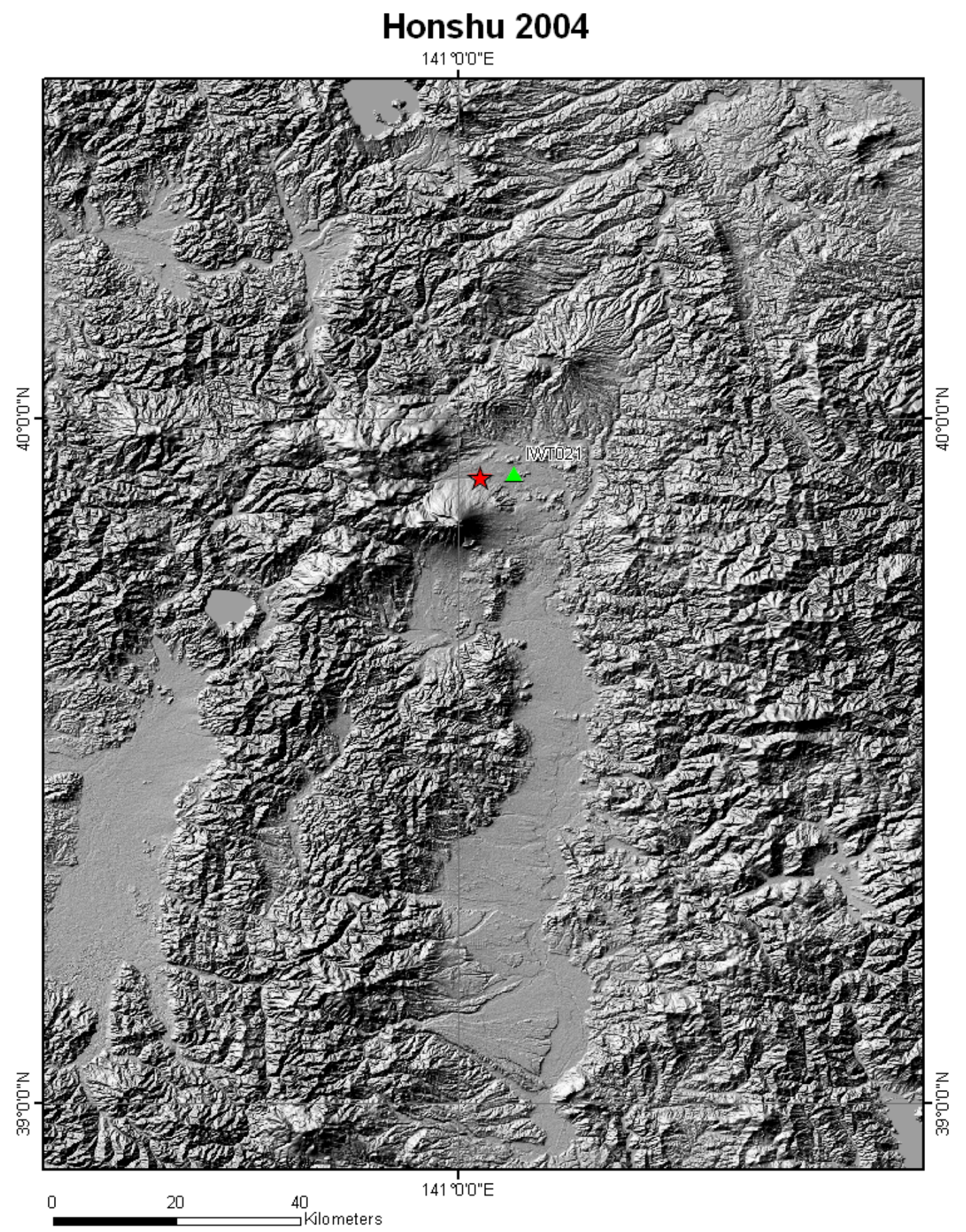

ORD-FY06-022 Subtask 2: Final Technical Report. 
Figure A55. Parkfield, September 28, 2004, 17:15:24, $M_{W} 6.00$

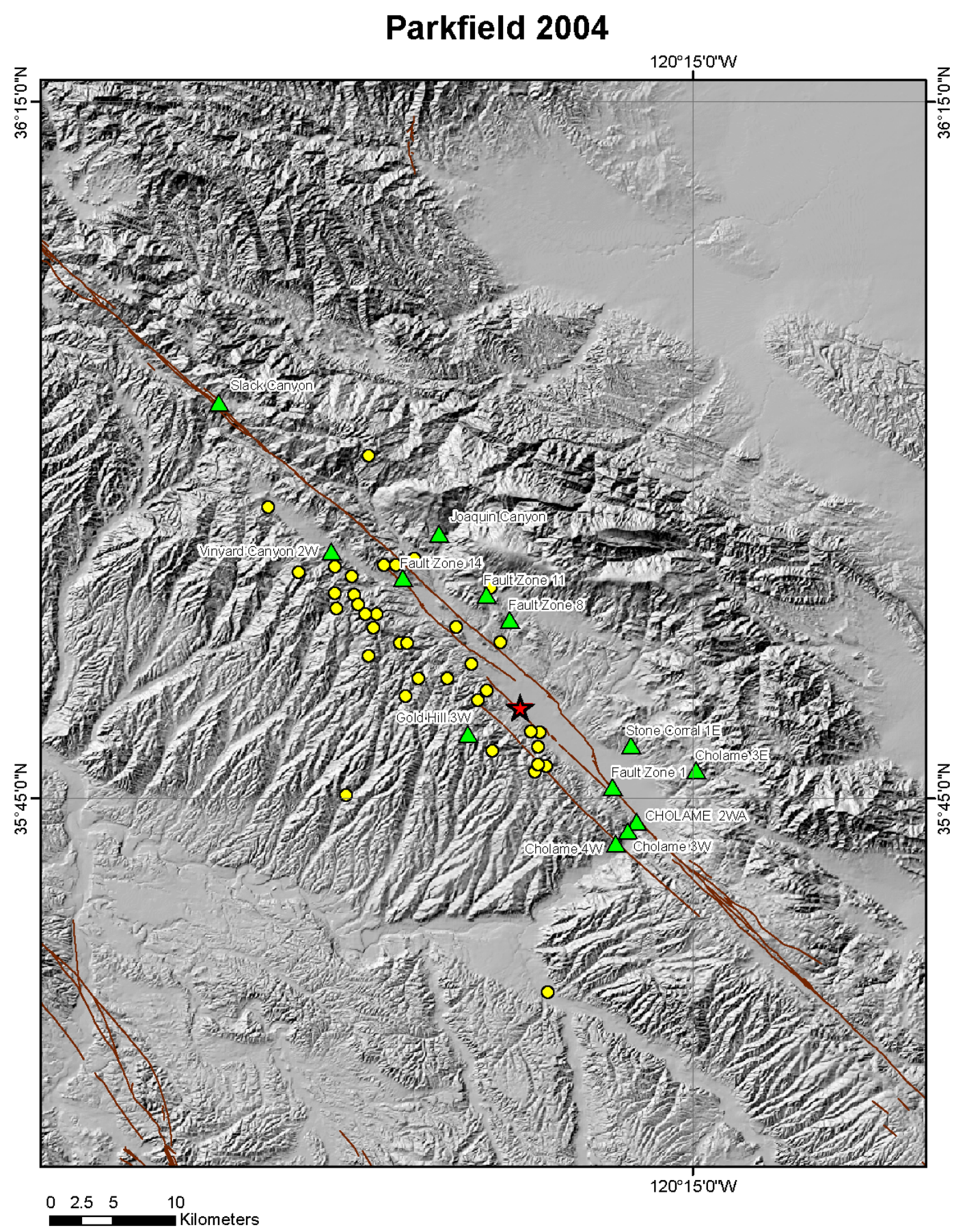

ORD-FY06-022 Subtask 2: Final Technical Report. 
Figure A56. Niigata-Ken Chuetsu, October 23, 2004, 08:56:00, $M_{W} 6.60$

\section{Niigata-Ken Chuetsu 2004}

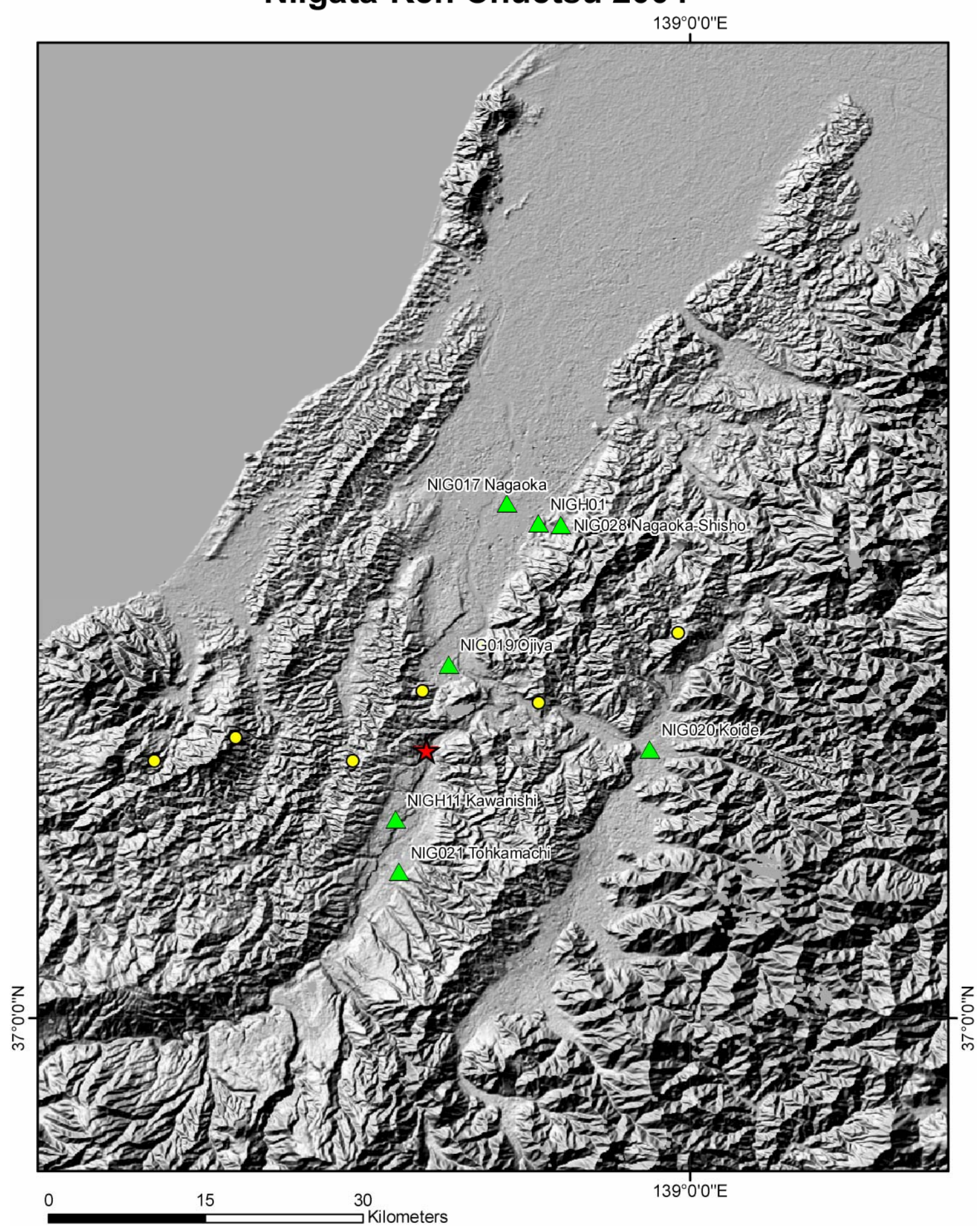


Figure A57. Niigata-Ken Chuetsu, October 23, 2004, 09:34:07 $M_{W} 6.30$

\section{Niigata-Ken Chuetsu 2004}

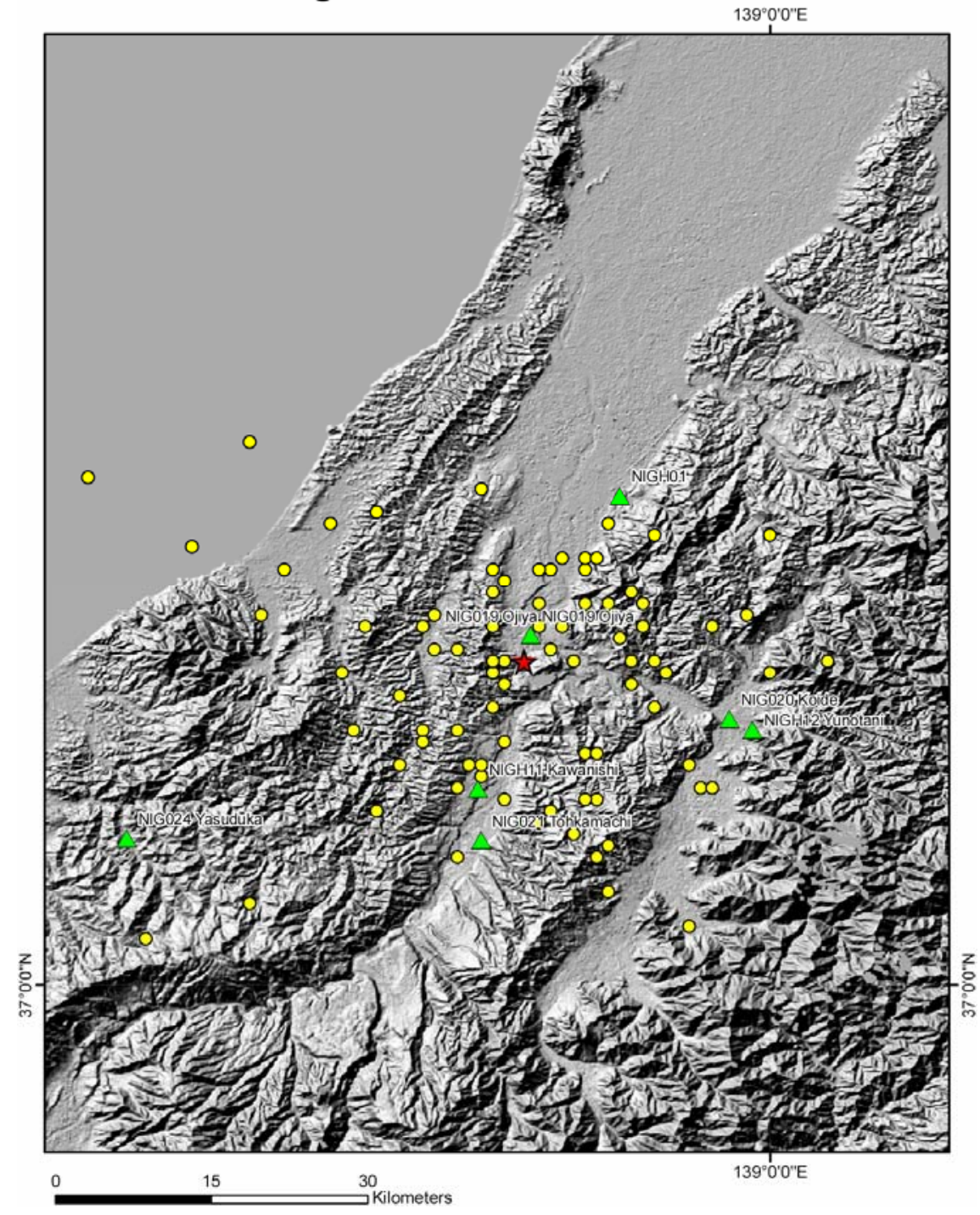

ORD-FY06-022 Subtask 2: Final Technical Report. 
Figure A58. Hokkaido, November 28, 2004, 18:32:00, Mjma 7.10

\section{Hokkaido 2004 Nov}

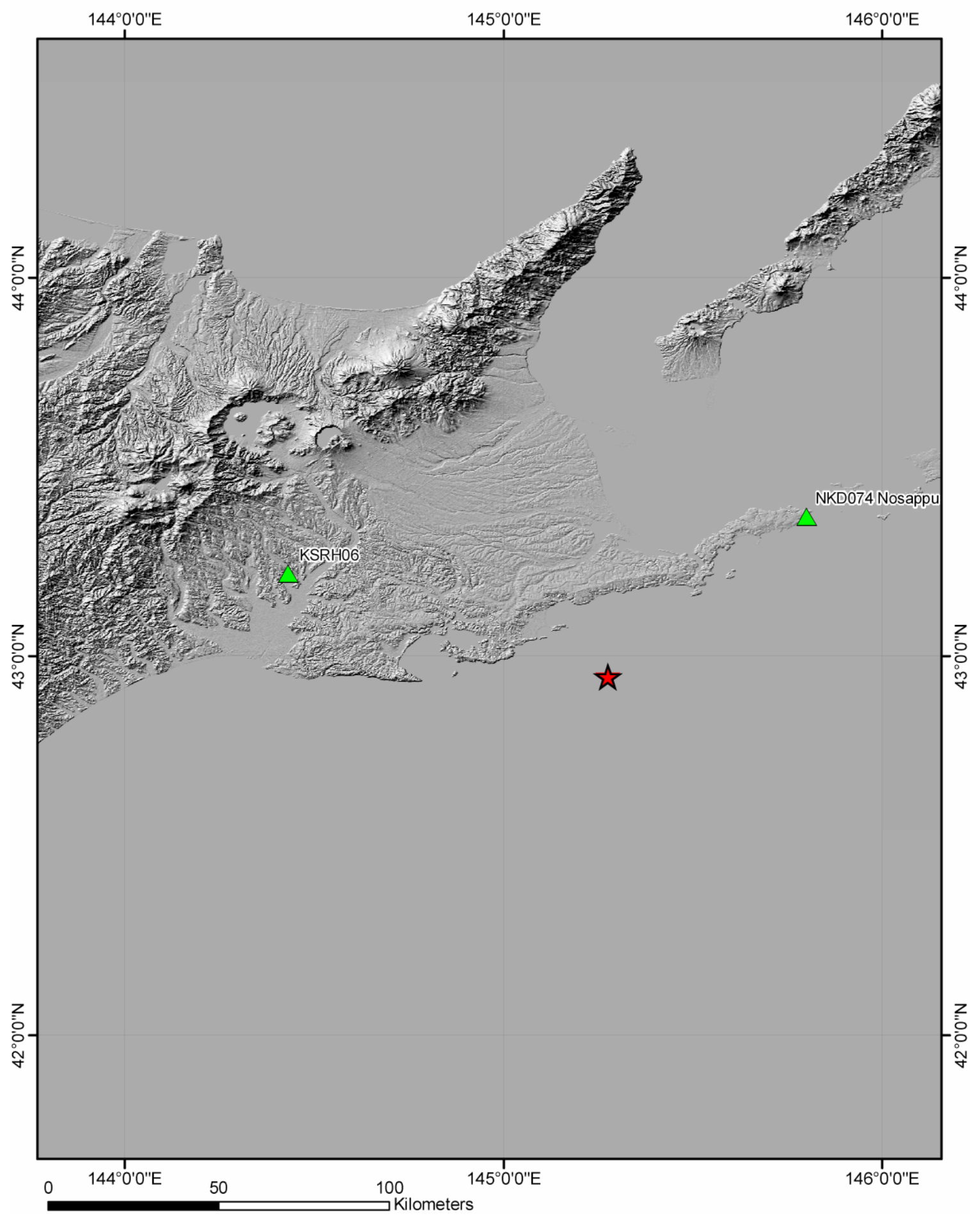


Figure A59. Hokkaido, December 14, 2004, 05:56:09, $M_{W} 5.80$

\section{Hokkaido 2004 Dec}

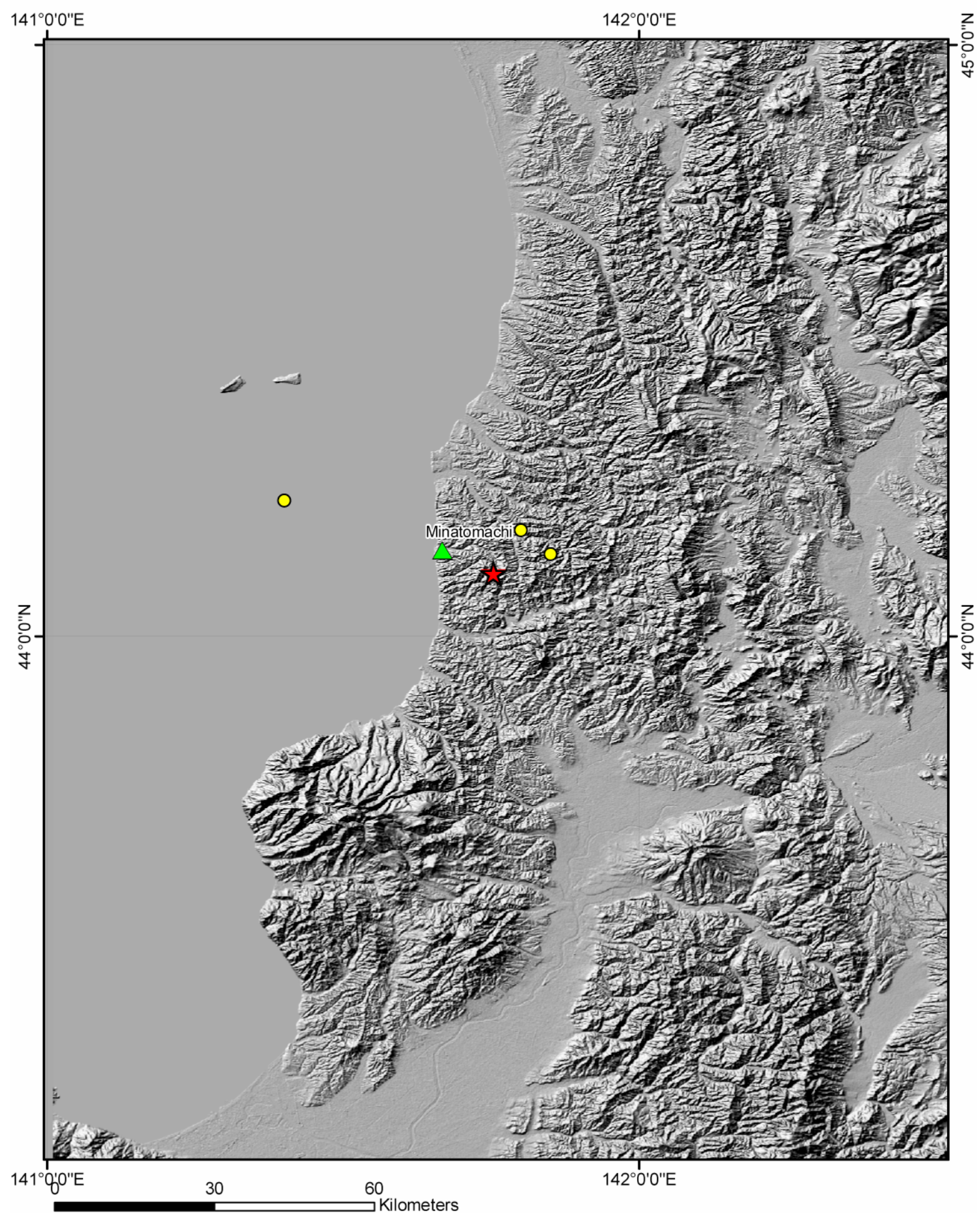


Figure A60. Honshu, August 16, 2005, 02:46:00, Mjma 7.20

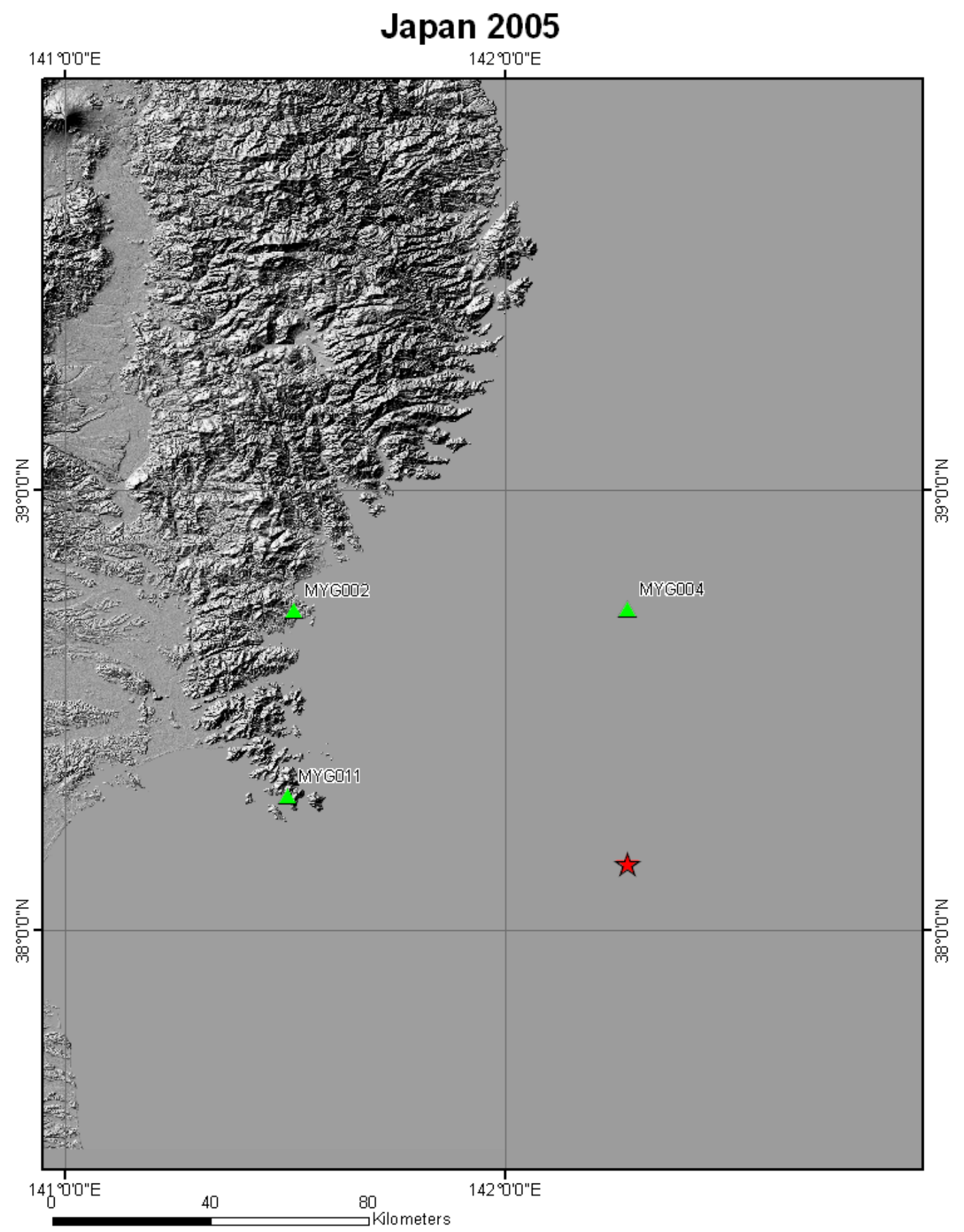

ORD-FY06-022 Subtask 2: Final Technical Report. 
Figure A61. Anza, June 12, 2005, 15:41:46, $M_{W} 5.20$

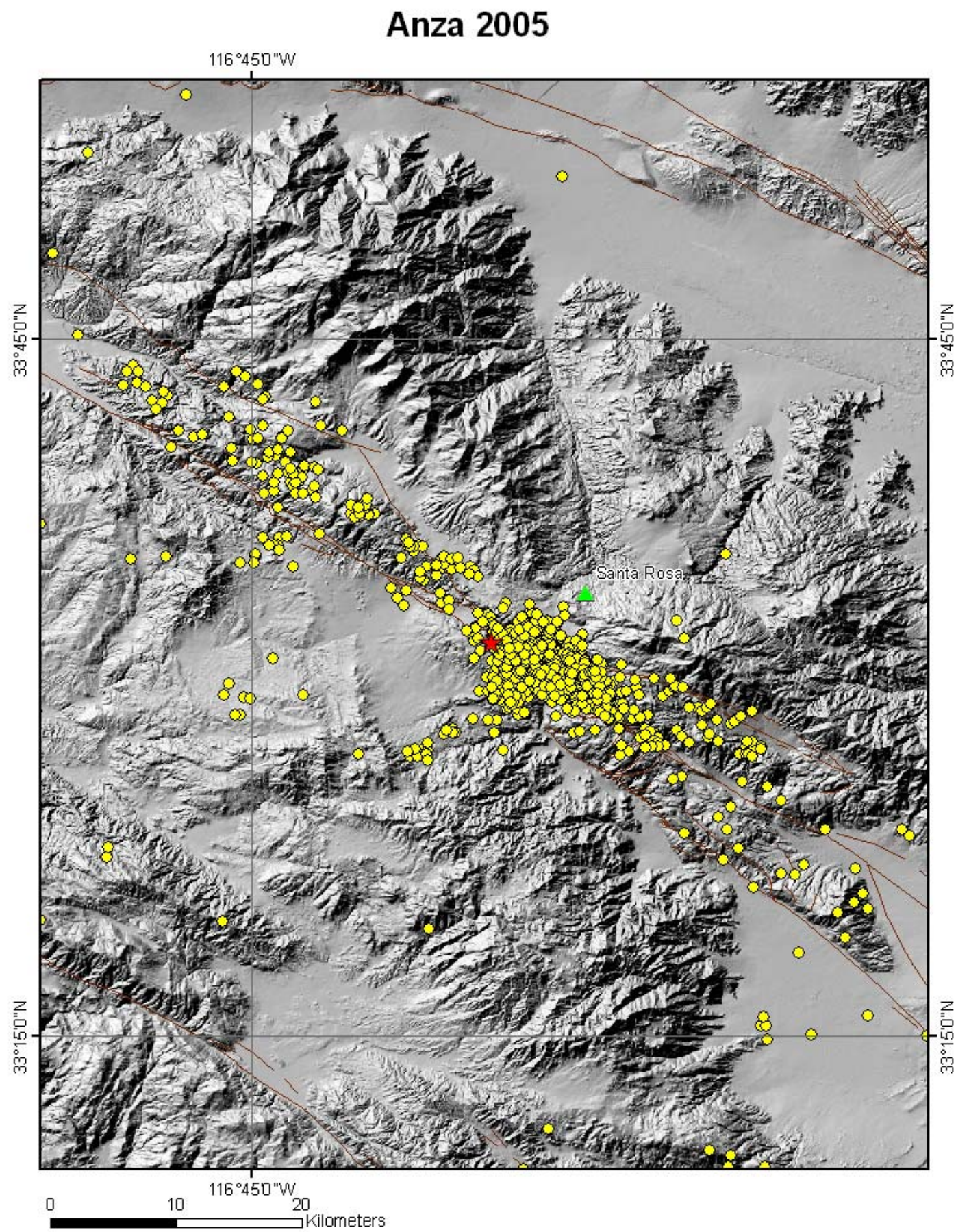

ORD-FY06-022 Subtask 2: Final Technical Report. 
Figure A62. Southern Honshu, March 25, 2007, 00:42:00, Mjma 6.90

\section{Southern Honshu 2007}

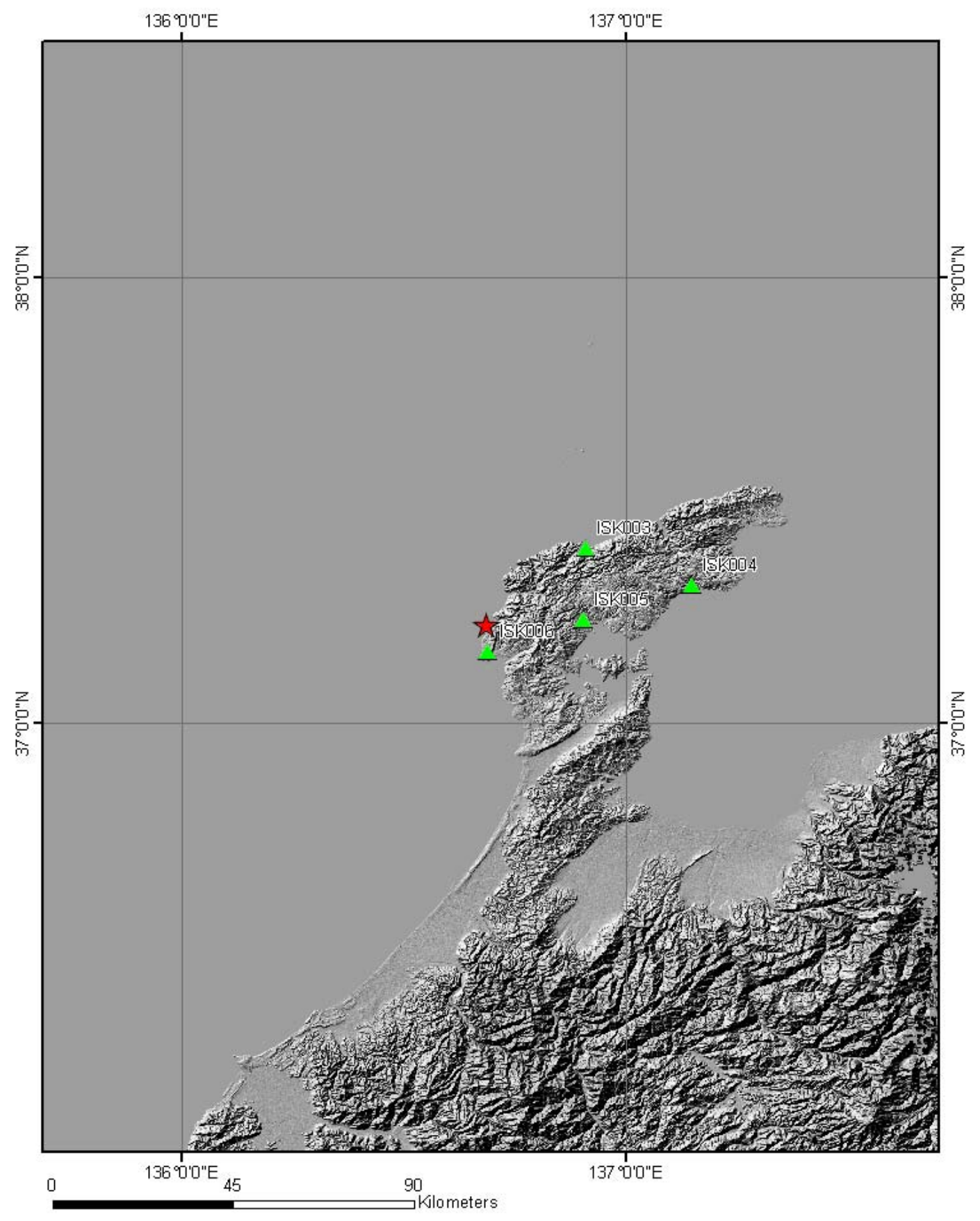


Figure A63. Southern Honshu, April 15, 2007, 03:19:00, Mjma 5.40

\section{Off Southern Honshu 2007}

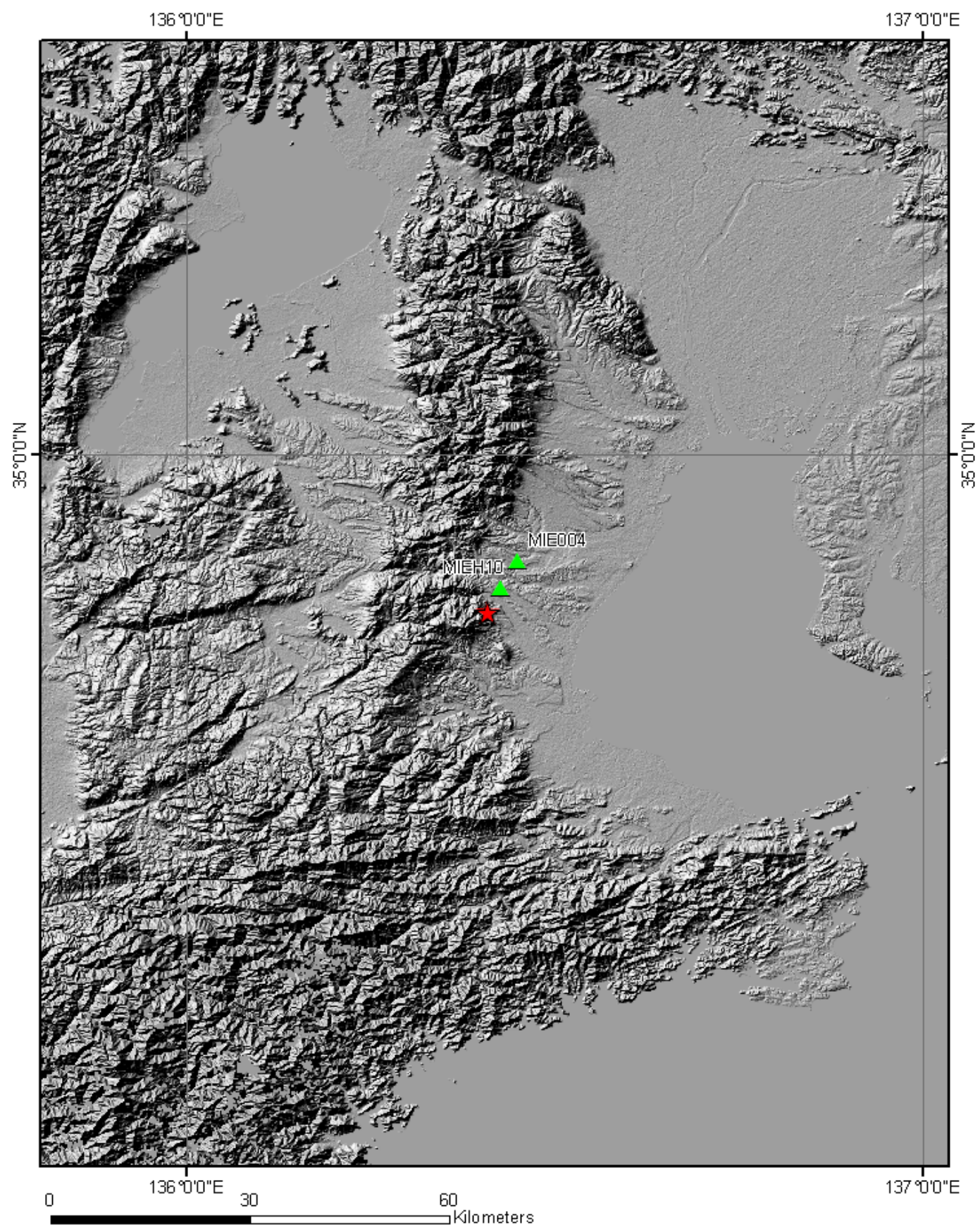


Figure A64. Off Southern Shikoku, April 26, 2007, 00:03:00, Mjma 5.30

Off Southern Shikoku 2007

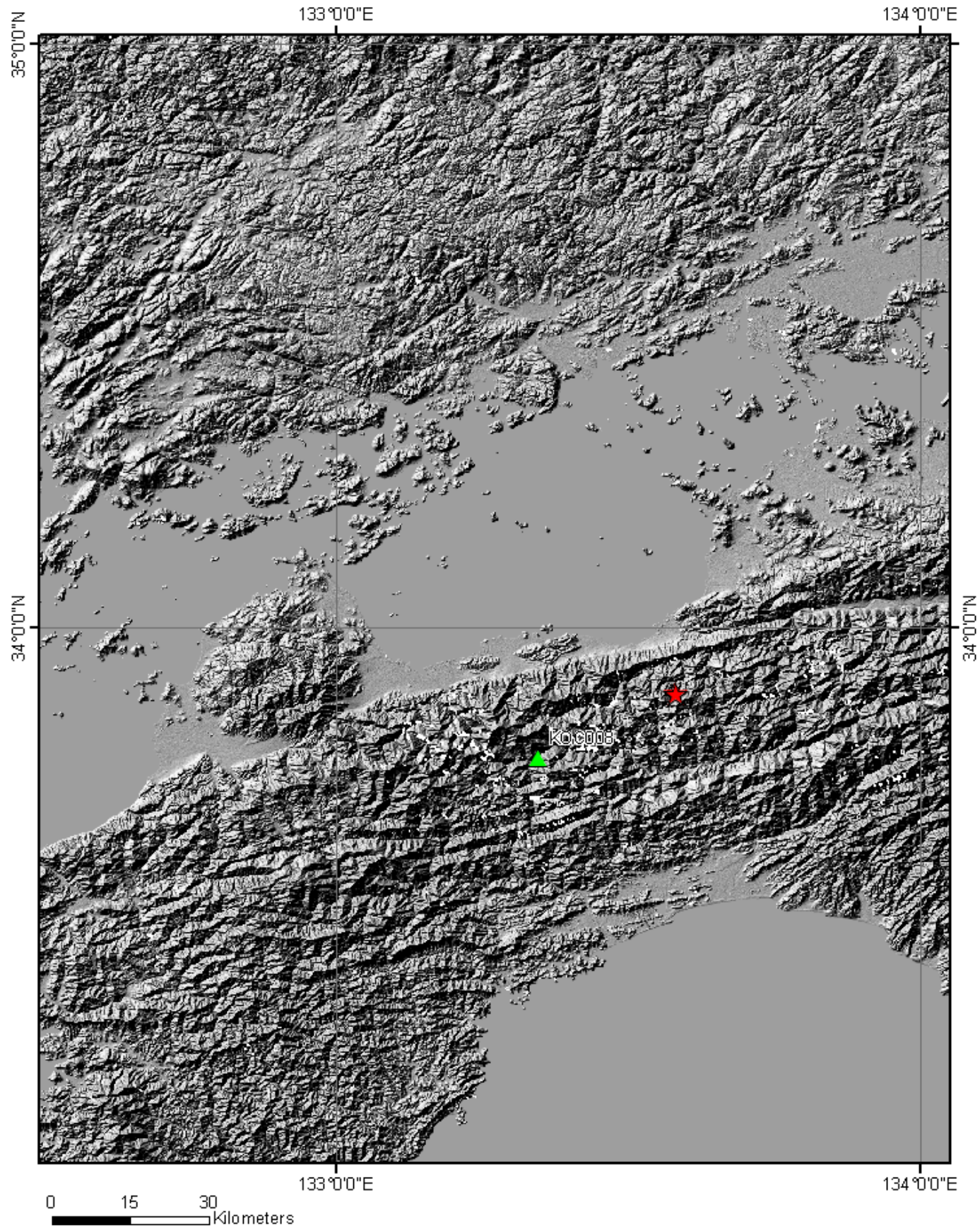

ORD-FY06-022 Subtask 2: Final Technical Report. 